\title{
Geophysical characterization of geothermal fields: Inversion of temperature data and ground motions
}

Geofysische karakterisatie van geothermische velden:

Inversie van temperatuur data en bodembeweging

(met een samenvatting in het Nederlands)

\section{Proefschrift}

ter verkrijging van de graad van doctor aan de Universiteit Utrecht op gezag van de rector magnificus, prof.dr. H.R.B.M. Kummeling, ingevolge het besluit van het college voor promoties in het openbaar te verdedigen op vrijdag 3 december 2021 des middags te 12.15 uur

door

\section{Eszter Békési}

geboren op 20 juli 1992 te Eger, Hongarije 


\section{Promotoren:}

Prof. dr. J.D.A.M. Van Wees

Prof. dr. S.A.P.L. Cloetingh

\section{Copromotoren:}

Dr. P.A. Fokker

Dr. D.D.P. Bonté

This thesis was financially supported by the European Union's Seventh Framework Programme under grant agreement no. 608553 Project IMAGE, and the European Union's Horizon 2020 research and innovation programme under grant agreement no. 727550 Project GEMex. 
"Joy in looking and comprehending is nature's most beautiful gift."

Albert Einstein 


\section{Members of the Reading Committee:}

Dr. H. Paulssen

Prof. Dr. C. Spiers

Prof. Dr. F. Van der Meer

Prof. Dr. T. Kohl

Prof. Dr. D. Bruhn
Utrecht University, Netherlands

Utrecht University, Netherlands

University of Twente, Netherlands

Karlsruhe Institute of Technology, Germany

GFZ Helmholtz Center Potsdam, Germany; Technical University of Delft, Netherlands

This is Utrecht studies in Earth Sciences volume 243

ISBN 978-90-6266-610-2

(C) Eszter Békési 2021

Printed in the Netherlands by Ipskamp Printing

Cover: Sentinel-1 interferogram of the 8 February 2016 Los Humeros (Mexico) earthquake.

All rights reserved. No part of this publication may be reproduced or transmitted in any form or by any means, electronic or mechanical, including photocopying, recording, or by any information storage and retrieval system without prior written permission from the author. 


\section{Contents}

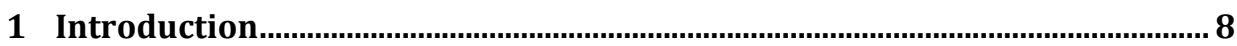

1.1 Geothermal resources and their utilization .............................................. 9

1.2 Geophysical methods in geothermal exploration and exploitation .................... 11

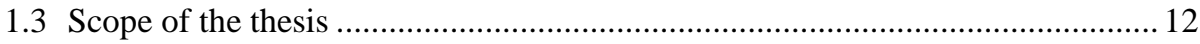

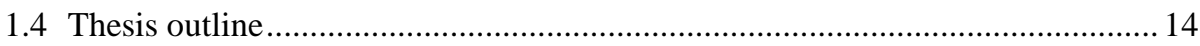

2 Subsurface temperature model of the Hungarian part of the Pannonian

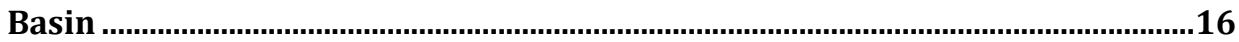

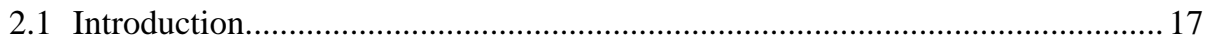

2.2 Formation and evolution of the Pannonian Basin ......................................... 18

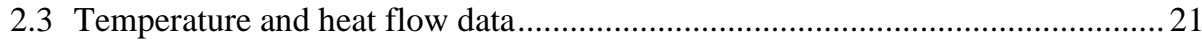

2.4 Hydraulic systems and geothermal resources ............................................. 23

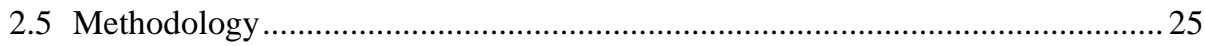

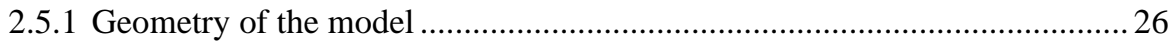

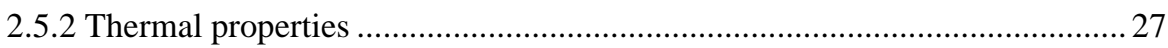

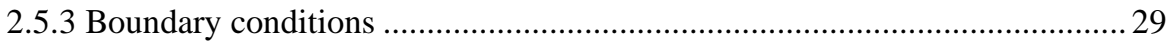

2.5.4 Controlling temperatures and data uncertainty...................................... 31

2.5.5 Ensemble smoother with multiple data assimilation ................................... 32

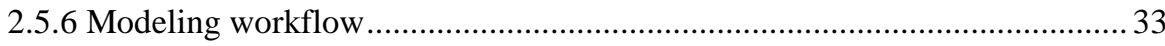

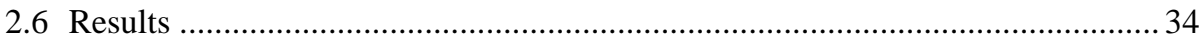

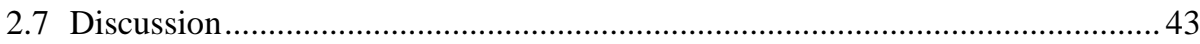

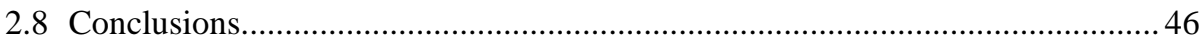

3 An updated geothermal model of the Dutch subsurface based on inversion

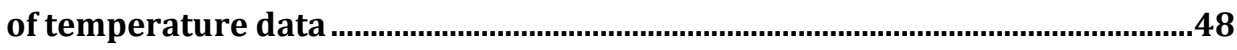

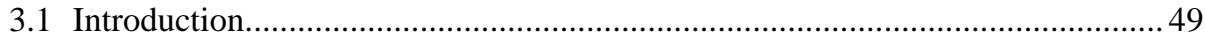

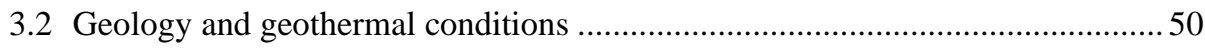

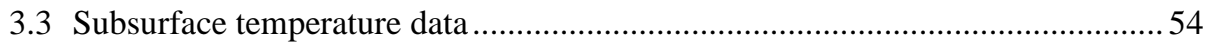

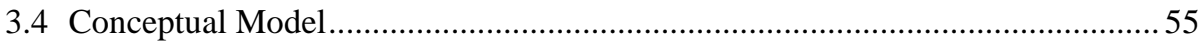


3.4.1 Forward model................................................................................... 55

3.4.2 Thermal convection in the Dinantian carbonate platforms...........................56

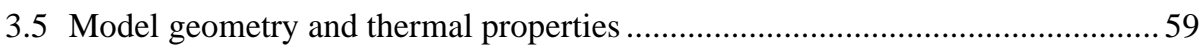

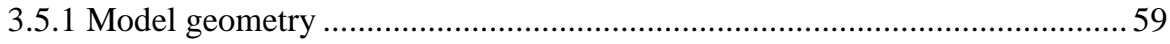

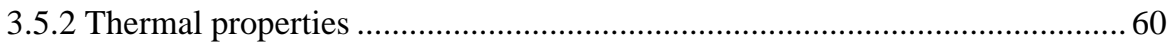

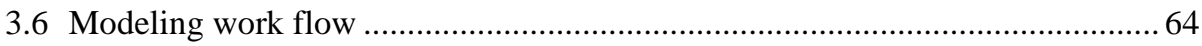

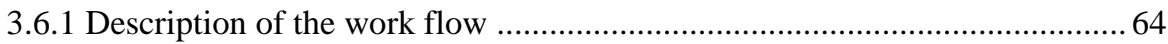

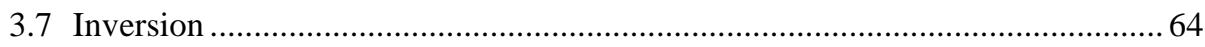

3.7.1 Ensemble Smoother with Multiple Data Assimilation (ES-MDA) ...............64

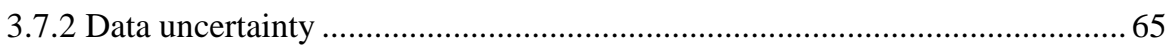

3.7.3 Description of the data assimilation procedure .......................................... 66

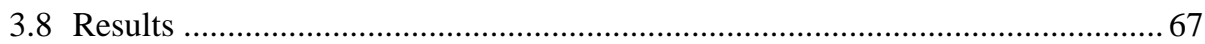

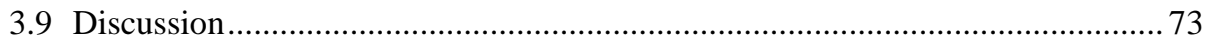

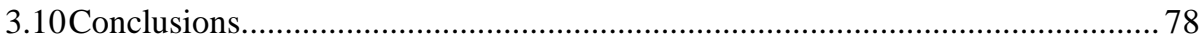

4 Ground motions induced by pore pressure changes at the Szentes geothermal area, SE Hungary ......................................................................... 79

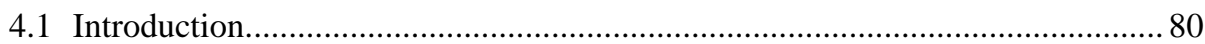

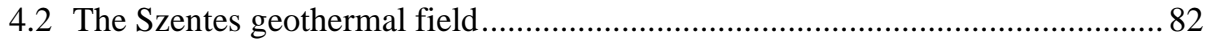

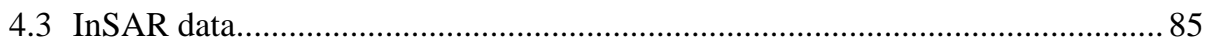

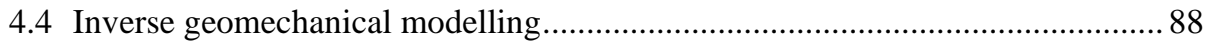

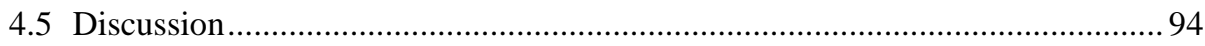

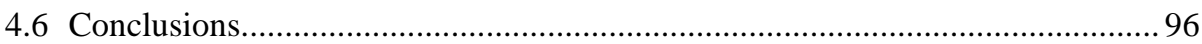

5 Production-induced subsidence at the Los Humeros Geothermal Field

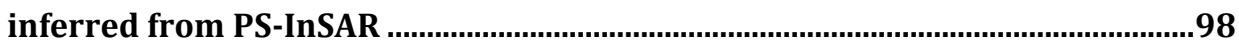

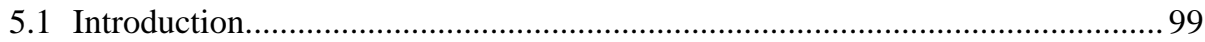

5.2 The Los Humeros Geothermal Field (LHGF) ............................................ 100

5.3 Interferometric Synthetic Aperture Radar monitoring .................................. 101

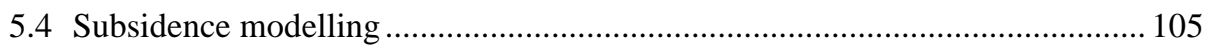

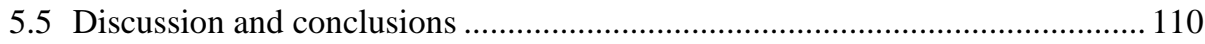


6 Source parameters of the 8 February 2016, Mw=4.2 Los Humeros earthquake by the inversion of InSAR-based ground deformation

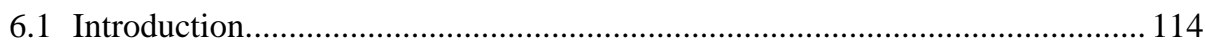

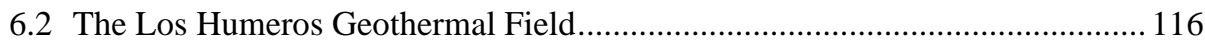

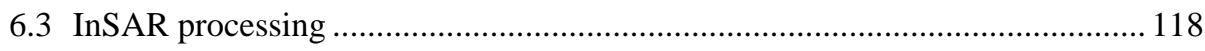

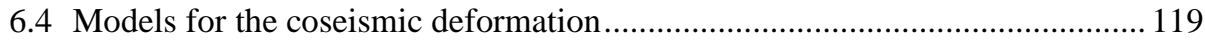

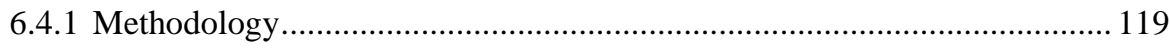

6.4.2 Model 1 - single fault .......................................................................... 122

6.4.3 Model 2 - segmented fault, identical slip .................................................. 123

6.4.4 Model 3 - segmented fault, independent slip .............................................. 123

6.5 Deformation between February 2016-May 2019 …………............................. 125

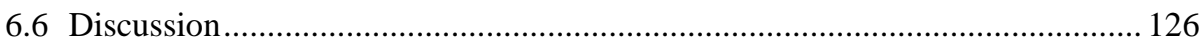

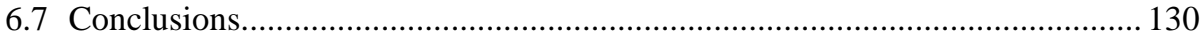

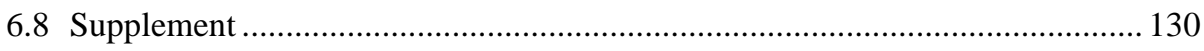

7 Synthesis ........................................................................................................132

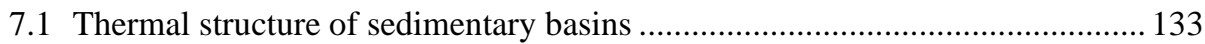

7.2 Interpretation of surface movements for geothermal reservoir characterization 135

7.3 Applicability of inversion methods for temperature measurements and ground

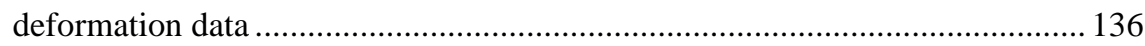

7.4 Integrated approach for geothermal reservoir characterization.......................... 137

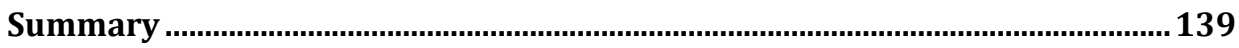

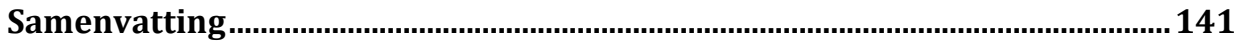

Acknowledgements ................................................................................................. 144

References ..................................................................................................146

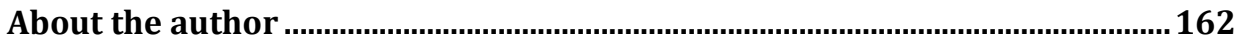


1 Introduction 


\subsection{Geothermal resources and their utilization}

In order to supply the increasing global energy demand while combating climate change, renewable energy resources are of key importance. In contrast to the majority of renewables, geothermal energy has the advantage of providing continuous, uninterrupted supply of energy.

Primordial heat associated with the formation of the Earth is one of the major sources of heat in the Earth's interior. Additionally, a large amount of heat is originated from the decay of radiogenic isotopes that have been accumulated in the continental upper crust. Heat is transferred from the interior towards the surface via two dominant mechanisms: convection and conduction. In the mantle, convection is dominant, where heat is transported by the movement of material. In the lithosphere, the main heat transfer mechanism is conduction, i.e. the transfer of energy by the collision of molecules, which is less effective than convection. Convective heat transfer can also be dominant in some parts of the lithosphere by fluid flow and magmatic activity. These phenomena can ensue in particular zones in tectonically active areas marked by volcanism. Such areas provide the most suitable conditions for geothermal development (Figure 1.1).

A popular classification of geothermal resources besides temperature and thermodynamic properties (e.g. Haenel et al., 1988; Hochstein, 1990; Muffler, 1979) is the geothermal play type (Moeck, 2014). Classifying geothermal systems based on their geological characteristics refers to the geological controls and plate tectonic settings, that have major influence on the heat flow and thermal state of resource areas. Moeck (2014) distinguished between convection-dominated and conduction-dominated geothermal plays, referring to the dominant heat transfer regime. Convection-dominated systems are restricted to active plate boundaries and areas with volcanic and/or tectonic activity (Figure 1.1), exhibiting high temperatures $\left(>160^{\circ} \mathrm{C}\right)$ and dynamic flow of geothermal fluids. Conduction-dominated plays are typically marked by lower reservoir temperatures $\left(<160{ }^{\circ} \mathrm{C}\right)$, which occur at relatively inactive tectonic settings (Figure 1.1). 


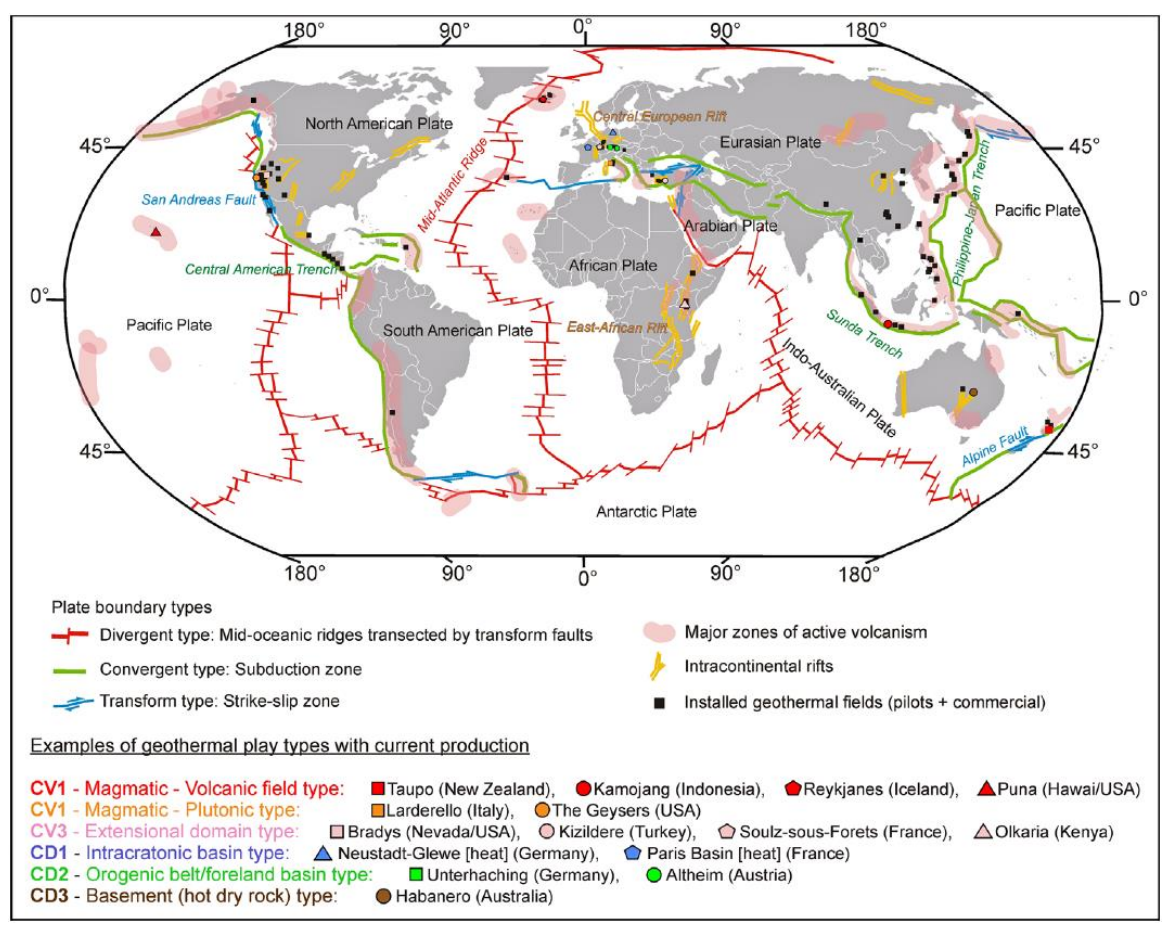

Figure 1.1: Locations of geothermal fields worldwide in a plate tectonic setting after Moeck (2014) as of 2014. Geothermal fields are located near active plate boundaries and areas with volcanic and/or tectonic activity. CV and CD refer to convection-dominated and conduction-dominated geothermal plays. For the detailed description of resource types see Moeck (2014).

Geothermal power generation primarily comes from the utilization of convectiondominated resources. The first application of geothermal energy for electricity generation took place more than 100 years ago in Lardarello, Italy, where geothermal fluids are present at shallow depth due to recent magmatism combined with the recharge of meteoric water (e.g. Bertini et al., 2006). During the past decades, the total installed capacity for geothermal power has increased significantly (Huttrer, 2020) and power plants are operating in various locations worldwide, but their spatial distribution is substantially limited by geological controls.

In the future, geothermal exploration must overcome the spatial limitations of convectiondominated systems by expanding geothermal energy production and power generation to less favorable areas, in order to achieve a more important role in the global energy sector. In conduction-dominated plays, power generation can be targeted by moving to significantly larger depth. However, at these depths the permeability and related fluid production capacity of the host rock can be low. Such geothermal reservoirs may require stimulation in order to create the fluid pathways necessary for economic utilization. Systems like these are referred to as Enhanced Geothermal Systems (EGS) (e.g. Breede et al., 2013; Lu, 2018; Olasolo et al., 2016). 
Heating (and cooling) plays the most important role in the global energy consumption, by covering approximately half of our demands. Therefore, the role of geothermal heat utilization is also highly relevant. Direct utilization of geothermal heat is less dependent on geological characteristics than geothermal power generation, as it requires lower reservoir temperatures. Consequently, conduction-dominated geothermal plays can be excellent candidates for heating applications. As play types are mostly permeable sedimentary rocks, suitable target formations can be exploited without reservoir stimulation, and their development can take considerable benefit from past hydrocarbon exploration (e.g. van Wees et al., 2017; van Wees et al., 2020). While the use of direct heat from geothermal is going through a rapid increase (e.g. Lund and Toth, 2020$)$, only a small portion $(\sim 0.3 \%$, REN21, 2020) of the global heat demand is currently covered by geothermal energy. The geothermal energy sector - including both electricity and direct heat applications - requires further exploration and technological developments to play a significant role in the global energy mix.

\subsection{Geophysical methods in geothermal exploration and exploitation}

Geophysical imaging of the subsurface, combined with geophysical monitoring of operating geothermal fields are essential for geothermal exploration and exploitation. Temperature is one of the key parameters of geothermal systems; information on the subsurface thermal field is thus paramount to identify potential areas for geothermal development. At continental to regional scale, physics-based thermal models calibrated with temperature measurements from boreholes are able to explain and quantify the driving subsurface processes and properties responsible for the temperature distribution. Since the thermal field within exploitation depth $(\sim 5 \mathrm{~km})$ is strongly influenced by lithospheric-scale processes, the thermal state of the whole lithosphere has to be assessed (e.g. Cloetingh et al., 2010). Physics-based thermal models have been constructed for various regions (e.g. Bonté et al., 2012; Freymark et al., 2017; Fuchs et al., 2020; Limberger et al., 2018). Such models require information on the geology of the subsurface and estimates of the thermal properties of the geological units. Subsurface temperature data collected from boreholes are used to refine the thermal models, often combined with the results from inverse modelling techniques.

The development of geothermal fields starts with detailed site-specific surveys including various geological and geophysical investigations. They target optimized economic operations, including a reduction of drilling and exploration risk, and of exploitation risks after the drilling and appraisal stage. Conventional geophysical methods, such as seismic surveys, magnetic, gravity, and electric methods are often conducted at potential areas, depending on site-specific settings. Further data from exploration boreholes or nearby wells may also be collected to estimate subsurface properties and provide additional input for geological and geophysical models. Subsequently, the joint interpretation of subsurface models allows for the better characterization of a geothermal system, towards the establishment of a production plan. 
Besides the conventional geophysical methods, remote sensing with Interferometric Synthetic Aperture Radar (InSAR) (e.g. Ferretti et al., 2001; Hanssen, 2001) provides external information in the form of ground movement estimates. In the exploration phase, these observations can help identifying active buried fault structures and magmatic activity that can indicate locations of geothermal resources. Additionally, they may show indications of recharge and discharge areas of geothermal fluids. InSAR monitoring of operated geothermal fields is also highly relevant for monitoring the stability of surface installations and nearby residential areas. This is important for reducing operational risks and can be useful for communications with the general public. In addition, the surface movement estimates may help identify reservoir compartmentalization and zones of pressure depletion and/or temperature changes due to production. Such analysis may thus contribute to identify hydraulic connection between geothermal wells. Injection and production operations can be further optimized and new well locations may be selected. Finally, InSAR monitoring may help assessing induced seismicity risks and can contribute to the understanding of the geometry and kinematics of active fault structures controlling geothermal reservoirs. Indeed, induced seismicity is among the most important risks occurring at geothermal fields - in some cases it has even resulted in the termination of production (e.g. Deichmann and Giardini, 2009; Kim et al., 2018). Because of this wide range of applications, in combination with recent advancements in technologies (for instance the launch of the Sentinel-1 satellites that facilitate the observation of surface movements with the temporal resolution of 6 days), remote sensing with InSAR is anticipated to become a widely used technique for the monitoring of geothermal activities.

The link between ground deformation and subsurface processes can be established with the geophysical modeling of surface movements. InSAR only provides information on the surface, therefore external geological and geophysical models and subsurface data are critical to constrain and interpret source models for ground movements. Models for ground deformation in geothermal applications are commonly based on single or distributed volume/pressure sources in the subsurface (e.g. Kiyoo, 1958; Okada, 1985; Segall, 2010; Yang et al., 1988). Previous studies have demonstrated that such models are capable of estimating first order processes at geothermal sites (Heimlich et al., 2015; Keiding et al., 2010; Parks et al., 2020; Trugman et al., 2014). More complex numerical models have also been applied to predict ground motions at geothermal areas (e.g. Vasco et al., 2013). Numerical models have the advantage of accounting for more complex reservoir behavior, however, surface movement observations through inversion cannot be easily incorporated in such models. The quantification of driving parameters through inverse modelling is facilitated better with fast analytical and semi-analytical models that allow quick evaluation of many scenarios.

\subsection{Scope of the thesis}

In this thesis I aim to deploy novel approaches improving the characterization of geothermal reservoirs with the use of subsurface temperature measurements and ground motion observations. I integrate various geological and geophysical datasets and models to 
describe geothermal reservoir thermal fields, deformation processes and associated properties and uncertainties. The quantitative assessment of driving parameters and uncertainties is achieved by inverse modeling methods applied to case studies. Access to high quality datasets and multi-disciplinary integration of conceptual models has been facilitated by the EU funded GEMex project, which financed this PhD work. GEMex is a EuropeanMexican collaboration for geothermal energy research in Mexico, focusing on two geothermal areas in the Trans-Mexican Volcanic Belt; Los Humeros and Acoculco. Additionally, the $\mathrm{PhD}$ work was performed in close cooperation with TNO and Hungarian partners for the case studies in the Netherlands and Hungary respectively.

To model the thermal field within the lithosphere and ground movements induced by subsurface volume/pressure changes, target observations such as temperature measurements collected from boreholes and InSAR observations have been used. This is necessary because most of the processes and the corresponding physical parameters are marked by abundant uncertainties. To incorporate large numbers of observations into inverse models, probabilistic ensemble-based approaches have been proven to be powerful. Data assimilation using the ensemble smoother have already been tested in several studies for both large-scale thermal modeling (e.g. Limberger et al., 2018) and ground deformation modeling outside the geothermal sector (Baù et al., 2015; Candela et al., 2021; Fokker et al., 2016). In this thesis I aim a further extension of inversion techniques to geothermal exploration and exploitation, and demonstrate their relevance to better characterize geothermal systems and to reduce risks related to subsurface uncertainties.

The first part of the thesis concerns country-scale physics-based temperature models for Hungary (Chapter 2) and the Netherlands (Chapter 3), calibrated with large numbers of temperature measurements. With their construction we approximate the thermal state within the whole lithosphere. The models aim to reveal the driving processes (e.g. local convective heat transfer) and properties (e.g. increased thermal conductivity or radiogenic heat production of geological units) responsible for temperature anomalies. Such subsurface temperature models can be relevant for highlighting prospective areas for geothermal exploitation, geothermal resource assessment studies, and may serve as boundary conditions for smaller-scale, site-specific studies.

The second part of the thesis aims to demonstrate the requirements, limitations, and usefulness of ground deformation modeling for geothermal sites through case studies from two geothermal areas. Ground motion predictions are generated using the InSAR technique for two geothermal sites; in Hungary (Szentes Geothermal field, Chapter 4) and in Mexico (Los Humeros Geothermal Field, Chapter 5 and 6). Surface movement observations together with inverse modeling are used to understand subsurface processes, such as the compaction behavior of reservoir-systems, the role of natural or anthropogenic recharge, structural controls on the geothermal reservoirs and their surroundings, and (induced) seismicity. The two investigated geothermal areas largely differ in terms of geothermal play types. The Szentes geothermal field is located in a conduction-dominated sedimentary basin setting, while Los Humeros is a convection-dominated system with recent magmatic activity. We 
utilize this difference in setting to highlight the similarities and differences between the response of the geothermal systems to changes in the subsurface stress field due to exploitation.

\subsection{Thesis outline}

Following this Introduction chapter, Chapter 2 presents the subsurface temperature model of the Hungarian part of the Pannonian basin. Hungary is among the most favorable countries within Europe for geothermal development, due to its elevated heat flow and geothermal gradient. The outstanding geothermal conditions are the result of the extension and thermal attenuation of the lithosphere in Miocene times (e.g. Horváth, 1993). To account for the interplay between deep and shallow processes, we have to link our observations near the surface with the thermal anomalies deeper down in the lithosphere. To this end, lithosphericscale thermal models were constructed, and the lower boundary condition of the models were derived from the surface heat flow. Temperature measurements from boreholes were incorporated in the models as target observations. The thermal properties of the layers have been updated through the Ensemble Smoother with Multiple Data Assimilation (ES-MDA) technique (Emerick and Reynolds, 2013a) to provide a better fit with temperature observations.

Chapter 3 describes the thermal state of the onshore Netherlands from the surface down to $10 \mathrm{~km}$ depth. The high-resolution temperature model is constructed in multiple steps, starting from a lithospheric-scale, physics-based forward model and progressively detailing and updating it using temperature data by the ES-MDA technique, similarly to Chapter 2 . The geometry of sedimentary units were derived from the detailed geological model of the onshore Netherlands (DGM-deep v4.0, nlog.nl), and the thermal properties of the sedimentary layers were selected based on their lithotypes. The model solves the heat equation in steady state, assuming conduction as the main heat transfer mechanism. Local convective heat transfer might be dominant in deeply buried Devonian-Carboniferous carbonate platforms, indicated by the thermal profile found in the Luttelgeest-01 well (Bonté et al., 2012; Lipsey et al., 2016). These reservoirs are potentially suitable for industrial heating applications and electricity production. To this end, one of the main aspects of this chapter was to incorporate the thermal effect of hydrothermal convection within the Dinantian carbonate platforms.

Chapters $4-6$ employ ground motion estimates obtained by InSAR for the characterization of geothermal fields. In Chapter 4, satellite images were collected and processed from the southeast part of Hungary, exhibiting the highest temperature gradients combined with the presence of porous sandstone reservoirs. It focuses on the Szentes geothermal area, where the first wells utilizing geothermal energy besides bathing purposes took place in Hungary. The complete lack of reinjection wells resulted in significant reservoir pressure decline and hydraulic head decrease, leading to compaction and land subsidence. Since the mid-90's, reservoir pressure recovery has initiated due to the slight decrease in production rates, allowing for the recharge of the area. Time series of ground motions covering the reservoir recovery period were generated by Persistent Scatterer Interferometry 
(PSI, e.g. Ferretti et al. (2001)). A geomechanical model was established based on the solution of Geertsma (1973) for surface movements above a disk-shaped reservoir with uniform pressure change. The model parameters were constrained by ES-MDA in order to estimate the driving properties (e.g. compaction coefficient of the reservoir-system) and processes (e.g. elastic vs inelastic deformation) that are responsible for ground movements, which can be relevant for reservoir management.

Chapter 5 moves from sedimentary-basin settings to the Trans-Mexican Volcanic Belt, focusing on the Los Humeros Geothermal Field (LHGF). Los Humeros is among the most important geothermal power plants in Mexico, with an installed capacity of ca. $95 \mathrm{MW}$ of electric power (Gutiérrez-Negrín, 2019). The field is located inside the Quaternary Los Humeros caldera, and the geothermal reservoir is built up by pre-caldera andesites with relatively low porosity (e.g. Carrasco-Núñez et al., 2017). The LHGF is controlled by an active fault system by providing permeability pathways for geothermal fluids (e.g. Norini et al., 2015). Ground movements at Los Humeros for the period of 2003-2007 were mapped using PSI, and associated subsurface processes were investigated through subsequent source modeling. The main goals of this chapter were to reveal the subsurface pressure distribution, identify reservoir compartments, and better understand the role of pre-existing structures in the migration of geothermal fluids. Surface movements were related to volume changes in the reservoir through analytical solutions for different types of nuclei of strain, constrained with the PS points as target observations.

Chapter 6 presents coseismic surface deformation observations and related source modeling of the 8 February 2016, Mw=4.2 earthquake at Los Humeros. The main motivation behind this chapter was to better understand the behavior, geometry and kinematics of the activated Los Humeros fault, which is assumed to have major control on the geothermal system. Models for the coseismic deformation were constructed based on uniform slip on a rectangle (Okada, 1985). Prior ranges for the model parameters were selected according to structural models for the area (e.g. Norini et al., 2019) and partly based on the seismological model for the seismic event (Lermo Samaniego et al., 2016). Models were interpreted by the integration of external geophysical and geological models to explain the estimated source parameters. Additionally, prolonged deformation for 3 years after the earthquake was mapped with Sentinel-1 interferometry, using the PSI technique. Ground motions between 2016-2019 were compared with the results of Chapter 5 to identify potential post-seismic deformation, and to infer for further subsurface processes (e.g. pressure/temperature changes related to geothermal production and/or magmatic activity) that are responsible for the observed ground deformation patterns.

Chapter 7 summarizes the main results of the case studies, describing the added value of advanced methodologies towards the characterization of geothermal reservoirs. 


\section{Subsurface temperature model of the Hungarian part of the Pannonian Basin 1}

${ }^{1}$ This chapter is based on Békési, E., Lenkey, L., Limberger, J., Porkoláb, K., Balázs, A., Bonté, D., Vrijlandt, M., Horváth, F., Cloetingh, S., and van Wees, J.D. (2018). Subsurface temperature model of the Hungarian part of the Pannonian Basin. Global and Planetary Change, 171, 48-64. 


\subsection{Introduction}

The Pannonian Basin is one of the most suitable areas for geothermal development in Europe (Cloetingh et al., 2010; Horváth et al., 2015; Limberger et al., 2014) due to the elevated geothermal gradient and high heat flow density values (Lenkey et al., 2002). The temperature gradient varies between 40 and $50 \mathrm{~K} / \mathrm{km}$ in the upper $5 \mathrm{~km}$, resulting in elevated temperatures in shallow depth. The $200{ }^{\circ} \mathrm{C}$ isotherm can be reached above $4 \mathrm{~km}$, ensuring favourable conditions for deep geothermal exploration. The geothermal prospectivity is largely due to Miocene extension, which resulted in the high thermal attenuation of the lithosphere (Horváth, 1993). The syn-rift phase was followed by thermal subsidence and continuous sedimentation, and the basin was finally filled by sediments up to 6-7 km thickness. The porous basin infill and fractured carbonatic rocks are of great interest for geothermal utilization. Thermal water production in the Pannonian Basin has been carried out since the $19^{\text {th }}$ century. On the other hand, fractured crystalline basement rocks are also considered as high potential targets for deep geothermal development (Dövényi et al., 2005), but production from these high-temperature high-pressure systems has not taken place yet.

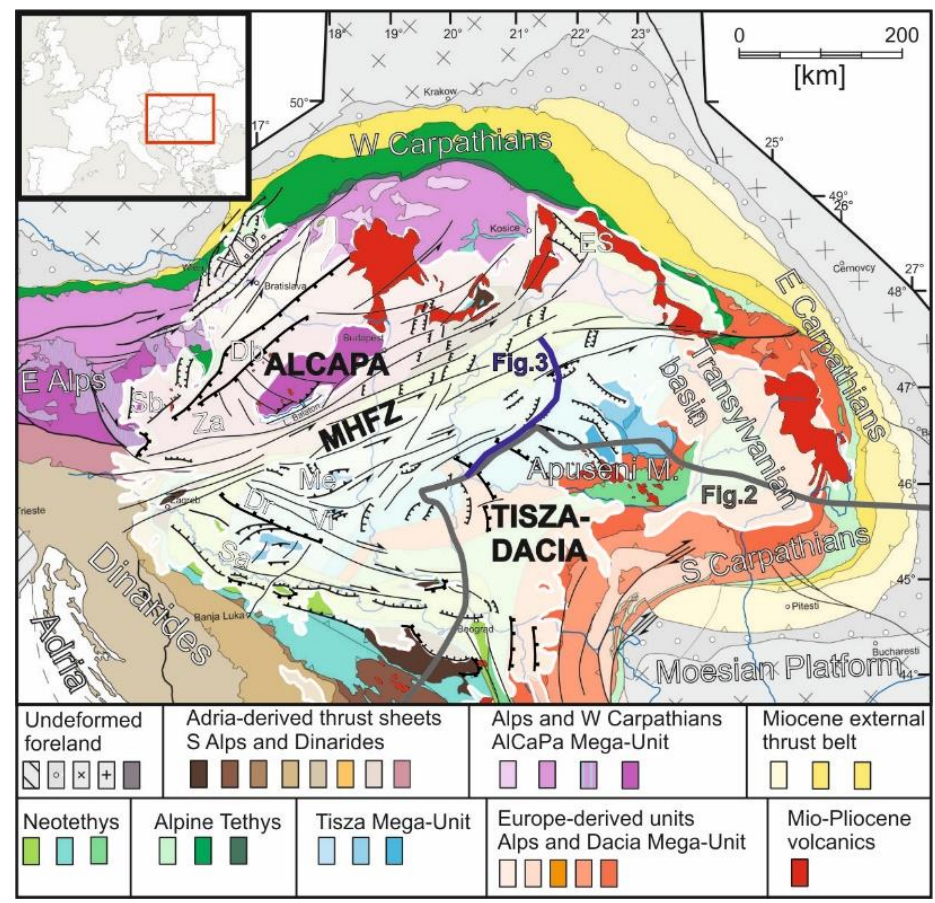

Figure 2.1: Miocene-Quaternary tectonic map of the Pannonian Basin showing the present-day extent of the Neogene sediment cover of the Pannonian, Vienna, and Transylvanian basins and the major Miocene to Quaternary faults after Balázs et al. (2016). $\mathrm{Vb}=$ Vienna Basin, Sb $=$ Styrian basin, $\mathrm{Dr}=$ Dráva sub-basin, $\mathrm{Sa}=$ Sava sub-basin, $\mathrm{Za}=$ Zala sub-basin, $\mathrm{Me}=$ Mecsek hill, Vi=Villány mountains, $\mathrm{Db}=$ Danube basin, ES = East Slovakian basin, MHFZ = Mid-Hungarian Fault Zone. 
The main controlling parameters of geothermal systems are the flow rate and the temperature of the reservoir fluid. The minimum production temperatures required for district heating and electricity are $70{ }^{\circ} \mathrm{C}$ and $130{ }^{\circ} \mathrm{C}$ respectively, but the exact temperature ranges vary due to the geothermal power plant configurations. Since the flow rate is strongly dependent on the permeability of the reservoir, in most cases treatment to enhance the permeability is necessary for geothermal power generation. High temperature basement rocks at relatively shallow depth are considered one of the most promising targets for Enhanced Geothermal Systems (EGS) due to the reduced costs of drilling and higher natural permeability. Therefore, to find the location of these reservoirs, it is crucial to have a good constraint on the subsurface temperature distribution.

Several studies on the heat flow density and subsurface temperature field of the Pannonian Basin have been performed. Čermák and Bodri (1986) calculated the temperature distribution in steady-state along regional deep seismic sections and found that the high heat flow in the Pannonian Basin originated from the mantle. Subsurface temperatures and the integrated strength in the lithosphere were calculated along two cross sections through the Western Carpathians - Pannonian Basin - Transylvanian basin - Eastern Carpathians by Lankreijer et al. (1999). They concluded that the internal part is characterized by hot and weak lithosphere, whereas the European foreland and Ukrainian Shield comprise the mechanically strong frame of the Carpathians. Lenkey (1999) corrected the surface heat flow density for the cooling effect of Neogene and Quaternary sedimentation by time-dependent thermal modeling. The subsurface temperature distribution of Hungary was constrained by Dövényi et al. (2005). They found that the most suitable areas for EGS plants are the basement highs of the Great Hungarian Plain. The geothermal resources of Hungary were evaluated in several earlier studies (Horváth et al., 2015; e.g. Rezessy et al., 2005). Lenkey et al. (2017) constructed both a steady-state and a time-dependent 3D lithospheric-scale thermal model of the Alpine-Pannonian transition zone.

In this paper we present the first 3D lithospheric-scale high-resolution thermal model of Hungary. Subsurface temperatures are shown in different depth intervals providing an insight into deep temperature anomalies. Therefore, our model can serve as a reference model to reveal potential areas for geothermal development in Hungary. Additionally, our model predicts subsurface temperature in larger depth, which is crucial to understand the thermomechanical state of the lithosphere (Cloetingh et al., 2010).

\subsection{Formation and evolution of the Pannonian Basin}

The Neogene formation of the Pannonian Basin by extension was preceded by Cretaceous-Paleogene contraction and nappe stacking in the Circum-Pannonian region. The former orogenic area now constitutes the basement of the Pannonian Basin and consists of two major structural units: the $\mathrm{AlCaPa}$ and the Dacia-Tisza mega-units (Figure 2.1). The evolution of these units reflects the opening and subsequent closure of the Neotethys and Alpine Tethys oceanic realms. (e.g. Csontos and Vörös, 2004; Schmid et al., 2008). The $\mathrm{AlCaPa}$ Mega-unit is an Adria-derived composite thrust sheet that was sutured to Europe as a result of the Cretaceous-Paleogene closure of the Alpine Tethys realm. The shortening and 
nappe stacking was followed by lateral extrusion in the $\mathrm{AlCaPa}$ due to the combination of overthickening in the Alps and the initiation of slab-rollback in the Carpathians (Ratschbacher et al., 1991). The Tisza-Dacia mega-unit was emplaced on top of the Dinaridic nappes by the final closure of the Neotethys during latest Cretaceous to Paleogene times. Onset of Oligocene-Early Miocene extrusion was accompanied by large-scale offsets along transcurrent shear zones and opposite sense rotations, i.e., counterclockwise in $\mathrm{AlCaPa}$ and clockwise in Tisza-Dacia (Balla, 1986, 1988; Márton and Fodor, 2003). These mega-units were juxtaposed along a major suture zone, the Mid-Hungarian Fault Zone (MHFZ) that accommodated the former subduction polarity change of the Alpine- and Neotethys (Csontos and Nagymarosy, 1998).

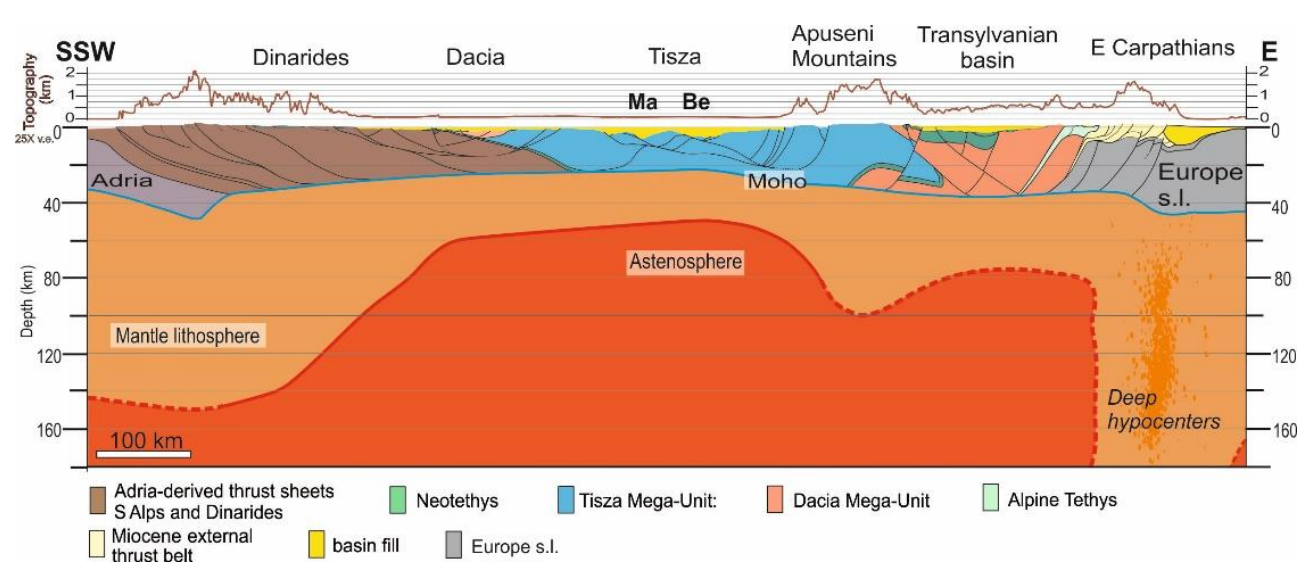

Figure 2.2: Lithospheric-scale cross-section over the Dinarides-Pannonian Basin-Apuseni MountainsTransylvanian Basin-East Carpathians after Balázs et al. (2017) (see for location Figure 2.1). Ma Makó sub-basin, Be - Békés sub-basin.

Similar to other Mediterranean back-arc basins (e.g. Faccenna et al., 2014) extensional deformation was localized at inherited weakness zones, led to asymmetric basin evolution (Figure 2.2; Balázs et al., 2017) and reactivated former thrust and nappe contacts (e.g. Horváth and Rumpler, 1984; Tari et al., 1992). This controlled the extensional exhumation of deep crustal rocks and the formation of metamorphic core complexes at the Alpine and Dinaridic basin margins (Fodor et al., 2008; Matenco et al., 2016; Tari et al., 1992; Ustaszewski et al., 2010). Initial pulses of back-arc extension were followed by the progressive opening of deep half-grabens between Early to Late Miocene (Matenco and Radivojević, 2012; Merten et al., 2010). The lithospheric structure and the geometry of the basin system is shown in Figure 2.2. The sub-basins are characterized by different timing of active extensional deformation and sedimentation, recorded by the syn-kinematic basin fill, proving that extension in the Pannonian basin migrated in space and time throughout the entire Miocene in the basin (Figure 2.3; Balázs et al., 2016). 


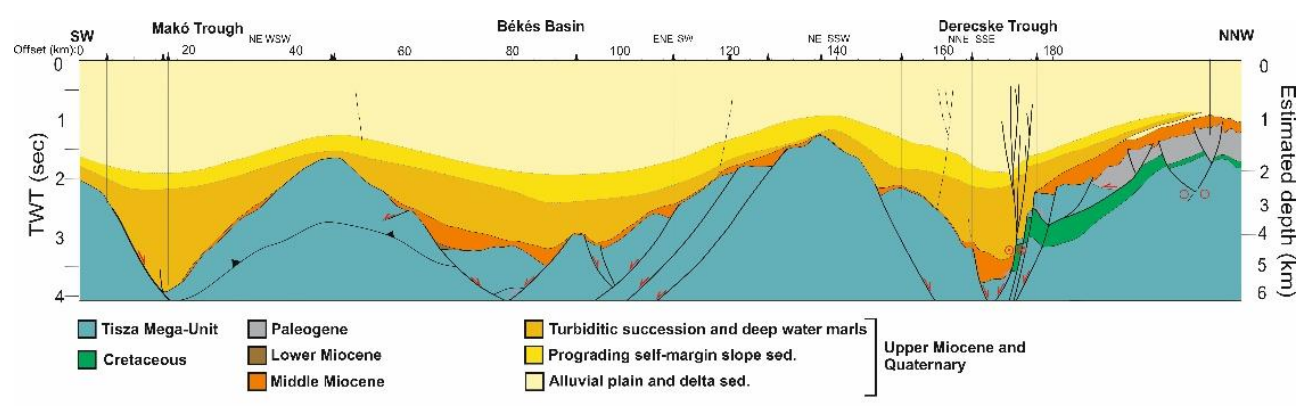

Figure 2.3: Interpreted composite reflection seismic transect from the eastern part of the Pannonian Basin simplified after Balázs et al. (2016) showing the main tectonic and stratigraphic features of the area (see for location Figure 2.1).

The sedimentary fill of the Pannonian Basin reflects the migration of extensional deformation and subsidence in time and space as well as the closure and re-opening of oceanic gateways, which happened repeatedly starting during late Eocene in the Paratethys region due to uplift of orogens surrounding the basin system. The closure of oceanic gateways resulted in a marine to brackish lacustrine environment in the Pannonian Basin characterized by an endemic fauna which required the establishment of a separate regional biostratigraphy in the Central Paratethys region (e.g. Báldi and Royden, 1986; Nagymarosy and Muller, 1988).

Early Miocene sedimentation was characterized by shallow marine deposits in the northwestern part of the Pannonian Basin (Hámor, 2001), contrasting the fluvial and lacustrine environment in the area of the Great Hungarian Plain (e.g. Pavelić et al., 2001). Continuous extension resulted in the deposition of deep basinal Middle Miocene sediments in the depocenters such as grabens and half-grabens (Figure 2.3), and near-shore shallow marine siliciclastic and carbonatic deposits along the uplifted footwalls of active normal faults.

Active extension was followed by post-rift thermal subsidence and basin inversion. The onset of post-extensional evolution in the Pannonian Basin appears to be older in the western parts and younger towards the SE Carpathians (Figures 2.1, 2.3). In the NW part of the basin system, significant normal displacements ceased in the Middle-Miocene (Tari et al., 1999), while in the Great Hungarian Plain cessation of active extensional deformation occurred during Late Miocene times, for instance in the Makó or Derecske sub-basins (Figure 2.3; Balázs et al., 2016).

Post-rift sedimentation took place in a completely restricted lake environment (i.e., Lake Pannon) following the final isolation of the region due to significant uplift in the Carpathians (Magyar et al., 1999). Sedimentation was controlled by a fluvial system which transported large amount of sediments from the neighboring orogenic areas and determined a characteristic pattern of shelf margin and slope progradation towards the deep basin (Magyar et al., 2013; Pogácsás et al., 1988; Vakarcs et al., 1994). Figure 2.3 shows the tectonosedimentary architecture of the post-rift basin fill; coeval but lithologically different 
sediments deposited in the confines of the progradational system: alluvial plain, delta, prograding shelf slope, turbiditic, and deep hemipelagic formations characterize the post-rift strata (e.g. Juhász, 1991). The thick post-rift siliciclastic deposits (up to $7 \mathrm{~km}$ beneath the Great Hungarian Plain) essentially determine the present hydraulic and thermal characteristics of the Pannonian Basin, and are discussed below in details.

The Neogene-Quaternary formation of the Pannonian basin was accompanied by diverse magmatism. Different stages of silicic, calc-alkaline, and alkaline basaltic volcanic activity were largely controlled by the lithospheric extension in the Pannonian basin and the dehydration of the subducting slab beneath the Carpathians (e.g. Kovács et al., 2004; Harangi and Lenkey, 2007).

Continuous push of the Adriatic microplate towards the thermally weakened Pannonian Basin combined with the cessation of slab-rollback process beneath the Carpathians resulted in Late Miocene to recent basin inversion marked by newly formed reverse faults, reactivated structures, and basin-scale folding effects (Bada et al., 2007; Fodor et al., 2005; Horváth and Cloetingh, 1996; Magyar and Sztanó, 2008).

\subsection{Temperature and heat flow data}

We calibrated our models with subsurface temperature and heat flow data obtained from the Geothermal Database of Hungary (Dövényi and Horváth, 1988; Dövényi et al., 2002; Figure 2.4). The dataset is based on Bottom Hole Temperature (BHT) measurements, inflowing and outflowing water temperatures, Drill-Stem Tests (DST) in hydrocarbon wells and steady-state temperature measurements from about 4800 boreholes.

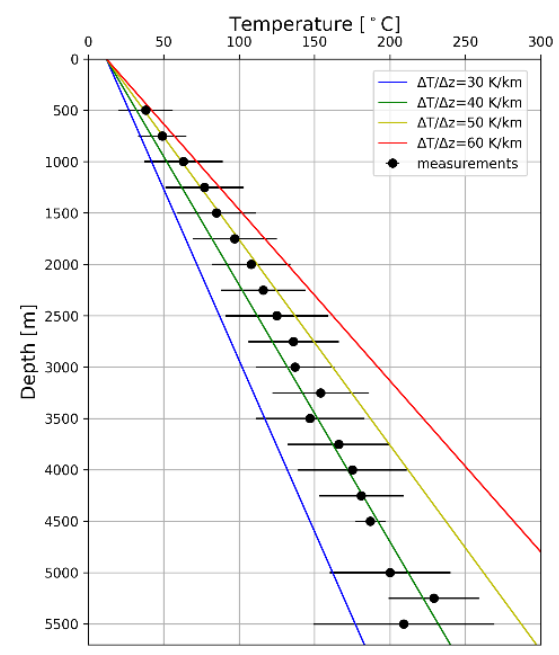

Figure 2.4: Characteristic temperature-depth profile from the Pannonian Basin modified after Dövényi and Horváth (1988). The circles and bars indicate the average value and variation of temperature measurements at certain depth (respectively). The lines represent geotherms corresponding to 30,40 , 50 and $60 \mathrm{~K} / \mathrm{km}$. 
Primary heat flow determinations are available from 28 boreholes in the central part of the Pannonian Basin with reliable temperature data from different depths and thermal conductivity measurements on core samples. Furthermore, heat flow was calculated in boreholes where the lithology and reliable temperature data were available using conductivity versus depth diagrams after (Dövényi and Horváth, 1988). The observed heat flow may be disturbed by fast sedimentation, erosion and groundwater flow. Heat flow determinations were corrected for the thermal effect of sedimentation taking into account the variation in sedimentation rate and change in the thermal properties due to compaction (Lenkey, 1999).

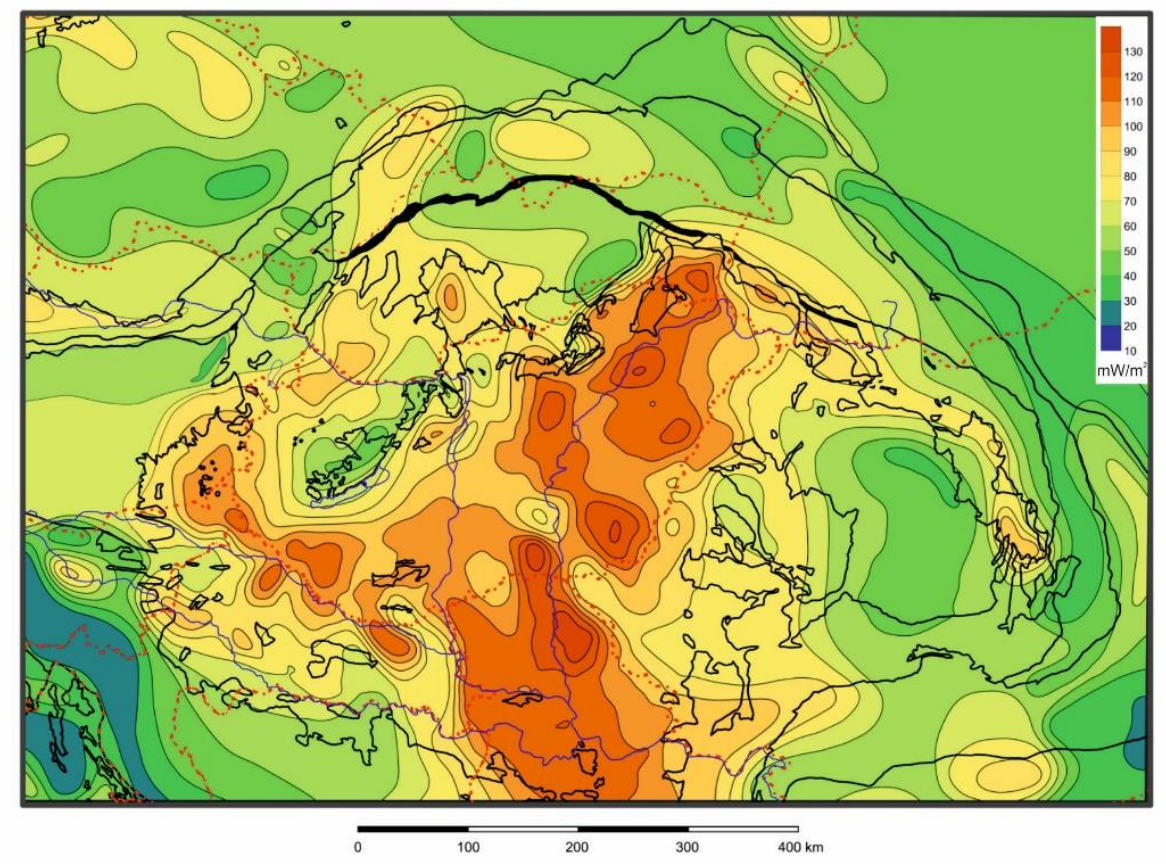

Figure 2.5: Surface heat flow map corrected for sediment blanketing effects of the Pannonian Basin and its surroundings after Lenkey et al. (2002) modified in the Eastern Alps after Hofmann and Schönlaub (2007).

Figure 2.5 shows the corrected surface heat flow map of the Pannonian Basin and its surroundings (Lenkey et al., 2002). Heat flow values are in the range of 50 to $130 \mathrm{~mW} / \mathrm{m}^{2}$ with a mean of $100 \mathrm{~mW} / \mathrm{m}^{2}$. In general, the Pannonian Basin can be characterized by considerably higher heat flow than the surrounding areas. The Ukrainien and Moesian Platforms exhibit low heat flow $\left(40-50 \mathrm{~mW} / \mathrm{m}^{2}\right)$. Extremely low values $\left(30 \mathrm{~mW} / \mathrm{m}^{2}\right)$ in the Outher Dinarides can be explained by the cooling effect of descending water flow in the karstified carbonate rocks (Ravnik et al., 1995). The Carpathians, Inner Dinarides and Bohemian Massif are marked by average continental heat flow around $50-70 \mathrm{~mW} / \mathrm{m}^{2}$. The average heat flow density in the Vienna basin is $50-70 \mathrm{~mW} / \mathrm{m}^{2}$, whereas the Danube basin 
exhibits elevated values $\left(80-90 \mathrm{~mW} / \mathrm{m}^{2}\right)$. The Transylvanian basin is considerably colder than the central basins, reflecting the differences in the mechanisms of basin evolution (e.g. Tiliţă et al., 2013). In the southern part of the Eastern Carpathians the heat flow is considerably higher related to recent volcanic activity (e.g. Karátson et al., 2013; Szabó et al., 1992). Heat flow density in the inner part of the Pannonian Basin shows a NW to SE trending pattern, with elevated values towards the SE. Surface heat flow in the Styrian basin and Zala-Mura basin is around 90 and $110 \mathrm{~mW} / \mathrm{m}^{2}$, respectively. Values in the southern, eastern (Great Hungarian Plain and its continuation into the Serbian basin and Vardar zone) and in the northeastern (Eastern Slovakian basin) part of the Pannonian Basin exceed $110 \mathrm{~mW} / \mathrm{m}^{2}$, forming the hottest areas of the region. On the other hand, lower heat flow in the Makó trough and Békés sub-basin can be explained by the cooling effect of the ca. 7-8 km thick young sediments (Lenkey, 1999). Significantly large heat flow anomaly can be attributed to the Serbian basin, which conforms well with the low crustal and lithospheric thickness of the region (Figure 2.2). The Transdanubian Range and some parts of the Hungarian mountains in the Northeast built up by fractured and karstified carbonates are characterized by low heat flow $\left(50 \mathrm{~mW} / \mathrm{m}^{2}\right)$, due to the infiltration of cold meteoric water. Descending water penetrating deep into the carbonates is heated up and may return to the surface along faults at hot springs near the foot of the mountains. Lenkey et al. (2002) has calculated the convective heat flow component caused by groundwater flow in recharge areas from the ratio of the total energy output and the area of the mountains. Results show that the heat flow corrected for convective effects is close to the heat flow observed around the exposed carbonates.

\subsection{Hydraulic systems and geothermal resources}

Two regional water flow systems exist in the Pannonian Basin representing an upper and lower domain (Tóth and Almási, 2001). The upper domain is characterized by gravity-driven flows directed downwards in recharge areas and upwards in discharge areas. These systems prevail both in porous Neogene and Quaternary sedimentary rocks and exposed Mesozoic carbonates together with their subsurface continuations. The subsurface extent of gravitydriven flows are mostly about $2 \mathrm{~km}$ in the basin infill, on the other hand flows can penetrate deeper in the permeable carbonates (Horváth et al., 2015). In the lower hydraulic domain an overpressure-driven flow system prevails in the Early and Middle Miocene synrift sediments and fractured pre-Cenozoic basement rocks. Lower Pannonian sediments (mainly marls, based on the regional stratigraphic subdivision (e. g. Piller et al., 2007)) form the upper lid of these systems. The upper and lower domains are separated by a pressure seal, but these systems are not completely isolated, since hydraulic communication between the different parts of the flow domains may exists along open faults (e.g. Mádl-Szönyi and Tóth, 2009; Mádl-Szőnyi et al., 2017).

The porous basin infill is made up of mainly sand and sandy clay layers representing shelf front, shelf, and alluvial plain deposits that form the largest hydrostratigraphic unit in the Pannonian Basin. In general, gravity-driven fluid flow systems are directed from the peripheral areas towards the central part of the Pannonian Basin. In the Great Hungarian Plain 
- where the relief is very smooth - local flow systems with shallow streamlines follow the local topographic variations. Additionally, the major recharge and discharge areas are connected by deeper penetrating streamlines. Gravity-driven flow systems in the Upper Pannonian (based on the regional stratigraphic subdivision (e. g. Piller et al., 2007)) geothermal aquifers in the western part of Hungary is strongly connected to the Austrian, Slovenian and Slovakian aquifers (Tóth et al., 2016).

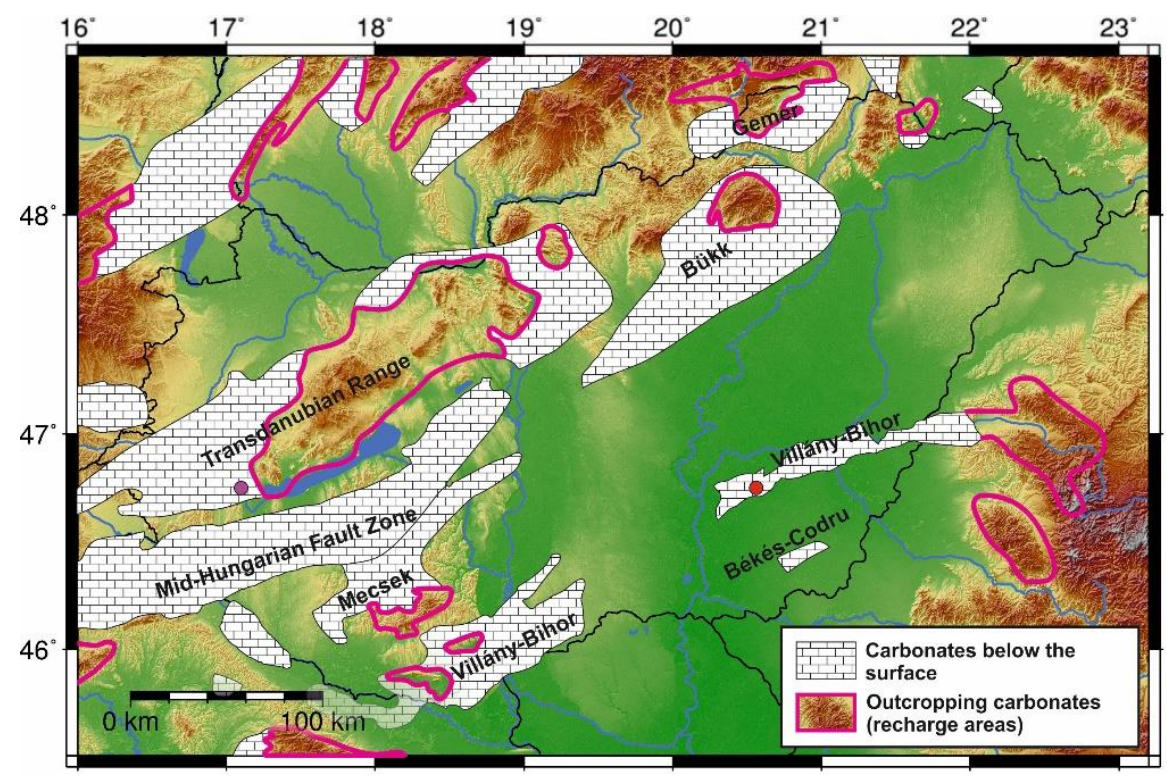

Figure 2.6: Map showing the outcropping fractured-karstified Mesozoic carbonates (recharge areas) and their subsurface extent (discharge areas) modified after Horváth et al. (2015). Purple and red dots indicate Hévíz and Fábiánsebestyén, where hydrothermal convection due to gravity-driven flow systems and overpressured systems occur, respectively.

Fractured and karstified Mesozoic carbonates representing upper nappes in the $\mathrm{AlCaPa}$ Mega-unit (e.g. Transdanubian Range) and Tisza-Dacia Mega-unit (e.g. Mecsek, VillányBihor, Békés-Codru nappes) and Dinaric units (e.g. below the Mid-Hungarian Fault Zone or Bükk) also exhibit considerable water resources (Figure 2.6). As discussed in the previous section (2.3), gravity-driven fluid flow systems cause the reduction of heat flow of large carbonate plateaus resulting in lower temperatures due to descending cold water (Figure 2.7). The penetration depth of streamlines can be approximated by the temperature of hot springs at discharge areas, suggesting that water emerges from even $3 \mathrm{~km}$ depth (Lenkey et al., 2002). Water circulation is mainly driven by the hydraulic head, but ascent of hot water is also enhanced by temperature-induced density and viscosity reduction (Goldscheider et al., 2010). Considerable amount of hot springs are located along fault zones, for instance, in Budapest and Hévíz (Figure 2.6), located East and West of the Transdanubian Range, respectively. 

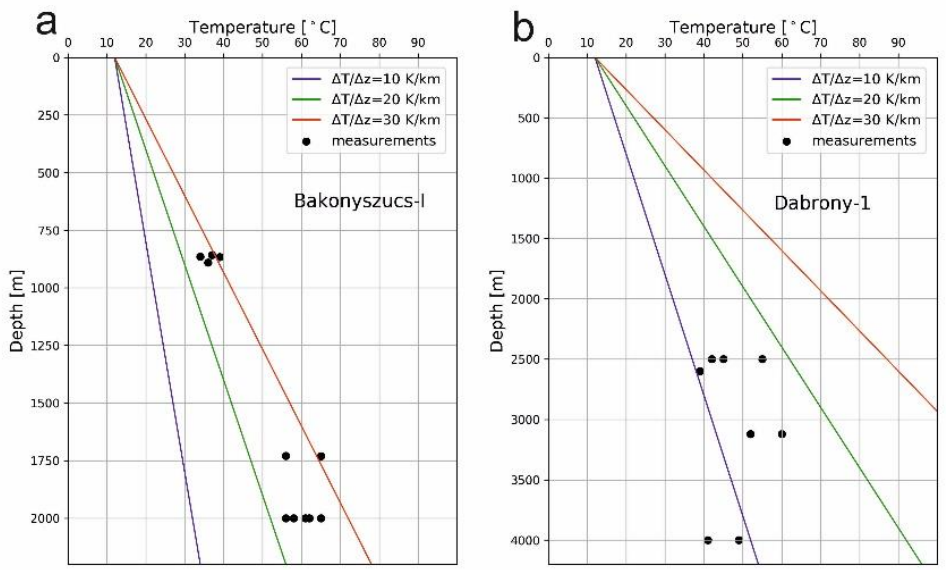

Figure 2.7: Temperature measurements (black circles) from wells drilled in the recharge area of the Transdanubian Range. The lines represent geotherms corresponding to 10, 20 and $30 \mathrm{~K} / \mathrm{km}$. Note the very low observed temperatures due to the infiltration of cold meteoric water.

It has been shown by Gordon and Flemings (1998) that overpressured hydrostratigraphic units are commonly observed in sedimentary basins with ongoing subsidence and sedimentation. This phenomena is also present in the deeper parts of the Pannonian Basin (e.g. Van Balen et al., 1999). In the fractured Mesozoic basement rocks, free convection systems can occur due to the high permeability, temperature and pressure (Lenkey et al., 2002). These systems are well-known from Fábiánsebestyén (Figure 2.6), where a dramatic blowout occurred when the drilling penetrated the Triassic carbonates of the Villány-Bihor basement unit.

Neogene to Quaternary clastic basin infill, Mesozoic carbonates and the fractured crystalline basement represent the main potential target zones for geothermal utilization in Hungary. Thermal water production rate from the porous Pannonian beds is typically 200$300 \mathrm{~m}^{3} /$ day with the production temperature in the range of $30-100{ }^{\circ} \mathrm{C}$. Flow rates of geothermal wells drilled into fractured Mesozoic rocks reach even $1000-1500 \mathrm{~m}^{3} /$ day due to their considerable subsurface extent and high permeability (Horváth et al., 2015), with production temperatures even above $150{ }^{\circ} \mathrm{C}$ (Rotár-Szalkai et al., 2017). Fractured crystalline basement rocks at larger depth are also high potential targets for deep geothermal development (Dövényi et al., 2005), however production from these high-temperature highpressure systems has not been carried out yet.

\subsection{Methodology}

We first adopt an a priori physics-based forward model in order to construct the thermal model of the deep subsurface of Hungary. Then, the prior parameterization of the model is updated through a data assimilation method in order to provide predicted temperatures to fit better with the observations (Figure 2.8). Subsurface temperatures are obtained by solving the heat equation in steady-state, assuming conduction as the main heat transfer mechanism. 
Initial calculations are performed in a multi-1D approach and are incorporated in the 3D forward model as initial information on the temperature and thermal properties in each of the grid cells. The 3D forward model solves the heat transport equation by finite-difference approximation using the Preconditioned Conjugate Gradient method (PCG). A variation in the basal condition (temperature or heat flow), radiogenic heat generation and the vertical thermal conductivity can be introduced through the ensemble smoother with multiple data assimilation technique (ES-MDA, Emerick and Reynolds, 2013a) to obtain a better fit with observed temperatures, described in section 2.5.5. The ES-MDA has also been applied by Fokker et al. (2016) for reservoir modeling to constrain subsurface model parameters. More details on the methodology can be found in the IMAGE-D6.01 report (http://www.imagefp7.eu/reference-documents/Pages/default.aspx) and Limberger et al. (2018).

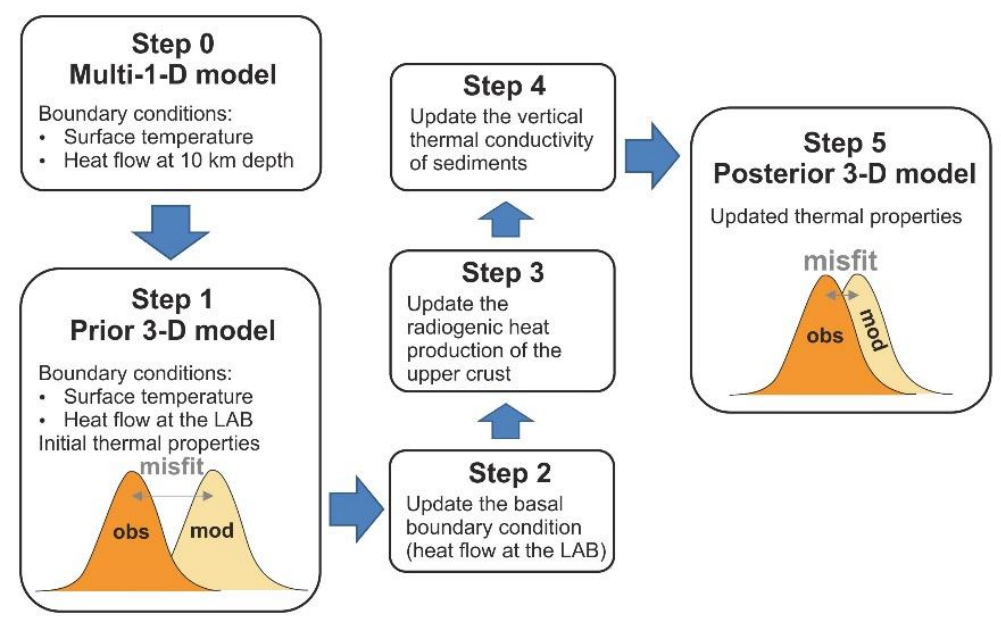

Figure 2.8: Overview of the modeling workflow.

\subsubsection{Geometry of the model}

The thermal model was built in the Hungarian National Coordinate System (EOV) extending vertically from the surface until the litosphere-astenosphere boundary (LAB). The outline of the model is identical with the political boundary of Hungary. Subsurface temperatures were calculated through a regular 3D grid with a horizontal resolution of 2.5 $\mathrm{km}$, a vertical resolution of $200 \mathrm{~m}$ for the uppermost $7 \mathrm{~km}$, and $3 \mathrm{~km}$ down to the depth of the LAB. The geometry of the model is outlined by 9 layers: 6 sedimentary layers, upper crust, lower crust and lithospheric mantle, where each layer is described by its own material properties. The crustal and lithospheric thickness are obtained from Horváth et al. (2006), with the average values of $27 \mathrm{~km}$ and $60 \mathrm{~km}$, respectively. For the sedimentary layers we follow horizons obtained from the map database of the Geological and Geophysical Institute of Hungary (https://map.mfgi.hu/) following the regional stratigraphic subdivision (e. g. 
Piller et al., 2007). The basement is defined by the pre-Cenozoic map of Haas et al. (2010) supplemented by the outcropping Mesozoic carbonates and their subsurface extent from Horváth et al. (2015). The division of crystalline and carbonate basement is particularly relevant to account for the contrast between the thermal properties and to model potential hydrothermal convection.

\subsubsection{Thermal properties}

The thermal conductivity values of the clastic sediments were adopted after (Dövényi and Horváth, 1988) using the porosity-dependent empirical formulas for sandstones and shales in the Pannonian Basin. The sediments are subdivided into lithotypes, and their thermal properties are represented by a mixture of typical lithologies listed in Table 2.1. The thermal conductivity of Mesozoic carbonates is defined as a mixture of typical values of limestones and dolomites after Hantschel and Kauerauf (2009). The matrix conductivities of the different sedimentary units were calculated as the arithmetic mean for horizontal conductivities, and harmonic mean for vertical conductivities following the methodology of (Hantschel and Kauerauf, 2009). To calculate the thermal properties of the crust and mantle, we follow the methodology that was applied by Limberger et al. (2017) and reported in Table 2.2. For the upper and lower crust, we adopted the temperature and pressure dependent function of Chapman (1986). With increasing temperature down to the lithospheric mantle, the contribution of the radiative component of the thermal conductivity increases compared to the lattice component. Therefore, the conductivity of the lithospheric mantle was calculated by taking into account the effect of the radiative component after Schatz and Simmons (1972). For the lattice thermal conductivity of the lithospheric mantle, we follow the formula of Xu et al. (2004). 


\begin{tabular}{|c|c|c|c|}
\hline Layer name & Lithology & $\begin{array}{l}\text { Radiogenic } \\
\text { heat } \\
\text { production } \\
{[\mu \mathrm{W} / \mathrm{m} 3]}\end{array}$ & $\begin{array}{l}\text { Thermal conductivity } \\
\qquad[\mathrm{W} / \mathrm{m} * \mathrm{~K}]\end{array}$ \\
\hline Quaternary (Q) & $\begin{array}{l}70 \% \text { Clastic Sediment Sand } \\
30 \% \text { Clastic Sediment Shale }{ }^{[1]}\end{array}$ & 1.0 & \multirow{5}{*}{$\begin{array}{c}\text { Bulk values per lithotypes } \\
\text { (mixed lithologies), dependen } \\
\text { on compaction (Dövényi and } \\
\text { Horváth, 1988) }\end{array}$} \\
\hline $\begin{array}{l}\text { Upper-Pannonian } \\
\text { (UP) }\end{array}$ & $\begin{array}{l}50 \% \text { Clastic Sediment Sand } \\
50 \% \text { Clastic Sediment Shale }{ }^{[1]}\end{array}$ & 1.2 & \\
\hline $\begin{array}{l}\text { Lower-Pannonian } \\
\text { (LP) }\end{array}$ & $\begin{array}{l}10 \% \text { Clastic Sediment Sand } \\
90 \% \text { Clastic Sediment Shale }{ }^{[1]}\end{array}$ & 1.6 & \\
\hline $\begin{array}{l}\text { Neogene (pre- } \\
\text { Pannonian) (N) }\end{array}$ & $\begin{array}{l}65 \% \text { Clastic Sediment Sand } \\
35 \% \text { Clastic Sediment Shale }{ }^{[1]}\end{array}$ & 1.0 & \\
\hline Paleogene (P) & $\begin{array}{l}20 \% \text { Clastic Sediment Sand } \\
80 \% \text { Clastic Sediment Shale }{ }^{[1]}\end{array}$ & 1.5 & \\
\hline $\begin{array}{c}\text { Mesozoic } \\
\text { carbonates (M) }\end{array}$ & $\begin{array}{l}50 \% \text { Limestone Typical } \\
50 \% \text { Dolomite Typical }\end{array}$ & 0.5 & $\begin{array}{l}\text { Bulk values per lithotypes } \\
\text { (mixed lithologies), dependent } \\
\text { on compaction and } \\
\text { temperature (Hantschel and } \\
\text { Kauerauf, 2009) }\end{array}$ \\
\hline
\end{tabular}

Table 2.1: Overview of the sedimentary layers and their corresponding lithologies. ${ }^{[1]}$ Lithological composition of the sedimentary layers were obtained from Berczi (1988).

The radiogenic heat production of each sedimentary unit was selected to constants calculated as a mixture of typical values of sandstones and shales after (Hantschel and Kauerauf, 2009). The volumetric heat production of the upper crust is considerably higher than the sediments and lower crust, since its typical lithotype is granite. In the prior model we set the heat generation of the upper crust to $1.4 \mu \mathrm{W} / \mathrm{m}^{3}$ corresponding to typical continental upper crustal values. The heat production of Neogene volcanic rocks in Hungary is similar in case of basalts and andesites, on the other hand rhyolites and dacites have higher values (Lenkey and Surányi, 2006). For the heat generation of the lower crust and lithospheric mantle, we prescribed 0.5 and $0.02 \mu \mathrm{W} / \mathrm{m}^{3}$ (Hasterok and Chapman, 2011), respectively. 


\begin{tabular}{|c|c|c|c|}
\hline Layer name & $\begin{array}{c}\text { Average } \\
\text { thickness }[\mathrm{km}]\end{array}$ & $\begin{array}{l}\text { Radiogenic heat } \\
\text { production } \\
{\left[\mu \mathrm{W} / \mathrm{m}^{3}\right]}\end{array}$ & $\begin{array}{l}\text { Thermal conductivity } \\
\qquad[\mathrm{W} / \mathrm{m} * \mathrm{~K}]\end{array}$ \\
\hline Upper crust (UC) & \multirow{2}{*}{$\begin{array}{l}27 \\
\text { (crustal } \\
\text { thickness) }\end{array}$} & 1.4 & $\begin{array}{l}\text { Pressure- and temperature- } \\
\text { dependent (Chapman, 1986) }\end{array}$ \\
\hline Lower crust (LC) & & 0.4 & $\begin{array}{l}\text { Pressure- and temperature- } \\
\text { dependent (Chapman, 1986) }\end{array}$ \\
\hline $\begin{array}{l}\text { Lithospheric mantle } \\
\text { (LM) }\end{array}$ & $\begin{array}{l}60 \\
\text { (lithosphere } \\
\text { thickness) }\end{array}$ & 0.02 & $\begin{array}{l}\text { Lattice thermal conductivity (Xu } \\
\text { et al., 2004) } \\
\text { and radiative thermal conductivity } \\
\text { (Schatz and Simmons, 1972) }\end{array}$ \\
\hline
\end{tabular}

Table 2.2: Overview of the average thickness, radiogenic heat production values and thermal conductivities of the crust and lithospheric mantle.

\subsubsection{Boundary conditions}

We constructed three models by adopting different basal boundary conditions. Our first and second model are based on surface heat flow observations, whereas the third model accounts for the time-dependent effect of sub-recent lithospheric extension. For the top of all models we prescribed the average surface temperature of $12{ }^{\circ} \mathrm{C}$ as a Dirichlet boundary condition. The vertical edges of the models were marked by zero heat flow.

Since the elevated surface heat flow and high geothermal gradient in the Pannonian Basin are due to lithospheric-scale tectonic processes, the thermal effect of extension can only be reproduced by lithospheric-scale modeling. To account for the interplay between deep and surface processes, we have to link our observations near the surface with the thermal anomalies deeper down in the lithosphere. Therefore, we derived the lower boundary condition of our models from the surface heat flow. First, we imposed a Neumann boundary condition on heat flow at $10 \mathrm{~km}$ depth for the multi 1D temperature calculations of both models. In Model 1 and Model 2, we opted for a constant value of $70 \mathrm{~mW} / \mathrm{m}^{2}$, which was calculated by subtracting the total radiogenic heat production of each vertical column from the surface heat flow after Lenkey et al. (2002) and taking their average value. Heat flow derived from the crustal and subcrustal stretching factors (Figure 2.9) after Lenkey (1999) was introduced in the multi-1D calculations as a boundary condition of Model 3 in $10 \mathrm{~km}$ depth. Similar to the previous model, tectonic surface heat flow was corrected for the effect of heat generated in rocks until $10 \mathrm{~km}$ depth. Heat flow at the LAB derived from the multi $1 \mathrm{D}$ models was used as a basal boundary condition for the $3 \mathrm{D}$ calculations summarized in Table 2.3. 

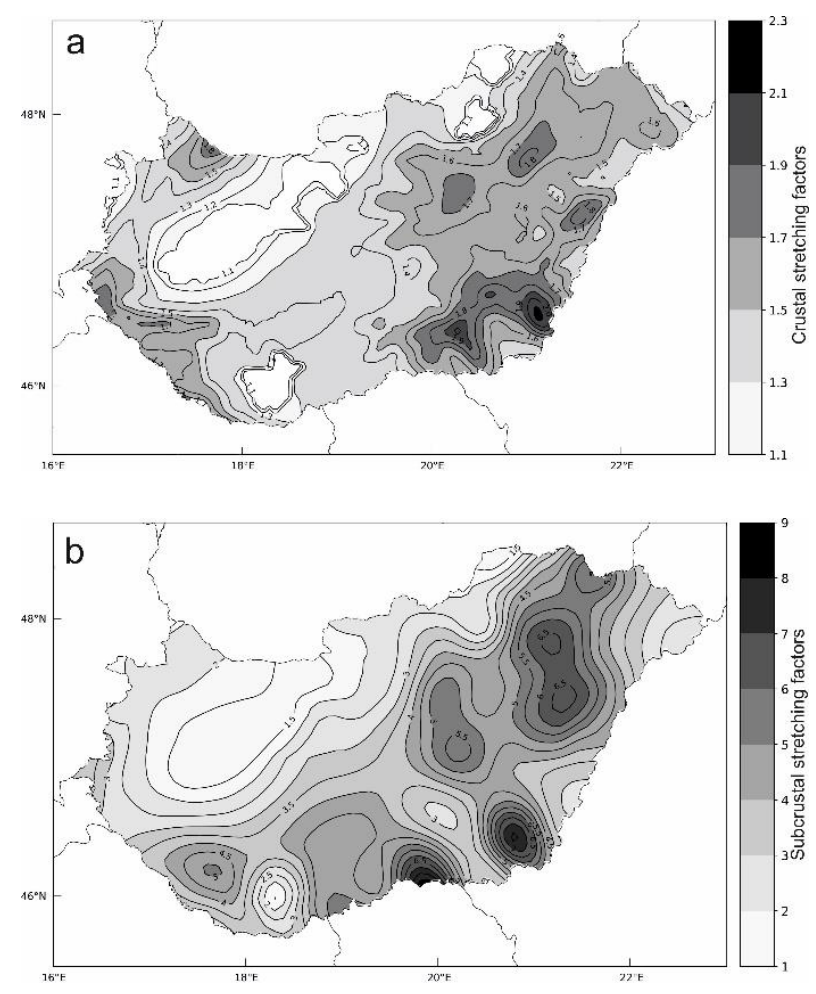

Figure 2.9: Crustal (a) and subcrustal (b) stretching factors after Lenkey (1999).

It has been shown by Sclater et al. (1980) and Royden et al. (1983) that the high post-rift subsidence rate and the elevated heat flow density of the Pannonian Basin could only be explained if the mantle part of the lithosphere was thinned more than the crust. Therefore, for Model 3, we calculated the surface heat flow from the stretching parameters by assuming instantaneous lithospheric thinning, which has occurred 17 Ma before present. We performed a multi-1D tectonic modeling following the depth-dependent extensional model of Royden and Keen (1980) with the corresponding parameters listed in Table 2.5. We assumed the original crustal and lithospheric thickness of $30 \mathrm{~km}$ and $120 \mathrm{~km}$, respectively. Furthermore, we took into consideration the effect of heat generation in the upper crust (and its reduction due to the thinning of the crust) and the influence of sediment infill on the surface heat flow evolution. The latter is of great importance for fast to moderate sedimentation rates (e.g. Theissen and Rüpke, 2010; Van Wees et al., 2009), which is especially relevant for the southeastern part of the Pannonian Basin. Following Pollack and Chapman (1977) we assumed that the radiogenic heat production rate within the upper crust accounts for $40 \%$ of the initial surface heat flow. The lower crustal heat generation was neglected. 


\begin{tabular}{|c|c|c|c|c|c|}
\hline \multirow{2}{*}{ Model } & \multirow{2}{*}{ Type of model } & \multicolumn{2}{|c|}{$\begin{array}{c}\text { Boundary conditions used for } \\
\text { the multi-1D calculations }\end{array}$} & \multicolumn{2}{|c|}{$\begin{array}{c}\text { Boundary conditions used for } \\
\text { the 3D calculations }\end{array}$} \\
\cline { 4 - 6 } & prior & Upper & Lower & Upper & Lower \\
\hline 1 & posterior & $12{ }^{\circ} \mathrm{C}$ & $\begin{array}{c}\text { Fixed heat } \\
\text { flow value of } \\
70 \mathrm{~mW} / \mathrm{m}^{2} \text { at } \\
10 \mathrm{~km} \mathrm{depth}\end{array}$ & $12{ }^{\circ} \mathrm{C}$ & $\begin{array}{c}\text { Heat flow at the } \\
\text { LAB derived } \\
\text { from the multi- } \\
1 \mathrm{D} \text { calculations } \\
\text { of Model } 1,2^{[1]}\end{array}$ \\
\hline 3 & posterior & \multicolumn{2}{|c|}{$\begin{array}{c}\text { Varying heat flow at } 10 \mathrm{~km} \\
\text { depth calculated from the } \\
\text { tectonic surface heat flow }\end{array}$} & $12{ }^{\circ} \mathrm{C}$ & $\begin{array}{c}\text { Heat flow at the } \\
\text { LAB derived } \\
\text { from the multi- } \\
1 \mathrm{D} \text { calculations } \\
\text { of Model 3. }\end{array}$ \\
\hline
\end{tabular}

Table 2.3: Overview of the boundary conditions. [1] Note that the multi-1D calculations of Model 1 and Model 2 are identical.

\subsubsection{Controlling temperatures and data uncertainty}

We calibrated the models with temperature measurements from the Hungarian Geothermal Database (Dövényi and Horváth, 1988; Dövényi et al., 2002). Prior to the modeling, measured temperature values were carefully evaluated, and observations with high error were discarded from the dataset. Errors of the remaining data were set in the range of 5 and $20{ }^{\circ} \mathrm{C}$, depending on the quality of the measurement. It is commonly accepted to mark the Drill-Stem Tests (DSTs) and Formation Tests by the uncertainty of $\pm 5{ }^{\circ} \mathrm{C}$ (e.g. Bonté et al., 2012). The uncertainty of the Bottom Hole Temperatures (BHTs) is estimated by lying within a deviation of $\pm 10{ }^{\circ} \mathrm{C}$ (Goutorbe et al., 2007). The remaining measurements were evaluated following the uncertainty given in the database. Since only one observation per grid cell is supported in the calculations, in case of multiple observations the measurement with lower uncertainty is selected. Finally, the number of temperature measurements used for calibration was 3858. The location of the data points is presented in Figure 2.10, and the number of measurements used for calibration between 1 to $6 \mathrm{~km}$ depth are reported in Table 2.4 .

\begin{tabular}{|c|c|c|c|c|c|c|c|}
\hline \multirow{2}{*}{ Model } & \multicolumn{7}{|c|}{ Number of temperature observations used for calibration } \\
\cline { 2 - 8 } & Total & $0-1 \mathrm{~km}$ & $1-2 \mathrm{~km}$ & $2-3 \mathrm{~km}$ & $3-4 \mathrm{~km}$ & $4-5 \mathrm{~km}$ & $5-6 \mathrm{~km}$ \\
\hline 2 & 5135 & 2879 & 1067 & 860 & 274 & 46 & 9 \\
\hline 3 & 3858 & 1602 & 1067 & 860 & 274 & 46 & 9 \\
\hline
\end{tabular}

Table 2.4: Number of temperature observations used for calibration of Model 2 and Model 3. 
To account for the variation of the heat flow in Model 2 without incorporating errors of surface heat flow determination ( $\pm 10-25 \%$, Lenkey et al., 2002), we sampled the heat flow observations at well locations. Since models can only be calibrated with temperature data (heat flow observations are not supported for calibration), it was necessary to calculate the corresponding temperatures. Resampled surface heat flow values were converted to equivalent temperature values at $400 \mathrm{~m}$ depth using the corresponding thermal conductivities of the sedimentary layers as:

$$
T_{z}=\frac{Q_{s}}{k} z+T_{S}
$$

where $T_{z}$ is the temperature at $\mathrm{z}=400 \mathrm{~m}, \mathrm{Q}_{\mathrm{s}}$ denotes the surface heat flow, and $T_{\mathrm{s}}$ is the surface temperature. The obtained temperature values were added to the calibration dataset for Model 2.

\subsubsection{Ensemble smoother with multiple data assimilation}

The prior parameterization of the model is updated trough the data assimilation procedure, adopting measured temperatures as target observations. The goal of the inversion is to find the solution which minimizes the weighted sum of differences with data and with a prior model estimate. In the ensemble smoother (ES), the equation for the assimilated model parameter vector $\boldsymbol{m}^{a}$ for multiple data assimilation is written as:

$$
\boldsymbol{m}_{j}^{a}=\boldsymbol{m}_{j}+\widehat{\boldsymbol{C}}_{m d}\left(\widehat{\boldsymbol{C}}_{d d}+\boldsymbol{C}_{d}\right)^{-1}\left(\boldsymbol{d}_{j}-\widehat{\boldsymbol{d}}_{j}\right)
$$

For $j=1,2,[\ldots], N_{e}$, where $N_{e}$ denotes the number of ensembles (Emerick and Reynolds, 2013a). Each ensemble consists of a stochastically sampled model parameter realization, and associated model forecast. $\widehat{\boldsymbol{C}}_{m d}$ is the cross-covariance matrix between the prior vector of model parameters, $\boldsymbol{m}$, and the vector of predicted data, $\boldsymbol{d}$. $\widehat{\boldsymbol{C}}_{d d}$ denotes the $N_{d} \times N_{d}$ autocovariance matrix of predicted data, where $N_{d}$ represents the number of measurements. $\boldsymbol{C}_{d}$ is the $N_{d} \times N_{d}$ covariance matrix of observed data measurement errors. $\widehat{\boldsymbol{d}}_{j}$ denotes forecasted values by the thermal model at the observation points. $\boldsymbol{d}_{j}=\boldsymbol{d}_{o b s}+\boldsymbol{\epsilon}_{j}$, where $\boldsymbol{d}_{o b s}$ is the data vector, and $\boldsymbol{\epsilon}$ denotes the data error vector.

Basically, an ensemble of solutions is produced, each consistent with the prior statistics. The mean of the ensemble is taken as the best guess, and the error-covariance of the updated model ensemble is calculated from the ensemble anomalies. If the relationship between the parameters and the forecast is linear, such as the basal temperature, the smoother gives a direct solution. In case of non-linear problems, as for the heat generation and thermal conductivity, multiple iterations with an inflated covariance matrix of the measurement errors $\left(\boldsymbol{C}_{d}\right)$ are required to obtain the results. This procedure can be interpreted as an iterative ES, where the number of iterations has to be chosen a priori. 


\subsubsection{Modeling workflow}

The modeling roadmap was to first construct a prior model with relatively low mean and median misfits with the observed temperatures, then use these results as an input for the further calculations with data assimilation, using ES-MDA. In this paper we represent 3 models, the first model was constructed without data assimilation, while the second and third model the prior parameterization is updated. The modeling workflow and the data assimilation parameters are summarized in Figure 2.8 and in Table 2.6, respectively. All of the models run the ES-MDA with 300 realizations, incorporating 4 iterations for the multiple data assimilation. Data assimilation included varying the basal heat flow, radiogenic heat generation of the upper crust and vertical thermal conductivity of the Mesozoic carbonates and the clastic sedimentary infill. Prior uncertainties in the model parameterization were described by scaling/shifting the thermal properties and boundary conditions to triangular distribution. The spatial variability of properties and boundary conditions are generated with spectral simulation, with a spherical variogram (Yao, 2004). Variogram ranges were selected prior to the data assimilation by defining the number of cells effected by the perturbation. We varied the thermal properties through separate model runs, adopting the output of a previous model as an input for the new calculations. First the basal condition, and subsequently the shallower part of the model was updated. We prescribed larger variogram range in case of the basal heat flow, because of the small wavelength, high amplitude anomalies in the surface heat flow smooth out with increasing depth. As for the basal heat flow, we introduced shifting parameters of $\pm 20 \mathrm{~mW} / \mathrm{m}^{2}$. After several runs and analysis of the results, the set of parameters listed in Table 2.5 seemed reasonable to capture the lateral variations. The upper crustal heat production was scaled between 0.6 and 1.4 to account for the increased volumetric heat generation of dacites and rhyolites with the corresponding values of 2.2 and $2.7 \mu \mathrm{W} / \mathrm{m}^{3}$ (Lenkey and Surányi, 2006), respectively. We introduced variation in the thermal conductivity of the sediments to account for potential uncertainty due to porosity-depth functions and the geometry of the layers. We allowed only a small variation in the conductivity of impermeable layers to ensure values to remain within reasonable bounds. Additionally, we tried to implicitly incorporate the thermal effect of (sub)vertical fluid transfer at recharge/discharge areas by higher than natural vertical thermal conductivity. It was performed by varying the vertical thermal conductivity of the permeable layers in a wider bandwidth (Table 2.6). 


\begin{tabular}{|c|c|c|}
\hline Parameter name & Value & Unit \\
\hline $\begin{array}{c}\text { Lithospheric thickness (before } \\
\text { thinning) }\end{array}$ & 120 & {$[\mathrm{~km}]$} \\
\hline $\begin{array}{c}\text { Crustal thickness (before } \\
\text { thinning) }\end{array}$ & 30 & {$[\mathrm{~km}]$} \\
\hline Crustal density & 2900 & {$\left[\mathrm{~kg} / \mathrm{m}^{3}\right]$} \\
\hline Mantle density & 3400 & {$\left[\mathrm{~kg} / \mathrm{m}^{3}\right]$} \\
\hline Crustal and mantle conductivity & 3 & {$\left[\mathrm{~W} / \mathrm{m}^{*} \mathrm{~K}\right]$} \\
\hline Sediment conductivity & Adopted after Dövényi and & Horváth $(1988)$ \\
\hline Heat production in upper crust & variable & {$\left[\mathrm{mW} / \mathrm{m}^{3}\right]$} \\
\hline Lithosphere thermal expansion & $3.2^{*} 10^{-5}$ & - \\
\hline Thermal diffusion & $10^{-6}$ & {$\left[\mathrm{~m} / \mathrm{s}^{2}\right]$} \\
\hline LAB temperature & 1330 & {$\left[{ }^{\circ} \mathrm{C}\right]$} \\
\hline
\end{tabular}

Table 2.5: Thermal properties used to calculate tectonic heat flow for Model 3.

\begin{tabular}{|c|c|c|c|c|c|}
\hline Model & Description & $\begin{array}{l}\text { Variogra } \\
\mathrm{m} \text { model }\end{array}$ & $\begin{array}{l}\text { Variogram } \\
\text { range in } \\
\text { cells }(1 \text { cell } \\
\approx 2.5 \mathrm{~km})\end{array}$ & $\begin{array}{c}\text { Prior } \\
\text { distribution }\end{array}$ & $\begin{array}{l}\text { Scaling/shifting } \\
\text { parameters }\end{array}$ \\
\hline \multirow[b]{3}{*}{2,3} & $\begin{array}{l}\text { Varying } \\
\text { basal heat } \\
\text { flow }\end{array}$ & \multirow{3}{*}{ spherical } & 15 & \multirow{3}{*}{ triangular } & shift with $\pm 20 \mathrm{~mW} / \mathrm{m}^{2}$ \\
\hline & $\begin{array}{l}\text { Varying heat } \\
\text { generation }\end{array}$ & & 10 & & $\begin{array}{c}\text { scale between } 0.6 \text { and } \\
1.4 \text { in UC }\end{array}$ \\
\hline & $\begin{array}{c}\text { Varying } \\
\text { vertical } \\
\text { thermal } \\
\text { conductivity }\end{array}$ & & 10 & & $\begin{array}{c}\text { scale between } 0.5 \text { and } \\
1.5 \text { in } \mathrm{Q}, \mathrm{UP}, \mathrm{N}, \mathrm{M} \\
\text { scale between } 0.8 \text { and } \\
1.2 \text { in LP, } \mathrm{P}\end{array}$ \\
\hline
\end{tabular}

Table 2.6: Overview of the data assimilation parameters. See for the abbreviations Table 2.1 and Table 2.2.

\subsection{Results}

The first and second model were calculated assuming steady-state conditions, neglecting transient geological processes. On the other hand, the thermal field in the Pannonian Basin is strongly influenced by the transient effect of recent lithospheric-scale tectonic events. To this end, the third model accounts for the thermal perturbation of recent lithospheric extension by 
adopting tectonic heat flow as a basal boundary condition derived from crustal and subcrustal stretching parameters.

Here we present the modeling results obtained by two different approaches. Temperature depth slices of Model 2 and Model 3 are presented between 1 to $6 \mathrm{~km}$ superimposed by the misfit of the modeled and observed temperatures in $\pm 200 \mathrm{~m}$ interval (Figure 2.10). Model 1 is presented only on the temperature-depth profiles due to the high misfits, and, therefore not realistic modeled temperatures. We have highlighted the areas where fractured and karstified carbonates are present. At these locations results should be treated carefully due to the influence of potential convection. Both models show a similar pattern as the surface heat flow density: in general, the models predict lower temperatures in the northwestern, and higher temperatures in the southern, eastern and southeastern part of Hungary. Modeled temperatures show a high variation in every depth interval. Some areas exhibit very high (about $200{ }^{\circ} \mathrm{C}$ ) temperature in approximately $3500 \mathrm{~m}$ depth, forming one of the hottest regions in Europe. 

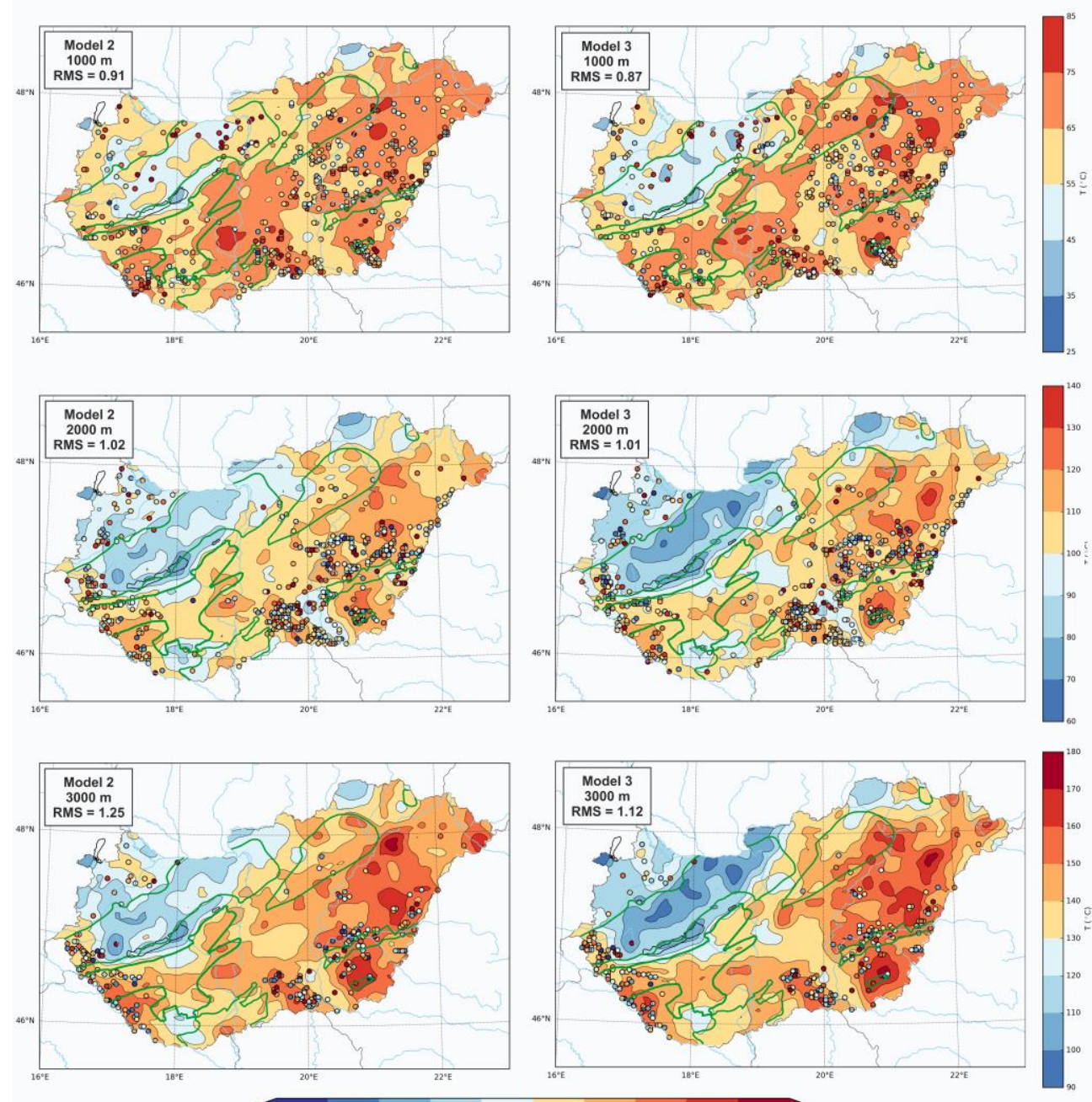

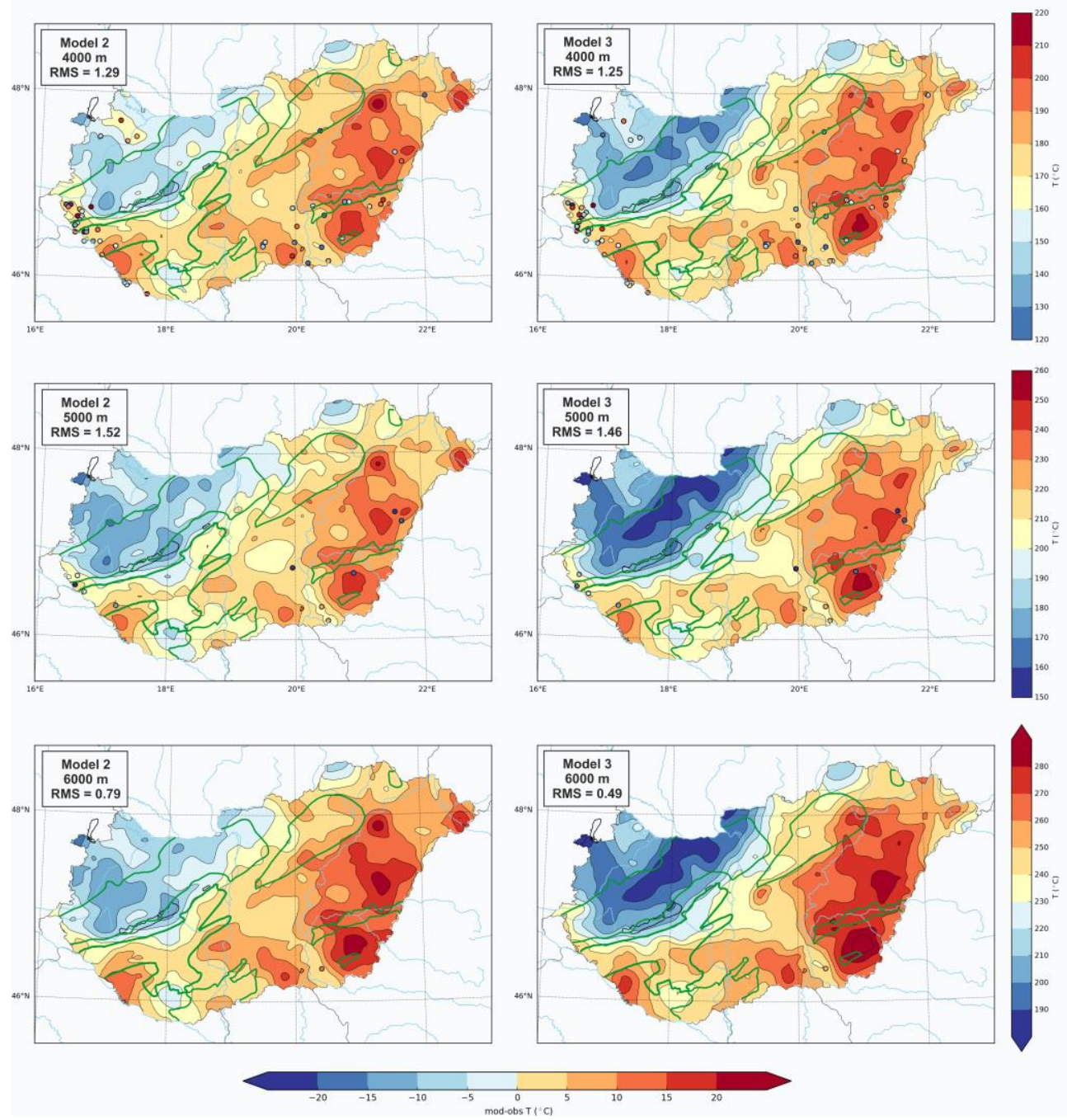

Figure 2.10: Isodepth temperature maps of Model 2 (left) and Model 3 (right) superimposed by the misfit of the modeled and observed temperatures in $\pm 200 \mathrm{~m}$ interval $\left(\mathrm{T}_{\text {mod }}-\mathrm{T}_{\mathrm{obs}}\right)$. The green contour indicates the location of the Mesozoic karstic reservoirs and their recharge areas in Hungary. The RMS misfit of every depth is indicated in the left upper corner.

The overall picture in all depth intervals suggests that the region of the Transdanubian Range is slightly colder in Model 3 than Model 2. As discussed above, low measured temperatures in this area are explained by the infiltration of cold meteoric water. Our tectonic model (Model 3) approximates the effect of downward groundwater flow with a lower error range than Model 2, but none of the models are suitable to reproduce the low measured values (note the high modeled-observed temperatures in Figure 2.10). Modeled subsurface 
temperatures below $3 \mathrm{~km}$ are not calibrated, because there are no reliable temperature records available. Since the temperature is calculated downwards, the conductive model is likely to uderestimate the temperature field. Cooling due to groundwater downwelling is also present in some parts of the North Hungarian Range in the Northeast, reflected by both of the models. Predicted temperatures at $1 \mathrm{~km}$ depth in the Mecsek and Villány mountains (Figure 2.1) are higher, fitting well with the high heat flow density of the area. Contrary, going deeper, temperatures only slightly increase.

Our models show a good fit with measured temperatures in the other parts of Transdanubia, except for a few outliers, where most likely convection due to groundwater flow occurs. The subsurface temperatures in the Danube basin are remarkably lower than in any other sub-basin in Hungary. It is in good agreement with the lower heat flow of the region compared to the other basins in Transdanubia. The warmest areas in Transdanubia can be attributed to the Drava Trough and Zala Basin, due to the blanketing effect of sediments.

In the central part of Hungary, along the River Danube, both models slightly underestimate the measured temperatures in the range of 1 to $3 \mathrm{~km}$, where deeper records are not available. Besides the high heat flow in the area, another explanation of the relatively lower modeled temperatures can be the lack of controlling points.

Regarding the Great Hungarian Plain, the subsurface temperatures follow a slightly similar pattern like the surface heat flow in all depth levels. In general, the blanketing effect of sediments results in elevated temperatures at shallow depth. On the other hand, the subbasins filled by more than $5 \mathrm{~km}$ thick sediments exhibit a relatively low heat flow, explained by the cooling effect of young sedimentation. The superposition of these two effects causes the temperature maximum to be slightly shifted towards the basement highs.

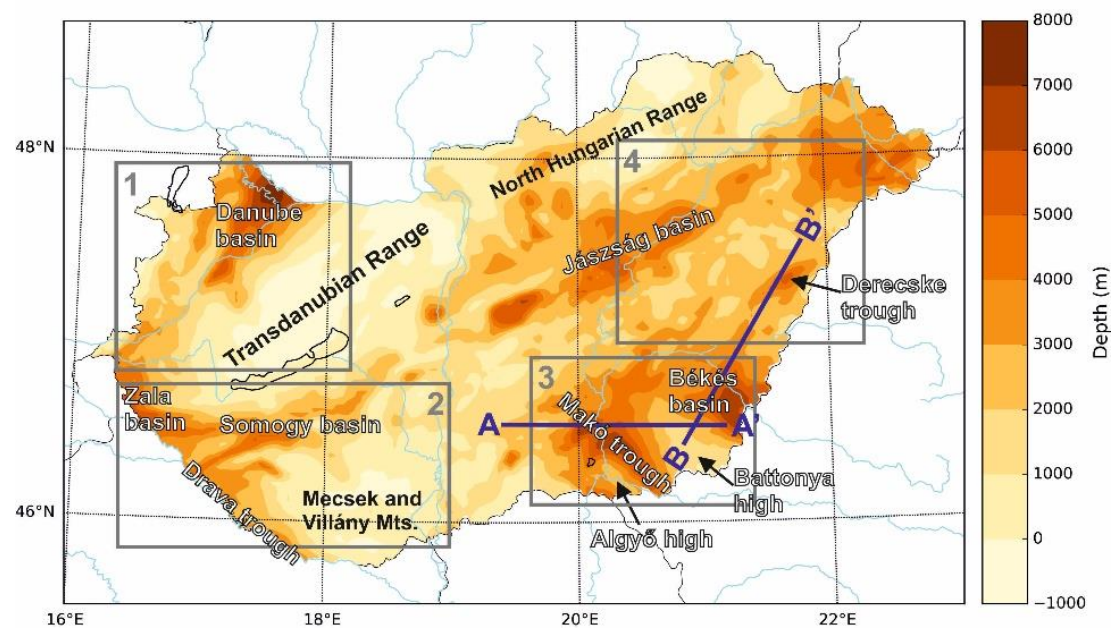

Figure 2.11: Depth of the pre-Cenozoic basement showing the most significant sub-basins and hills of Hungary. Grey boxes indicate the location of the regions where temperature-depth profiles are available. 
We have selected several wells to demonstrate the temperature-depth and thermal conductivity-depth profile of all the models (Figure 2.12). Results are presented from four regions shown in Figure 2.11. Region 1 represents the northwestern part of Hungary, including wells located near the Transdanubian Central Range and the Danube basin. The prior model systematically overestimates temperatures in all locations, suggesting that the model cannot account for the lower heat flow characterizing the northwestern part of Hungary. In wells Tét-5 and Szombathely-II, both Model 2 and Model 3 show a good fit with measured temperatures. Temperature records in Bősárkány-1 suggest that upwelling groundwater flow along fractured zones may be present below $4 \mathrm{~km}$. On the other hand, shallower temperature records are significantly lower, which may explain that our models were not able to reproduce the potential effect of hydrothermal convection. In wells Gönyü1 and Kehida-3, downward flow in fractured carbonatic rocks explains low measured temperatures. In Gönyü-1, Model 2 and partly Model 3 can account for the effect of downwelling by increasing the thermal conductivity of the carbonates, which force the geothermal gradient to decrease. Contrary, neither of the models can reproduce the extremely low temperature record at ca. $3200 \mathrm{~m}$ depth and very high values near the surface in Kehida3. Region 2 includes the southwestern part of Hungary, demonstrating mostly the modeling results in the Zala and Drava basins. All models fit quite well with the measured records. However, subsurface temperatures are slightly underestimated in well 2D and Nagyatád-K1. In well PAET-34, the geothermal gradient suggested by the measurements is very high, which would result in remarkably high temperatures at deeper levels. This well is located in the eastern part of the region, showing a good example of slightly underestimated temperatures if the surrounding area.
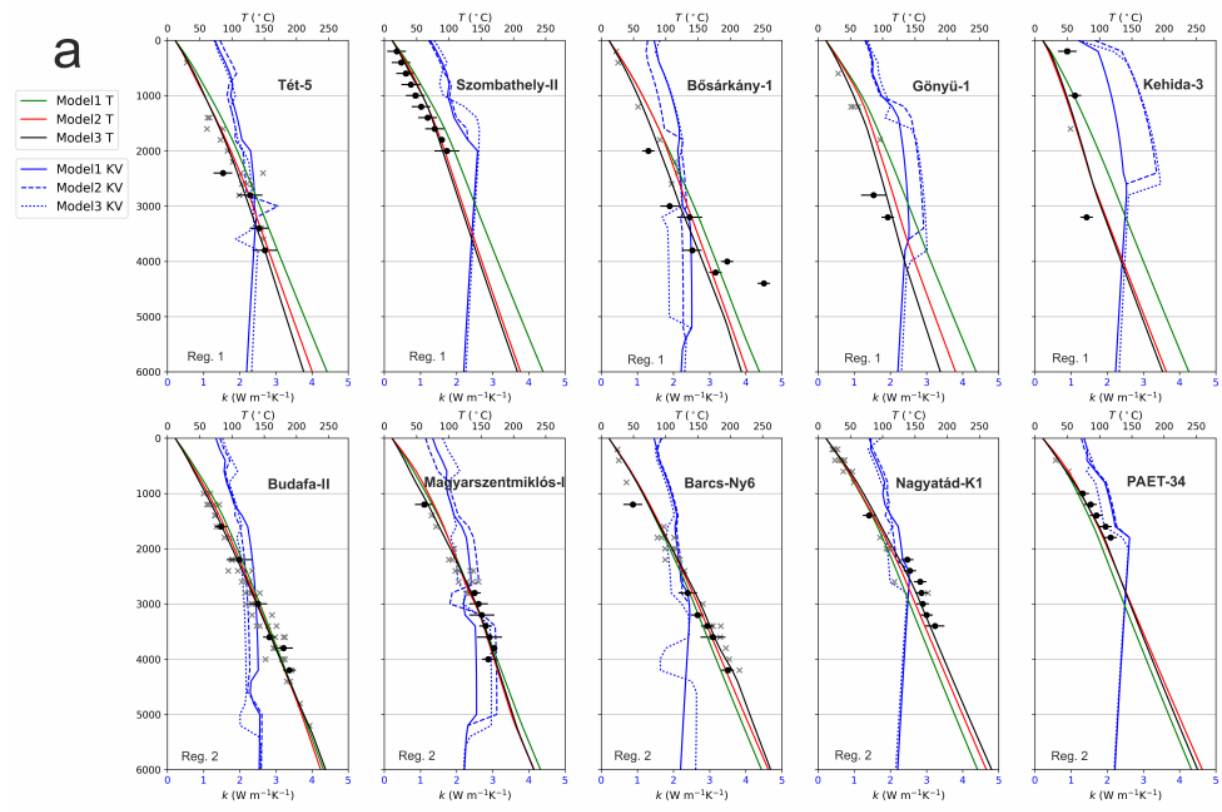

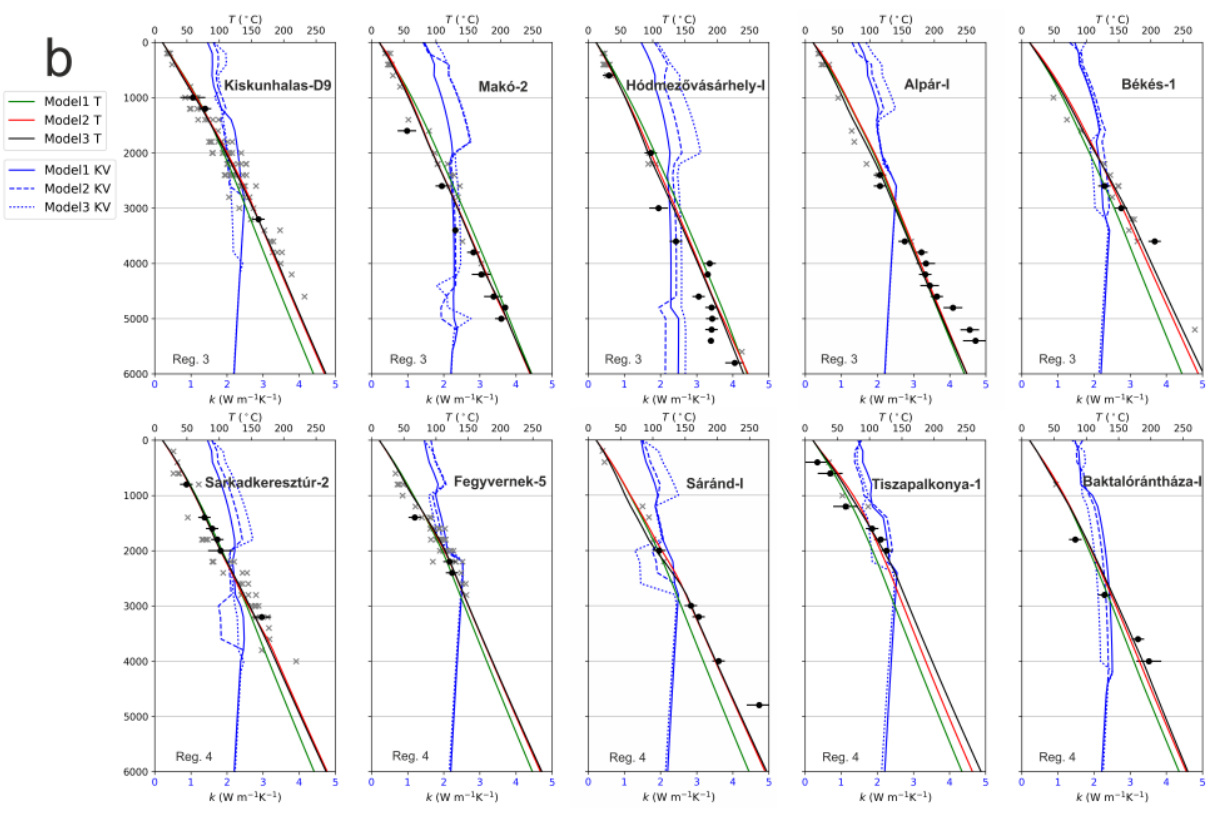

Figure 2.12: Temperature (T)-depth and vertical thermal conductivity (KV)-depth profiles of wells located at different regions of Hungary (a: first row: Region 1, second row: Region 2; b: first row: Region 3, second row: Region 4). Measured temperatures and the corresponding uncertainties are plotted with black circles and error bars. Temperature records from wells within $10 \mathrm{~km}$ are indicated with grey crosses.

Region 3 represents the southern part of the Great Hungarian Plain, including the deepest sub-basins. It is clear that our prior model underestimates temperatures in the basement highs. On the other hand, it shows a better fit in the deep sub-basins. Model 2 and Model 3 are almost identical at all locations and predict high temperatures in the basement highs. At the same time, the deeper part of the models cannot capture adequately the very high temperature records: modeled-observed temperatures show a negative misfit in wells Alpár-I and Békés1. Cooling due to young sediments with considerable thickness in deep troughs are quite well modeled, for instance in Makó-2. In the northern part of the Great Hungarian Plain (Region 4), the prior model is too cold at all locations, but both Model 2 and Model 3 are in good agreement with almost all of the measured records. In contrast, Sáránd-I is an exception, where the temperature-depth profiles show a misfit with an extremely high measurement. High values deep down in the basement rocks in both regions may be attributed to hydrothermal convection. The fixed thermal conductivity of the upper crust can be an explanation why our models cannot reproduce the effect of convection in the basement.

Figure 2.13 shows the predicted temperatures along two profiles from the Great Hungarian Plain (for location see Figure 2.11.). The isotherms of the two posterior models are almost identical, the maximum deviation is $\sim 10^{\circ} \mathrm{C}$, therefore only Model 3 is plotted on the cross-sections. In Figure 2.13a, subsurface temperatures show an eastward increasing 
trend towards the Battonya high, especially in the deeper part: the $300{ }^{\circ} \mathrm{C}$ isotherm is only present in the eastern part of the cross-section. In the southern part of Békés basin (Figure $2.13 \mathrm{~b}$ ), the blanketing effect of sediments is clearly visible and results in hardly elevated temperatures compared to the basement highs towards North. On the other hand, the temperature maximum is shifted towards the southern rim of the Battonya high. The temperature contrast between deep sub-basins and basement highs in Figure 2.13a is more relevant: isotherms are remarkably depressed below $2 \mathrm{~km}$ in the Makó trough, reflecting the cooling effect of the thick sedimentary succession. The hottest region through the cross sections is linked to the Battonya high, where the modeled temperatures reach $200{ }^{\circ} \mathrm{C}$ in ca. $3500 \mathrm{~m}$ depth. High temperatures can be attributed to the low thermal conductivity of the very thick sedimentary cover in the surrounding sub-basins, from where heat is diverted towards the more conductive basement flank.

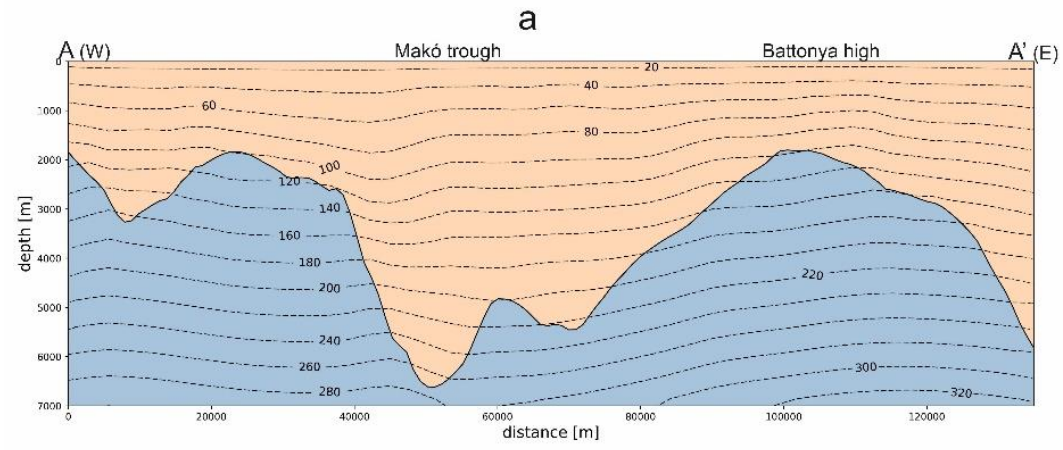

b

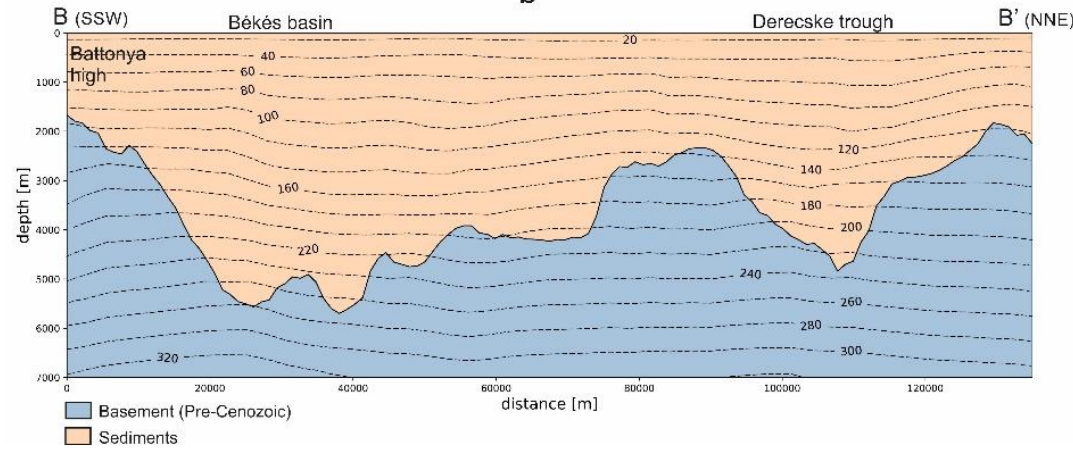

Figure 2.13: Cross-sections from the southeastern part of Hungary (for location see Figure 2.11). Subsurface temperature contours $\left({ }^{\circ} \mathrm{C}\right)$ are transferred from Model 3 (dashed black lines).

To outline the potential areas for EGS development, temperature at the top of the preCenozoic basement is shown in Figure 2.14, of course the temperature values follow the same trend as the basement depth. The most promising areas are located in the Great Hungarian Plain, where an EGS project is currently in progress near Battonya (e.g. Osvald et al., 2017). 
Furthermore, deep geothermal exploration would also be cost-effective in the northern part of the Great Hungarian Plain.

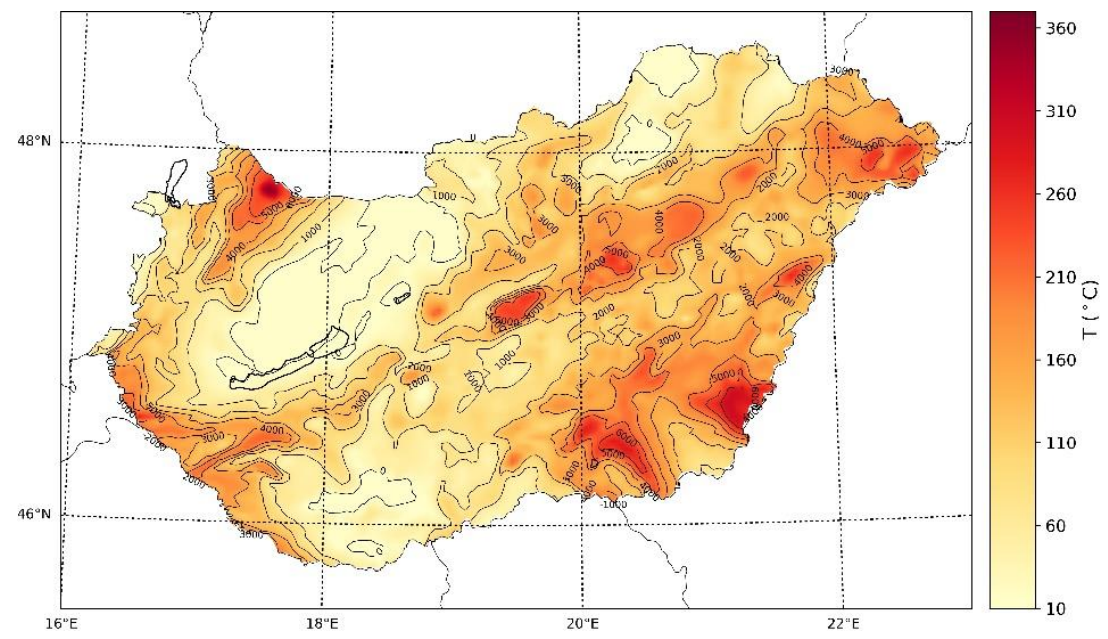

Figure 2.14: Temperature at the top of the pre-Cenozoic basement predicted by Model 3 superimposed by the depth of the basement $(\mathrm{m})$ indicated with isolines.

The mean, median and Root Means Square (RMS), normalized to data error, of the modeled-observed temperatures suggest that the overall misfit is decreasing through the data assimilation. In general, Model 1 and Model 2 (with the median of -0.49 and -0.15) slightly underestimate, and Model 3 (with the median of 0.78 ) slightly overestimates the measured temperatures, respectively. Although, these numbers are not entirely representative, due to the difference between the number of observations from shallow depth (in case of Model 1 and Model 2, the calibration dataset was supplemented by temperature observations calculated from the surface heat flow). For this reason, we compared the uncertainty of the three models in $1 \mathrm{~km}$ intervals between 1 to $6 \mathrm{~km}$ depth (Figure 2.15), including misfits in the range of $\pm 500 \mathrm{~m}$. Results show that all of the models overestimate temperatures at shallow depth. One explanation of the positive misfits can be that groundwater flow systems cause net temperature reduction. This phenomena clearly exists in groundwater basins according to the numerical stimulations of Kooi (2016). Additionally, overestimated temperatures due to the uncertainty in the porosity-depth curves, or the influence of the last ice age cannot be ruled out either. Model 1 systematically underestimates the temperatures measured between 2 to $5 \mathrm{~km}$ depth. The mean and median misfits of the posterior models are relatively close to zero, except for the $5 \mathrm{~km}$ depth level with increasing negative misfits. It may be attributed to the uncertainty in the porosity-depth curves or basement depth. On the other hand, most of the negative misfits belong to wells located in the Great Hungarian Plain, where free convection of overpressured water can take place (Lenkey, 1999). 


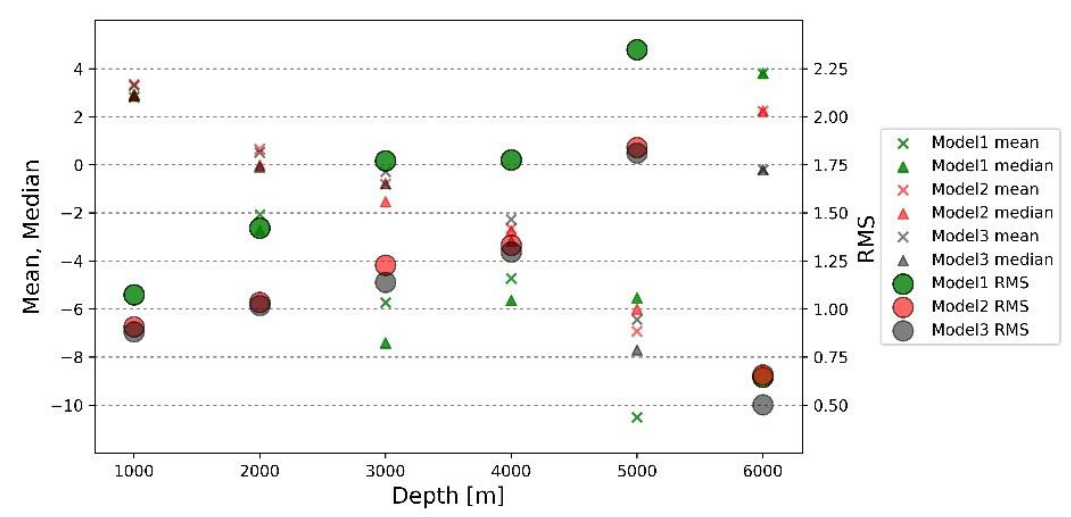

Figure 2.15: Mean, median and RMS misfits of the three models between 1-6 km depth in $\pm 500 \mathrm{~m}$ interval.

\subsection{Discussion}

We have established 3D lithospheric-scale temperature models for Hungary by adopting two different approaches. Subsurface temperature calculations were performed in steadystate assuming conduction as the main heat transfer mechanism. At the same time, one of our preferred models accounts for the time-dependent thermal effect of recent lithospheric extension by adopting tectonic heat flow as a basal boundary condition. Subsurface temperatures predicted by the two models are in good agreement, apart from that Model 2 predicts lower temperatures in the Transdanubian Central Range, and is slightly warmer in the Great Hungarian plain, especially below $3 \mathrm{~km}$. This deviation can be attributed to the limited area with controlling points with surface heat flow observations in case of Model 2.

We first established prior models, which were updated through the data assimilation procedure to obtain a better fit with measured temperatures. Beyond changing the vertical thermal conductivity of sediments and heat generation in the upper crust, the basal boundary condition (heat flow) was also updated. Prior and posterior heat flow at $60 \mathrm{~km}$ depth are presented in Figure 2.16. Prior heat flow in case of Model 1 and Model 2 is relatively smooth with values between 50 and $65 \mathrm{~mW} / \mathrm{m}^{2}$, that corresponds to the fixed heat flow condition of $70 \mathrm{~mW} / \mathrm{m}^{2}$ at $10 \mathrm{~km}$ depth in the multi-1D model. Prior heat flow of Model 3 calculated from tectonic heat flow shows significant variations. In general, it follows similar pattern to the stretching factors (Figure 2.9). Posterior heat flow in both cases is lower in the deep subbasins of the Great Hungarian Plain, especially in the Makó trough, which can be attributed to the lower surface heat flow of the area due to the cooling effect of fast sedimentation. Updated heat flow values are relatively higher in the Great Hungarian Plain and near the Dráva trough and Zala basin, and lower in the northwestern part of Hungary. It is important to note that the lateral variations in posterior heat flow may not be entirely realistic, but these values provide the best fit with measured temperatures through steady-state conductive modeling. The significant difference between prior and posterior heat flow, especially in case 
of Model 1 and model 2 can be explained by transient effects and non-conductive heat transfer.
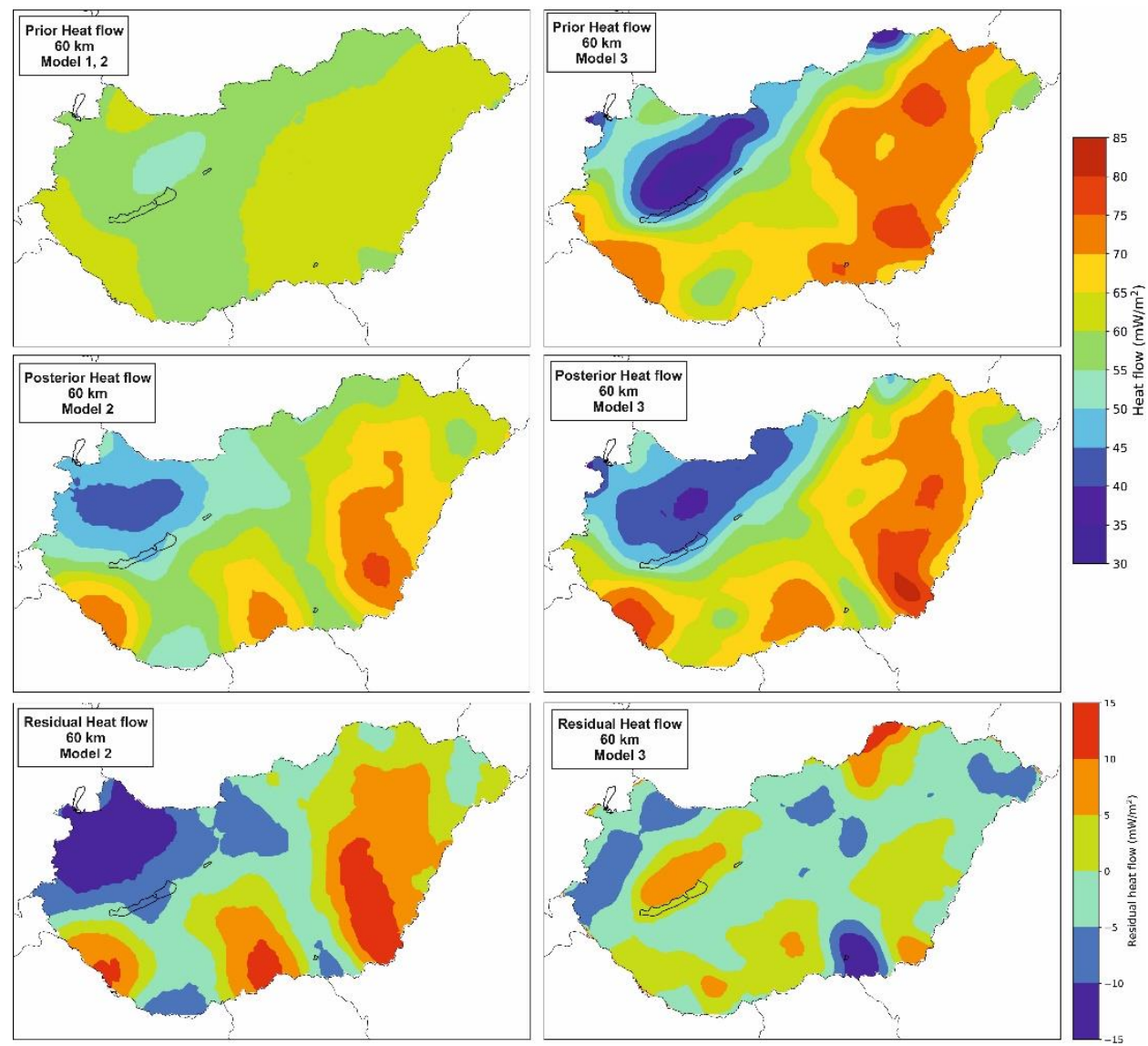

Figure 2.16: Prior (top), posterior (middle), and residual (posterior-prior, bottom) heat flow at $60 \mathrm{~km}$ depth of Model 1, Model 2(left) and Model 3 (right). Note the different scale for the residual maps.

Our models fit well with measured temperatures, suggesting that the thermal field is predominantly conductive and is in good agreement with earlier findings of Lenkey (1999). On the other hand, convection clearly occurs at several sites in the porous sedimentary infill and fractured or karstified basement rocks. Despite the higher misfit of modeled-observed temperatures where groundwater flows disturb the conductive regime, temperature measurements affected by fluid convection can be approximated by increasing the thermal conductivity of the corresponding layers. Regional fluid flow systems in the Pannonian Basin has the highest influence on the temperature field in the Transdanubian Range, Mecsek, Villány and Bükk mountains and their discharge areas. Therefore, the uncertainty of the models is considered higher at these locations, as temperatures in recharge and discharge 
areas may be overestimated and underestimated, respectively. For instance, in Kehida-3 well, only $80{ }^{\circ} \mathrm{C}$ is measured at ca. $3200 \mathrm{~m}$ depth, while the model predicts ca. $110{ }^{\circ} \mathrm{C}$ (Figure 2.12a), meaning that the model overshoots the observed value with $30{ }^{\circ} \mathrm{C}$. Additionally, convection due to overpressured systems can cause high negative misfits. It might be the case in Alpár-1 well with measured temperatures above $250{ }^{\circ} \mathrm{C}$ in ca $5200 \mathrm{~m}$, with the corresponding misfits of $-20^{\circ} \mathrm{C}$ (Figure $2.12 \mathrm{~b}$ ). To this end, to correct for deviations due to convective effects, a coupled modelling should be performed for the adjacent areas. Additionally, one explanation of low modeled temperatures at larger depth at AggtelekGemer can be the presence of deeply infiltrating cold meteoric water, but this region is only supported by one controlling point. Therefore, models cannot be considered reliable enough to draw this conclusion.

Prior uncertainty of the model parameters is described by triangular distribution with the variogram for spatial variation reported in Table 2.6. The reliability of posterior model temperatures is indicated by the misfits with measured values, described in Figure 2.15. On the other hand, some regions remain uncalibrated, meaning that there is no direct measure of the misfits. Posterior uncertainties of the updated model parameters are described by the mean and standard deviation of the updated thermal properties, e.g. the basal heat flow. As the model uncertainty is set very wide and the observation error rather narrow, posterior values are also narrow, resulting in low posterior uncertainties. Standard deviation of modeled temperature varies after each data assimilation step (depending on the varied thermal property). After each modeling step, standard deviation values remain below $10{ }^{\circ} \mathrm{C}$ in the top $6 \mathrm{~km}$, which therefore can be considered as the general reliability of the models. Additionally, the degrees of freedom in the model parameters is much larger than the number of calibration data points, meaning that the inverse problem is underdetermined. Therefore, model solutions are non-unique and the modeled temperatures of uncalibrated regions are considered ambiguous.

We have compared our results with the isodepth temperature maps based on the interpolation of measured temperatures after Dövényi et al. (2005). These maps are only available in 1 and $2 \mathrm{~km}$ depth, but our posterior models conform well with them, especially where controlling points are present and the thermal field is dominantly conductive. Moreover, Model 3 predicts similar subsurface temperatures in the western part of Hungary to the time dependent lithospheric-scale thermal model (of the Alpine-Pannonian transition zone) of Lenkey et al. (2017). Extremely elevated temperatures modeled in the Great Hungarian Plain is in agreement with the high heat flow related to the asthenospheric dome below the area (Horváth et al., 2015). Additionally, local reduction of the heat flow in the sub-basins due to thick, young sediments (Lenkey et al., 2002) is also reflected by the modeled temperature field. Modeled Moho temperatures in the most extended part of the Pannonian Basin reach even $850{ }^{\circ} \mathrm{C}$ (Figure 2.17), which is significantly higher than previous results of Tesauro et al. (2009). This is fundamentally due to the different lithospheric thickness used for modeling. On the other hand, the peripheral parts of the basin exhibit lower modeled temperature at the Moho (around $700{ }^{\circ} \mathrm{C}$ ). 
In theory, it is possible to reach even lower misfits by decreasing the variogram sizes and/or applying a wider range for the scaling/shifting parameters of the thermal properties, but high-amplitude local variations in these properties may be unrealistic. Therefore, data assimilation parameters of each thermal properties should be selected carefully: variation and spatial correlation lengths should be introduced within reasonable bounds.

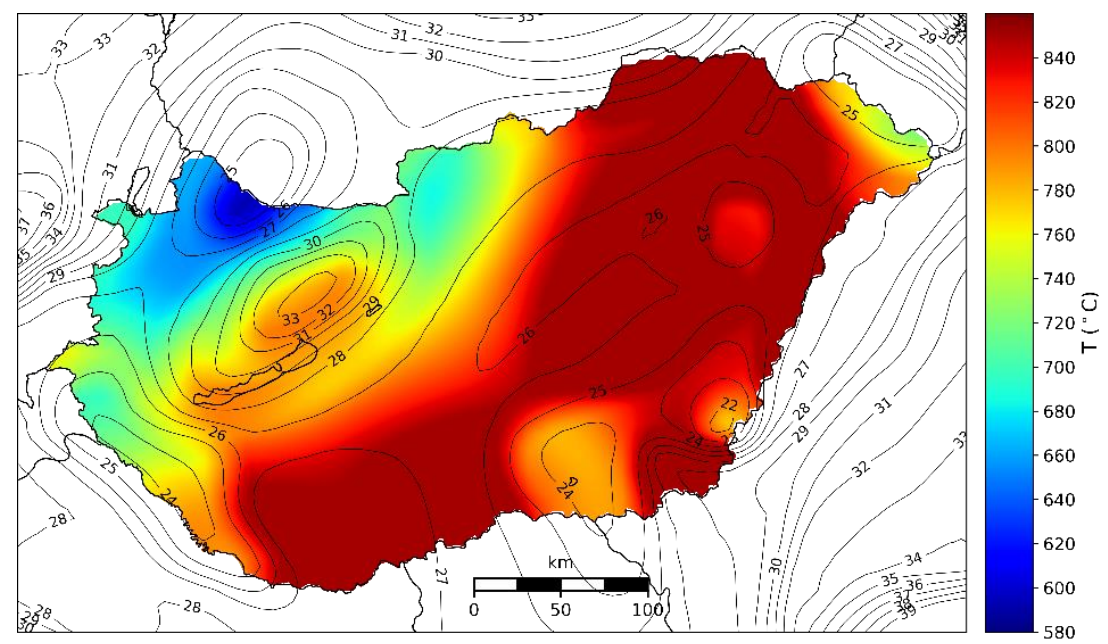

Figure 2.17: Moho temperature map predicted by Model 3 superimposed by the crustal thickness $(\mathrm{km})$ after Horváth et al (2006) indicated with isolines. Note that the modeled temperature in regions where convective effects in the top $5 \mathrm{~km}$ strongly influence the thermal field (e.g. Transdanubian Range), Moho temperatures are underestimated. Additionally, high amplitude local variations may not be entirely realistic, but these values provide the best fit with measured temperatures through steady-state conductive modeling.

\subsection{Conclusions}

In this paper we have presented a new lithospheric-scale 3D temperature model of Hungary. The most important innovation of the applied method is that the thermal properties of the layers are updated through the ensemble smoother with multiple data assimilation technique. Our model is capable to account for observed thermal anomalies due to potential variations in the lithospheric thickness and processes in the underlying mantle by laterally varying the basal heat flow boundary condition. Temperature-depth profiles and the uncertainties clearly support the added value of the data assimilation: our posterior models show considerably better fit with measured records than the prior model. The updated models approximate temperature measurements disturbed by fluid convection by modifying the thermal conductivity of the layers. On the other hand, results should be treated carefully in recharge and discharge areas connected to gravity-driven fluid flows and in the overpressured domain, and also in regions with lack of controlling points. Our models are able to reproduce the thermal effect of lithospheric extension and sediment infill of the Pannonian Basin. Furthermore, the variation in the onset and rate of sedimentation between the northwestern 
and southeastern part of Hungary is also mirrored in the subsurface temperatures. In spite of the sediment blanketing, results suggest that the hottest areas below $3 \mathrm{~km}$ are linked to the basement highs surrounded by deep sub-basins of the Great Hungarian plain. Subsurface temperatures predicted by the two different models are in good agreement, suggesting the stability of the solution. Therefore, it appears that our models are capable to describe the subsurface temperature distribution in the whole lithosphere. Furthermore, our models reveal potential target areas for deep geothermal development and can serve as an input for geothermal resource assessment. In future, the models may further be refined by having better constraints on the depth of the basement and the geometry and thermal properties of the sedimentary layers. The method can also be used for smaller-scale models, in order to predict the temperature distribution at a specific site. 


\section{An updated geothermal model of the Dutch subsurface based on inversion of temperature data $^{2}$}

${ }^{2}$ This chapter is based on Békési, E., Struijk, M., Bonté, D., Veldkamp, H., Limberger, J., Fokker, P. A., Vrijlandt, M., and J.D. van Wees (2020), An updated geothermal model of the Dutch subsurface based on inversion of temperature data. Geothermics, 88, 101880. 


\subsection{Introduction}

Due to the increasing global energy demand, the shortage of conventional energy sources, and environmental aspects, the exploitation of renewable energy sources are gaining importance quickly. Geothermal energy is a good alternative to non-renewable energy sources, but geothermal energy systems need to satisfy several constraints to become economic. The key parameters of geothermal systems are the reservoir temperature and the fluid flow rate. The latter is strongly dependent on the reservoir permeability that should be sufficiently high to support the flow rate. Alternatively, favorable reservoir conditions should be present to allow for enhancement of the permeability (e.g. Enhanced Geothermal Systems; Breede et al., 2013). To assess potential areas for geothermal exploration, large-scale physicsbased models integrating geophysics, geology, and geochemistry are required (e.g. Cloetingh et al., 2010). However, for the development of a geothermal project, detailed site-specific studies are indispensable in order to minimize the pre-drilling risks associated with uncertainties in the subsurface.

In this paper we present a 3D thermal model of the onshore Netherlands. We describe the thermal state of the subsurface in order to identify thermal anomalies within the basins and basement, highlighting potential areas for geothermal development. Geothermal resources in the Netherlands can be classified as conduction dominated intracratonic basin plays (Moeck and Beardsmore, 2014). Geothermal projects focus on direct heat uses, targeting formations restricted to 2-3 km depth. At those depths, the average geothermal gradient of $\sim 31^{\circ} \mathrm{C} / \mathrm{km}$ prohibits electricity production, since sufficiently high temperatures are only reached at larger depth, below 4-5 km. For clastic reservoirs in the Netherlands, permeability at 4-5 km depth is not high enough for geothermal exploitation. The only exception, could be the Dinantian carbonate platforms with their natural fracture networks. Typically, deep geothermal projects in low to medium enthalpy reservoirs are mostly exploiting granite or sandstone reservoirs. However, in the Netherlands the focus is on the fractured carbonate platforms. The 4-km deep Luttelgeest carbonate platform drilled by the LTG-01 well, shows evidence for the presence of hydrothermal convection (Bonté et al., 2012; Lipsey et al., 2016; Van Oversteeg et al., 2014). Higher than average temperatures and the presence of fluids provide favorable conditions for deep geothermal exploitation. Therefore, one of the main aspects of the present study is to identify possible locations where convection in these carbonate platforms might occur and that currently lack temperature measurements.

Investigation of the subsurface temperature distribution in the Netherlands has been carried out for several decades. The first temperature maps of the Dutch subsurface are reported in the Atlas of subsurface temperatures in the European Community (Haenel, 1980), although the temperature dataset used to construct these maps is not available. In the update of the geothermal atlas (Haenel and Staroste, 1988) a temperature dataset of the Netherlands including measurements from 388 wells is reported. A larger dataset containing 334 bottom hole temperatures (BHT) and 53 drill stem tests (DST) is available in the third edition of the geothermal atlas (Hurtig et al., 1992). The majority of measurements are obtained from the uppermost $3 \mathrm{~km}$ of the subsurface, except two values at $5 \mathrm{~km}$ depth. Temperature maps in 
the atlas are only available at European scale and are constructed based on the extrapolation of measured values from shallower depth. Temperature measurements from 464 wells were incorporated into the latest geothermal atlas (Hurter and Haenel, 2002). The maps for the Netherlands in this latter atlas were constructed by Rijkers and Van Doorn (1997) who updated the maps published in older versions of the atlases for the Lower Triassic and the Lower Cretaceous formations that have geothermal potential. The temperature maps were generated by kriging, showing significant improvements. Large-scale temperature models for Europe including the Netherlands, calibrated with a compilation of temperature models based on measurements were also constructed by Limberger et al. (2014, 2018). Verweij (2003) further characterized the temperature distribution in the onshore Netherlands using not only temperature measurements but also a physics-based approach, taking into account calculated estimates of the thermal conductivity and heatflow of the main lithostratigraphical units. Since then the onshore temperature dataset of the Netherlands has been continuously updated (e.g Bonté et al., 2012; Boxem, 2010). The first 3D temperature model of the onshore Netherlands has been constructed by Bonté et al. (2012). Here we present an update of their work using the most recent temperature data, an updated geological model and a significantly improved inverse modeling approach.

We modeled the thermal field of the deep subsurface of the Netherlands in 7 steps. We first constructed a physics-based lithospheric-scale thermal model, hereafter referred to as prior model. The resulting thermal model shows a misfit with the observed temperatures, highlighting areas where the steady-state conductive thermal field is perturbed by transient effects and/or convective heat transport (i.e. paleo-temperature fluctuations, groundwater flow). This misfit is reduced with sequential data-assimilation and more detailed modeling procedures, by updating the thermal properties of the layers using ES-MDA (Emerick and Reynolds, 2013a). Ensemble methods such as the Ensemble-Kalman Filter (EnKF) and the Ensemble Smoother (ES) are applicable for large problems having many parameters. Emerick and Reynolds (2013b) showed that in case of non-linear problems, ES-MDA performs better and is computationally more efficient than EnKF. ES-MDA is most commonly applied for history matching in reservoir modeling. For instance, Fokker et al. (2016) constrained the model parameters of a compacting gas field in the Netherlands with ES-MDA using satellite data. Inversion using ES-MDA to calibrate temperature models was previously applied by Békési et al. (2018) and Limberger et al. (2018). We followed a similar methodology by applying the ES-MDA to constrain the thermal conductivity of the sedimentary units and heat generation in the upper crust. This work flow yielded our final thermal model hereafter referred to as posterior model, describing the thermal state of the uppermost $10 \mathrm{~km}$ of the Dutch subsurface.

\subsection{Geology and geothermal conditions}

The geological structure of the sedimentary cover of the Netherlands was described in detail by Kombrink et al. (2012) (Figure 3.1). A high resolution 2.5D model (DGM-deep v4.0) representing the main sedimentary units to the base of the Carboniferous, reaching a depth up to $3-4 \mathrm{~km}$ in most of the country, is available from the Netherlands Oil and Gas 
Portal website (www.nlog.nl). A cross section is presented in Figure 3.2. Detailed descriptions of the units are available from the www.dinoloket.nl website (Van Adrichem Boogaert and Kouwe, 1993). Units of Devonian, Silurian and Ordovician and older age have seldomly been drilled onshore. The descriptions of those units in the Dutch stratigraphic nomenclator are therefore incomplete and limited due to the lack of data available. The preVariscan basement is unknown in the Netherlands itself, but is considered to consist of Avalonian crust (Pharaoh et al., 2010), which forms the core of the London Brabant Massif south of the Netherlands. Wong et al. (2007) provide a concise description of the Devonian and younger rocks in the Netherlands. Below, only a short description is given, largely based on Wong et al. (2007), Kombrink et al. (2012), Bonté et al. (2012) and Smit et al. (2018).

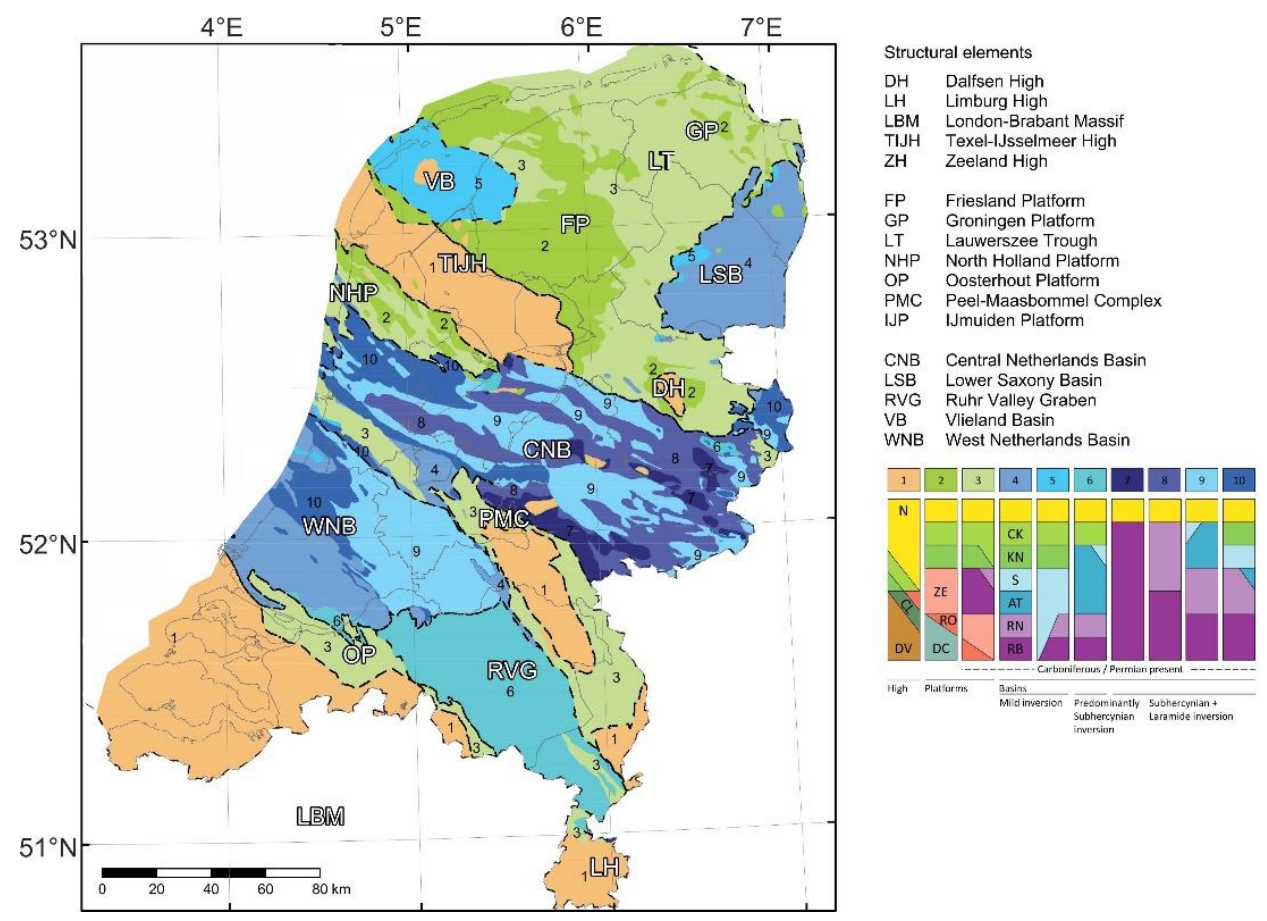

Figure 3.1: Early Carboniferous - Late Jurassic structural elements of the Netherlands. The colour coding reflects the remaining sedimentary succession. Areas that have been relatively stable in green and orange, inverted basins in blue (after Kombrink et al., 2012).

In the Devonian and Carboniferous, lithospheric stretching and subsidence associated with the Variscan orogeny enabled the deposition in the Devonian of sandstones and shales in the southern Netherlands (Kombrink, 2008) and reefal limestones in the north (Van Hulten and Poty, 2008). During the Early Carboniferous carbonate ramps in the south, and isolated platforms in the north were formed (Reijmer et al., 2017), in response to widespread SW-NE directed extension in an extensional collapse setting (Smit et al., 2018), and forming the structural grain of major fault structures in Late Paleozoic and Mesozoic basin history. In the 
Late Carboniferous increased siliciclastic input from the Variscan thrust front buried the carbonate platforms. Thick shales filled the deep basin north of the orogen, followed by the deposition of fluvio-deltaic sandstones, shales and coals. The collapse of the Variscan orogen led to the formation of the Southern Permian Basin (Doornenbal and Stevenson, 2010; Van Wees et al., 2000; Ziegler, 1990). Permian deposits, in the Netherlands, are mainly aeolian and fluvial sandstones (Rotliegend Group) overlain by evaporites (Zechstein Group). The evaporites are thick in the north, leading to the occurrence of salt diapirs, walls and domes (Ten Veen et al., 2012). Further south, the salt is absent and the Zechstein deposits are developed in a basin margin facies (Geluk, 2005). The breaking up of Pangea in the Triassic caused subsidence and deposition of shales, followed by fluvial and aeolian sandstones in fault-bounded depocentres (Lower Germanic Trias, De Jager (2007). During the deposition of sediments of the Upper Germanic Trias, subsidence gradually increased, and evaporites (Röt), fluvio-lacustrine and marine marls and limestones of the Muschelkalk were deposited (Geluk et al., 2007). Increased sediment input led to the deposition of lagoonal and evaporite sediments of the Keuper Formation. During the Jurassic, smaller fault bounded basins and highs developed, in the Early Jurassic marine shales were deposited (De Jager, 2007). Rifting in the North Sea leading to doming caused erosion and non-deposition (Wong et al., 2007). In the Late Jurassic and Early Cretaceous, fluvial to shallow marine siliciclastic sediments were deposited in small fault-bound basins (Schieland and Rijnland Groups, De Jager (2007), Willems (2017)). By the end of the Cretaceous, marine shales and carbonates are deposited. In the Late Cretaceous, the northward movement of Africa towards Europe caused the Alpine orogeny, leading to inversion tectonics with uplift and erosion. Increased sediment input led to the deposition of siliciclastic sediments of the Cenozoic North Sea Group. The Quaternary is dominated by fluvio-deltaic, glacial, and coastal depositional siliciclastic sediments. Figure 3.1 illustrates the tectonic history. It shows areas that, between the Early Carboniferous and Late Jurassic, have remained relatively undisturbed highs in orange, platform areas in green, and inverted basins in blue. The colour coding used in Figure 3.1 reflects the sedimentary succession that currently exists, and therefore the tectonic history. For instance, in the Friesland Platform area, shown in dark green in the North, Cretaceous sediments are directly overlying Permian Zechstein evaporites, Rotliegendes sandstones and sandstones and shales of the Carboniferous. This is also illustrated in the cross section of Figure 3.2, which shows the sedimentary units. Note that faults are not shown in Figure 3.2 because they are not available in the online version of the DGM-deep model, and fault structures were also not incorporated to the thermal model. Also note that the units shown are based on seismic interpretations, and that they do not necessarily correlate fully to the units defined in the ICS timescale. 


\section{Chapter 3: An updated geothermal model of the Dutch subsurface}

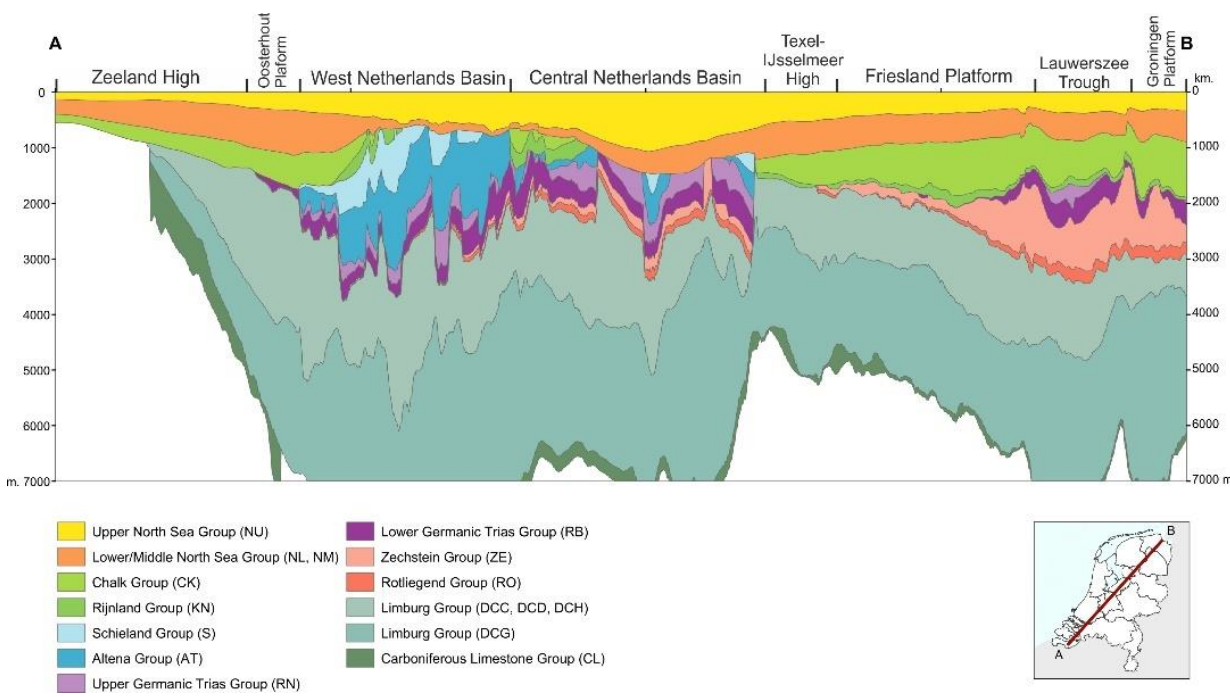

Figure 3.2: Cross section through the Netherlands showing the the main sedimentary units to the base of the Namurian, adopted from the Netherlands Oil and Gas Portal website (www.nlog.nl). Fault structures are not shown in the section as they were not incorporated to the thermal model.

The tectonic evolution of the Netherlands described above has led to a situation where the reservoirs that have been targeted by the oil and gas exploration for more than 70 years are the same a currently targeted by geothermal exploration now. If earlier unsuccessful attempts like the Asten geothermal well of 1988 are ignored, the exploration for geothermal energy started in the Netherlands around 2006, when the first doublet was drilled. Currently, 25 doublets have been drilled, of which 16 are producing, 4 are suspended, and 5 are not yet producing (source: www.nlog.nl). The energy is used for direct heating purposes, especially greenhouses and in a few cases city heating. This requires temperatures between about 60 and $100{ }^{\circ} \mathrm{C}$. Assuming a geothermal gradient of about $31.3{ }^{\circ} \mathrm{C} / \mathrm{km}$ and an average surface temperature of $10{ }^{\circ} \mathrm{C}$ (Bonté et al., 2012), this temperature range exists approximately between 1.5 and 3.0 kilometers depth. With the exception of two doublets that targeted a fault in Carboniferous limestones, all doublets target sandstone reservoirs having sufficient primary porosity and permeability to produce hot water at such rates that stimulation of the reservoir is not required. Figure 3.2, a generalized cross section through the Netherlands, shows which reservoirs are found at these depths. The main targets for geothermal exploration are the sandstones from the Rotliegend (mainly in the Northern part of the country), Lower Germanic Trias and Upper Jurassic/Lower Cretaceous (mainly in the West Netherlands Basin). To a lesser extent, fractured Devonian quartzites and Carboniferous Limestones are targeted, and Paleogene sandstones. 


\subsection{Subsurface temperature data}

Subsurface temperature data from the onshore Netherlands are available on the Dutch Oil and Gas portal (http://www.nlog.nl) and on the Dutch Geothermal Platform (https://geothermie.nl). These temperature measurements are based on Bottom Hole Temperature (BHT) data, Drill-Stem Tests (DST) and Repeat Formation Tests (RFT). Although a large number of BHT data are available for the Dutch onshore, correction is required before they can be used for modeling.

BHTs are recorded as maximum temperatures from well logs and are assumed to be the highest at the bottom of the drilled well. These temperatures may differ from the actual formation temperatures due to the drilling operations. Corrections of BHT data are most commonly based on analytical methods (e.g. Goutorbe et al., 2007) or statistical methods such as the American Association of Petroleum Geologists (AAPG) correction. Numerous modelling methods are also available (e.g. Luijendijk et al., 2011; Rühaak, 2015) but remain difficult to apply for large datasets.

The temperature dataset we used in this study is based on the original database from Bonté et al. (2012), extended with new temperature measurements (Figure 3.3). For correction of the new BHTs we followed the same workflow as Bonté et al. (2012). The new dataset contains 438 BHTs corrected with the analytical method sampled from 199 wells and 987 statistically corrected BHTs from 401 wells, yielding a total of 1425 BHT temperature values. The total number of raw BHTs is significantly larger than the amount of corrected data, as analytical corrections require multiple measurements (Figure 3.3c). In addition, the new dataset contains 65 DST and RFT measurements from 36 wells. We also included 17 production temperature measurements from geothermal wells collected from the Dutch Geothermal Platform (https://geothermie.nl).

The new database consists of 1507 temperature measurements from 505 wells (Figure 3.3a,b). The measurements yield an average geothermal gradient of $31{ }^{\circ} \mathrm{C} / \mathrm{km}$. However, there are some deep anomalies with high temperatures such as the LTG-01, TJM-02-S2, and WSK-01 wells (see Figure 3.9 for locations). 

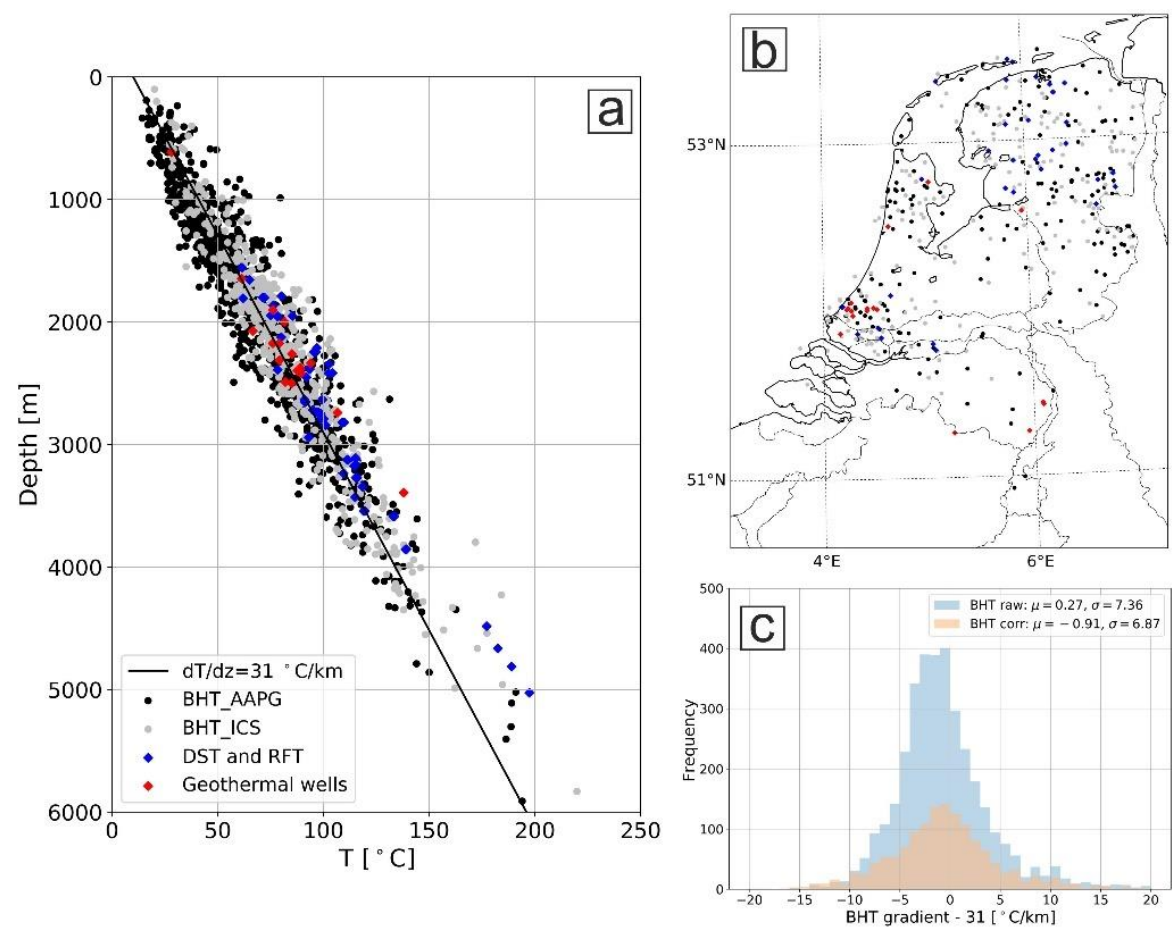

Figure 3.3: Temperature dataset including BHTs, DSTs, RFTs and production temperatures from geothermal wells modified after Bonté et al. (2012) (a). BHT_ICS: BHTs corrected with analytical method, BHT_AAPG: BHTs corrected with statistical method. The temperature measurements were collected from wells drilled in the onshore Netherlands (b). In case of multiple measurement types in a single well, the one with the lower uncertainty is shown in (b). The misfit of raw and corrected BHT gradients with the average Dutch geotherm are shown in (c), with the mean and standard deviation of the fitted Gaussian functions.

\subsection{Conceptual Model}

\subsubsection{Forward model}

The temperature field is forward modeled solving the heat equation in $3 \mathrm{D}$, assuming steady-state conditions and conductive heat transfer only:

$$
0=\nabla \cdot(\lambda \nabla \mathrm{T})+\mathrm{A}
$$

where $\lambda$ is the thermal conductivity, $T$ is the temperature, $A$ is the radiogenic heat generation, and $\nabla=\left(\frac{\partial}{\partial x}, \frac{\partial}{\partial y}, \frac{\partial}{\partial z}\right)$ is the nabla operator. We solve the equation for a low and high resolution hexahedral grid with geometry specifications presented in section 5 . Solutions were obtained by a finite-difference approximation using the Preconditioned Conjugate Gradient method (PCG). The boundary conditions at the top were identical for all models: a stationary surface temperature of $8{ }^{\circ} \mathrm{C}$. This value deviates from the average 
observed yearly surface temperature, which is 10 degrees. We first tested our models with a fixed top boundary condition of $10{ }^{\circ} \mathrm{C}$. Such models systematically overestimated the temperature measurements at depth shallower than $2500 \mathrm{~m}$. To decrease these misfits, we tested our workflow with a lower value of $8{ }^{\circ} \mathrm{C}$, that provided a better fit with the data: the root mean square (RMS) errors at $1000 \mathrm{~m}$ and $2000 \mathrm{~m}( \pm 500 \mathrm{~m})$ depth decreased from 0.8 ${ }^{\circ} \mathrm{C}$ and $0.84{ }^{\circ} \mathrm{C}$ to $0.71{ }^{\circ} \mathrm{C}$ (Table 3.3). Therefore, we choose a lower value to our final model to account for the paleo-surface temperatures affected by the recent ice age (e.g. Donders et al., 2009; Verweij et al., 2012). The boundary conditions at the bottom were different for the low- and high-resolution models. We chose a fixed temperature at the bottom of the lithosphere with a corresponding value of $1200{ }^{\circ} \mathrm{C}$ for the low-resolution models. The heat flow at $10 \mathrm{~km}$ depth, obtained from the low-resolution model, was used as boundary condition for the high-resolution models. The vertical edges of all models were assumed to be insulating with a fixed heat flow of zero.

The motivation to use a steady-state model, excluding transient thermal effects, is computational performance for the ES-MDA inversion which requires 100s of model runs. We argue that the use of a steady state model is justified since in most of the Netherlands active tectonic processes are absent or marked by very low sedimentation rates, up to a maximum of $0.1 \mathrm{~mm} / \mathrm{y}$ in the southeast of the Netherlands, and have resulted in less than 1.5 $\mathrm{km}$ of sediments in the last 20 million years. Previously studies, incorporating transient effects, demonstrate that such low sedimentation rates do not deviate considerably from the steady state assumptions (e.g. Van Wees et al., 2009).

\subsubsection{Thermal convection in the Dinantian carbonate platforms}

The previous 3D temperature model from Bonté et al. (2012) could not reproduce the thermal anomaly measured at a depth below $4 \mathrm{~km}$ in the LTG-01 well (see Figure 3.4 for location). Bonté et al. (2012) suggested that higher than expected temperatures and the abnormally low thermal gradient observed within the Dinantian carbonates might be explained by the occurrence of hydrothermal convection. Another possible explanation of the thermal profile observed in the LTG-01 well is the large thermal conductivity contrast between the overlying Westphalian and Namurian layers and the Dinantian carbonates, based on petrophysical analysis in the framework of the SCAN project (Veldkamp and Hegen, 2020). Van Oversteeg et al. (2014) and Lipsey et al. (2016) investigated the potential for thermal convection at the LTG-01 well and confirmed that convection is likely to occur in the Dinantian carbonate platform. To come to this conclusion, they assessed the minimum permeability $\left(k_{\min }\right)$ required for convection based on Rayleigh number analysis following Horton and Rogers Jr (1945) and Lapwood (1948). Lipsey et al. (2016) also supported the occurrence of fluid convection with permeability assessment on core samples and numerical modeling.

The Rayleigh number is a dimensionless value that indicates the likelihood of natural or free convection. The equation for the Rayleigh number in a porous medium is written as: 


$$
R a=\frac{k \rho_{f}^{2} c_{p} g \alpha_{f} \Delta T H}{\mu \lambda}
$$

where $k$ is the permeability, $g$ is the gravitational acceleration, $\Delta T$ is the temperature difference between the top and the bottom of the layer, $H$ is the thickness of the layer and $\rho_{f}, c_{p}, \alpha_{f}$ are the density, the specific heat capacity, the thermal expansion coefficient of the pore fluid, respectively. $\mu$ and $\lambda$ denote the viscosity of the fluid and the bulk thermal conductivity of the of the medium. If $R a$ exceeds a certain threshold value, referred to as the critical Rayleigh number $\left(R a^{*}\right)$, convection can take place in the medium. For a horizontal, homogenous isotropic porous medium bounded by fixed temperature conditions, $R a^{*}=4 \pi^{2}$. Equation (3.2) can be rewritten to determine $k_{\min }$ using $R a^{*}$ :

$$
k_{\min }=\frac{R a^{*} \mu \lambda}{\rho_{f}^{2} c_{p} g \alpha_{f} \Delta T H}
$$

The minimum permeability to initiate hydrothermal convection, $k_{\min }$, for the Dinantian carbonates was calculated to be $3 \times 10^{-14} \mathrm{~m}^{2}$ (Van Oversteeg et al., 2014) and $1.9 \times 10^{-14} \mathrm{~m}^{2}$ (Lipsey et al., 2016). The difference between the two values mostly originates from the different values used for the thickness of the convective layer in the Dinantian carbonates, being $600 \mathrm{~m}$ and $800 \mathrm{~m}$, respectively. Since the proposed permeability for the interval of the Dinantian by Van Oversteeg et al. (2014) was estimated to be $6 \times 10^{-14} \mathrm{~m}^{2}$ and Lipsey et al. (2016) reported the possibility of even higher values (up to $10^{-13} \mathrm{~m}^{2}$ ), convection is likely to explain the temperature profile in the LTG-01 well.

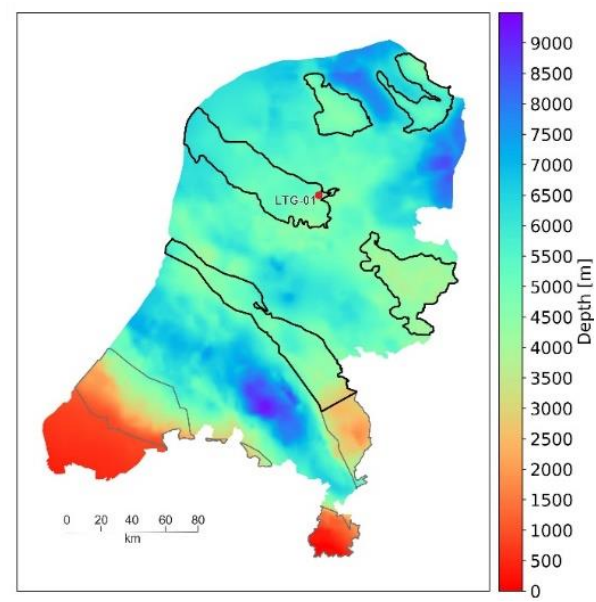

Figure 3.4: Depth of the top of the Carboniferous Limestone Group (Dinantian). The extent of the carbonate platforms within the group based on seismic data and well logs, adopted from Kalkman (2016), is outlined. We assumed that convection may occur in the deeper platforms, marked by the thick black outline. 
Based on these findings, we assumed potential hydrothermal convection in the carbonate platforms all over the Netherlands. However, these carbonate platforms are found at significantly different depths in the Netherlands: in the south the platforms are located much shallower than in the north. (Figure 3.4). $R a$ is dependent on the pore fluid properties, which show a significant variation with depth. Van Oversteeg et al. (2014) analyzed the effect of pressure and temperature on $k_{\min }$ and showed that $k_{\min }$ strongly decreases with depth. We constructed similar $\mathrm{k}_{\min }$-depth curves for different layer thicknesses (Figure 3.5) to assess if convection could occur in the carbonate platforms in the south of the Netherlands. We calculated fluid properties using a model dependent on temperature, pressure, and salinity (after Van Wees et al. (2012)), where the temperature, pressure and salinity dependence of density and viscosity is incorporated after Batzle and Wang (1992), and the temperature and salinity dependence of specific heat capacity is based on Grunnberg (1970). The temperature was calculated with a constant geothermal gradient of $31{ }^{\circ} \mathrm{C} / \mathrm{km}$, and the pressure was assumed to be hydrostatic. The minimum Rayleigh permeability at larger depth is relatively small: between 3.5-5.5 $\mathrm{km} k_{\min }$ ranges from 1 to $5 \times 10^{-14} \mathrm{~m}^{2}$ (Figure 3.5a). At shallower depth, however, the values are significantly larger (Figure $3.5 \mathrm{~b}$ ): at $2 \mathrm{~km}$ depth and shallower, $k_{\min }$ is larger than $\sim 10^{-13} \mathrm{~m}^{2}$, which is equal to the highest permeability of the Dinantian (Lipsey et al., 2016). We thus concluded that thermal convection is not likely to occur in the carbonate platforms in the south.
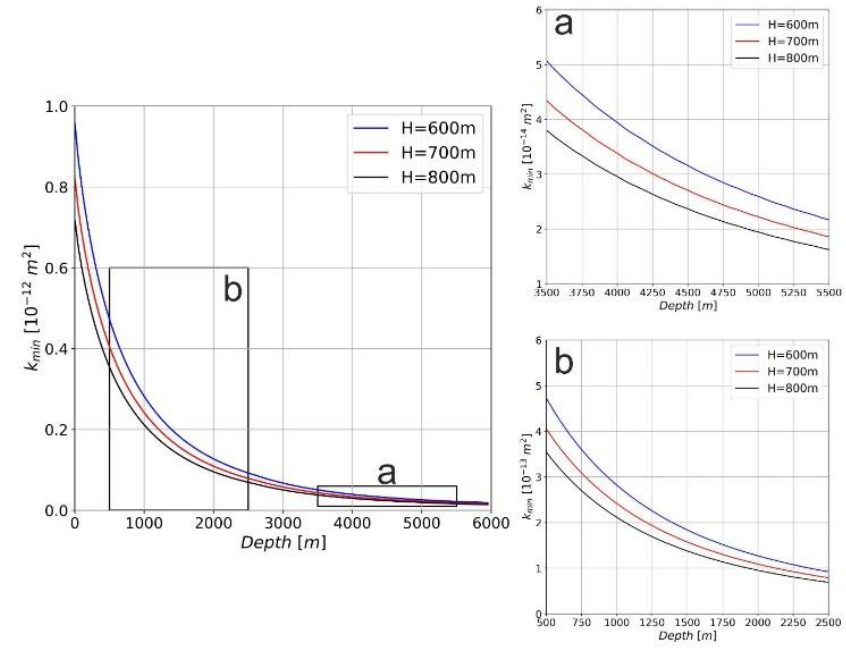

Figure 3.5: The dependence of minimum Rayleigh permeability on depth. The curves were constructed by taking into consideration the temperature, pressure, and salinity dependency of water properties following Van Wees et al. (2012). Note the different scales for depth and $\mathrm{k}_{\min }$.

Our calculations are based on several assumptions: we adopted a horizontal, homogenous isotropic porous medium bounded by fixed temperature conditions. Other factors such as the effect of the extent and geometry of the platform, heterogeneity in permeability can play an 
important role in the presence/absence of convection (Lipsey et al., 2016). These factors need to be taken into account for site-specific studies. Still, our calculations can be used as an approximation to assess the potential for hydrothermal convection in the Dinantian carbonate platforms all over the Netherlands.

\subsection{Model geometry and thermal properties}

\subsubsection{Model geometry}

The thermal models have been built in the Dutch coordinate system (EPSG:28992) and their outline has been defined by the political boundaries of the Netherlands. We performed the modelling in two resolutions: the low resolution models extend from the surface up to the depth of the Lithosphere-Asthenosphere Boundary (LAB), while the high resolution models only include the uppermost $10 \mathrm{~km}$ of the subsurface. For the low resolution models, temperatures were calculated through a regular 3D grid with a horizontal resolution of $2.5 \times 2.5 \mathrm{~km}$, a vertical resolution of $200 \mathrm{~m}$ for the uppermost $10 \mathrm{~km}$, and $3 \mathrm{~km}$ down to the LAB. The high resolution models are defined by $1 \times 1 \mathrm{~km}$ and $200 \mathrm{~m}$ grid spacing in horizontal and vertical directions, respectively.

The model was built as a layered structure that includes the lithospheric mantle, lower crust, upper crust and 14 sedimentary units, summarized in Table 3.1. For the thickness of the lithosphere we used a constant value of $110 \mathrm{~km}$. We also tested models for the LAB depth after Tesauro et al. (2009) and Artemieva (2019), but the thermal effect of the different LAB models in the shallow part of the model $(0-10 \mathrm{~km})$ was negligible. The crustal thickness was adopted from the EuCRUST-07 model (Tesauro et al., 2008) with an average thickness of 32 $\mathrm{km}$ in the Netherlands. For the subdivision of the sedimentary layers we followed the DGMdeep v4.0 onshore model (adopted from nlog.nl, Figure 3.2). The sedimentary model is available to the base of the Limburg Group, since the depth of the base of the Carboniferous Limestone Group (Dinantian) is not yet well constrained in all parts of the Netherlands. We estimated the thickness of the Dinantian to be $700 \mathrm{~m}$, which is a rough average of the thicknesses found in the LTG-01 and UHM-02 wells that drilled the entire Dinantian section. It is important to note that the thickness of the Dinantian might be lower in some areas. For example, in the southern part of the Netherlands, where the Dinantian is shallower, the estimated thickness is mostly below $500 \mathrm{~m}$ (Reijmer et al., 2017). We selected a constant thickness of $700 \mathrm{~m}$ based on the assumption that older sediments with similar thermal properties are likely to be present below the Dinantian.

Following the example of the thermal anomaly found in the Dinantian carbonates in the Luttelgeest-01 (LTG-01) well, we assumed that hydrothermal convection may occur in the carbonate platforms. To distinguish between the basin facies and platform areas of the Dinantian, we treated the carbonate platforms as a separate layer by adopting their geometry after Kalkman (2016) (Figure 3.6), based on 2D and 3D seismic data and 15 well logs. The outline of the platforms is marked by larger uncertainty in the northern part of the country, where the platforms are deeply buried (Figure 3.4). Also, in the South there are multiple wells drilling the Dinantian carbonates, providing constraints for the seismic data. We excluded 
the platforms in the South from the new layer, assuming that hydrothermal convection is most likely restricted to larger depths.

In the southern part of the Netherlands we included a new layer to represent the deeply buried Palaeozoic sediments with low porosity below the Dinantian (Figure 3.10, layer 12). We constructed this layer based on cross-sections from Duin et al. (2006), although its geometry is poorly constrained due to the lack of available data.

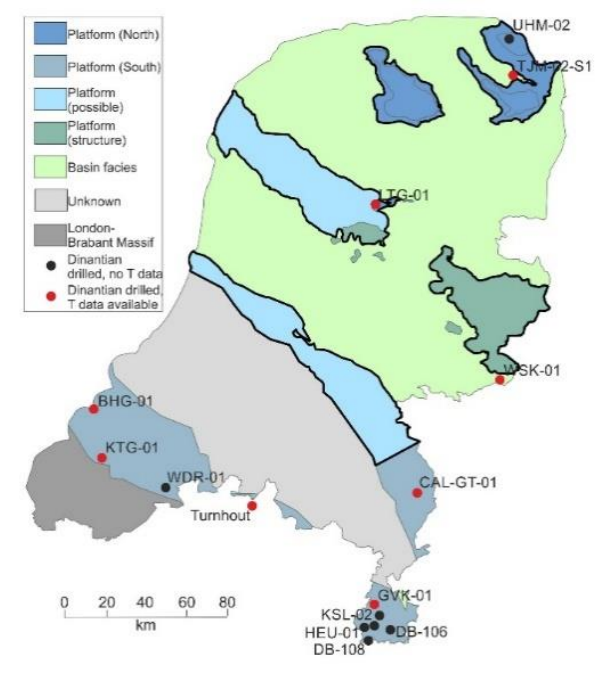

Figure 3.6: Map showing the locations of the Dinantian carbonate platforms and other rocks of Dinantian age modified after Kalkman (2016). We use scaling of the thermal conductivity to approximate the thermal effects of convection. Outlined in black are the areas below the carbonate platforms for which we scaled the thermal conductivity values.

\subsubsection{Thermal properties}

\subsubsection{Thermal conductivity}

We defined the thermal properties of each sedimentary unit based on their lithologies following the methodology of Hantschel and Kauerauf (2009) (Table 3.1). The bulk matrix thermal conductivity $\left(\lambda_{\mathrm{m}}\right)$ of the lithological components were corrected for pressure conditions and the in-situ temperature after Sekiguchi (1984). For shales and carbonates, we took into consideration the change in anisotropy with increasing compaction (Hantschel and Kauerauf, 2009). The horizontal matrix conductivity was calculated from $\lambda_{\mathrm{m}}$ using the anisotropy factors of the corresponding lithology. We obtained the bulk thermal conductivity $\left(\lambda_{\text {bulk }}\right)$ for each lithology by taking the geometric mean of $\mathrm{k}_{\mathrm{m}}$ and the temperature-dependent thermal conductivity of the pore fluid $\left(\lambda_{\mathrm{w}}\right)$ as follows:

$$
\lambda_{\text {bulk }}(z)=\lambda_{m}^{1-\phi} * \lambda_{w}^{\phi}
$$


where $\phi$ is the porosity. If a sedimentary unit consisted of different lithologies, the bulk thermal conductivity within the layer was calculated by taking the harmonic mean of the bulk conductivities.

Because our forward thermal model only solves the steady-state heat equation for conduction, we used a pseudo-convective approach to reproduce the deep thermal anomaly found in the LTG-01 well: we scaled the prior thermal conductivity of the layer corresponding to the carbonate platforms. This method, together with a similar modelling technique, was applied by Békési et al. (2018) for the Pannonian basin. After several model runs to test different thermal conductivity values of the platform layer, we could not reproduce the deep thermal anomaly. Our models managed to fit the convective profile only by the combination of increasing the thermal conductivity of the platforms and decreasing the conductivity of the layer overlain by the Dinantian (Limburg Group). We tried to choose the thermal conductivity of the layer corresponding to the Limburg Group close to its original value, but low enough to fit the temperature measurements in the Dinantian. We tested numerous combinations before attaining acceptable values. We fixed the thermal conductivity of the Limburg Group to $1.5 \mathrm{~W} \mathrm{~m}^{-1} \mathrm{~K}^{-1}$, and the Dinantian carbonate platforms to $5.0 \mathrm{~W} \mathrm{~m}^{-1} \mathrm{~K}^{-1}$ (Table 3.1). It is important to note that scaling the thermal conductivities of limestones to unrealistic values of $5 \mathrm{~W} \mathrm{~m}^{-1} \mathrm{~K}^{-1}$ was required to approximate the effect of convection with a purely conductive model. The low thermal conductivity of $1.5 \mathrm{~W} \mathrm{~m}^{-1} \mathrm{~K}^{-1}$ assigned to the Limburg Group is also rather unrealistic, considering its compaction and low porosity. However, Silesian sediment with high coal content might explain such low values. We used these values as prior thermal conductivities before applying the data assimilation.

The thermal conductivity of the upper and lower crust were estimated with the temperature- and pressure-dependent relation of Chapman (1986). With increasing temperature down to the lithospheric mantle, the contribution of the radiative component of the thermal conductivity increases compared to the contribution of the lattice component. Therefore, the thermal conductivity of the lithospheric mantle was calculated as the sum of the temperature-dependent radiative contribution obtained after Schatz and Simmons (1972) and the temperature- and pressure-dependent lattice component following the formula of $\mathrm{Xu}$ et al. (2004). More details on the calculations of the thermal conductivity values of the different units are described by Limberger et al. (2018).

\subsubsection{Radiogenic heat production}

For the radiogenic heat production of each sedimentary unit, a constant value was selected based on generic values of typical lithologies from Hantschel and Kauerauf (2009). The heat production of the layers consisting of more than one lithology was calculated as the geometric mean of the corresponding lithologies. We chose $1 \mu \mathrm{W} \mathrm{m}{ }^{-3}$ as a prior value for heat generation in the upper crust, which was then updated through data assimilation to account for potential under/overestimation of the initial radiogenic heat production. For heat generation in the lower crust and lithospheric mantle, we assigned 0.5 and $0.02 \mu \mathrm{W} \mathrm{m}{ }^{-3}$, respectively, also following Hantschel and Kauerauf (2009). 


\begin{tabular}{|c|c|c|c|c|c|c|}
\hline ID & Layer name & $\begin{array}{c}\text { Age of } \\
\text { sedimentary } \\
\text { units }\end{array}$ & Lithology & $\begin{array}{l}\text { Thermal } \\
\text { conductivity } \\
{\left[\mathrm{W} \mathrm{m}^{-1} \mathrm{~K}^{-1}\right]}\end{array}$ & $\begin{array}{l}\text { Anisotropy } \\
\text { factor }\end{array}$ & $\begin{array}{c}\text { Radiogenic } \\
\text { heat } \\
\text { generation } \\
{\left[\mu \mathrm{W} \mathrm{m}^{-3}\right]}\end{array}$ \\
\hline 1 & $\begin{array}{l}\text { Upper North } \\
\text { Sea Group }\end{array}$ & $\begin{array}{l}\text { Neogene and } \\
\text { Quaternary }\end{array}$ & $\begin{array}{l}50 \% \text { Shale } \\
-50 \% \\
\text { Sandstone }\end{array}$ & \multirow{10}{*}{ 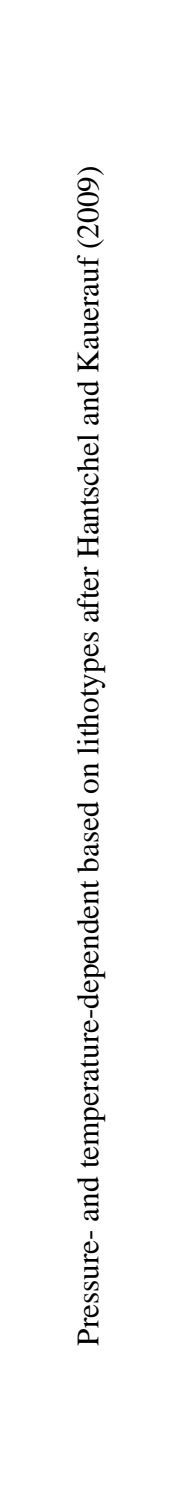 } & \multirow{11}{*}{ 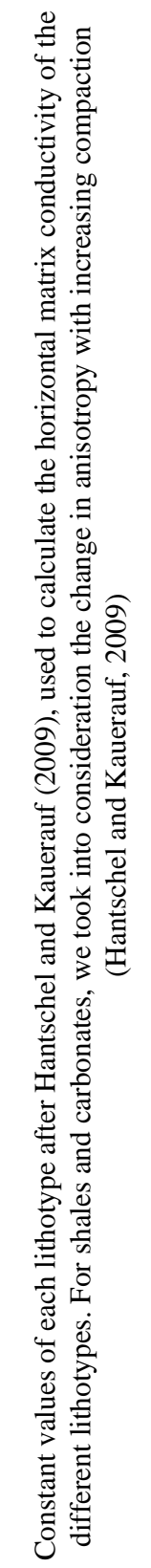 } & \multirow{11}{*}{ 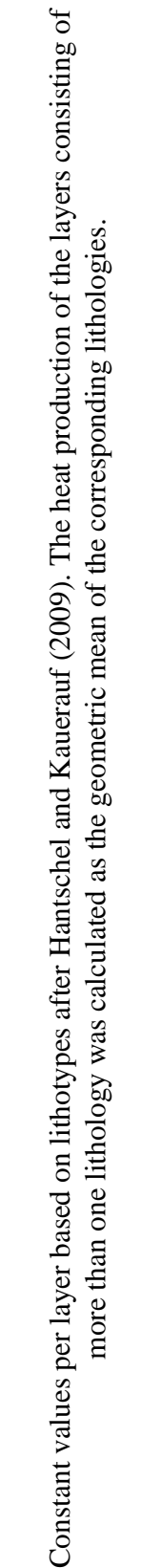 } \\
\hline 2 & $\begin{array}{l}\text { Lower and } \\
\text { Middle North } \\
\text { Sea Group }\end{array}$ & Paleogene & $\begin{array}{l}50 \% \text { Shale } \\
-50 \% \\
\text { Sandstone }\end{array}$ & & & \\
\hline 3 & Chalk Group & $\begin{array}{c}\text { Upper } \\
\text { Cretaceous }\end{array}$ & $\begin{array}{l}100 \% \\
\text { Chalk }\end{array}$ & & & \\
\hline 4 & $\begin{array}{l}\text { Rijnland } \\
\text { Group }\end{array}$ & $\begin{array}{l}\text { Lower } \\
\text { Cretaceous }\end{array}$ & $\begin{array}{c}50 \% \text { Shale } \\
-25 \% \\
\text { Marl - } 25 \\
\% \\
\text { Sandstone }\end{array}$ & & & \\
\hline 5 & $\begin{array}{l}\text { Upper } \\
\text { Jurassic } \\
\text { Groups }\end{array}$ & Upper Jurassic & $\begin{array}{l}50 \% \text { Shale } \\
-50 \% \\
\text { Sandstone }\end{array}$ & & & \\
\hline 6 & Altena Group & $\begin{array}{c}\text { Lower and } \\
\text { Middle Jurassic }\end{array}$ & $\begin{array}{l}75 \% \text { Shale } \\
-25 \% \text { Silt }\end{array}$ & & & \\
\hline 7 & $\begin{array}{l}\text { Lower and } \\
\text { Upper } \\
\text { Germanic } \\
\text { Groups }\end{array}$ & Triassic & $\begin{array}{c}40 \% \text { Shale } \\
-30 \% \\
\text { Limestone } \\
-30 \% \\
\text { Sandstone }\end{array}$ & & & \\
\hline 8 & $\begin{array}{l}\text { Zechstein } \\
\text { Group }\end{array}$ & $\begin{array}{l}\text { Lopingian (Late } \\
\text { Permian) }\end{array}$ & $\begin{array}{l}\text { Zechstein } \\
\text { layer } \\
\text { (Shale to } \\
\text { the South - } \\
\text { Salt to the } \\
\text { North) }\end{array}$ & & & \\
\hline 9 & $\begin{array}{l}\text { Upper } \\
\text { Rotliegend } \\
\text { Group }\end{array}$ & $\begin{array}{c}\text { Late } \\
\text { Guadalupian } \\
\text { (Middle } \\
\text { Permian) }\end{array}$ & $\begin{array}{c}70 \% \\
\text { Sandstone - } \\
15 \% \text { Shale } \\
-15 \% \text { Silt }\end{array}$ & & & \\
\hline 10 & $\begin{array}{l}\text { Caumer } \\
\text { Subgroup }\end{array}$ & $\begin{array}{c}\text { Westphalian } \\
\text { (Carboniferous, } \\
\text { Middle Silesian) }\end{array}$ & $\begin{array}{l}60 \% \text { Shale } \\
-40 \% \\
\text { Sandstone }\end{array}$ & & & \\
\hline 11 & $\begin{array}{l}\text { Limburg } \\
\text { Group }\end{array}$ & $\begin{array}{c}\text { Namurian } \\
\text { (Carboniferous, } \\
\text { Lower Silesian) }\end{array}$ & $\begin{array}{l}60 \% \text { Shale } \\
-40 \% \\
\text { Sandstone }\end{array}$ & 1.5 & & \\
\hline
\end{tabular}




\begin{tabular}{|c|c|c|c|c|c|c|}
\hline 12 & $\begin{array}{c}\text { Carboniferous } \\
\text { Limestone } \\
\text { Group - } \\
\text { carbonate } \\
\text { platforms }\end{array}$ & $\begin{array}{c}\text { Dinantian } \\
\text { (Lower } \\
\text { Carboniferous) }\end{array}$ & $\begin{array}{c}100 \% \\
\text { Limestone }\end{array}$ & 5 & & \\
\hline 13 & $\begin{array}{c}\text { Carboniferous } \\
\text { Limestone } \\
\text { Group }\end{array}$ & $\begin{array}{c}\text { Dinantian } \\
\text { (Lower } \\
\text { Carboniferous) }\end{array}$ & $\begin{array}{c}100 \% \\
\text { Limestone }\end{array}$ & \multirow{2}{*}{$\begin{array}{c}\text { Pressure- } \\
\text { and } \\
\text { temperature- } \\
\text { dependent } \\
\text { based on } \\
\text { lithotypes } \\
\text { after } \\
\text { Hantschel } \\
\text { and } \\
\text { Kauerauf } \\
(2009)\end{array}$} & & \\
\hline 14 & $\begin{array}{l}\text { Old Paleozoic } \\
\text { sediments }\end{array}$ & $\begin{array}{c}\text { Paleozoic } \\
\text { (Devonian and } \\
\text { older) }\end{array}$ & $\begin{array}{l}60 \% \text { Shale } \\
-40 \% \\
\text { Sandstone }\end{array}$ & & & \\
\hline-1 & Upper crust & - & $\begin{array}{l}100 \% \\
\text { Granite }\end{array}$ & \multirow{2}{*}{$\begin{array}{l}\text { Pressure- } \\
\text { and } \\
\text { temperature- } \\
\text { dependent } \\
\text { after } \\
\text { Chapman } \\
\text { (1986) }\end{array}$} & - & 1 \\
\hline-2 & Lower crust & - & $\begin{array}{c}100 \% \\
\text { Anorthosite }\end{array}$ & & - & 0.5 \\
\hline-3 & $\begin{array}{l}\text { Lithospheric } \\
\text { mantle }\end{array}$ & - & $\begin{array}{c}100 \% \\
\text { Peridotite }\end{array}$ & $\begin{array}{l}\text { Pressure- } \\
\text { and } \\
\text { temperature- } \\
\text { dependent } \\
\text { after Schatz } \\
\text { and } \\
\text { Simmons } \\
\text { (1972) and } \\
\text { Xu et al. } \\
\text { (2004) }\end{array}$ & - & 0.02 \\
\hline
\end{tabular}

Table 3.1: Lithological composition and prior thermal properties of the layers. 


\subsection{Modeling work flow}

\subsubsection{Description of the work flow}

To construct the thermal model of the deep subsurface of the Netherlands, we first adopted the prior thermal properties of the layers listed in Table 3.1. Initial calculations were made by solving the heat equation in multi-1D (step 1, Figure 3.7) in the low resolution grid, in order to obtain default values for thermal conductivity in agreement with first order estimates for temperature and pressure. Subsequently, based on these default properties we calculated a prior 3D thermal model (step 2 Figure 3.7).

The misfit between modeled and observed temperatures was subsequently reduced by updating the thermal properties of the layers using ES-MDA in step 3-4 (Figure 3.6). The results are subsequently used in a higher resolution grid and the final posterior thermal model is obtained in step 7, as shown in Figure 3.7 and described in the following sections.

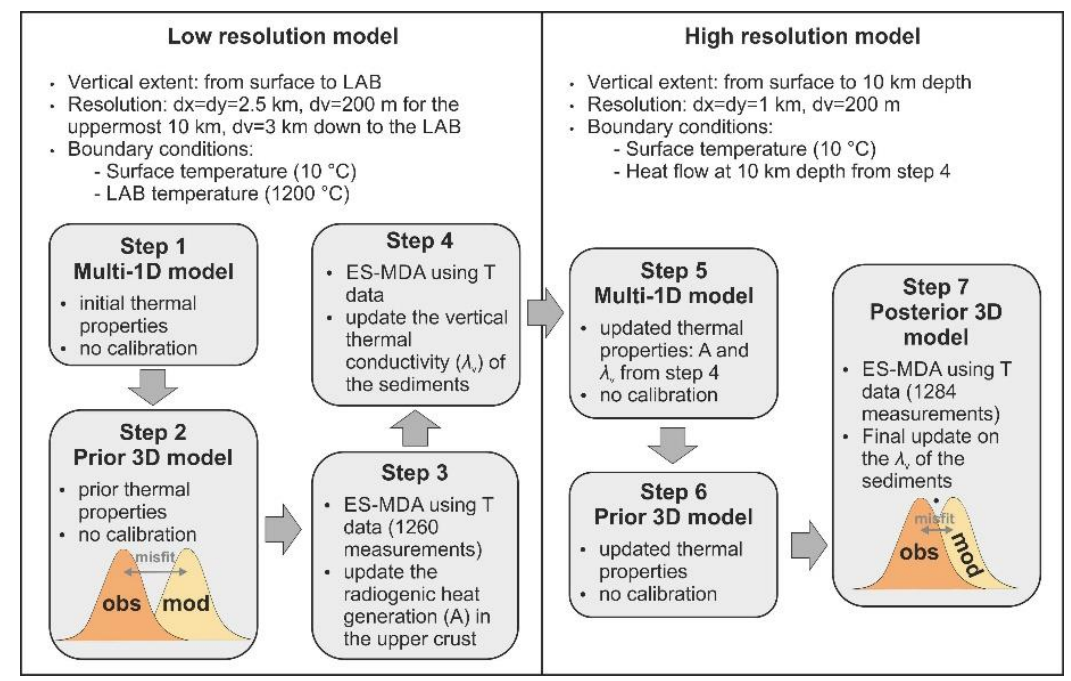

Figure 3.7: Description of the modeling work flow.

\subsection{Inversion}

We used inversion of subsurface temperature data to infer the thermal field by varying a selection of the thermal properties of the layers: the radiogenic heat generation of the upper crust and the thermal conductivity of the sedimentary units.

\subsubsection{Ensemble Smoother with Multiple Data Assimilation (ES-MDA)}

We solved the inverse problem using the Ensemble Smoother (ES), which estimates the parameters in a single step by a global update incorporating all data available (Emerick and Reynolds, 2013a). Ensemble-based methods, such as the Ensemble-Kalman Filter (EnKF) and the ES, are suitable for systems with large numbers of parameters. Emerick and Reynolds 
(2013b) investigated different ensemble methods and found that in case of non-linear forward models, the Ensemble Smoother with multiple data assimilation (ES-MDA) performs better than the EnKF. Additionally, the ES-MDA is computationally less demanding. Therefore, we applied the ES-MDA for handling the non-linearity between the observations and model parameters.

For the ES, the assimilated model parameter vectors $\mathrm{m}^{\mathrm{a}}$ are written as (Emerick and Reynolds, 2013a):

$$
m_{j}^{a}=m_{j}^{f}+C_{M D}^{f}\left(C_{D D}^{f}+C_{D}\right)^{-1}\left(d_{u c, j}-d_{j}^{f}\right)
$$

for $j=1,2,[\ldots], N_{e}$, where $N_{e}$ denotes the number of ensembles, $C_{M D}^{f}$ is the crosscovariance matrix between the prior vector of model parameters, $\mathrm{m}^{f}$, and the vector of predicted data, $d^{f} . C_{D D}^{f}$ is the $N_{d} \times N_{d}$ auto-covariance matrix of predicted data, and $C_{D}$ is the $N_{d} \times N_{d}$ covariance matrix of the measurement errors, where $N_{d}$ denotes the number of measurements assimilated. $d_{u c} \sim N\left(d_{o b s}, C_{d}\right)$ is an ensemble of vectors with the measurements vector $d_{o b s}$, perturbed normally according to the covariance matrix $C_{d}$. An ensemble of solutions is produced by the ensemble update, consistent with the prior statistics, and the mean of the ensemble is taken as the best estimate. In case of the ES-MDA, an ES is applied multiple times, with the output ensemble used as input for the next update. The number of data assimilation steps or iterations, $\mathrm{N}_{\mathrm{a}}$ must be selected a-priori. The data covariances used for the update steps are increased by a multiplication factor, $\alpha_{i}$ for $i=1,2 \ldots$, $N_{a}$, and $\alpha_{\mathrm{i}}$ must be selected as $\sum_{i=1}^{N_{a}} \frac{1}{\alpha_{i}}=1$. This covariance adjustment to increase ensemble variance is required to reduce filter divergence and to improve performance of the state vector.

\subsubsection{Data uncertainty}

We used the temperature measurements as observations for the inversion. We assigned uncertainties to the temperature data based on measurement quality and assuming a Gaussian error distribution. We made this assumption after assessing the misfits of the raw and corrected BHT gradients with the average geothermal gradient, that can be approximated with normal distribution (Figure 3.3c). It is important to note that measurement errors are not necessarily symmetric and they are depth-dependent (e.g. Agemar et al., 2012). Here we select identical uncertainties for the same measurement types with the same correction method for simplicity. Uncertainties may be overestimated due to the fact that we choose maximum values assigned to each category. We marked the DSTs and RFTs with an uncertainty of $\pm 8^{\circ} \mathrm{C}$ (e.g. Bonté et al., 2012). For the BHTs, we chose different uncertainties based on the correction method applied to the measurement. We used $\pm 10{ }^{\circ} \mathrm{C}$ for BHTs corrected with the analytical method and $\pm 15^{\circ} \mathrm{C}$ for values obtained by the statistical method (Goutorbe et al., 2007). The production temperatures of the geothermal wells were treated with an uncertainty of $5{ }^{\circ} \mathrm{C}$. Saeid et al. (2013) suggested that the maximum drop in in production temperatures occur within the first years of operation. Additionally, temperatures 
of the extracted fluids decrease before reaching the wellhead. Since $\sim$ half of the production temperatures were obtained within the first year of production (geothermie.nl), we concluded that the uncertainty of \pm 5 degrees is a good approximation.

During the inversion, only one observation within a grid cell is used. When multiple measurements were present, inversion was limited to the measurement with the lowest uncertainty. As a result, the number of observations in the high-resolution model (1284) was larger than for the low-resolution models (1260, Figure 3.7). Most of the temperature measurements $(\sim 85 \%)$ were conducted at depths below $3 \mathrm{~km}$, ensuring a good calibration for the upper part of the model. At larger depths, the amount of controlling points significantly decreases (Figure 3.3, Table 3.3:).

\subsubsection{Description of the data assimilation procedure}

Through the data assimilation, the prior thermal properties including the heat production in the upper crust and thermal conductivity of the sediments were updated to achieve a better fit with the temperature observations. The prior uncertainty in the thermal properties was taken into account by scaling the parameters to a triangular distribution. The spatial variability of the parameters was determined through a spherical variogram. The radius of the variogram is expressed in cells, which corresponds to a certain distance in kilometers.

We obtained the posterior thermal model in 7 steps (Figure 3.7), where steps 3, 4 and 7 included the parameter updates summarized in Table 3.2. In each step the ES-MDA was run with 600 ensembles and 4 iterations. We chose 4 iterations following the example of Emerick and Reynolds (2013b). In step 3, we scaled the upper crustal heat generation between 0.6 and 1.6 of the prior value, with a variogram range of 14 cells (corresponding to $\sim 42 \mathrm{~km}$ ). Then, the thermal conductivity of the sediments was scaled between 0.7 and 1.3, except for the Zechstein Group (layer 8) and the Carboniferous Limestone Group (layers 12 and 13), where a larger variation was allowed. We chose scaling factors of 0.7 and 1.4 for the Zechstein Group (layer 8 ) to account for potential higher thermal conductivity of salts. We scaled the thermal conductivity of the Carboniferous Limestone Group (layers 12 and 13) using a larger range, to allow for more variance approximating the thermal effect of hydrothermal convection (especially in the platform areas). We assumed a smaller-scale lateral variation in the thermal conductivity of the sediments (layer 1-11,13): in step 4, the range of variations was set to 8 cells $(\sim 24 \mathrm{~km})$. In the last modelling step (step 7), further refinement of the thermal conductivity of the sediments was achieved by scaling the values between 0.8 and 1.2 with a variogram range of 30 cells $(\sim 30 \mathrm{~km})$. 


\begin{tabular}{|c|c|c|c|c|c|c|}
\hline $\begin{array}{l}\text { Modeling } \\
\text { step }\end{array}$ & Description & $\begin{array}{c}\text { Prior } \\
\text { distribution }\end{array}$ & $\begin{array}{c}\text { Scaling } \\
\text { parameters }\end{array}$ & $\begin{array}{l}\text { Variogra } \\
\text { m model }\end{array}$ & $\begin{array}{l}\text { Variogra } \\
\mathrm{m} \text { range }\end{array}$ & $\begin{array}{c}\text { Number of } \\
\text { ensemble } \\
\text { runs and } \\
\text { iterations }\end{array}$ \\
\hline 3 & $\begin{array}{l}\text { update the } \\
\text { heat } \\
\text { production } \\
\text { (A) in the } \\
\text { upper crust }\end{array}$ & \multirow{3}{*}{ Triangular } & $\begin{array}{c}\text { A: } 0.6 \text { and } 1.6 \\
\text { for layer }-1\end{array}$ & \multirow{3}{*}{ Spherical } & $\begin{array}{l}14 \text { cells } \\
(\sim 42 \mathrm{~km})\end{array}$ & $\begin{array}{c}\quad 600 \\
\text { ensembles, } \\
4 \text { iterations }\end{array}$ \\
\hline 4 & $\begin{array}{l}\text { update the } \\
\text { vertical } \\
\text { thermal } \\
\text { conductivit } \\
y(\lambda v) \text { in } \\
\text { the } \\
\text { sediments }\end{array}$ & & $\begin{array}{c}\lambda \mathrm{v}: 0.7-1.3 \\
\text { for layer } 1-7 \text {, } \\
\quad 9-10,14 \\
\lambda \mathrm{v}: 0.7-1.4 \\
\text { for layer } 8 \\
\lambda \mathrm{v}: 0.6-1.4 \\
\text { for layer } 12- \\
13\end{array}$ & & $\begin{array}{c}8 \text { cells } \\
(\sim 24 \mathrm{~km})\end{array}$ & $\begin{array}{c}\quad 600 \\
\text { ensembles, } \\
4 \text { iterations }\end{array}$ \\
\hline 7 & $\begin{array}{l}\text { update } \\
\text { (refine) } \lambda_{\mathrm{V}} \\
\text { in the } \\
\text { sediments }\end{array}$ & & $\begin{array}{l}\lambda_{\mathrm{V}}: 0.8-1.2 \\
\text { for layer } 1-13\end{array}$ & & $\begin{array}{l}30 \text { cells } \\
(\sim 30 \mathrm{~km})\end{array}$ & $\begin{array}{c}\quad 600 \\
\text { ensembles, } \\
4 \text { iterations }\end{array}$ \\
\hline
\end{tabular}

Table 3.2: Overview of the data assimilation procedure.

\subsection{Results}

We show the results of the 7-step modeling workflow, yielding the posterior 3D temperature model of the onshore Netherlands in Figure 3.8. Temperature slices of 1-6 km depth are presented in $1 \mathrm{~km}$ intervals (Figure 3.8). Modeled temperatures at 1 and $2 \mathrm{~km}$ depth show a similar pattern: the hottest area is located in the north, corresponding to the youngest sedimentary units of Neogene to Upper Cretaceous age (Upper North Sea Group, Lower and Middle Sea Group and Chalk Group). At larger depths, the most significant positive anomaly is observed near the location of the LTG-01 well. At $3 \mathrm{~km}$ depth, the highest temperatures are modeled near the Belgian border in the south, where Dinantian carbonate platforms are located at relatively shallow depth. Higher temperatures at $4 \mathrm{~km}$ depth correlate with the extent of the Dinantian carbonate platforms. This correlation is also observed in the 5 and 6 $\mathrm{km}$ depth slices, although the anomalies are more pronounced towards the north and near the LTG-01 well. The Zeeland High and Limburg High appear to be relatively cold at larger depth. 

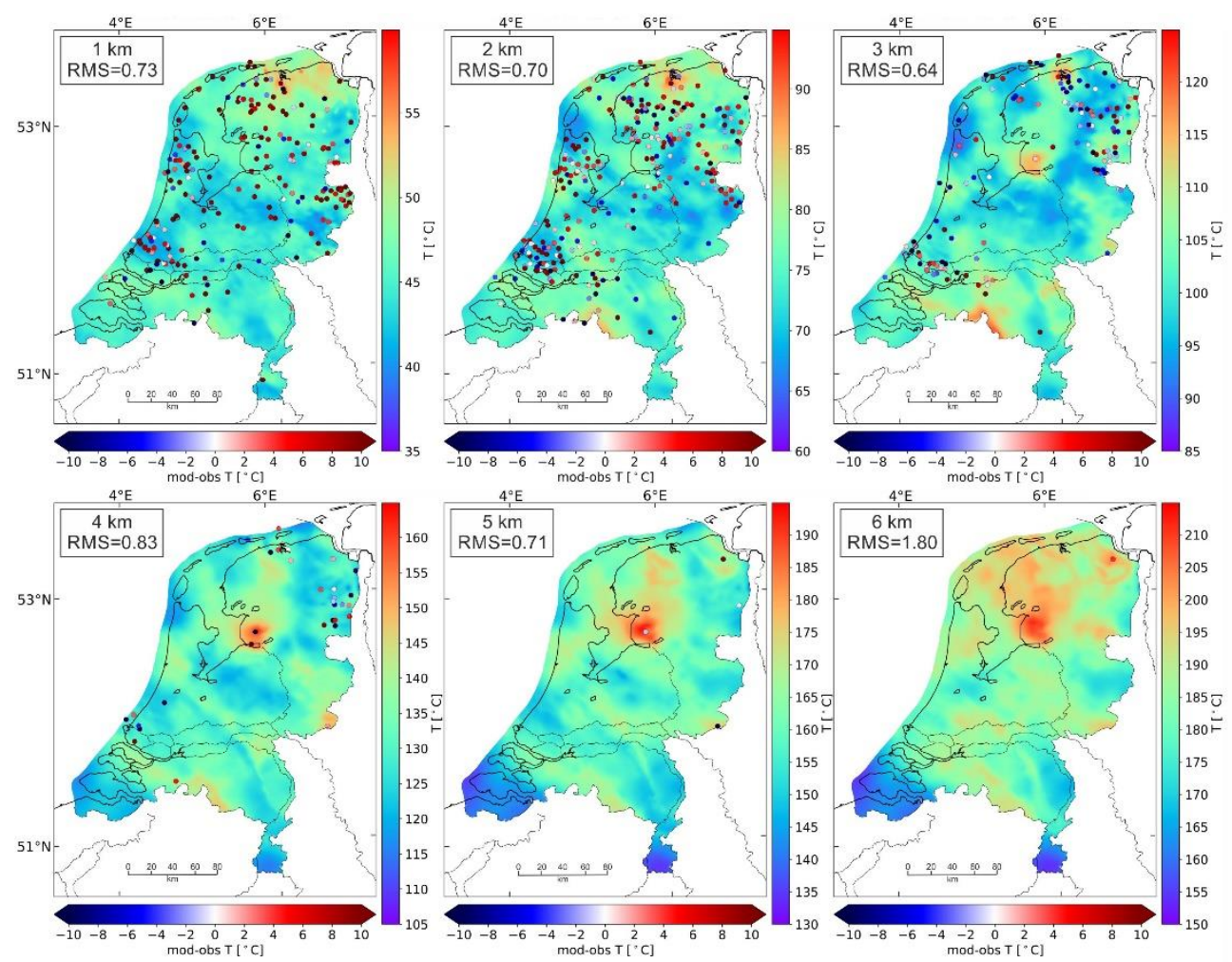

Figure 3.8: Temperature maps of the final posterior model (step 7 in Figure 3.7) at 1-6 km depth. The misfits between modeled temperature and measurements (modeled-observed values) within a $\pm 200 \mathrm{~m}$ interval are plotted with circles. $80 \%$ of the misfits lie within the $\pm 10{ }^{\circ} \mathrm{C}$ interval, where the remaining $20 \%$ are dominantly attributed to measurements with the largest uncertainty $\left( \pm 15^{\circ} \mathrm{C}\right.$, BHTs corrected with statistical method). Note the different color scale for the modeled temperatures at various depth.

To compare our models with the temperature measurements, we constructed 1D profiles at several well locations (Figure 3.9). We show both the prior and the posterior model results to demonstrate the model improvements after calibration. As prior model we use the uncalibrated model from step 2 in Figure 3.7.

Prior and posterior model temperatures are almost identical at the locations of the KTG01, LUT-06, HLH-GT-01, and WWK-01 wells, showing a good fit with the measured temperatures (Figure 3.9). The thermal conductivity profiles show little variation, suggesting calibration was not necessary to improve the fit. For the remaining profiles, the thermal conductivity of the layers was varied resulting in a better fit of the posterior model with the measurements. For instance, the prior model overestimates temperatures at the location of the MKP-14 well. Decreasing the thermal conductivity of the Rijnland Group (layer 4) and increasing the thermal conductivity of the Altena Group (layer 6), resulted in a reduced average geothermal gradient, in good agreement with the measurements. In the LTG-01 and WSK-01 wells, the prior model underestimates the temperatures especially below $3 \mathrm{~km}$ 
depth. To fit the high temperatures in the LTG-01 well, an even lower thermal conductivity was required for the Caumer Subgroup (layer 10) and Limburg group (layer 11) to increase the geothermal gradient above the Dinantian carbonate platform (layer 12). Even though the misfit of our prior model with the WSK-01 well measurement is low, a small reduction $(\sim 0.2$ $\mathrm{W} \mathrm{m} \mathrm{m}^{-1} \mathrm{~K}^{-1}$ ) of the conductivity for layer 11 was still necessary to reproduce the measured values. 

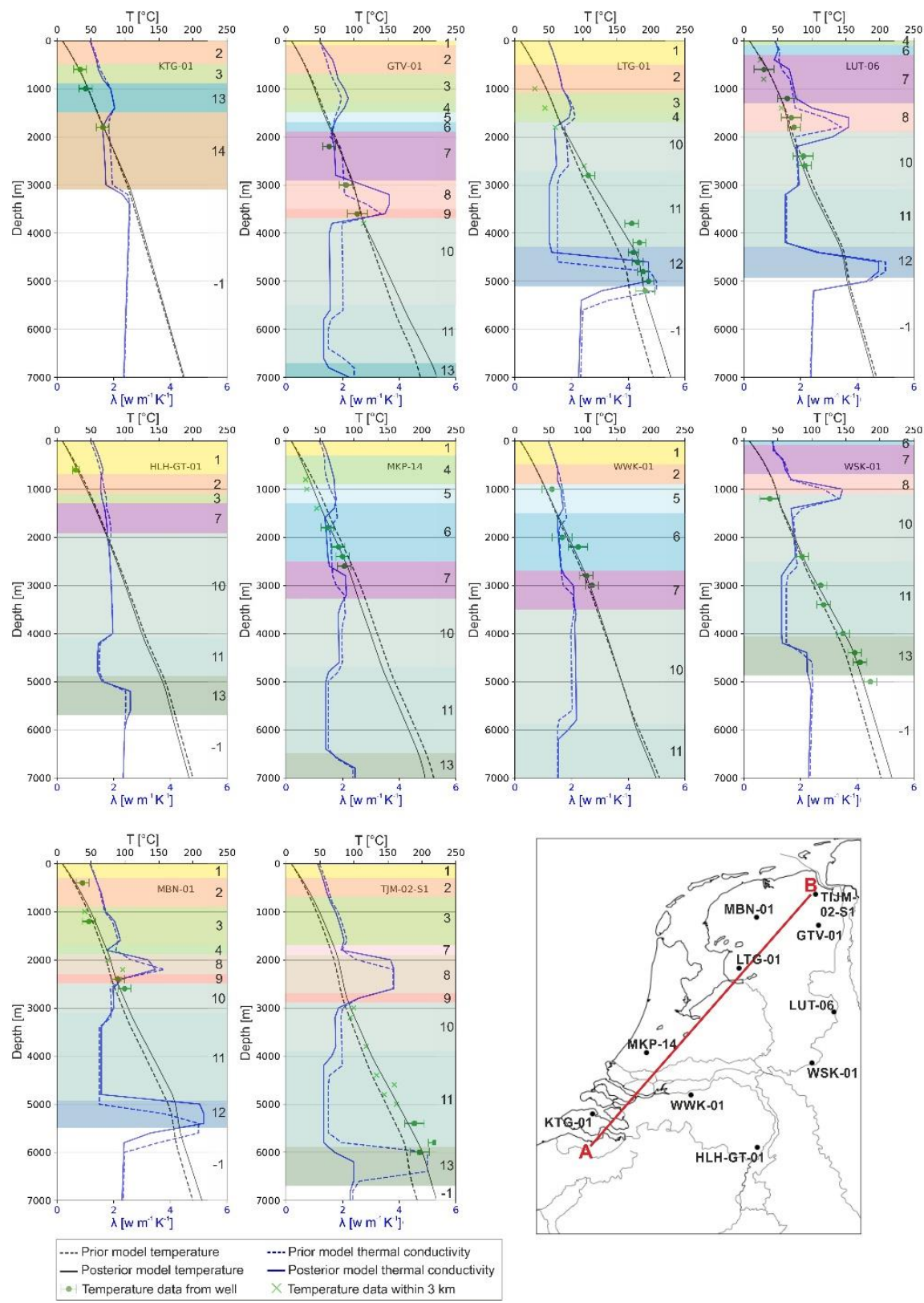

Figure 3.9: Temperature-depth (black) and thermal conductivity-depth (blue) profiles of the prior model (dashed lines) and posterior model (solid lines) at different well locations. The temperature measurements from the wells are marked by green dots with corresponding error bars. Measurements from wells within $3 \mathrm{~km}$ distance are plotted with green crosses. The numbering of the layers corresponds to Table 3.1. Note that the depth ranges of the prior and posterior thermal conductivities are shifted in depth for some layers as a result of depth and composition differently averaged due to the different horizontal resolution. For locations of the wells see the map in the lower right. 
Posterior model temperatures are presented along a section crossing the onshore part of the Netherlands from SW to NE (Figure 3.10). Temperatures up to $1 \mathrm{~km}$ depth show slight variations corresponding to changes in the lithology of the layers. At larger depths, more fluctuations are observed within the sediments. For instance, in the NE, where the thickness of the Zechstein Group (layer 8) is the largest, temperatures are higher above and lower below the salt layer. The geothermal gradient in the top $3 \mathrm{~km}$ corresponds to $\sim 30{ }^{\circ} \mathrm{C} / \mathrm{km}$. The insulating effect of the sediments is observed at larger depth: temperatures are lower within the basement and higher in the basins in the SW at 3-7 km depth. The heat chimney effect of the Dinantian carbonate platforms (layer 12) approximated by increasing thermal conductivity, results in generally higher temperatures above, and lower temperatures below the layer. The hottest area along the section below $3 \mathrm{~km}$ depth corresponds to the location of the LTG-01 well, where temperature measurements suggest the presence of hydrothermal convection. The geothermal gradient varies significantly with larger depth: it is generally lower in the basement and in the highly conductive carbonate platforms, and higher in the sediments with a lower conductivity, especially in the layers overlaying the platforms.

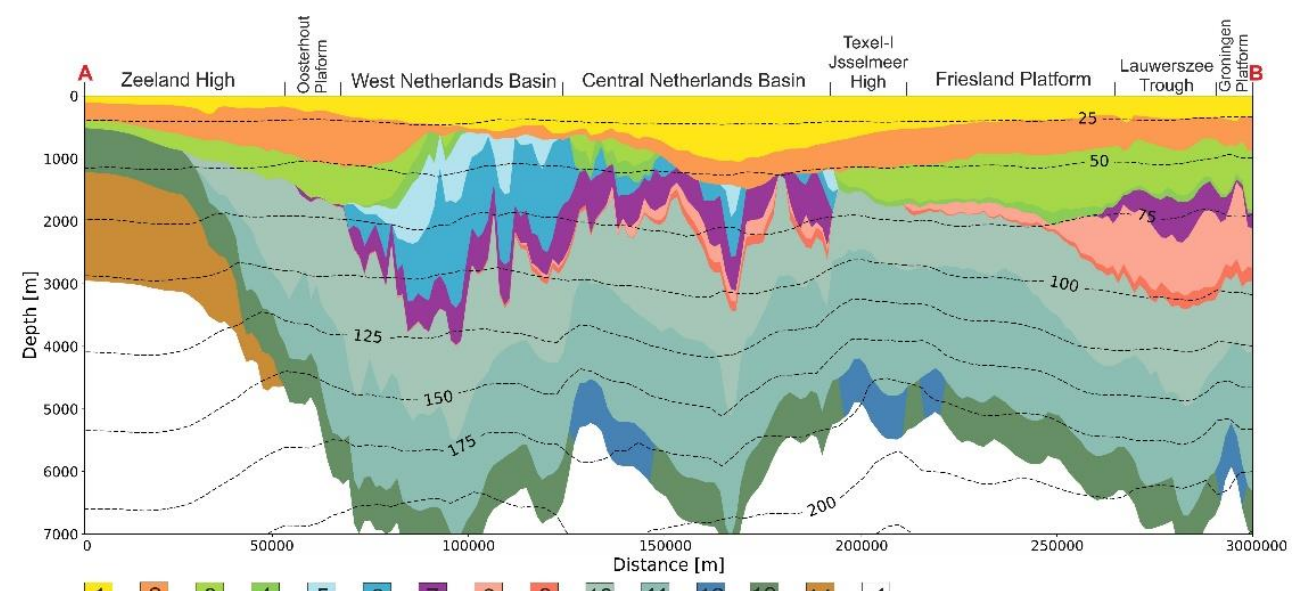

Figure 3.10: NW-SE cross-section through the onshore Netherlands showing the geometry of the sedimentary units and the depth of the top of the basement (white) used for the modeling. Superimposed are the isotherms from the posterior temperature model. The trace of the cross-section is shown in Figure 3.9. Layer numbering corresponds to Table 3.1. The extent of the main Jurassic and Early Cretaceous basins, highs, and platforms along the section is adopted from Kombrink et al. (2012). Fault structures are not shown in the section as they were not incorporated to the thermal model.

After ES-MDA calibration the posterior model shows an improved fit with the measurements compared to the prior model: temperature observations are closer to the P50 results of the posterior model (Figure 3.11). On the other hand, some of the data points fall outside the bandwidth of the variation of the ensembles. It suggests that the ensemble variance generated with the data assimilation procedure was not entirely sufficient to reproduce the observed variation within the data, especially at shallow depth. 
The mean, median, and RMS misfits normalized to data error of the prior and posterior model are summarized in Table 3.1. After ES-MDA calibration, overall RMS, including all the measurements, decreases from a value of 0.95 for the prior model to 0.70 for the posterior model. Analyses of the misfits at different depth intervals suggest that the prior model overestimates temperatures at shallower depth (1-2 km), but underestimates temperatures at larger depth. The posterior model shows the same trend, but with lower misfits, especially below $3 \mathrm{~km}$ depth. The total mean and median of the prior model are smaller than the corresponding values of the posterior model. This is due to the fact that the positive and negative misfits at different depth cancel out, and it is not representative in terms of the goodness of the fit.
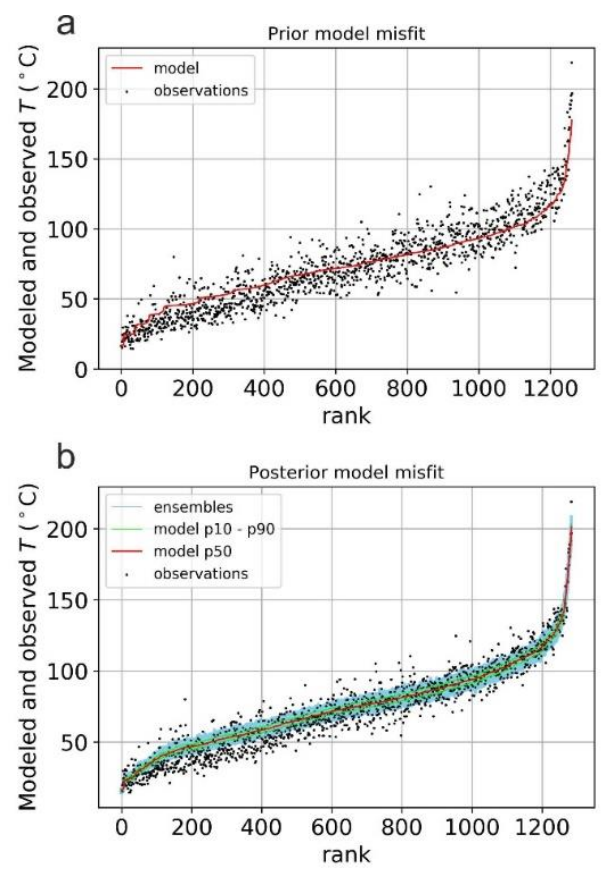

Figure 3.11: Distribution of the modeled and observed temperatures ranked by the modeled temperatures at the observation points for the prior (a) and posterior (b) models. Temperature measurements are marked by black dots. The red curves indicate the model results (in (b) the P50 values), the green lines in (b) are the P10 and P90 values. The blue interval in (b) indicates the modeled temperatures for all the 600 ensemble members of the last iteration. 


\begin{tabular}{|c|c|c|c|c|c|}
\hline Depth [m] & $\begin{array}{l}\text { Number of } \\
\text { observations } \\
\text { for prior } \\
\text { model }\end{array}$ & $\begin{array}{l}\text { Number of } \\
\text { observations } \\
\text { for posterior } \\
\text { model }\end{array}$ & $\begin{array}{c}\text { Type of } \\
\text { misfit }\end{array}$ & $\begin{array}{l}\text { Prior model } \\
\text { misfit }\end{array}$ & $\begin{array}{l}\text { Posterior } \\
\text { model misfit }\end{array}$ \\
\hline \multirow{3}{*}{$1000 \pm 500$} & \multirow{3}{*}{368} & \multirow{3}{*}{377} & Mean & 5.88 & 4.85 \\
\hline & & & Median & 7.16 & 6.03 \\
\hline & & & RMS & 0.80 & 0.71 \\
\hline \multirow{3}{*}{$2000 \pm 500$} & \multirow{3}{*}{474} & \multirow{3}{*}{487} & Mean & 2.04 & 2.03 \\
\hline & & & Median & 2.31 & 2.32 \\
\hline & & & RMS & 0.86 & 0.71 \\
\hline \multirow{3}{*}{$3000 \pm 500$} & \multirow{3}{*}{286} & \multirow{3}{*}{288} & Mean & -4.84 & -1.44 \\
\hline & & & Median & -4.39 & -1.21 \\
\hline & & & RMS & 1.03 & 0.67 \\
\hline \multirow{3}{*}{$4000 \pm 500$} & \multirow{3}{*}{77} & \multirow{3}{*}{77} & Mean & -10.25 & -1.83 \\
\hline & & & Median & -9.65 & -1.92 \\
\hline & & & RMS & 1.49 & 0.76 \\
\hline \multirow{3}{*}{$5000 \pm 500$} & \multirow{3}{*}{12} & \multirow{3}{*}{12} & Mean & -19.66 & -3.21 \\
\hline & & & Median & -21.39 & -3.91 \\
\hline & & & RMS & 2.21 & 0.70 \\
\hline \multirow{3}{*}{$6000 \pm 500$} & \multirow{3}{*}{2} & \multirow{3}{*}{2} & Mean & -32.01 & -10.12 \\
\hline & & & Median & -32.01 & -10.12 \\
\hline & & & RMS & 3.41 & 1.80 \\
\hline \multirow{3}{*}{$\begin{array}{c}\text { Total }(0- \\
6000)\end{array}$} & \multirow{3}{*}{1260} & \multirow{3}{*}{1284} & Mean & 0.48 & 1.67 \\
\hline & & & Median & 1.68 & 1.97 \\
\hline & & & RMS & 0.95 & 0.70 \\
\hline
\end{tabular}

Table 3.3: Mean, median, and RMS misfits in ${ }^{\circ} \mathrm{C}$ of the prior and posterior models normalized to data error. The misfits are reported at 1-6 km depth, including measurements within a $\pm 500 \mathrm{~m}$ interval. The overall misfits are calculated using all the measurements.

\subsection{Discussion}

We constructed 3D physics-based temperature models for the onshore Netherlands calibrated with 1507 temperature measurements. We performed the modeling in seven steps, starting from lithospheric-scale models with two different resolution steps in vertical direction. The advantage of such large-scale temperature models is that they are able to 
account for the thermo-mechanical state of the whole lithosphere, which has major influence on temperatures at depths relevant for geothermal exploration (Cloetingh et al., 2010). The boundary conditions of the high-resolution models, extending from the surface to $10 \mathrm{~km}$ depth, were derived from these low-resolution lithospheric-scale models. We incorporated temperature measurements for subsequent model steps through an inversion procedure using ES-MDA. Misfits between modeled and observed temperatures decreased during the data assimilation by varying the thermal properties of the sedimentary units and the upper crust. To account for uncertainties of the thermal conductivity in different sedimentary units and the radiogenic heat generation in the upper crust, we scaled the values to triangular distributions. Scaling parameters were determined according to the uncertainties we assigned to each layer. The spatial variation in the properties was introduced through variograms. We selected the size of the variograms based on the wavelengths of perturbations we expected for the thermal properties.

One of the main aspects of our study was to account for the thermal anomaly found in the LTG-01 well. Bonté et al. (2012) suggested that the high temperatures that were measured could be explained by the presence of a magmatic intrusion with high radiogenic heat production formed during the Variscan orogeny (Ziegler, 1990). As an alternative, they proposed the occurrence of hydrothermal convection in the Dinantian carbonate platform situated at depths below $4 \mathrm{~km}$. Based on fracture permeability assessments and numerical modeling, Van Oversteeg et al. (2014) and Lipsey et al. (2016) concluded that convection is likely to occur in the carbonate platforms at the location of the LTG-01 well. The thermal state of the deep subsurface is important for geothermal exploration that targets the deeply buried Devonian-Carboniferous carbonate formations in the Netherlands. These reservoirs are potentially suitable for industrial heating applications and electricity production. To this end, our goal was to identify possible locations where convection in these carbonate platforms might occur and that currently lack temperature measurements.

We assessed the minimum permeability required for convection in different depth intervals based on Rayleigh-number analysis. Given the permeabilities derived from petrophysical data on the Dinantian carbonates, we found that the occurrence of convection is unlikely in carbonate platforms at depths shallower that $2 \mathrm{~km}$. Locally, karstification or faults and fractures might still lead to sufficient secondary permeability allowing for hydrothermal convection. However, this is currently not supported by observations. We assumed that convection might only occur in Dinantian carbonate platforms below $2 \mathrm{~km}$ depth, having sufficient permeabilities due to karstification. We assumed that the carbonate platforms in the Dutch subsurface have similar properties. However, the tectonic setting, sea level and burial/diagenesis history vary for the areas, resulting in different platform geometries and reservoir properties (Lipsey et al., 2016).

Since our forward model is purely conductive, we approximated the thermal effect of hydrothermal convection by varying the thermal conductivity of the platforms and the overlying layers. We applied this method based on the fact that long term thermal effects can be approximated by a pseudo-convective approach, where the convective layer is marked by 
a higher than natural thermal conductivity (e.g. Beglinger et al., 2012; Luijendijk et al., 2011; Schmeling and Marquart, 2014). A similar approach was applied by Békési et al. (2018) for the Pannonian Basin. They showed that regional fluid flow systems have major influence on the temperature field, resulting in large model uncertainties. We established an a-priori conductivity profile for the carbonate platforms to fit the temperature profile in the LTG-01 well. We allowed prior conductivities to vary in certain bounds in order to obtain a satisfying fit with temperature measurements at shallower depth. Our approach results in relatively high modeled temperatures at larger depth. These show a good correlation with the locations of the carbonate platforms (Figure 3.8, 4-6 km depth) and could highlight potential target areas for deep geothermal exploration. The application of a conductive model to convective areas has several limitations. For instance, convective cells cannot be properly modeled with conduction, as their extent and geometry cannot be taken into account. The pseudoconvective approach results in larger modeled temperatures throughout the whole convective layer. However, the structure of hydrothermal convection is much more complex (e.g. Guillou-Frottier et al., 2013). The temperature distribution inside convection cells is not homogenous: lower temperatures are associated with downwellings, and warmer areas correspond to upwellings. Additionally, hydrothermal convection is more likely to occur locally, and convective cells may extend beyond the carbonate platforms (Lipsey et al., 2016). Therefore, our model overestimates temperatures at the depth of the carbonate platforms without the presence of fluid convection and at downwelling zones. Also, the thermal effect of convection beyond the platform areas cannot be captured. Our model is only able to indicate potential locations where higher temperatures might be present. Successful development of the Dinantian carbonates requires site-specific studies taking into account the local geometry of the carbonate platforms and incorporating convective heat transfer.

It is important to note that the LTG-01 well is the only indication for potential convection in the platforms. Another explanation of the thermal anomaly might be the large thermal conductivity contrast between the Numerian and Westpalian sediments and the Dinantian carbonate platforms (Veldkamp and Hegen, 2020). Our model with a modified thermal conductivity values aims for approximating fluid convection, but the modified thermal conductivities could also account for the case of a strong thermal conductivity contrast. Without the observations from this well, our modeling approach would have most likely been different, with less focus and constraints on the carbonate formations. It demonstrates the need for deep exploration wells that can not only provide more information on deep geological structures, layers, and reservoir properties, but also on the deep thermal structure. The restricted amount of information available at larger depths, leads to a significant increase in uncertainty with depth for our thermal models.

The previous temperature model of the onshore Netherlands was constructed by Bonté et al. (2012). We incorporated their work in our study and we added several new aspects to the modeling. To improve our model calibration results, we updated the temperature database with more recent temperature measurements, including production temperatures from geothermal wells. We constructed our sedimentary layers based on the sedimentary model of 
the onshore Netherlands (DGM-deep v4.0). Furthermore, we added new layers corresponding to the Dinantian (Carboniferous) and older Palaeozoic sediments. By taking into account the thermal effect of convection in the Dinantian carbonate platforms, we reproduced the thermal anomaly observed in the LTG-01 well. However, our model only solves the heat equation in steady state, without taking into account transient effects of vertical tectonic motions and paleo surface temperature fluctuations. Vertical motions originate from sedimentation/erosion and large-scale deformations such as lithospheric stretching. Bonté et al. (2012) incorporated vertical motions for the latest stage of basin evolution from $20 \mathrm{Ma}$ until recent, originating from the accumulation of sediments. Since large-scale lithospheric deformations with significant temperature perturbations have no effect on the present-day temperatures in the Netherlands (major tectonism associated with the stretching of the lithosphere and inversion took place over $100 \mathrm{My}$ and $\sim 65 \mathrm{My}$ ago (e.g. Van Wees et al., 2009), we concluded that a steady-state temperature model would suffice for the Netherlands.

Our model show a good correspondence with the German temperature maps (Agemar et al., 2012) along the eastern border of the Netherlands between 2 and $4 \mathrm{~km}$ depth. Large temperature variations (up to $\pm 10^{\circ} \mathrm{C}$ ) can be observed in 1 to $3 \mathrm{~km}$ depth (Figure 3.8) due to the presence of the highly conductive evaporites within the Zechstein Group (layer 8) mostly in the northern part of the country, where salt diapers are present (Geluk, 2005). The top of the salt layer is marked by high temperatures, for instance in the Friesland Platform, Lauwerszee Trough, Groningen High and Lower Saxony Basin, whereas isotherms are depressed below the highly conductive salts (e.g. Figure 3.10). The same thermal effect is observed in the westernmost part of the North German Basin (Lower Saxony) (Agemar et al., 2012) and in the in the central Polish Basin (Zielinski et al., 2012). Elevated temperatures above salt layers provide potential target areas for geothermal exploitation in the northeastern part of the Netherlands (Daniilidis and Herber, 2017). Daniilidis and Herber (2017) show that the thermal anomaly is not only dependent on the thickness of the salt layer, but the shape of the salt intrusion also plays an important role. Detailed site-specific studies taking into account the local geology including the potential for a suitable aquifer are necessary to exploit the geothermal potential of salt bodies in sedimentary basin settings. Temperature anomalies attributed to the Silesian sediments with low thermal conductivity can also be observed throughout the Netherlands. These sediments are predominantly shales with relatively high coal content, resulting in an insulating thermal effect (e.g. Figure 3.10). Modeled temperatures above $3 \mathrm{~km}$ depth are lower than average observed temperatures in the West Netherlands Basin, Roer Valley Graben, and Central Netherlands Basin, in agreement with the earlier findings of Bonté et al. (2012). These pronounced negative anomalies can be explained by the large thickness of the Silesian sediments. The Dinantian carbonate platforms marked by high conductivity appear as positive temperature anomalies at larger depth. Additionally, the carbonate platforms in the south are identified as areas with larger than average temperatures, except for the Limburg High. The coldest areas below $3 \mathrm{~km}$ depth 
correspond to the Zeeland High and Limburg High and are likely caused by the absence of a thick sedimentary cover on top of the highly conductive basement rocks.

Different horizontal mesh resolutions may influence the calculation of thermal properties, resulting in slight variations in predicted temperatures (Figure 3.9). This effect is negligible in areas where the thermal field is dominantly conductive and no steep temperature gradients are present (Figure 3.9). On the other hand, within the highly conductive layers including the Dinantian carbonate platforms where convection is approximated by a higher than normal thermal conductivity, modeled temperatures are dependent on the horizontal mesh resolution (Figure 3.9). The posterior model with a finer horizontal discretization can better capture the variations in the input geological model, providing more reliable results and an improved fit with measured temperatures where steep gradients occur. We did not test different vertical resolution of the models. Kaiser et al. (2013) concluded that horizontal mesh resolution has a more significant effect on modeled temperatures. They suggested that effects on temperatures modeled with conduction are almost independent from mesh resolution, however, discrepancies may occur at steep gradients or high thermal conductivity contrasts. Our models with a different horizontal discretization agree with their findings. Since the thermal field of the onshore Netherlands is dominantly conductive, we can conclude that both horizontal mesh resolutions are able to approximate the thermal field sufficiently. On the other hand, at locations where fluid convection exists, discrepancies in modeled temperatures may arise.

Calibrating the model with ES-MDA, reduces misfits of the prior model, although the variation in the data is not entirely captured by the ensembles (Figure 3.11). The required variation within the measurements could be reached by allowing more variation within the model parameters, especially in the shallower part of the model. On the other hand, a larger variation within these thermal properties would not be realistic. We only allowed unrealistic thermal conductivity values in the carbonate platforms and in the Limburg group (overlaying layer) in order to approximate the thermal effect of convection in the deeply buried carbonates. For the rest of the layers, we chose the scaling parameters to ensure that the thermal conductivities remain realistic. It was important especially in the shallow part of the model, where large amounts of measurements are available, many of them having errors up to $\pm 15^{\circ} \mathrm{C}$. Allowing a wider scaling range would provide better fit with the temperature data, although the predicted temperatures would vary significantly in a small spatial proximity, resulting in unrealistic anomalies. We assume that the misfits are partly caused by transient effects or convective heat transfer. Fluid flow along fault structures is commonly identified as a cause of misfits of conductive models (e.g. Freymark et al., 2017). Both the prior and posterior models show a remarkable positive misfit at shallow depth: temperatures are systematically overestimated at 1 and $2 \mathrm{~km}$ depth (Figure 3.11, Table 3.3). The most pronounced misfits are observed in the shallowest depth interval (Table 3.3, $1000 \mathrm{~m} \pm 400$ $\mathrm{m})$. We explain these misfits with the transient thermal effect of the paleo-temperature fluctuations (e.g. Donders et al., 2009; Verweij et al., 2012). We attempted to account for the thermal effect of recent glaciation by choosing a lower surface temperature as a boundary 
condition, although we cannot entirely reproduce it with our steady-state model. Ter Voorde et al. (2014) also concluded that the misfits with the steady-state thermal profile in shallow depth reflect a transient condition inherited from past climate change. Alternatively, groundwater flows can also explain local anomalies at shallow depth. Measurements errors are also partly responsible for misfits, especially at 1-2 km depth, where a large number of data points are available in close spatial proximity (e.g. in the WNB, CNB-NHP border). Systematic small under- or overestimates might be caused by boundary conditions and/or heat generation in thick layers that have a larger lateral extent (e.g. upper crust or a sedimentary layer that is widespread across the Netherlands. Other local misfits might be caused by uncertainties in model geometry, lithology mixtures (e.g. thermal properties of the sedimentary layers), etc.

\subsection{Conclusions}

We established a 3D high-resolution subsurface temperature model of the onshore Netherlands. One of the most important aspects of this study is the validation of the thermal model with 1507 temperature measurements. We calibrated our model with temperature observations through inversion with ES-MDA. We took into consideration both the data and model uncertainties by assuming a Gaussian distribution for measurement errors and a triangular distribution for scaling the thermal properties. Misfits of the prior model are reduced through the data assimilation procedure: the overall RMS, including all the measurements, decreases from a value of $0.95{ }^{\circ} \mathrm{C}$ for the prior model to $0.70{ }^{\circ} \mathrm{C}$ for the posterior model. It demonstrates the effectiveness of ES-MDA as a tool for calibrating temperature models, supporting high-resolution external constraints. On the other hand, for areas without temperature data available, especially in the deeper parts of the model, predicted temperatures are strongly dependent on conceptual constraints. Therefore, a reliable geological model and reasonable thermal properties are crucial as modelling input.

By taking into account the thermal effect of convection in the Dinantian carbonate platforms, we reproduced the thermal anomaly observed in the LTG-01 well. Our model reveals areas with potential for hydrothermal convection in the deep carbonate platforms. These locations can be suitable for deep geothermal development of both electricity generation and direct heat uses due to the sufficiently high temperatures and inferred high permeabilities that are required for convection. The temperature model has been incorporated into the updated ThermoGIS project and is available online at thermogis.nl. 


\section{Ground motions induced by pore pressure changes at the Szentes geothermal area, SE Hungary ${ }^{3}$}

${ }^{3}$ This chapter is based on Békési, E., Fokker, P. A., Candela, T., and van Wees, J.D., under revision in Geothermal Energy 


\subsection{Introduction}

Hungary is among the most favorable countries for geothermal development within Europe (e.g. Békési et al., 2018; Cloetingh et al., 2010; Horváth et al., 2015; Lenkey et al., 2021; Limberger et al., 2014; Limberger et al., 2018), with an average geothermal gradient of $\sim 45^{\circ} \mathrm{C} / \mathrm{km}$, and a mean surface heat flow of $100 \mathrm{~mW} / \mathrm{m}^{2}$ (Lenkey et al., 2002). The highest values occur in the SE part of the country, corresponding to the thinnest parts of the crust and lithosphere (e.g. Horváth et al., 2006). The outstanding geothermal conditions of Hungary originate from Miocene extension of the Pannonian Basin, related to subduction and rollback in the Eastern Carpathians, resulting in the thermal attenuation of the lithosphere (e.g. Horváth, 1993; Horváth et al., 2006). The different timing of syn-rift sediment infill in the sub-basins indicates that extension in the Pannonian Basin migrated in space and time (e.g. Figure 4.1b) (Balázs et al., 2016). Subsequent to the syn-rift phase, thermal subsidence of the Pannonian Basin initiated, accompanied by continuous post-rift sedimentation (e.g. Juhász, 1991; Sztanó et al., 2013). From Late Miocene to recent times, basin inversion has occurred due to a push from the Adriatic microplate towards the Pannonian Basin (Bada et al., 2007; Horváth and Cloetingh, 1996), forming its present-day basement geometry (Figure 4.1a, b).

Thermal water production in Hungary has already started in the $19^{\text {th }}$ century for bathing purposes, and the country is still famous for its large amounts of hot springs and thermal spas. Geothermal wells most commonly target Upper Miocene and Quaternary porous sedimentary reservoirs (Figure 4.1b). Fractured Mesozoic carbonate rocks also have significant geothermal potential, and are being utilized in several locations within Hungary (e.g. Goldscheider et al., 2010; Horváth et al., 2015; Mádl-Szőnyi et al., 2015; Szanyi and Kovács, 2010). Additionally, fractured Mesozoic basement rock are also suitable targets for deep geothermal developments (e.g. Békési et al., 2018; Horváth et al., 2015; Vass et al., 2018), however, there has been no active exploitation of such resources yet. Until 2018, geothermal energy was exclusively used for direct heat purposes in Hungary. Since then, the first geothermal power plant has become operational in Tura, with an installed capacity of 3.0 $\mathrm{MW}_{\mathrm{e}}$ (Nádor et al., 2019). Compared to its vast potential, Hungary is still lagging behind in geothermal energy production. Further geothermal developments are crucial to increase the role of renewable energy resources withing Hungary's (and Europe's) energy demand. However, the long-term sustainable production of geothermal energy requires cautious planning and regulation. Exploitation in excess of natural recharge can result in reservoir pressure decline, causing a decrease in production rates. Furthermore, such "overexploitation" of geothermal reservoirs may lead to compaction, land subsidence, or even induced seismicity (e.g. Allis, 2000; Békési et al., 2019a; Keiding et al., 2010; Maghsoudi et al., 2018; Trugman et al., 2014; van der Meer et al., 2014).

Previous studies have demonstrated the effectiveness of InSAR based monitoring combined with (inverse) modelling of geothermal fields (Heimlich et al., 2015; Keiding et al., 2010; Parks et al., 2020; Trugman et al., 2014; Vasco et al., 2013; Vasco et al., 2002). In case of geothermal applications, inverse models constrained with ground motion data are commonly based on single or distributed volume/pressure sources in the subsurface (e.g. 
Kiyoo, 1958; Okada, 1985; Segall, 2010; Yang et al., 1988). Ground deformation due to seismic events occurring at geothermal areas has also be modeled using analytical methods in order to estimate source parameters (e.g. Békési et al., 2021). More complex numerical models have also been applied to predict ground motions at geothermal sites. For instance, Vasco et al. (2013) applied coupled numerical modelling to resolve the observed ground deformation at the Geysers Geothermal Field, however, such coupled models cannot easily incorporate robust calibration to detailed surface movements. The advantages of probabilistic ensemble-based approaches for inversion of surface subsidence have already been shown in several studies outside the geothermal energy arena (Baù et al., 2015; Candela et al., 2017; Fokker et al., 2016). Such ensemble-based approaches have limitations in terms of model parameters, including only a limited number of reservoir properties, and cannot directly distinguish between different subsurface processes. Still, ensemble-based techniques are capable of dealing with large amounts of measurements and they can successfully estimate driving parameters of subsurface processes. A recently developed ensemble-based subsidence interpretation and prediction tool (ESIP) is capable to distinguish between different compaction behaviors, and allows to predict a wide range of subsurface parameters (Candela et al., 2021; Candela et al., 2020). However, ESIP requires detailed information on the local geology and pressure history of a study area for the whole operation period, that are not always available. In this study, we combine the Ensemble Smoother with Multiple Data Assimilation (ES-MDA, Emerick and Reynolds (2013a)) with the analytical solution of Geertsma (1973), in order to estimate first-order properties of the Szentes geothermal area, without the requirement of high-resolution subsurface measurements, such as pressure time series. This study is the first application of mapping and modelling ground motions due to geothermal activities in Hungary, that aims to demonstrate the usefulness, requirements, and limitations of inverse geomechanical models for geothermal sites in Hungary and worldwide. 

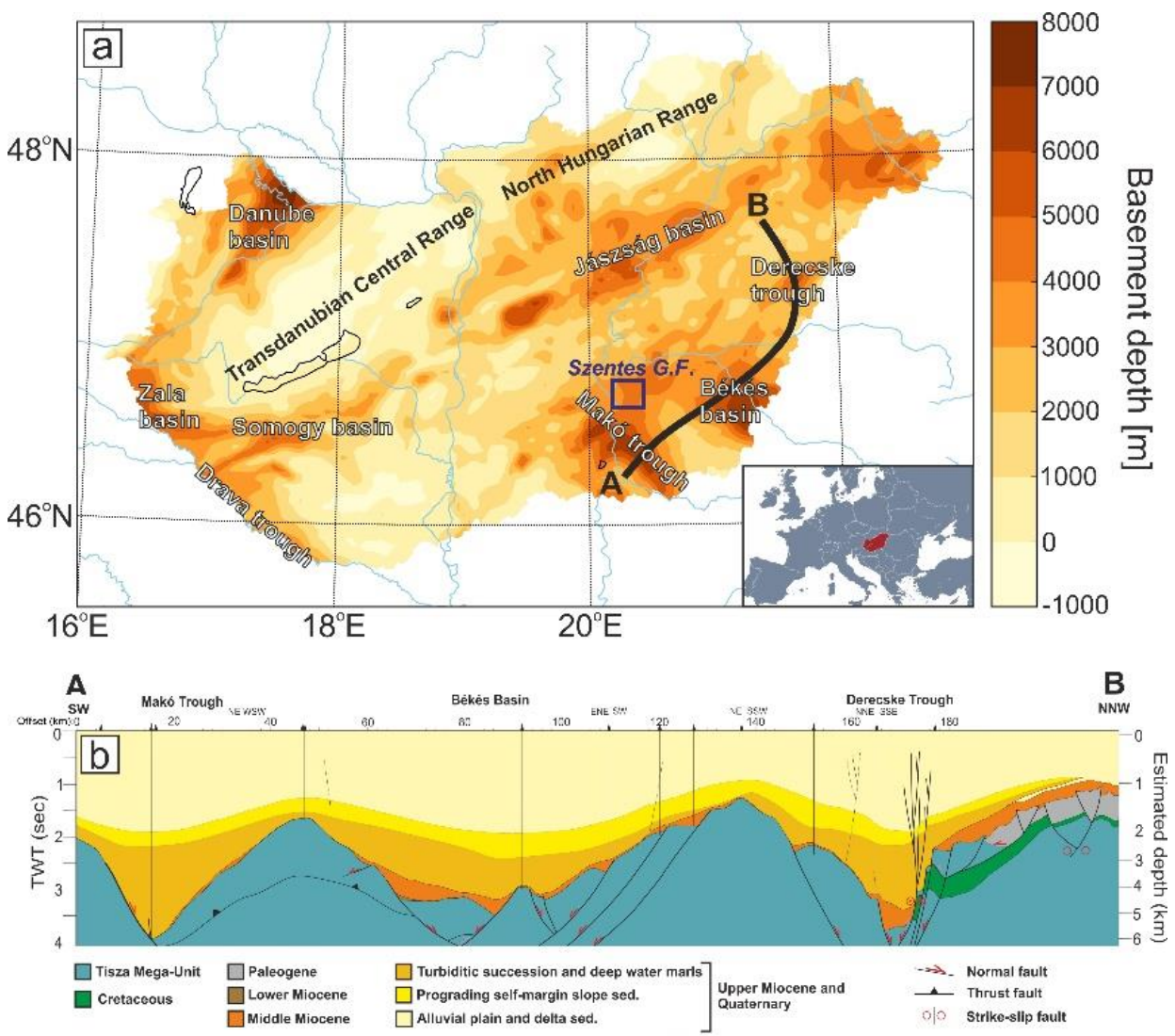

Figure 4.1: (a) Depth of the pre-Cenozoic basement showing the most significant sub-basins and hills of Hungary, and the location of the Szentes Geothermal Field, based on Haas et al. (2014) and modified after Békési et al. (2018). (b) Interpreted composite reflection seismic transect from the eastern part of Hungary, with the main tectonic and stratigraphic features of the area, after Balázs et al. (2016).

\subsection{The Szentes geothermal field}

The Szentes geothermal field is located in SE Hungary, in the northern part of the Makó trough (Figure 4.1a). Upper Miocene delta front and delta plain sediments (Upper Pannonian Ujfalu Formation) and delta top and alluvial plain sediments (Upper Pannonian Zagyva Formation) host the geothermal reservoir, deposited in the confines of a progradational delta system (e.g. Figure 4.1b) (Juhász, 1991; Sztanó et al., 2013). The targeted Upper Pannonian formations are largely heterogeneous; built up by the alternation of sandstone, silty sand, silty clay and clay layers (e.g. Juhász, 1991). Geothermal production primarily targets the Újfalu formation, with a vertical extent of approximately $600 \mathrm{~m}$, and a mean top depth of $\sim 1500 \mathrm{~m}$. The individual sandstone layers have small lateral extent, therefore, it is difficult to correlate the sand bodies drilled in different wells. Still, hydraulic connection between the individual sand bodies exist. Natural pore pressure in the Upper Pannonian formations of the Szentes 
area is slightly above hydrostatic with a gradient of $10.2 \mathrm{MPa} / \mathrm{km}$, however, extreme overpressure in the underlaying Lower Pannonian strata $(71 \mathrm{MPa} / \mathrm{km}$ ) is observed (Bálint and Szanyi, 2015). Such high overpressure in the low permeability Lower Pannonian sediments is present in several locations of the Great Hungarian Plain, and most likely explained by tectonic processes (Almasi, 2002; Tóth and Almási, 2001; Van Balen and Cloetingh, 1995).

Szentes is the first area where geothermal energy has been produced for industrial application in Hungary, with the first well drilled in 1958 (Bálint and Szanyi, 2015; Szanyi and Kovács, 2010). There are 45 wells drilled in total (including the Szegvár and Fábiánsebestyén areas), and 32 of them were producing thermal water up to $90{ }^{\circ} \mathrm{C}$ in 2010 . Starting from the early 70 's, thermal water production reached $\sim 6.5$ million $\mathrm{m}^{3} /$ year, which has decreased to an average of 5.7 million $\mathrm{m}^{3} /$ year from the early 90's (Szanyi and Kovács, 2010). Geothermal wells have not been continuously operated; production during the summer period has been terminated in several wells. Yearly thermal water withdrawal has slightly varied depending on winter temperatures. The complete lack of reinjection wells resulted in significant reservoir pressure decline and hydraulic head decrease (Figure 4.3, Figure 4.2a, b). Since the mid-90's, reservoir pressure recovery has initiated due to the decrease in production rates in the western part of the geothermal filed, accompanied by 4-8 $\mathrm{m}$ of hydraulic head increase by 2004 (Figure 4.2b, Szanyi et al., 2016; Szanyi and Kovács, 2010). The largest drawdown occurred in the eastern area, with a decrease in hydraulic heads up to $36 \mathrm{~m}$ by 2000 (Figure 4.2a, b) (Szanyi and Kovács, 2010). 

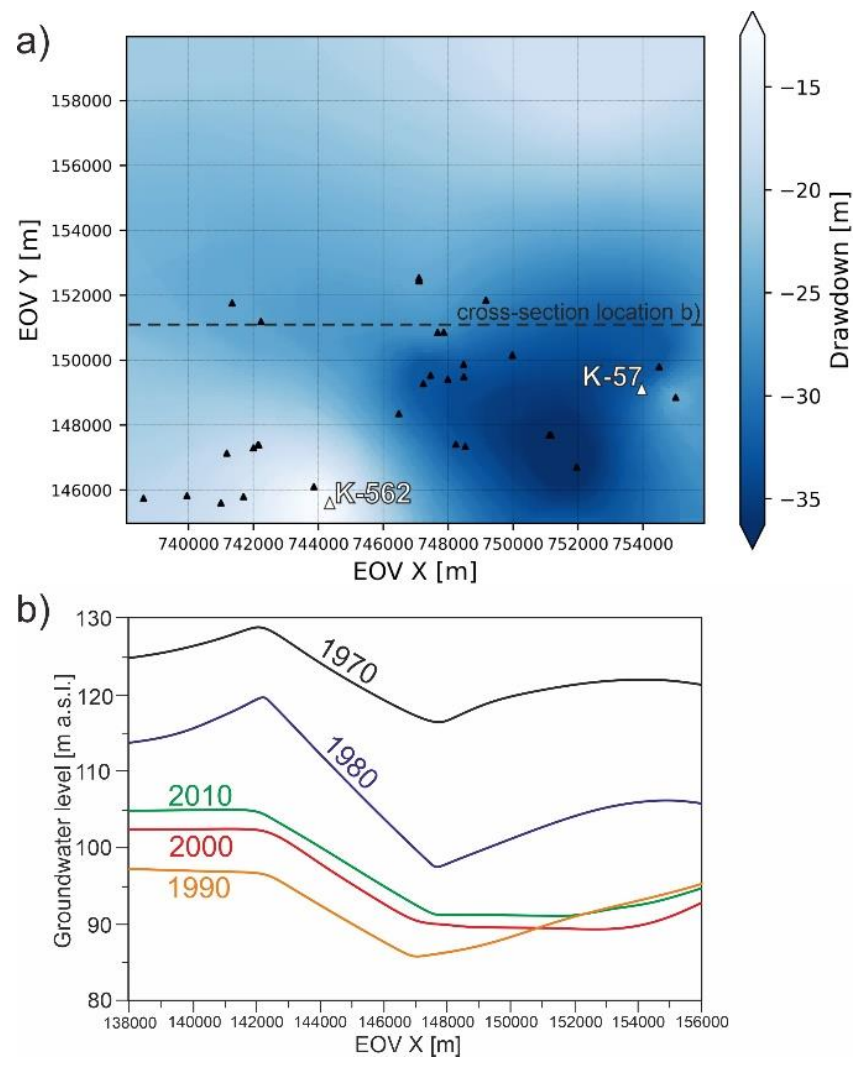

Figure 4.2: (a) Drawdown measured at the bottom of the Upper Pannonian sequences at the Szentes geothermal field by 2000, and (b) cross-section showing the groundwater variations from 1970 until 2010, after Bálint and Szanyi (2015) and Szanyi and Kovács (2010). The largest decrease of hydraulic heads in 2000 occurred in the eastern part of the geothermal field, whereas hydraulic recovery of the western area has already started in the mid 90's. The locations of wells K-562 and K-57 are labelled in (a) with white, where hydraulic head time series and InSAR-derived ground motions are plotted in Figure 4.5.

Regular monitoring of the Szentes geothermal wells from the beginning of thermal water withdrawal has not taken place, therefore, it is difficult to fully understand reservoir behaviour through time. There are multiple factors responsible for the lack of regular measurements, for instance the different owners and operators of geothermal wells, inconsistencies in regulations of thermal water production in Hungary. We gathered downhole pressure measurements from the Szentes area (Figure 4.3), showing that in some cases 2-3 decades were spent between measurements. During 2009-2010, an investigation of 20 geothermal wells took place in the framework of the Jedlik project (Bálint and Szanyi, 2015), including reliable downhole pressure measurements, showing that pore pressures were still below natural conditions in 2009-2010. (Figure 4.3). Pore fluid pressures in 2010 were up to $0.6 \mathrm{MPa}$ lower than in 1980 (Figure 4.3), and depletion has probably reached its 
maximum in the early 90's. Bálint and Szanyi (2015) studied the possible effect of reinjection towards a more sustainable field operation, by investigating the most suitable location and depth for an injection well. Since then reinjection in a single well has initiated, while production using downhole pumps is still ongoing.

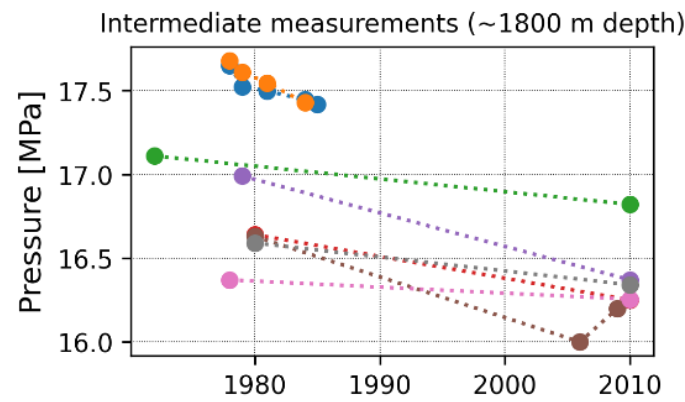

Figure 4.3: Pore pressure measurements from the geothermal wells of Szentes after Bálint and Szanyi (2015), Szanyi et al. (2016) and the dataset of the Geo-Log Ltd. Measurements are plotted from 1800 $\mathrm{m}$ depth. Different colours correspond to individual wells. Multiple observations from the same well are connected with a dotted line, however, these lines do not represent the pressure history.

\subsection{InSAR data}

We used C-band radar acquisitions of the European Space Agency's (ESA) Envisat satellites in order to map the ground motions for the period of November 2002 - June 2010, summarized in Table 4.1. To create the individual interferograms, we used the ESA SNAP software (S1TBX - ESA Sentinel-1 Toolbox, http://step.esa.int). We applied orbital corrections on the individual scenes of both ascending and descending satellite geometries using DORIS Precise orbits. We selected a single master image using a criterion of minimizing the temporal and perpendicular baselines in case of the two separate (ascending and descending) datasets and we co-registered the images to the master geometries. We used the 1-arc-second $(30 \mathrm{~m})$ resolution Shuttle Radar Topography Mission Digital Elevation Model (SRTM DEM) to compute the topographic phase, that we subsequently removed from the interferograms. We introduced a criterion on the perpendicular baselines; and we discarded scenes with baselines over $800 \mathrm{~m}$. This criterion has reduced the number of scenes, this was however necessary in order to exclude interferograms with no visual interferometric coherence.

We obtained the time series of ground motions by Persistent Scatterer Interferometry (PSI), within the Matlab-based workflow of STAMPS (Hooper et al., 2012; Hooper et al., 2007). In STAMPS, PS pixels are initially selected based on their amplitude dispersion, initially described by Ferretti et al. (2001). We selected a threshold of 0.4 for the amplitude dispersion index, allowing for a large number of pixels to be included in further analysis. Later, the number of PS was reduced during an iterative process based on phase stability. 
Interferograms were then corrected for spatially-correlated and uncorrelated error terms as described by Hooper et al. (2012).

\begin{tabular}{|c|c|c|c|}
\hline InSAR data type & Track/frame number & Observation period & Number of scenes \\
\hline Envisat Descending & $136 / 3697$ & $\begin{array}{c}\text { November 2002- } \\
\text { February 2007 }\end{array}$ & 17 \\
\hline Envisat Ascending & $143 / 3704$ & $\begin{array}{c}\text { November 2002 - June } \\
2010\end{array}$ & 16 \\
\hline
\end{tabular}

Table 4.1: C-band InSAR datasets that we selected for time series processing.

Average interpolated Line of Sight (LOS) velocities of the two InSAR datasets are shown in Figure 4.4. Both the ascending and descending time series indicate positive LOS movements at the Szentes geothermal field (Figure 4.4, outlined with black rectangle) for the total period of November 2002 - June 2010, except for a minor negative anomaly in the northeast, centered around production wells. Negative LOS velocities are shifted slightly towards the west in the descending time series (Figure 4.4b), that can partly be explained by satellite view geometries. Positive LOS movements of the center of the geothermal area are identified with slightly lower magnitudes on the ascending deformation map. The area north of the geothermal field exhibits significant positive LOS movements ( uplift), indicated by both ascending and descending observations. South of the Szentes area, near the location of the production wells of Szegvár, movements are directed towards the satellite in case of the ascending track from 2002 until 2010, whereas the descending observations (2002-2007) show negative ground displacement. This discrepancy can suggest that pressure recovery of the area occurred after 2007. Another major positive anomaly on the descending map is present southeast of the geothermal area, although these movements are not identified on ascending geometries. 

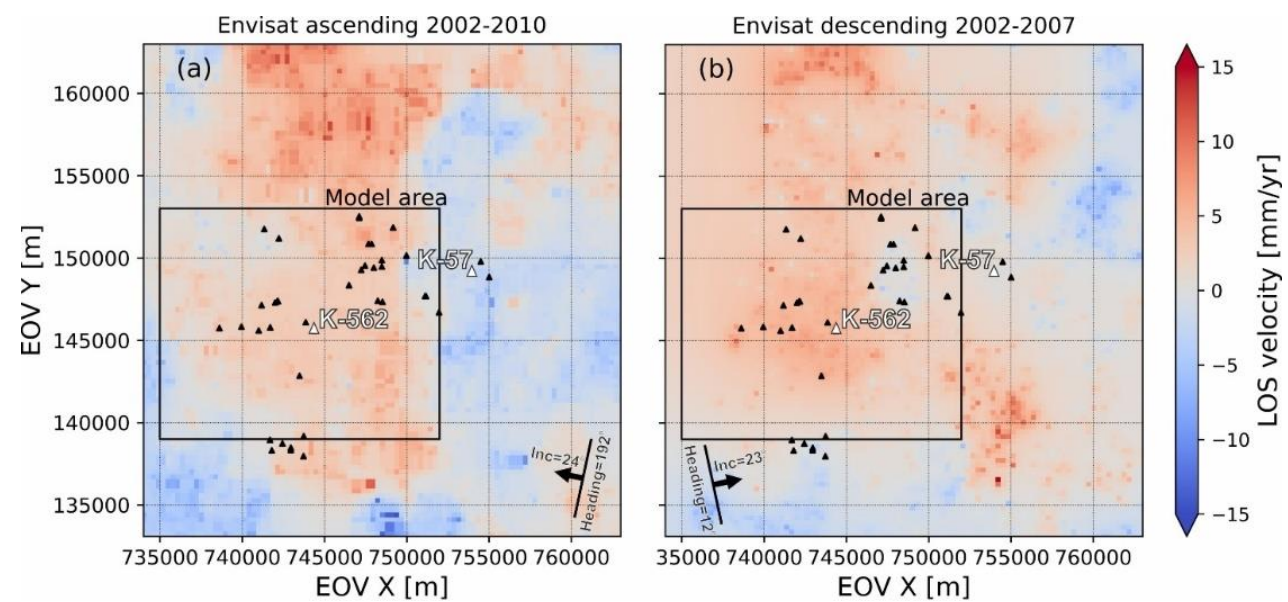

Figure 4.4: Mean interpolated LOS velocities estimated for (a) ascending and (b) descending satellite orbits, for the periods of 2002-2010 and 2002-2007, respectively. Negative LOS velocities indicate movement away from the satellite ( subsidence) and positive values show movement towards the satellite ( uplift). Arrows indicate the flight direction of the satellite and the look direction with the corresponding incidence angles. The locations of the geothermal wells are plotted with black triangles. The modelling area that corresponds to the Szentes geothermal filed, excluding the Szegvár and Fábiánsebestyén thermal wells, is outlined with black rectangles.

We plotted groundwater levels from two geothermal wells and LOS velocities of PS pixels within $200 \mathrm{~m}$ distance from the wells (Figure 4.5). Hydraulic head measurements from the Szentes area are rather limited; wells K-562 and K-57 were chosen because they have the most frequent observation history. Hydraulic head data in the K-562 well, located in the southern part of the geothermal field, show a decreasing trend until 1995, when the recovery of water levels started Figure 4.5a, top panel). Water levels in the K-57 well (western production area) are continuously declining until the early 2000 's, although with decreasing rates (Figure 4.5b, top panel). Measurements are only available until 2007 and 2002 from wells K-562 and K-57, respectively, therefore, water level changes cannot be entirely compared with the InSAR observations. It is also important to note that the open sections of both wells only partly cover the vertical extent of the geothermal reservoir. Therefore, if pressure changes are restricted to certain parts of the reservoir, the measured groundwater levels may not reflect these changes. Additionally, formation pressures might be different away from the boreholes, since the initially artesian wells required pumping after several years of production. Envisat ascending and descending time series can be approximated with a linear trend (Figure 4.5a, b, middle and bottom panels). In the vicinity of well K-562, both Envisat datasets indicate positive LOS motions ( uplift) of the area, although groundwater levels do not show any significant variation between 2002-2007 (Figure 4.5a). Near well K57 , no clear trend on the ascending time series is identified. The descending period indicates negative ground motion ( subsidence) (Figure 4.5b), suggesting that groundwater levels have 
continued to decline, or a time lag between hydraulic head variations and ground motion predictions exist.

(a)
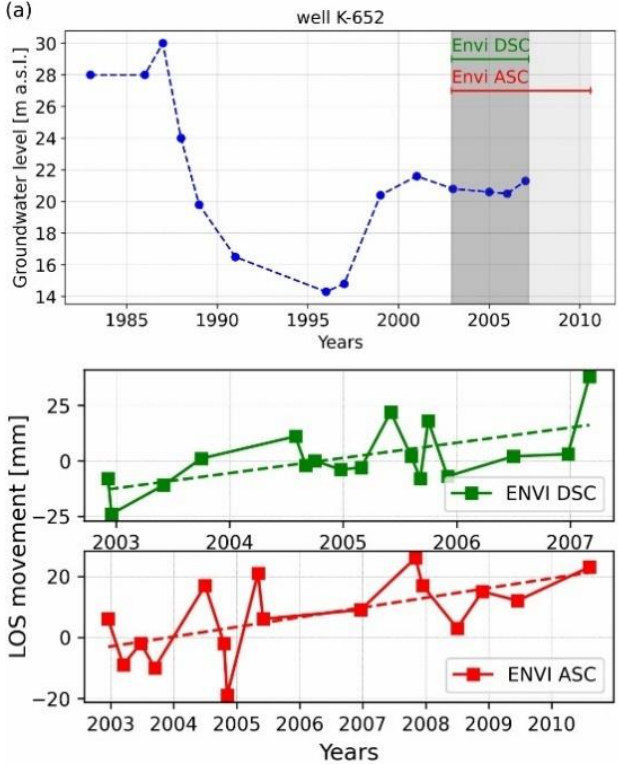

(b)
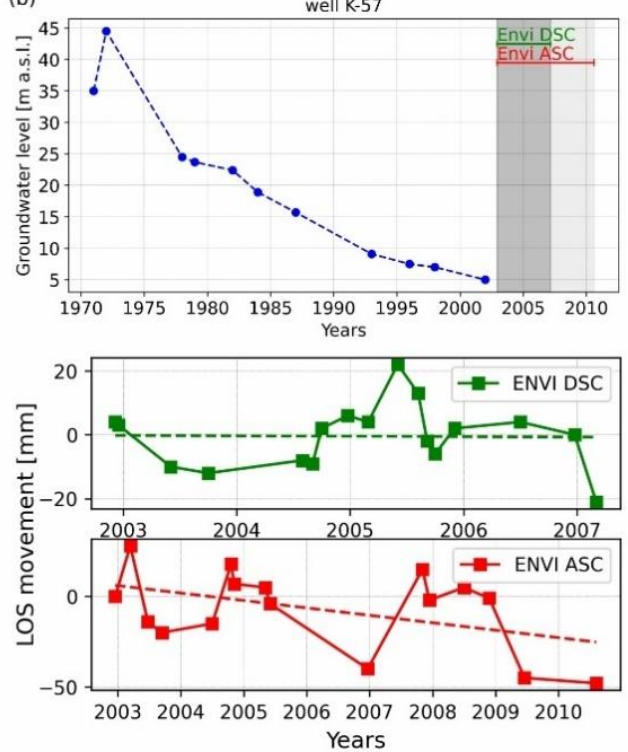

Figure 4.5: Hydraulic head measurements (top panel) and PS-InSAR time series of descending (middle panel) and ascending (bottom panel) satellite orbits at well locations in the (a) southern and (b) eastern part of the Szentes geothermal field. For the InSAR time series plots, only PS points with a standard deviation $<2 \mathrm{~mm} /$ year are included. For the locations of the geothermal wells, see Figure 4.2 and Figure 4.4.

\subsection{Inverse geomechanical modelling}

We modeled ground movements using the analytical solution of Geertsma (1973), for a disk-shaped reservoir undergoing a uniform pore pressure increase/decline, embedded in a homogeneous elastic half-space. In the Geertsma model, the vertical $\left(u_{z}\right)$ and radial $\left(u_{r}\right)$ components of movements at the surface due to pressure change, $\Delta p$, attributed to a diskshaped source with radius, $R$, and height, $h$, compaction coefficient, $c_{m}$, and burial depth, $D$, can be obtained as (Geertsma, 1973):

$$
\begin{aligned}
& u_{z}(r, 0)=2(1-v) c_{m} h \Delta p R \int_{0}^{\infty} e^{-D \alpha} J_{1}(\alpha R) J_{0}(\alpha r) d \alpha \\
& u_{r}(r, 0)=2(1-v) c_{m} h \Delta p R \int_{0}^{\infty} e^{-D \alpha} J_{1}(\alpha R) J_{1}(\alpha r) d \alpha
\end{aligned}
$$

where $J_{0}$ and $J_{1}$ are first-type Bessel functions of order 0 and 1 , respectively. The formula can be simplified by substituting $c_{m} h \Delta p=\Delta h$, where $\Delta h$ is the height change of the reservoir. This simple model cannot take into account complex geological settings and variations in subsurface geomechanical and petrophysical properties, but it can be efficient 
for a first approximation of ground deformation induced by injection/production activities. Due to its simplicity, the driving parameters of the Geertsma model can be estimated in a computationally inexpensive way by inversion techniques. Estimates of reservoir parameters and related uncertainties, for instance the compressibility, is highly relevant for more complex 3D reservoir models, to increase their reliability by choosing reasonable input parameters.

For the modelling of ground deformation, we selected an area of approximately $16 \times 14$ $\mathrm{km}$ outlined in Figure 4.4, based on the observed surface movements and well locations at Szentes. We primarily concentrated on the major positive LOS anomaly identified on descending satellite orbits for the period of November 2002 and February 2007 (Figure 4.4a). Ascending InSAR time series cover a longer time period of 2002-2010, which had to be reduced to match the descending observation period for the parameter estimation procedure. Therefore, following the time series analysis we estimated movements in the ascending geometry by excluding the interferograms with dates after February 2007 by fitting a linear trend to the remaining interferograms. We first tested the model with one single Geertsma source with uniform pressure increase (source 1), selecting broad prior ranges of model parameters. We assumed a uniform pressure increase based on the InSAR observations and the hydraulic head profile (Figure 4.2b), indicating increasing groundwater levels at the bottom of the geothermal reservoir (base of the Újfalu formation). Having only one source, significant unmapped negative LOS movements remained, that are present on both ascending and descending observations northeast of the main uplift signal (Figure 4.6b, e). To account for this subsidence, we included an additional source with negative pressure change (source 2) to the model (Figure 4.6a, c) based on the InSAR measurements.

To estimate the model parameters and uncertainties, we applied ensemble-based probabilistic inversion, having the ascending and descending InSAR datasets as target observations. The Ensemble Smoother (ES, Emerick and Reynolds (2013a)) estimates the model parameters by a global update, incorporating all data available. Therefore, inverse problems with large number of observations can be solved by the ES in a computationally efficient way. For non-linear forward models, the ES requires several iterations, where the predictions of the previous run is used as an input for the subsequent data assimilation step (ES-MDA, Emerick and Reynolds, 2013a). In case of the forward model based on the analytical solution of Geertsma (1973), only a weak nonlinearity between ground motion and certain model parameters (radius and depth of the disk-shaped sources) exist. Still, we choose ES-MDA as we expected a better performance than a single ES and to be able to evaluate the improvement of the solution with each DA steps.

The solution for a single data assimilation for the updated model ensemble is:

$$
\widehat{M}=M+M^{\prime}\left[G M^{\prime}\right]^{T}\left\{G M^{\prime}\left[G M^{\prime}\right]^{T}+\left(N_{e}-1\right) C_{d}^{-1}\right\}^{-1} \times(D-G M)
$$

In equation (4.3), $M$ is the prior ensemble of model parameters, $G M$ represents the result of the forward model working on all ensemble members, and $G M^{\prime}$ is the difference between $G M$ and its mean. $N_{e}$ is the number of ensembles, and $D$ is an ensemble of data realizations, 
created by perturbing the measurements according to their covariance matrix $\left(C_{d}\right)$. The mean of the ensemble is taken as the best estimate, which is used as input for the next update in case of ES-MDA. The number of data assimilation steps, $N_{a}$ must be selected a-priori. The data covariances used for the update steps are increased by a multiplication factor, $\alpha_{\mathrm{i}}$ for $\mathrm{i}=1,2 \ldots, N_{a}$, and $\alpha_{\mathrm{i}}$ must be selected as $\sum_{i=1}^{N_{a}} \frac{1}{\alpha_{i}}=1$ (Emerick and Reynolds, 2013a). This is necessary to compensate for the effect of multiple application of an ES.

For the inverse modelling with ES-MDA, we fixed the depth of the sources to $1500 \mathrm{~m}$, which was identified as the mean depth of the top of the reservoir from well logs and seismic data. We approximated the subsurface with an elastic half space, with a Poission's ratio $v=0.28$, that we selected based on average values for the area inferred from well logs. The model parameters include the location (X and $\mathrm{Y})$, radius $(\mathrm{R})$ and height change $(\Delta h)$ of the two disk-shaped sources, 8 parameters in total. We assigned prior values for the parameters assuming normal distribution, except for the height change of both sources, where a lognormal distribution was chosen (Table 4.2). We selected prior values for the height change to be positive in case of source 1, accounting for a positive pressure change at depth attributed to the major positive LOS displacement anomaly. The height change of source 2 was assumed to be negative, approximating pressure decline and corresponding subsidence. Measurement errors of the InSAR observations were set to $4 \mathrm{~mm}$, after testing the influence of different values $(2-8 \mathrm{~mm})$ on the inversion procedure. We first included only one source in the parameter estimation procedure allowing for broad prior values, to get a first-pass model for the major positive pressure source. Using the mean posterior model parameters of the one source model, we estimated the parameters of the second source combined with the first source having fixed parameters. We iteratively fixed one source at a time, until no significant improvement compared to the previous model was achieved. Then, we assigned relatively narrow ranges to the prior parameters, with mean and standard deviation reported in Table 4.2. Having these prior statistics, we estimated all model parameters of the two sources through the same ES-MDA run, using ground motion observations on both ascending and descending tracks for the period of November 2002 and February 2007 simultaneously. The data assimilation procedure was performed with 100 ensemble members and 4 iterations or data assimilation steps. 


\begin{tabular}{|c|c|c|c|c|c|}
\hline \multirow[b]{2}{*}{ Parameter [unit] } & \multirow[b]{2}{*}{ Symbol } & \multicolumn{2}{|c|}{ Prior statistics } & \multicolumn{2}{|c|}{ Posterior statistics } \\
\hline & & mean & $\begin{array}{l}\text { Standard } \\
\text { deviation }\end{array}$ & mean & $\begin{array}{l}\text { Standard } \\
\text { deviation }\end{array}$ \\
\hline $\begin{array}{l}\text { X coordinate of } \\
\text { source } 1[\mathrm{~m}]\end{array}$ & $\mathrm{X}_{1}$ & $\mu \times 1=743500$ & $\sigma \times 1=500$ & $\mu \times 1=743428$ & $\sigma \mathrm{x}_{1}=24$ \\
\hline $\begin{array}{l}\text { Y coordinate of } \\
\text { source } 1[\mathrm{~m}]\end{array}$ & $\mathrm{Y}_{1}$ & $\mu_{\mathrm{Y} 1}=145500$ & $\sigma_{Y 1}=500$ & $\mu_{Y 1}=145657$ & $\sigma_{\mathrm{Y} 1}=21$ \\
\hline $\begin{array}{l}\text { Radius of } \\
\text { source } 1[\mathrm{~m}]\end{array}$ & $\mathrm{R}_{1}$ & $\mu_{\mathrm{R} 1}=5500$ & $\sigma_{\mathrm{R} 1}=200$ & $\mu_{\mathrm{R} 1}=5743$ & $\sigma_{\mathrm{R} 1}=17$ \\
\hline $\begin{array}{l}\text { Height change } \\
\text { of source } 1[\mathrm{~m}]\end{array}$ & $\Delta \mathrm{h}_{1}$ & $\mu_{\log (\Delta \mathrm{h} 1)}=-3.9$ & $\sigma_{\log (\Delta h 1)}=0.18$ & $\mu_{\log (\Delta \mathrm{h} 1)}=-3.88$ & $\sigma_{\log (\Delta h 1)}=0.0025$ \\
\hline $\begin{array}{l}\text { X coordinate of } \\
\text { source } 2[\mathrm{~m}]\end{array}$ & $\mathrm{X}_{2}$ & $\mu \times 2=748000$ & $\sigma \times 2=300$ & $\mu \times 2=748028$ & $\sigma \times 2=14$ \\
\hline $\begin{array}{l}\text { Y coordinate of } \\
\text { source } 2[\mathrm{~m}]\end{array}$ & $\mathrm{Y}_{2}$ & $\mu_{Y 2}=148000$ & $\sigma_{Y 2}=300$ & $\mu_{Y 2}=148256$ & $\sigma_{Y 2}=11$ \\
\hline $\begin{array}{c}\text { Radius of } \\
\text { source } 2[\mathrm{~m}]\end{array}$ & $\mathrm{R}_{2}$ & $\mu_{\mathrm{R} 2}=1000$ & $\sigma_{\mathrm{R} 2}=100$ & $\mu_{\mathrm{R} 2}=883$ & $\sigma_{\mathrm{R} 2}=30$ \\
\hline $\begin{array}{l}\text { Height change } \\
\text { of source } 2[\mathrm{~m}]\end{array}$ & $\Delta \mathrm{h}_{2}$ & $\mu_{\log (-\Delta h 2)}=-1.8$ & $\sigma_{\log (-\Delta \mathrm{h} 2)}=0.14$ & $\begin{array}{c}\mu_{\log (-\Delta \mathrm{h} 2)}= \\
-1.68\end{array}$ & $\sigma_{\log (-\Delta \mathrm{h} 2)}=0.06$ \\
\hline
\end{tabular}

Table 4.2: List of model parameters and their prior and posterior statistics.

Modelling results indicate the presence of an a extensive positive pressure source, with a radius of $5743 \pm 17 \mathrm{~m}$ (source 1, red dashed circle in Figure 4.6a, d), and a smaller negative source with a radius of $883 \pm 30 \mathrm{~m}$ (source 2, blue dashed circle in Figure 4.6a, d). Source 1 is located at the center of the Szentes geothermal field, covering the locations of most of the geothermal wells. The location of source 2 corresponds to the vicinity of production wells in the northeastern part of the field. Source 2 is positioned almost entirely inside the large positive source (Figure 4.6a, d), suggesting that source 2 is superimposed on top of the significantly larger source 1 . 

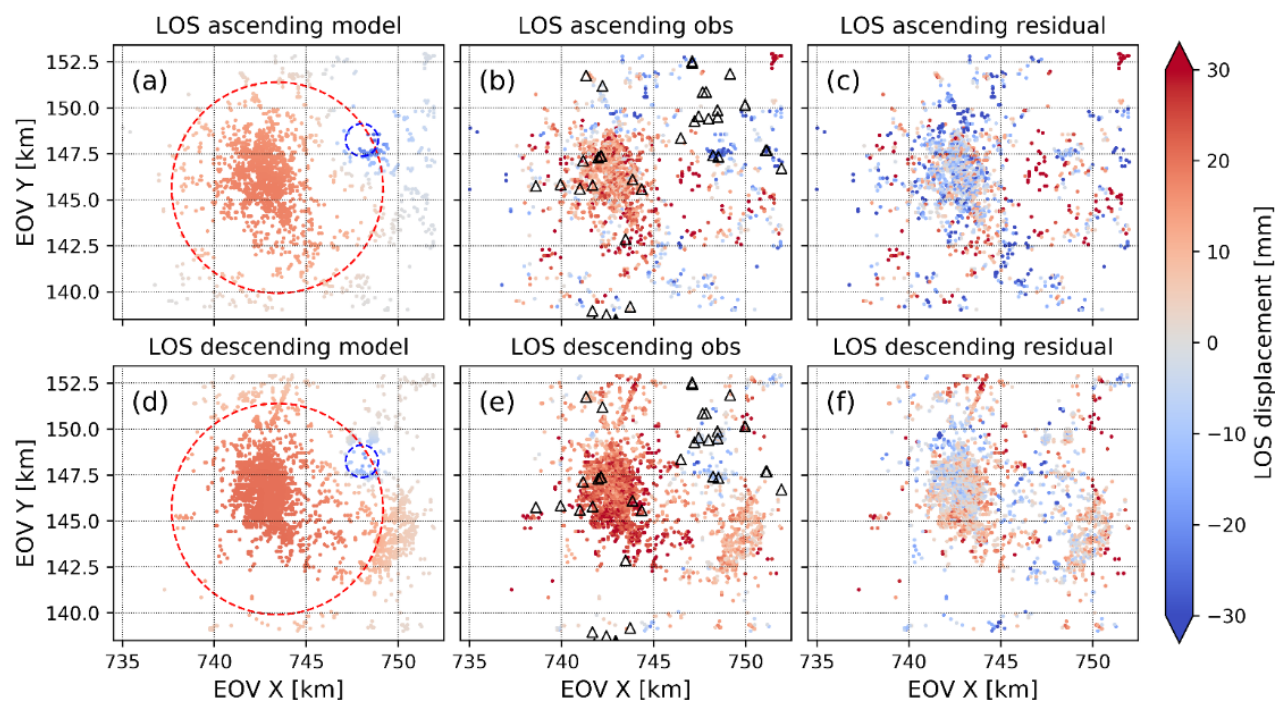

Figure 4.6: Modeled (a, d), observed (b, e), and residual (c, f) displacements in the LOS direction for ascending (top) and descending (bottom) satellite passes. Red and blue dotted circles in (a) and (b) show the locations of the best fitting Geertsma sources, using the mean values from the posterior model run. The large, red circle corresponds to the positive pressure source that is responsible for the major uplift signal, and the small blue circle accounts for pressure decrease due to prolonged production in the SE part of the geothermal field.

The model can adequately approximate the major structures of the ground motion observations on both ascending and descending geometries (Figure 4.6). Still, residual surface movements (Figure 4.6c, f) are significant at certain areas, suggesting that the simple model could not entirely reproduce the InSAR time series displacements. The overall RMSE of the model is $9.97 \mathrm{~mm}$, with $13.2 \mathrm{~mm}$ with the ascending, and $7.36 \mathrm{~mm}$ with the descending data separately. Residuals show that the model performed better on descending geometries. The relatively poor fit with the ascending data can be partly due to measurement errors, explained by the lower number of acquisitions available for the time series analysis (Table 4.1). Additionally, the relatively large overall RMSE shows that the complexity of the subsurface cannot be captured by the model. Still, the motivation for such simple model was to have an estimate on the sources that are responsible for the major pattern of ground movements and to find reasonable intervals for compaction coefficients that are mapped within $\Delta h_{1}$ and $\Delta h_{2}$ and related uncertainties of the reservoir system.

The resulting posterior model parameters and their standard deviations suggest that all model parameters are well constrained compared to their prior statistics (Table 4.2, Figure 4.7). Figure 4.7 demonstrates the improvement of the uncertainties of model parameters through each data assimilation run. No clear correlation between model parameters have been identified except for the height change $\left(\Delta h_{2}\right)$ and the radius $\left(\mathrm{R}_{2}\right)$ of source 2 (Figure 4.7d). The correlation between $\Delta h_{2}$ and $\mathrm{R}_{2}$ is clearly shown by Figure 4.8 , identified as a linear 
relationship between the logarithm of the parameters with a slope close to -0.5. Apparently, all posterior parameters can be constrained independently, but the product $\Delta h_{2} R^{2}$ can be estimated better than the two parameters separately. This is related to the fact that the subsidence of a relatively small source is in first order proportional to its compacting volume, for which $\pi \Delta h_{2} R^{2}$ is the measure.
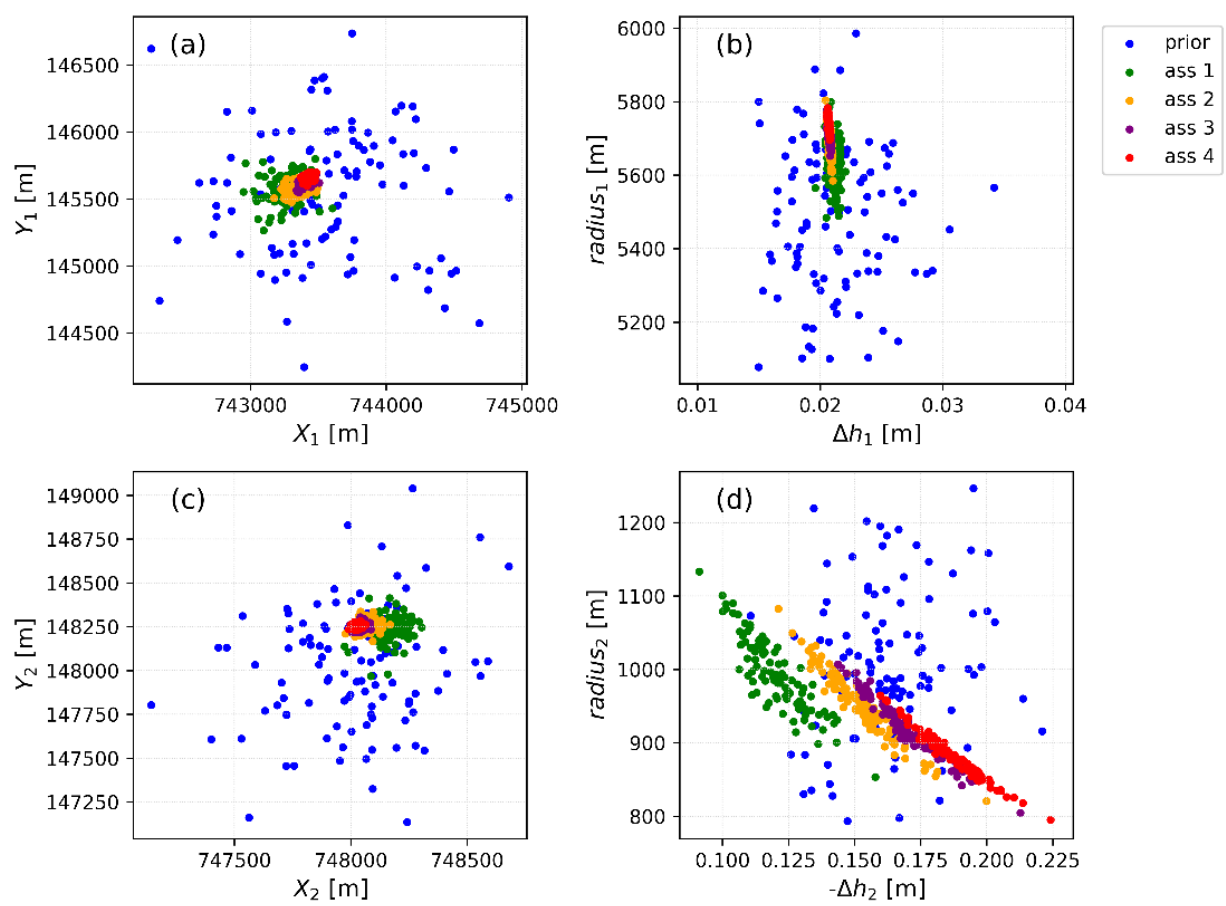

Figure 4.7: Prior (blue circles) and posterior ensembles of the model parameters for source 1 (a-b) and source 2 (c-d), including all 4 data assimilation steps. The final parameters are shown with red circles. 


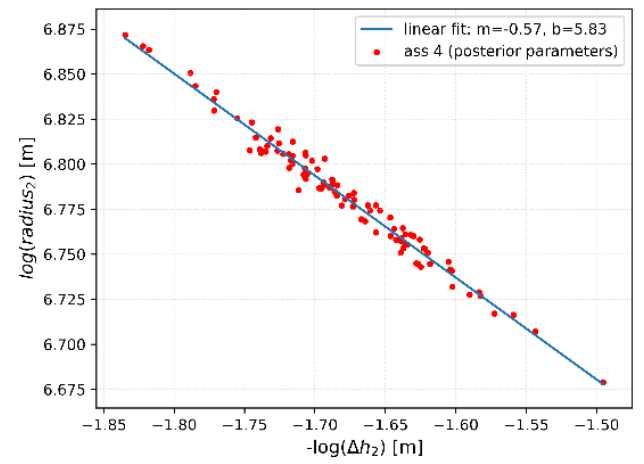

Figure 4.8: Plot showing the correlation between the logarithm of the height change $(\Delta \mathrm{h} 2)$ and the radius (R2) of the small compaction source (source 2), and corresponding parameters of the linear fit.

\subsection{Discussion}

PS-InSAR time series of ground deformation together with the modelling results suggest that uplift of the Szentes geothermal field due to pore pressure recovery occurred between 2002-2010. Since no injection wells were operated at Szentes before 2018, and production temperatures remained relatively constant through the entire production period (Bálint and Szanyi, 2015), we explain ground uplift with pore pressure increase due to natural recharge. Additionally, on top of the recharge of the whole area, subsidence of the northeastern part of the geothermal field is observed. The inferred pressure recovery of the Szentes geothermal area is in agreement with increasing water levels measured at the bottom of the Upper Miocene (Upper Pannonian) sediments between 2000-2010 by Bálint and Szanyi (2015) (Figure 4.2b). Unexpectedly, the north-eastern part of the area also experienced a moderate increase in hydraulic heads (Bálint and Szanyi, 2015), whereas the InSAR data and modelling results suggest pressure decline indicated by the second source. However, the hydraulic head cross-section showing increasing groundwater levels between 2000-2010 is located further to the north from the inferred second source (Figure 4.2a, b). The relatively small extent of source 2, with a radius of $883 \mathrm{~m}$ can explain the fact that pressure recovery further away to the north took place. Additionally, pressure recovery of the area of source 2 may started after the observation period, from 2007.

With the Geertsma models for surface displacement due to two disk-shaped reservoirs embedded in an elastic half-space with uniform pressure increase and decline we managed to reproduce the major anomalies observed on the ground movement maps (Figure 4.6). However, significant misfits between observed and modeled surface deformation remained at certain locations (Figure 4.6c, f). We attribute those to the limitations of the model, assuming constant reservoir properties and a perfectly circular shape. As a matter of fact, sedimentation in the Makó trough followed aggradational and progradational cycles, with various lithologies (e.g. Sztanó et al., 2013). The resulting local variations in sand and clay 
content of the reservoir cause heterogeneous properties, most importantly a highly variable compaction coefficient. This directly causes variations in the magnitude of ground deformation. InSAR can thus be useful for mapping local variations in sand and clay contents within the reservoir, even if they are below the resolution of other conventional geophysical measurements like seismic data.

The formula of Geertsma (1973) shows a linear relationship between ground motion and the product of reservoir compaction coefficient, reservoir height, and pressure change. Inversion techniques fail to constrain each of these parameters individually. Therefore, we constrained the product of the three parameters of both sources (Table 4.2 Figure 4.7). Then, we plotted the (de)compaction coefficients associated with the two sources as a function of reservoir pressure, with constant reservoir heights of $200 \mathrm{~m}, 400 \mathrm{~m}$ and $600 \mathrm{~m}$ (Figure 4.9), based on the mean posterior products of the three parameters $\left(\Delta h_{1}\right.$ and $\left.\Delta h_{2}\right)$. We outlined intervals with reasonable values for pressure change based on water level variations (Figure $4.2 \mathrm{~b}$ ) and downhole pressure measurements in case of sources 1 (Figure 4.9). For source 2, instead of the hydraulic head section showing pressure recovery, located more to the north, we assigned pressure changes by interpolating the water levels measured in well K-57 to the observation period. The inferred decompaction coefficient of source 1, with a positive pressure change, varies between $\sim 0.7-2.1 \times 10^{-9} \mathrm{~Pa}^{-1}$ (Figure 4.9a), characterizing the elastic behavior of the Szentes geothermal reservoir. The estimated decompaction coefficients of the pressure recovery period are lower than the reported average compaction coefficients of the Upper Pannonian sediments with a porosity of $21-28 \%$ at Szentes, at 1500-2000 m depth (e.g. Bálint and Szanyi, 2015). Additionally, the Upper Pannonian sediments are largely heterogenous, with small clay layers separating the water-bearing sand bodies. The individual compaction coefficient of clays are considered to be significantly higher than the sand bodies. As a result, they contribute significantly to the overall compaction coefficient of the reservoir system.

The compaction coefficient attributed to the small source with pressure decline (Figure $4.9 \mathrm{a}$ ) is an order of magnitude larger than the coefficient of the large source (Figure 4.9b). We already showed that these values are subject to a larger uncertainty due to the correlation between the radius and the height change of source 2, as shown in Figure 4.7d and Figure 4.8. Therefore, the compaction coefficient varies within a significantly wider range; between $\sim 0.1-2 \times 10^{-8} \mathrm{~Pa}^{-1}$.This is related to the fact that the subsidence of a relatively small source is in first order proportional to its compacting volume, and therefore the product $\Delta h_{2} R^{2}$ can be estimated better than the parameters separately. Considering the uncertainties related to source 2, the inferred parameters still suggest that the decompaction coefficient corresponding to the unloading period (pressurization) is significantly smaller than the compaction coefficient of the loading period (depressurization). We explain this discrepancy with the permanent deformation of the reservoir during the pressure depletion period until $\sim 1996$ (Figure 4.5a) in the western part of the field, while permanent deformation associated with the prolonged local pressure decline in the eastern part of the field occurred at least until 2007. Permanent deformation is attributed to the time-dependent consolidation of clay layers 
within the reservoir-system, and possibly intergranular clay films, as observed for instance at the Groningen Gas Field (Pijnenburg et al., 2019). Compaction of highly compressible lithologies (mudstones) were identified as main sources of ground subsidence for instance at the Wairakei-Tauhara and Ohaaki geothermal areas in New-Zealand, with up to $15 \mathrm{~m}$ (Hole et al., 2007). To properly assess the contributions of elastic and inelastic deformation at the study area and fully understand the compaction behavior of the reservoir, ground deformation observations and more frequent pressure measurements of the major depletion period are required.
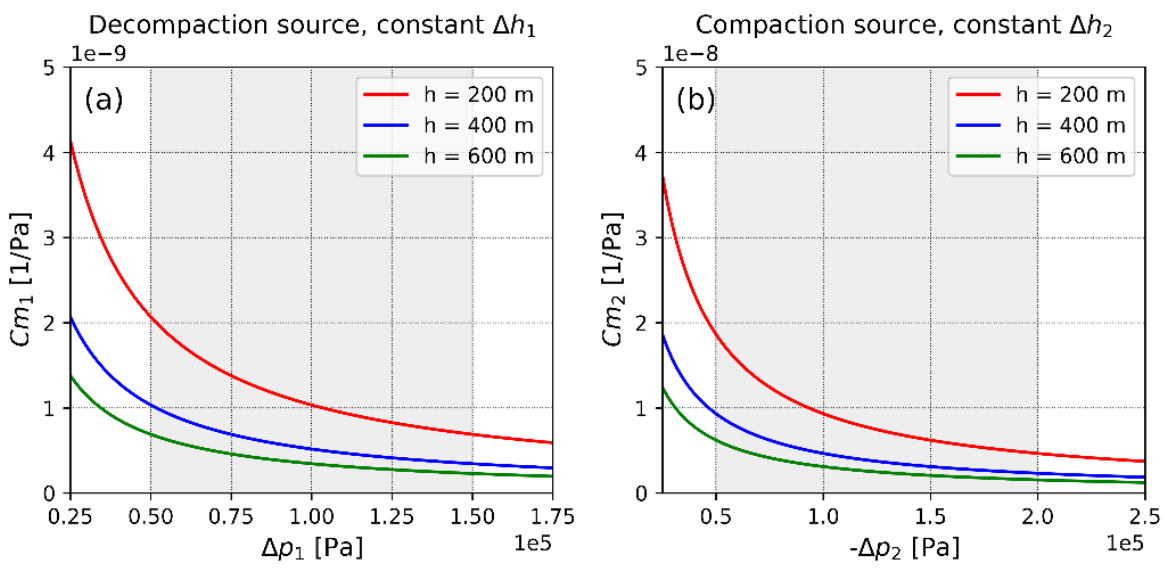

Figure 4.9: Decompaction and compaction coefficients associated with (a) sources 1 and (b) source 2, as a function of reservoir pressure, with constant reservoir heights of $200 \mathrm{~m}, 400 \mathrm{~m}$ and $600 \mathrm{~m}$. Intervals with reasonable values for pressure change based on water level observations and downhole pressure measurements from the locations of the corresponding sources are outlined with grey. $\mathrm{C}_{\mathrm{m}}$ values that lie within the grey interval indicate reasonable estimates for the (de)compaction coefficients of the reservoir system. Note the one order of magnitude difference between the $\mathrm{C}_{\mathrm{m}}$ scales.

\subsection{Conclusions}

We performed PS-InSAR time series analysis of Envisat images acquired on ascending and descending satellite tracks, for the period 2002-2010, covering the Szentes geothermal area in SE Hungary. The ground movement observations were used in inverse models based on the analytical function of Geertsma (1973), for ground deformation induced by a constant pressure change in a cylindrical source at depth. We constrained the model parameters with an ensemble smoother with multiple data assimilation and we managed to reproduce the main features of the observed surface movements with the combination of a larger source with positive pressure change, and a smaller depleting source. The procedure yielded reasonable estimates of the model parameters and their uncertainties.

Ground movements together with the modelling results suggest that uplift of the Szentes geothermal field occurred between 2002-2010, which is explained by pore pressure recovery 
supported by natural recharge. The estimated decompaction coefficient of the reservoir ( 0.7$\left.2.1 \times 10^{-9} \mathrm{~Pa}^{-1}\right)$ appears to be lower than expected for the Upper Miocene sediments at reservoir depth. Additionally, the inferred compaction coefficient attributed to the minor negative pressure source is estimated to be a magnitude larger than the decompaction coefficient of the large source, suggesting that permanent deformation of the geothermal reservoir occurred during the main depletion period, from $\sim 1970$ until the late 90's. Prolonged permanent deformation associated with a local decrease in reservoir pressures in the eastern part of the field took place until at least 2007, as suggested by the InSAR measurements and source modelling.

The InSAR surface movement estimates, employed in an ES-MDA inverse modelling scheme, have shown to combine to an efficient tool to make a first-order estimate of the properties and processes at the Szentes geothermal area. The inferred properties and processes are highly relevant as an input of more complex reservoir models and for predictions for future production scenarios, targeting a sustainable production plan. To achieve more reliable estimates on the reservoir behaviour, ground motion observation of the entire thermal water extraction period, and more frequent pressure/hydraulic head measurements would be required. Future projects combining InSAR with forward and inverse modelling with high-resolution subsurface datasets potentially have an important role in in the sustainable exploitation of the highly prospective geothermal resources in the Pannonian Basin. 


\section{Production-induced subsidence at the Los Humeros Geothermal Field inferred from PS- InSAR $^{4}$}

${ }^{4}$ This chapter is based on Békési, E., P. A. Fokker, J. E. Martins, J. Limberger, D. Bonté, and J.D. Van Wees (2019), Production-induced subsidence at the los Humeros geothermal field inferred from PS-InSAR. Geofluids (online), 2019. 


\subsection{Introduction}

Good understanding of reservoir processes and properties is crucial to optimize subsurface operations. Uncertainty in future production and potential risks such as induced seismicity can be reduced by detailed information about the mechanical and hydraulic properties of the reservoir and its surroundings. These properties affect the ground surface movements induced by subsurface activities. Therefore, such information may be achieved by monitoring surface deformation. Relating surface deformation to the process of subsurface extraction or injection can give an indication on the spatial distribution and the amount of volume and pressure changes in the subsurface.

The deployment of DInSAR (Differential Interferometric Synthetic Aperture Radar) allows to detect small movements on the Earth's surface (e.g. Ferretti et al., 2001; Hanssen, 2001). It utilizes the phase difference between two SAR images to estimate displacement along the satellite line-of-sight (LOS). Time-series analysis facilitates the monitoring of gradual changes in ground movements by selecting stable point-scatterers (Persistent Scatterers - PS) in multiple interferograms, while decreasing atmospheric disturbances and improving the performance of the phase unwrapping.

Numerous studies have applied the DInSAR technique and modeled the source of deformation associated with the exploitation of subsurface resources. These models most commonly relate surface deformation to subsurface extraction or injection processes through so-called influence functions that are based on analytical solutions for different nuclei of strain. For instance, Trugman et al. (2014) and Samsonov et al. (2017) used inflation point sources to model subsidence due to production at the world's second largest geothermal field, Cerro Pietro. Surface subsidence at the Reykjanes geothermal field was modeled with point and ellipsoidal pressure sources (Keiding et al., 2010). Other nuclei of strain solutions than the inflation sources were also applied in several studies. As an example, Atefi-Monfared and Rothenburg (2011) employed Okada's solution for expansion or contraction in one direction (Okada, 1992) as reservoir deformations are mostly one-dimensional. Vasco et al. (2010) modeled the horizontal opening of a vertically-oriented fracture due to $\mathrm{CO}_{2}$ injection using Okada's solution.

In this paper we present a case study of the Los Humeros Geothermal Field (LHGF). LHGF is among the largest geothermal fields in Mexico with an installed capacity of $~ 93.6$ MW for an operational capacity of $68.6 \mathrm{MW}$ and is operated by the national Mexican Electrical company (Comisión Federal de Electricidad, CFE). We show the first results of PS-InSAR (Persistent Scatterer by Synthetic Aperture Radar Interferometry) time-series over the LHGF. We analyzed 13 C-band Single Look Complex (SLC) images acquired by the European Space Agency's (ESA) Envisat satellite between April 2003 - March 2007 to detect surface movements due to field operations and potential discharge and recharge zones. We relate ground deformation with volume changes in the reservoir through analytical solutions for different nuclei of strain. The main goal of this study is to have a better understanding on the subsurface processes at the LHGF based on surface movements. Furthermore, we intend to reveal the pressure distribution within the reservoir and identify 
reservoir compartmentalization, which may help with future planning and optimization on the production of the geothermal field.

\subsection{The Los Humeros Geothermal Field (LHGF)}

The LHGF is a superhot geothermal system connected to the Los Humeros caldera complex located in the eastern sector of the Trans-Mexican Volcanic Belt (Figure 5.1). The basement of the LHGF is composed of granites and schists of Paleozoic age, overlain by a thick metamorphosed Mesozoic limestone succession. Volcanic activity in the area initiated during Miocene times ( $\sim 10 \mathrm{Ma}$ ) and produced andesites that outcrop in the eastern part of the Los Humeros caldera (Figure 5.1) (Ferriz and Mahood, 1984). The LHGF is connected to a caldera system that has been active from 0.46 Ma until recent (Ferriz and Mahood, 1984), although according to the most recent studies the Los Humeros caldera is considerably younger (0.16 Ma, (Carrasco-Núñez et al., 2018)). The Los Humeros caldera complex was formed by at least two major rhyolitic eruptions, and multiple minor to medium eruptions and lava flows. The duration of the caldera forming period was $~ 410 \mathrm{ky}$ (Ferriz and Mahood, 1984), or alternatively significantly shorter (94 ky, (Carrasco-Núñez et al., 2018)). Recent andesitic and basaltic volcanism is poorly dated, but considered to be <20-40 ky old (Ferriz and Mahood, 1984).

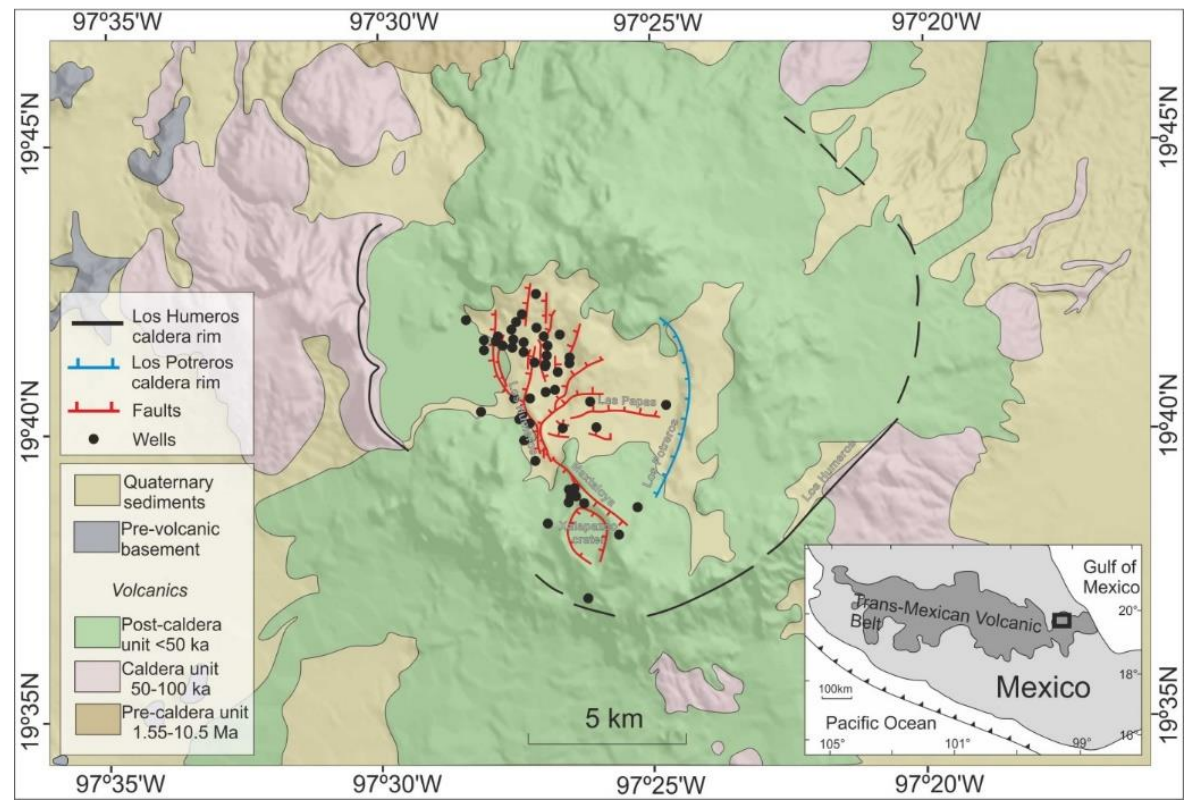

Figure 5.1: Simplified geological map of the Los Humeros geothermal field and it surroundings, highlighting major faults, the caldera rims, and the location of the wells. Modified after Norini et al. (2015) and Carrasco-Núñez et al. (2017). 
Commercial exploitation of the LHGF started in the early 90's. Reinjection began few years after production, in 1995, however injection rates are about an order-of-magnitude smaller than the produced volumes (Figure 5.2). Since the beginning of production, more than 50 wells have been drilled. The main production wells are located in the northern part of the LHGF. Average yearly production and injection rates during the period of the InSAR monitoring (2003 - 2007) are $\sim 5 \times 10^{6} \mathrm{~m}^{3}$ and $\sim 5 \times 10^{5} \mathrm{~m}^{3}$, respectively (Figure 5.2). Precaldera ( 10.5-1.5 Ma) andesites of low to medium porosity provide the main reservoir formation. In addition to faults and fractures, microporosity is considered to be a major source of reservoir permeability, as suggested by experimental measurements on core samples (Cid et al., 2021). The reservoir consists of several blocks separated by mostly normal faults (Figure 5.1) (e.g. Carrasco-Núñez et al., 2017; Norini et al., 2015). Two main fault systems can be distinguished, one with NE-SW to E-W striking structures (e.g. Las Papas), and a second one with NW-SE to NS orientation (e.g. Maxtaloya). These structures have major control on the geothermal system. Neotectonic deformation of the caldera floor is recorded based on field observations, associated with movements along the inner-caldera faults due to recent/active resurgence processes (Norini et al., 2015).

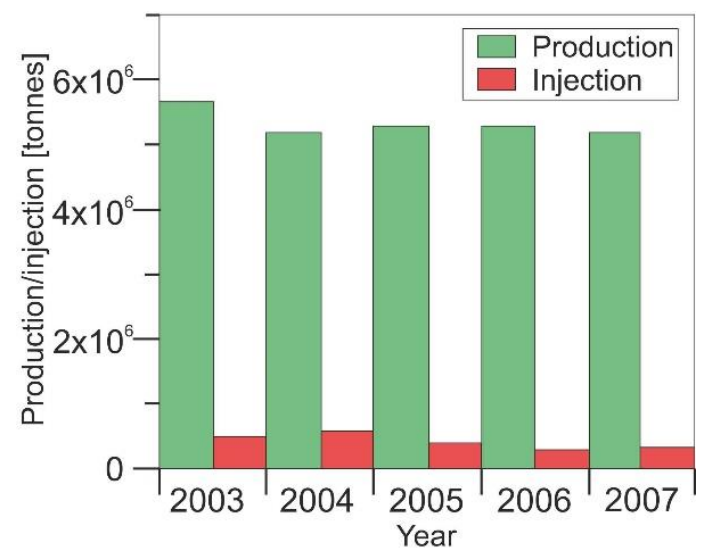

Figure 5.2: Yearly production and injection rates at the LHGF between 2003 and 2007.

\subsection{Interferometric Synthetic Aperture Radar monitoring}

We performed PS-InSAR time-series analysis to resolve ongoing ground deformation due to geothermal exploration at the Los Humeros geothermal field. We analyzed SLC images (descending track 212) acquired in C-band by ESA's Envisat satellite between April 2003 March 2007 (Table 5.1). We selected a subset of 30x35 km covering the Los Humeros caldera system for the time series processing. 


\begin{tabular}{|c|c|c|}
\hline Number of scene & Date & Perpendicular baseline [m] \\
\hline 1 & 08-Apr-2003 & -67 \\
\hline 2 & 17-Jun-2003 & 84 \\
\hline 3 & 26-Aug-2003 & 164 \\
\hline 4 & 13-Jan-2004 & -495 \\
\hline 5 & 06-Jul-2004 & -364 \\
\hline 6 & 10-Aug-2004 & -99 \\
\hline 7 & 28-Dec-2004 & 0 \\
\hline 8 (master) & 08-Mar-2005 & 389 \\
\hline 9 & 21-Jun-2005 & 500 \\
\hline 10 & 30-Aug-2005 & -408 \\
\hline 11 & 21-Feb-2006 & 235 \\
\hline 12 & 02-Jan-2007 & 186 \\
\hline 13 & 13-Mar-2007 & \\
\hline
\end{tabular}

Table 5.1: List of scenes that were used for PS-InSAR processing acquired on descending orbits, track 212.

The selection of the master image follows the criteria of minimizing the perpendicular and temporal baselines, therefore we coregistered the images to the master geometry. We used DORIS Precise orbits provided by the ESA for the orbital correction and the topographic phase was computed and removed from the interferograms using the 1 arc-second $(30 \mathrm{~m})$ resolution Shuttle Radar Topography Mission Digital Elevation Model (SRTM DEM). For the time-series processing, we discarded the interferograms with no visible coherence and perpendicular baselines above $500 \mathrm{~m}$. Interferograms were geocoded and imported into the MATLAB-based StaMPS (Stanford Method for Persistent Scatterers) framework (Hooper et al., 2007). The PS processing in StaMPS started with an initial selection of PS candidates based on the amplitude dispersion of the pixels (Hooper et al., 2010). The number of PS candidates were further reduced in an iterative process. We correct the interferograms for the spatially correlated and uncorrelated look angle phases, orbital errors and master atmosphere. Spatially uncorrelated errors are proportional to the perpendicular baselines and their phases are estimated during the PS selection and removed from the wrapped phase prior to unwrapping. All the others are estimated after unwrapping and then removed before performing unwrapping again. Even though we are using a $30 \mathrm{~m}$ SRTM DEM, it has been shown that the influence of DEM on the deformation rate calculation is small and inversely proportional to the wavelength ( $\mathrm{Du}$ et al., 2017). In Figure 5.3c, we observe that the 
maximum DEM error is observed outside the area of interest reaching $\sim 0.01 \mathrm{rad} / \mathrm{m}$, which corresponds to $\sim 12 \mathrm{~m}$ of DEM error for Envisat.

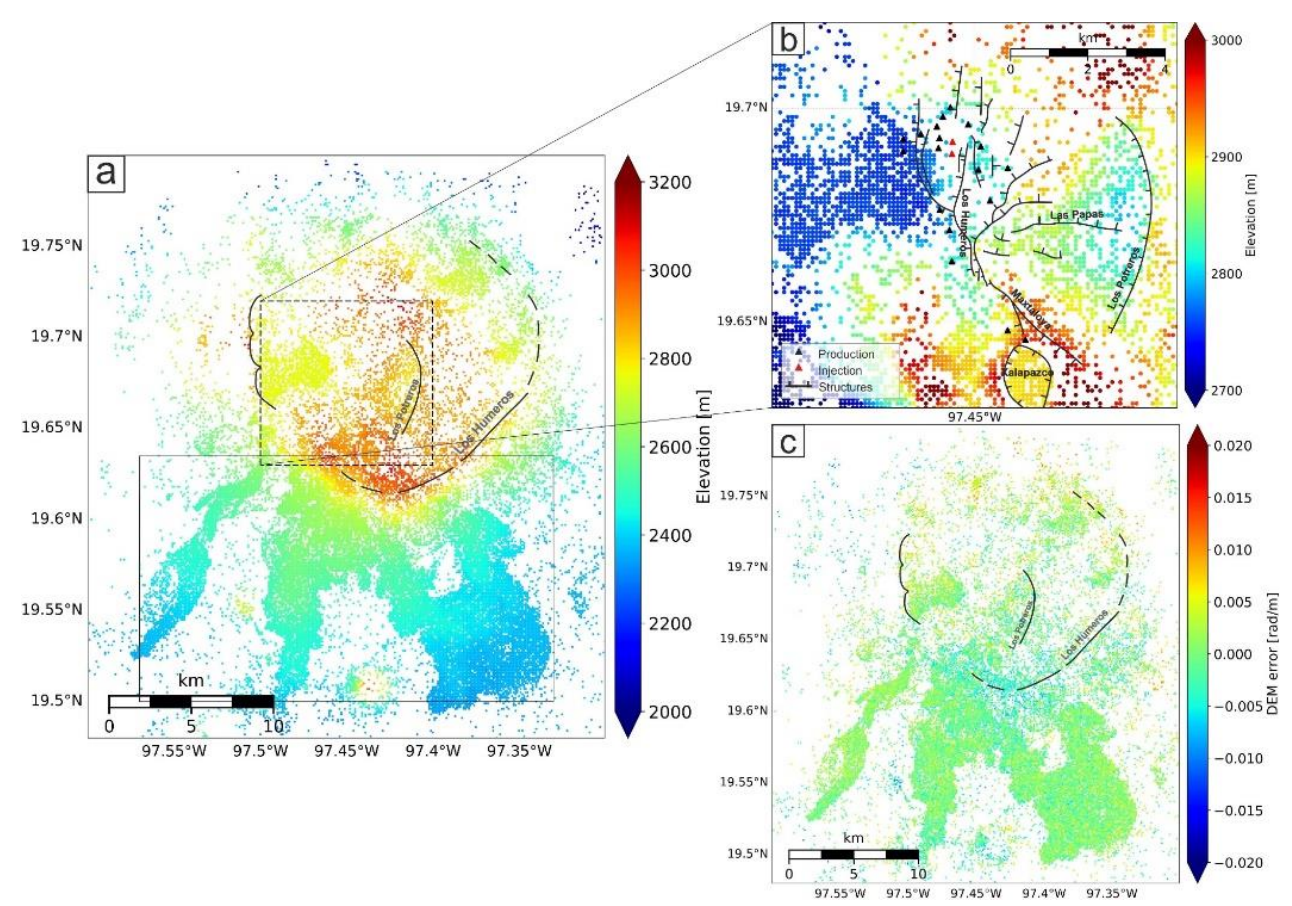

Figure 5.3: Elevation of the PS points of the entire study area (a) and at the LHGF (b) and the error associated with the DEM (c). The black rectangle in figure (a) highlights the region used for tropospheric correction.

The individual interferograms are generally of good quality, fairly coherent even over long time scales. On the other hand, dense vegetation especially in the northern part of the study area decreases the interferometric coherence. Most parts of the study area are located at high altitudes (above $2500 \mathrm{~m}$ ) with strong relief. As a result, some interferograms, and consequently the mean line-of-sight (LOS) velocities, seem to be influenced by topographyrelated tropospheric phase delays (e.g. Cavalié et al., 2007; Hanssen, 2001) (Figure 5.3a,b, Figure 5.4). We corrected the topography-related tropospheric artifacts based on a linear relationship between phase and elevation using the Toolbox for Reducing Atmospheric InSAR Noise (TRAIN) (Bekaert et al., 2015). We selected a region outside the geothermal field (Figure 5.3a, black box) to estimate the tropospheric contribution and removed them from the interferograms. The correlation between elevation and unwrapped phase was identified on many, but not on all interferograms (Figure 5.4). The correction was performed for each interferogram individually. 

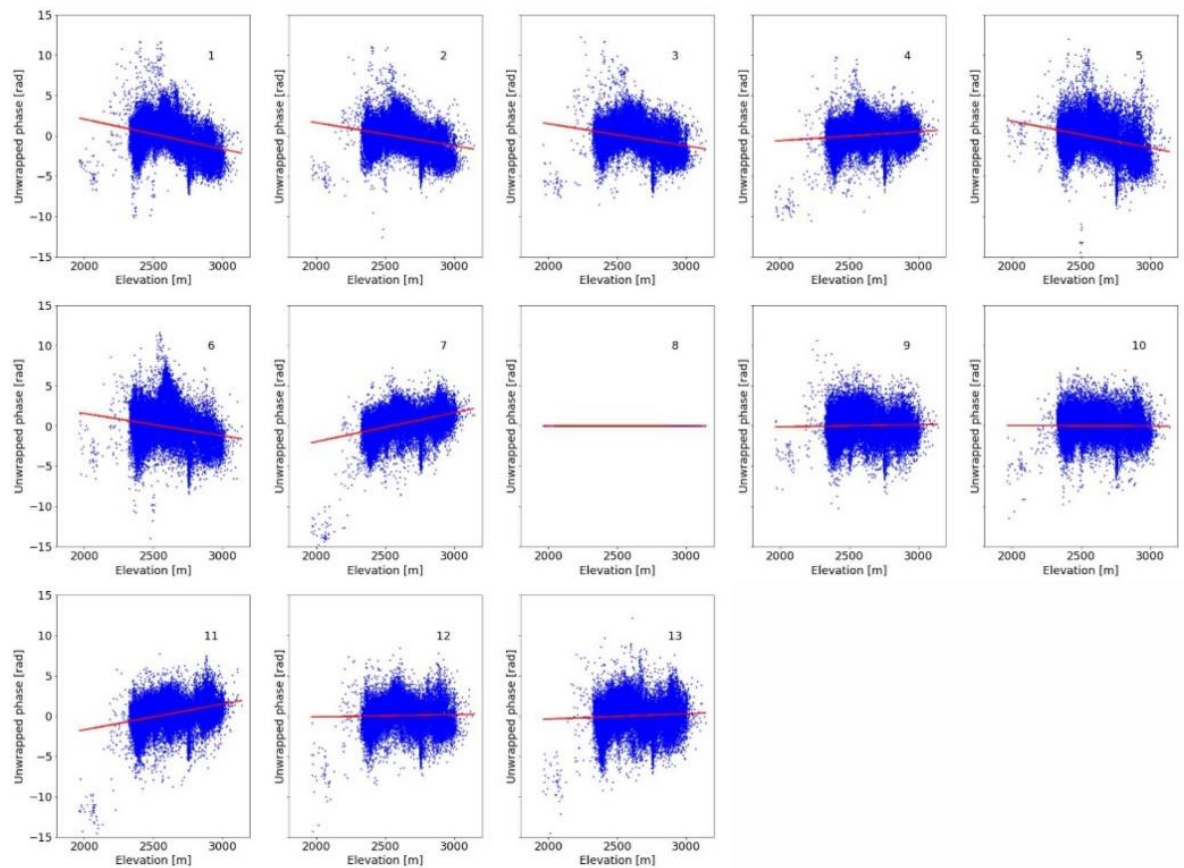

Figure 5.4: Relationship between elevation and unwrapped phase for all interferograms. Red lines represent the linear trend used for the corrections of the tropospheric phase delays. The numbering of the interferograms corresponds to the slave images listed in Table 5.1.
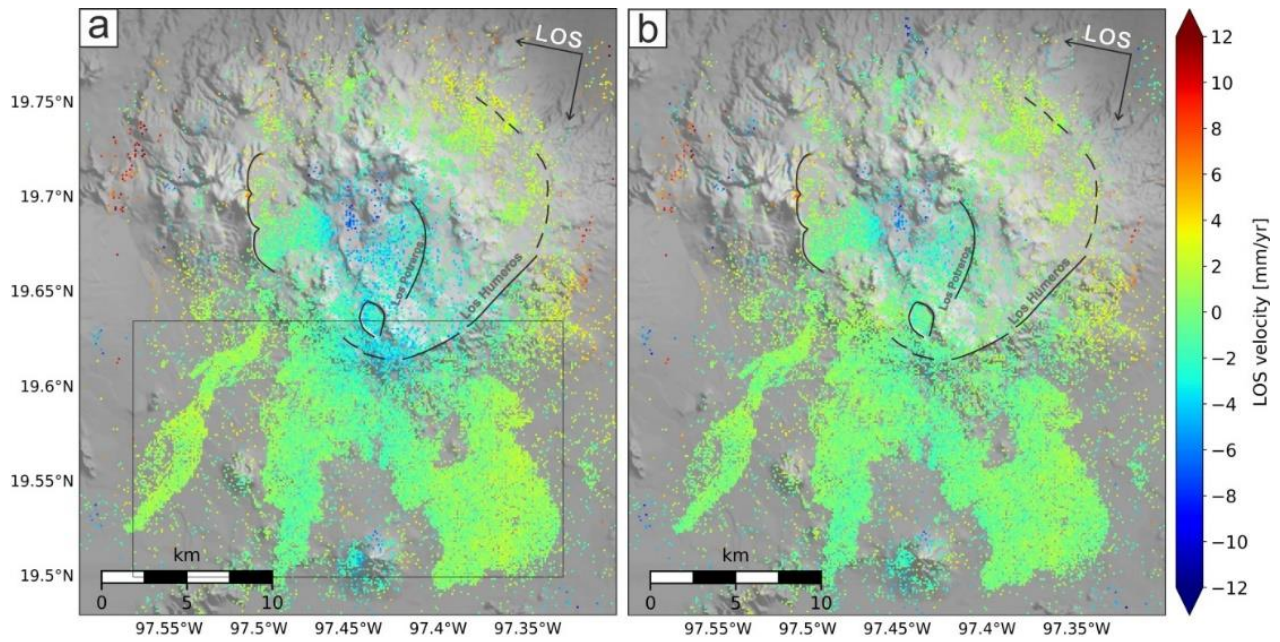

Figure 5.5: Deformation maps showing the mean velocities in the satellite line of sight (LOS) in $\mathrm{mm} /$ year (a) without tropospheric correction, (b) corrected for topography-related tropospheric phase delays. Movements are relative to the mean of the whole area. Negative values indicate movement away from the satellite ( subsidence) and positive values indicate movement towards the satellite ( uplift). The black rectangle in figure (a) highlights the region used to calibrate the tropospheric corrections. 
The mean LOS velocities over the Los Humeros geothermal field vary between -2 and $8 \mathrm{~mm} / \mathrm{year}$ (Figure 5.6), where negative values indicate movements away from the satellite. The largest subsidence was observed in the northeastern part of the field, east of the two injection wells operating during the period of the InSAR. The largest subsidence was observed in the northeastern part of the field, east of the two injection wells operating during the period of the processed InSAR. Further explanation of the estimated subsidence is addressed in the discussion part.

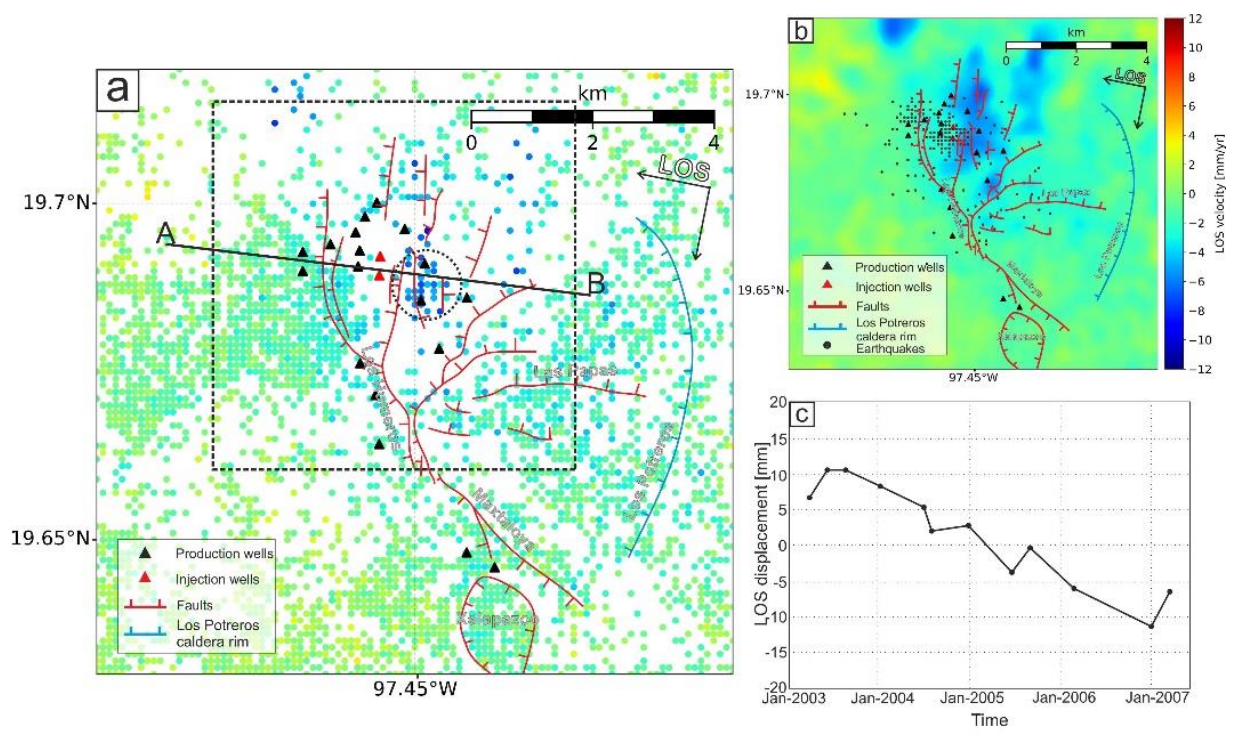

Figure 5.6: Mean (a) and interpolated (b) PS velocities in the LOS direction at the LHGF. Negative LOS velocities indicate movement away from the satellite ( subsidence) and positive values indicate movement towards the satellite ( uplift). The main structures after Norini et al. (2015) and CarrascoNúñez et al. (2017) and the wells operating during the period of the InSAR are shown in both figures. The black dashed rectangle marks the outline of the area selected for modeling. The epicenters of induced earthquakes between December 1997 to October 2008 after Urban and Lermo (2013) are plotted in (b). The time series of the mean LOS velocities from the area where the largest subsidence is observed (highlighted in (a) with dotted circle) is shown in (c).

\subsection{Subsidence modelling}

Subsurface extraction or injection processes induce movements on the ground surface with variable amplitude primary through poro-elastic coupling. Other factors such as subsurface induced pressures compared to the in situ stress field, depth of the reservoir, properties of the reservoir rock and over- and underburden medium can also influence the observed surface movement pattern. Volume changes in the subsurface due to, for instance, the extraction of fluids result in pressure reduction leading to compaction strain, which is a function of elastic strength or compaction coefficient. Furthermore, injection processes can generate thermo-poro-elastic or thermo-poro-elasto-plastic deformation due to the 
temperature difference between the injected fluid and reservoir. Since cold fluids are injected into the reservoir, temperature near the injection wells drops, leading to thermal contraction. Our models only account for expansion due to the injected volumes, resulting in uplift on the surface. Therefore, there might be a biased estimation of surface movements close to the injectors due to the effect of thermal contraction that we do not take into account.

We related subsidence with fluid extraction from the geothermal field through influence functions like fast forward models. Such models most commonly apply nuclei of strain solutions based on a center of compression (equivalent to an inflation point source), although these functions may show a mismatch with measurements (e.g. Segall, 1992). Fokker and Osinga (2018) have shown that the geometry of the reservoir and the elasticity contrast with its surroundings have a major influence on the shape of the subsidence bowl. Therefore, we tested different strain nuclei to construct the influence functions.

We compared the movements of the PS (for the period of one year) as observations to the responses of a number of solution scenarios. We used nuclei of strain solutions for point sources in an elastic half-space based on a center of compression (Mindlin, 1936) (model 1, model 3) and a tensile, horizontally oriented fault (opening in vertical direction) (Okada, 1992) (model 2, model 4). In case of the center of compression we used the equation after Segall (2010) to calculate the displacement vector at the surface. For a point source located at $\left(x_{0}, y_{0},-d\right)$ with the associated volume change $\Delta V$ the surface displacements $u_{x}, u_{y}, u_{z}$ are written as:

$$
\left(\begin{array}{l}
u_{x} \\
u_{y} \\
u_{z}
\end{array}\right)=\Delta V \frac{1-v}{\pi}\left(\begin{array}{c}
\left(x-x_{0}\right) / R^{3} \\
\left(y-y_{0}\right) / R^{3} \\
(-d) / R^{3}
\end{array}\right)=\frac{\Delta V}{R^{3}} \cdot \frac{1-v}{\pi}\left(\begin{array}{c}
x-x_{0} \\
y-y_{0} \\
-d
\end{array}\right)
$$

where $R=\sqrt{\left(x-x_{0}\right)^{2}+(y-y)^{2}+(-d)^{2}}$ is the distance from the source to the surface observation point and $v$ is the Poisson's ratio. Equation (5.1) assumes a relationship between pressure and volume change:

$$
\Delta V \approx \frac{\Delta P}{\mu} \pi \alpha^{3}
$$

where $\Delta P$ is the pressure change associated with the source, $\mu$ is the shear modulus, and $\alpha$ is the radius of the source $(\alpha \ll d$ i.e. point source).

The formula for the tensile sources is more complicated, we followed Okada (1985) to calculate the displacement vectors at the surface. The equation contains the same parameters as the one for the center of compression, including the coordinates describing the location of the source, the Poisson's ratio of the elastic half-space, and the volume change associated with the tensile dislocation. We constructed our forward models using the MATLAB-based dislocation models after Nikkhoo et al. (2016). In addition to the point sources, we employed these solutions for finite rectangular sources. Finite rectangular sources are equivalent to the integration of the displacements attributed to the point sources through a rectangle (Okada, 
1985).We tested two configurations for the modeling: first we performed the fitting along a section, then we modeled the northern part of the field area, where a clear subsidence signal was observed. We tested numerous cross-sections and found the most suitable having a sufficient number of PS (Figure 5.6a, Figure 5.8). We included PS data within $130 \mathrm{~m}$ distance from the section as target observations for the subsidence modeling, yielding 81 PS in total. We placed three sources according to the location of the production and the injection wells. We located the sources at the main extraction/injection depth of $1650 \mathrm{~m}$. The layout of the sources is illustrated in Figure 5.7. The easternmost and westernmost sources employ contraction due to production, while the middle one uses expansion as a result of injection. The centers of the sources are located $700 \mathrm{~m}$ and $800 \mathrm{~m}$ from each other.

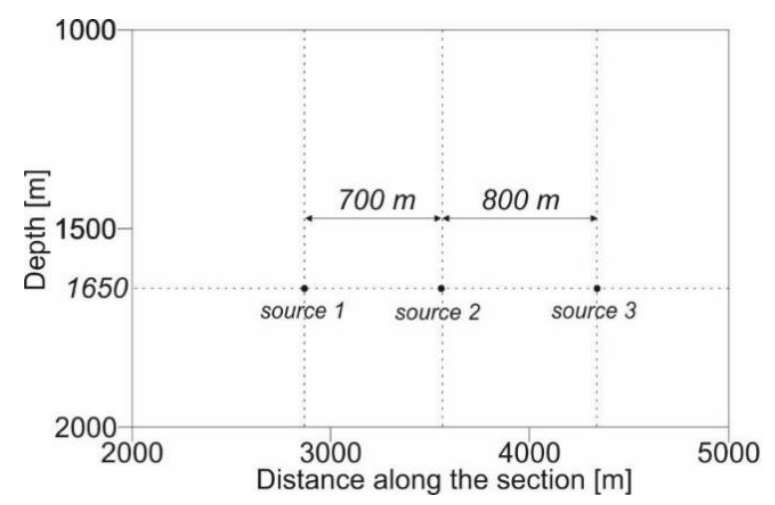

Figure 5.7: Illustration of the layout of the sources along the cross section in Figure 5.6a.

The layout of the modeled area covering the northern part of the geothermal field area is shown in Figure 5.9. Based on the locations of the wells and the subsidence pattern, we used 7 sources in total: 6 contraction sources and 1 expansion source placed between the two injectors (Figure 5.9b). We employed nuclei of strain solutions for inflation/deflation point sources (model 3) and for tensile point sources opening in vertical direction (model 4), equivalent to the sources used for model 1 and model 2, respectively.

We selected a Poisson's ratio of the elastic half-space to 0.265 based on laboratory experiments on rock samples from the field. Since we simplified the subsurface to an elastic half-space, the geological units with different elastic properties are not distinguished. Considering that the Poisson's ratios of the volcanic rocks at the LHGF are almost identical, $( \pm 0.002)$ we found this approximation acceptable.

The sources, be they a center of compression or a tensile source, result in an extended movement signal at the surface - with the distribution of movement due to a tensile source more concentrated above it. As a result, patterns in the source, like a steep gradient in the pressure, do not propagate to the same pattern at the surface but are smoothed. Thus, as sources at different positions influence the surface movement data, inverse modelling or simultaneous parameter estimation is required. 
We fitted the influence functions to the PS observations using a weighted least-squares approach. The fitting parameters were the volume changes attributed to the sources. We minimized the weighted sum of the residuals using the standard deviations of the LOS velocity estimates to construct the weighting factors. The best fitting volume changes for the different models are listed in Table 5.2. We report the weighted RMS of each model to represent the goodness of the fit. In case of the inflation/deflation sources along the section (model 1), the volume change of the westernmost source was negligible. For the tensile sources along the section (model 2) the volume changes were in the same order of magnitude. The total amount of volume changes attributed to the 7 sources are approximately two times larger for model 3 than for model 4 . The RMS values in case of all models are below 1 (Table 5.2), suggesting that the fits are reasonably good.

\begin{tabular}{|c|c|c|c|c|c|c|c|c|}
\hline \multicolumn{9}{|c|}{ Model results along the cross-section (including 81 PS observations) } \\
\hline & Description & $\begin{array}{c}\text { Depth } \\
{[\mathrm{m}]}\end{array}$ & \multicolumn{2}{|c|}{$\begin{array}{c}\text { Volume } \\
\text { change }\left[10^{4}\right. \\
\mathrm{m}^{3} \text { ] attributed } \\
\text { to source } 1\end{array}$} & $\begin{array}{c}\text { Volume } \\
\text { change }\left[10^{4}\right. \\
\left.\mathrm{m}^{3}\right] \text { attributed } \\
\text { to source } 2\end{array}$ & \multicolumn{2}{|c|}{$\begin{array}{c}\text { Volume } \\
\text { change }\left[10^{4}\right. \\
\left.\mathrm{m}^{3}\right] \text { attributed } \\
\text { to source } 3\end{array}$} & RMS \\
\hline Model 1 & $\begin{array}{c}\text { Inflation/ } \\
\text { deflation } \\
\text { point sources }\end{array}$ & 1650 & \multicolumn{2}{|c|}{0.0} & 2.6 & \multicolumn{2}{|r|}{-5.8} & 0.64 \\
\hline Model 2 & $\begin{array}{l}\text { Tensile point } \\
\text { sources }\end{array}$ & 1650 & \multicolumn{2}{|c|}{-2.3} & 1.2 & & -4.3 & 0.59 \\
\hline \multicolumn{9}{|c|}{ Areal model results for the northern part of the LHGF (including 1337 PS observations) } \\
\hline & \multicolumn{2}{|c|}{ Description } & \multicolumn{2}{|c|}{ Depth $[\mathrm{m}]$} & \multicolumn{2}{|c|}{$\begin{array}{c}\text { Total volume } \\
\text { change attributed } \\
\text { to the } 7 \text { sources } \\
{\left[10^{4} \mathrm{~m}^{3}\right]}\end{array}$} & \multicolumn{2}{|c|}{ RMS } \\
\hline Model 3 & \multicolumn{2}{|c|}{$\begin{array}{l}\text { Inflation/deflatio } \\
\mathrm{n} \text { point sources }\end{array}$} & \multicolumn{2}{|c|}{1650} & \multicolumn{2}{|l|}{-10.0} & \multicolumn{2}{|c|}{0.74} \\
\hline Model 4 & \multicolumn{2}{|c|}{$\begin{array}{l}\text { Tensile point } \\
\text { sources }\end{array}$} & \multicolumn{2}{|c|}{1650} & \multicolumn{2}{|l|}{-5.5} & \multicolumn{2}{|c|}{0.83} \\
\hline \multicolumn{9}{|c|}{$\begin{array}{c}\text { Average yearly produced and injected volumes during the period of the InSAR based on well data } \\
\text { provided by CFE }\end{array}$} \\
\hline \multicolumn{4}{|c|}{$\begin{array}{l}\text { Total produced volume for one year period }\left[10^{4}\right. \\
\left.\qquad \mathrm{m}^{3}\right]\end{array}$} & \multicolumn{5}{|c|}{$\begin{array}{l}\text { Total injected volume for one year period }\left[10^{4}\right. \\
\left.\qquad \mathrm{m}^{3}\right]\end{array}$} \\
\hline \multicolumn{4}{|c|}{$\sim 500$} & \multicolumn{5}{|c|}{$\sim 50$} \\
\hline
\end{tabular}

Table 5.2: Description of the models, the best fitting volume changes attributed to the sources, and the average yearly produced and injected volumes. Note that the volume changes are reported for the period of one year. 


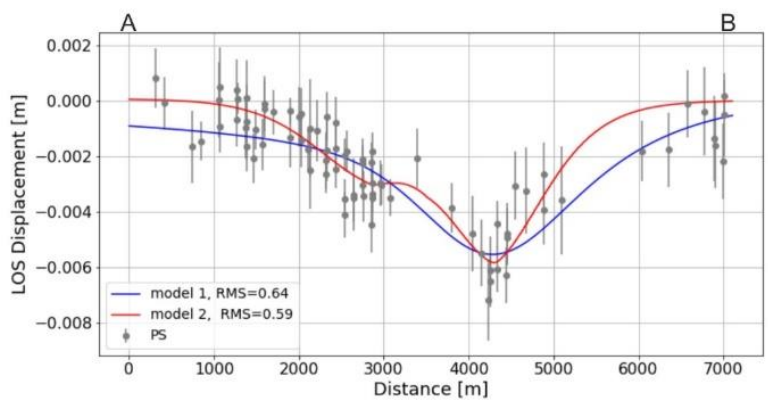

Figure 5.8: The best fitting influence functions derived from the nuclei of strain solutions along the cross section. For the trace of the section see Figure 5.6a. Model 1: inflation point sources, model 2: vertical tensile point sources. The PS observations and their standard deviations marked by error bars are plotted in both figures. Note that the LOS displacements are reported for the period of one year.

Figure 5.8 shows the responses derived from the strain nuclei placed at $1650 \mathrm{~m}$ depth along the cross section. A good fit was achieved by the tensile point source (model 2). The misfits are a bit larger for the inflation sources (model 1), the influence function is wider and also slightly less deep. Furthermore, the strength of the westernmost source is negligible in contrast with the production data. We only show the models using point sources because our modeling results of the point and rectangular sources are almost identical. The error estimates around the InSAR observations corresponds to the standard deviation of the mean velocity estimates. The standard deviation from the mean velocity was estimated from the average velocity with respect to the mean of all pixels without a selection of a reference point. The reasoning behind not selecting a reference point is because we have no external information on which area is eventually stable. The maximum standard deviation estimated in our area of interest is $\sim 1.5 \mathrm{~mm} /$ year. 

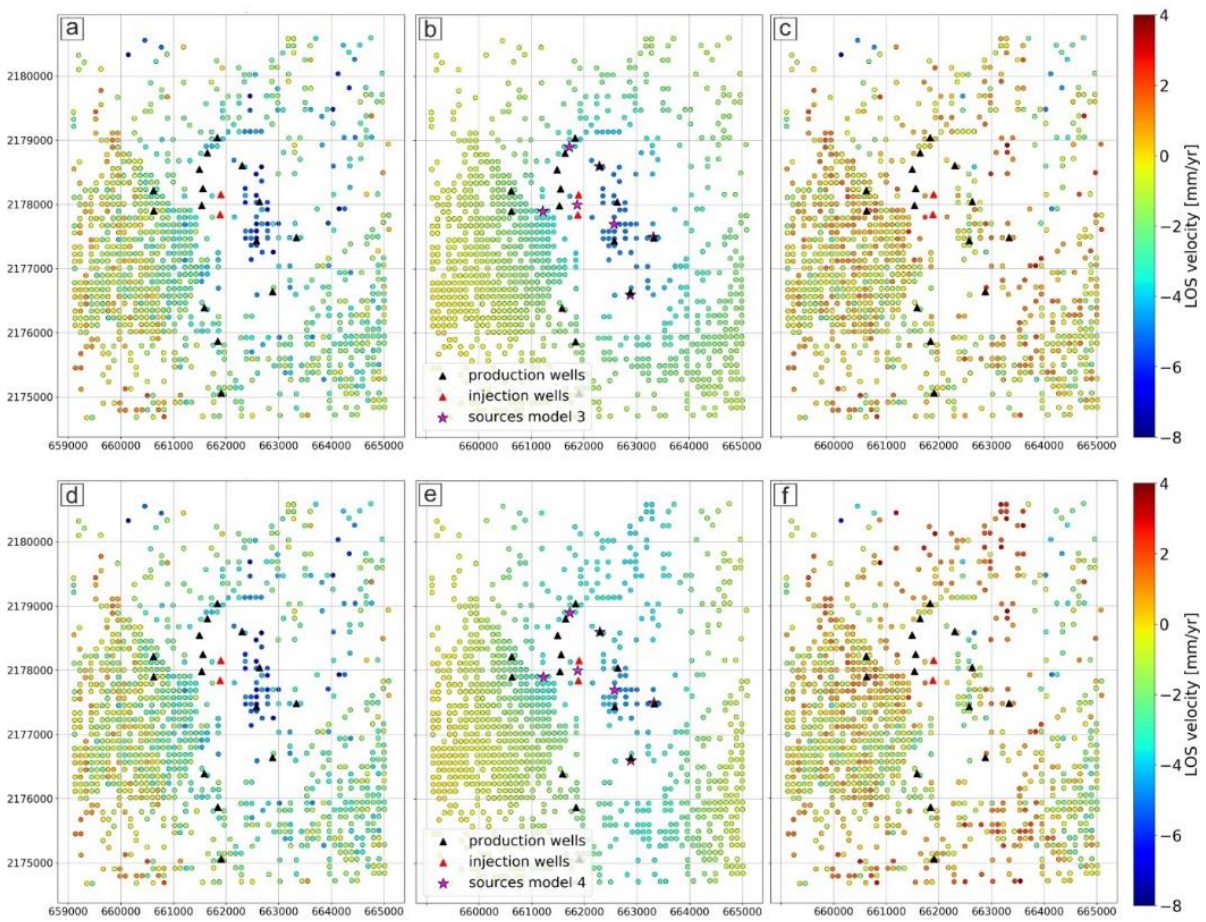

Figure 5.9: Observed (a, d), modeled (b, e), and residual (c, f) movements in the LOS direction in $\mathrm{mm} / \mathrm{yr}$. The coordinates are in UTM zone $14 \mathrm{~N}$. The outline of the modeled area is shown in Figure 5.6a.

Figure 5.9 illustrates the modeling results of the northern part of the field. In contrast with the results through the section, the inflation point sources (model 3) are fitting better than the vertical tensile sources (model 4). The extent and geometry of the subsiding area only slightly differ (Figure 5.9b and 5.9e).

\subsection{Discussion and conclusions}

We processed $13 \mathrm{C}$-band radar images acquired by the ESA's Envisat satellite between April 2003 - March 2007, to monitor surface movements at the LHGF. The geothermal field is located at high altitudes inside the Los Humeros caldera. Therefore, it was necessary to perform corrections for artifacts due to topography-related phase delays on the interferograms.

The PS-InSAR analysis shows that the LHGF is characterized by up to $8 \mathrm{~mm} / \mathrm{year}$ of subsidence during the period of the InSAR monitoring (Figure 5.6). We attribute this deformation to field operations given that the estimated maximum subsidence is located around the production wells. Given the concentration of deformation around the wells, the estimated source depth and the short wavelength deformation pattern, we think that the estimated deformation is only due to geothermal production and not volcano-tectonic related. 
The area of maximum subsidence is relatively small, located at the northern part of the geothermal field. This area appears to be isolated from the injection wells that were operational during the period of the InSAR analysis. This isolation is supported by the epicenters of the induced earthquakes (Urban and Lermo, 2013), most of which are located west from the injectors, suggesting that the majority of the injected fluids are directed westwards (Figure 5.6b). No clear subsidence signal is observed in the southern and western part of the field, although large numbers of production wells have been drilled in these areas. This indicates a significant pressure support that might originate from deep recharge and partly from the injected volumes. Pressures cannot be supported only by the injectors, since the injected volumes are about ten times smaller than the produced volumes. Additionally, due to the low PS density of the northwestern part of the geothermal field and the lack of pressure measurements, we cannot be sure about the contribution of the injectors to the pressure support. Pressure drop in the reservoir is most likely restricted below the clearly subsiding area. As a result, the pressure distribution does not deviate much from the virgin one. As regular pressure measurements from the wells are not available to support these findings, this conclusion demonstrates the versatility of the use of surface movement data combined with inversion.

The procedure that we have employed propagates the measured surface movement directly to the driving parameters, i.e. the pressure magnitude and distribution. As such, it bypasses intermediate results like patterns of, e.g., a steeper edge of the subsidence bowl over a sealing fault. Such patterns would indeed be very hard to identify without prior knowledge about the pressure distribution, due to the combination of the small magnitude of the signals and the smooth signature at the surface of a steep pressure gradient at depth.

We modeled the subsidence using influence functions based on different nuclei of strain solutions. Our model results, combined with the deformation estimation from InSAR as observations along a cross-section, show that the vertical tensile point sources having deeper and steeper responses fit better with the observed subsidence pattern. However, when the entire field was used, the inflation point sources performed slightly better. Atefi-Monfared and Rothenburg (2011) suggested that Okada's solution for expansion/contraction in the vertical direction is more applicable to model reservoir deformations, as they are laterally more extensive. Fokker and Osinga (2018) extended this conclusion with numerical experiments, showing that the shape of the influence function depends on the geometry of the reservoir and on the elasticity contrast between the reservoir and its surroundings. Considering that the Los Humeros reservoir is laterally extensive and there is only a slight difference between the fitted responses of the nuclei of strain solutions, our results are inconclusive on this issue.

The corresponding rock compaction volume from the inversion exercise is of the order of $5-10 \times 10^{4} \mathrm{~m}^{3}$ over the period of one year. This is at least $\sim 50$ times smaller than the net production volume during the period of the InSAR of about $4.5 \times 10^{6} \mathrm{~m}^{3} /$ year. This ratio is much larger than the corresponding ratio of many other geothermal fields. For Cerro Pietro, for instance, the produced volume is only about 3 times larger than the modeled subsurface 
volume change (Samsonov et al., 2017). Of course, the extracted volume cannot be directly associated with the volume change within the reservoir: the reservoir compressibility, in combination with the pressure reduction of the reservoir, results in a smaller subsurface volume change than the extracted volume. For a closed system, the ratio of bulk moduli of the rock and the water is of the order of the ratio of the produced water volume and the rock compaction volume. Since that would imply an unrealistically high rock bulk modulus of hundreds of GPa, we conclude that there must be pressure support of the porous medium originating most likely from recharge. Recharge supported by meteoric water may occur locally in the northern part of the field, but it is limited to $1-10 \%$ of the total produced fluids (Pinti et al., 2017). Minor subsidence can also be identified on the InSAR outside the production area in the north that may be attributed to these small recharge zones of the production area. Regional recharge outside the study area through deep structures may contribute to the recovery of the extracted fluid volume.

The InSAR data together with the modeling results suggest two reservoir characteristics. First, they indicate that the pressure within the reservoir is well supported suggesting that recharge is taking place. Second, they imply that the Los Humeros geothermal field is controlled by sealing faults that separate the reservoir into several blocks. However, additional subsurface data, for instance regular pressure measurements from the wells, are needed to improve our modelling results. This would also allow us to study fault sealing behaviour that controls reservoir compartmentalization. Still, our results make clear that based on the subsidence pattern we have obtained a better understanding of the pressure conditions within the reservoir and potential local recharge zones. This will facilitate better quality decisions on well planning and operations. Additionally, the surface deformation pattern can contribute to our understanding on superhot geothermal systems, that are of high potential for geothermal energy development. 


\section{Source parameters of the 8 February 2016, $M w=4.2$ Los Humeros earthquake by the inversion of InSAR-based ground deformation ${ }^{5}$}

${ }^{5}$ This chapter is based on Békési, E., Fokker, P. A., Martins, J. E., Norini, G., and van Wees, J.D. (2021), Source parameters of the 8 February 2016, Mw= 4.2 Los Humeros earthquake by the inversion of InSAR-based ground deformation. Geothermics, 94, 102133. 2019. 


\subsection{Introduction}

Superhot Geothermal Systems (SGHS) with their high enthalpies are important geothermal reservoirs. These systems, with temperatures often exceeding $350^{\circ} \mathrm{C}$, are frequently marked by recent or even active tectonic or volcanotectonic deformations. This results in complex reservoirs in which fault structures may act as prolific permeability pathways for geothermal fluids. Conversely, exploitation of such fields may yield considerable risks for induced seismicity. Indeed, seismic events can cause significant damage in the vicinity of the geothermal sites and may even lead to the termination of production (e.g. Deichmann and Giardini, 2009; Kim et al., 2018). The understanding of fault geometry and behavior is therefore crucial for a safe and sustainable exploitation of these important resources.

Synthetic Aperture Radar Interferometry (InSAR) can be used to estimate ground movements and the increased temporal resolution of recent satellite missions bolsters its deployment as a cost-effective method for long-term monitoring of SHGS. Previous studies based on InSAR time series analysis, for instance at the Reykjanes Geothermal Field, Iceland (Keiding et al., 2010; Receveur et al., 2018) and the Los Humeros Geothermal Field, Mexico (LHGF, Békési et al., 2019a) demonstrate the added value of surface deformation studies to understand reservoir dynamics and induced seismicity. The interpretation of ground deformation together with other geological and geophysical measurements can contribute to understand the complex behavior of fault structures controlling a geothermal field and provide valuable information for geothermal exploitation. 


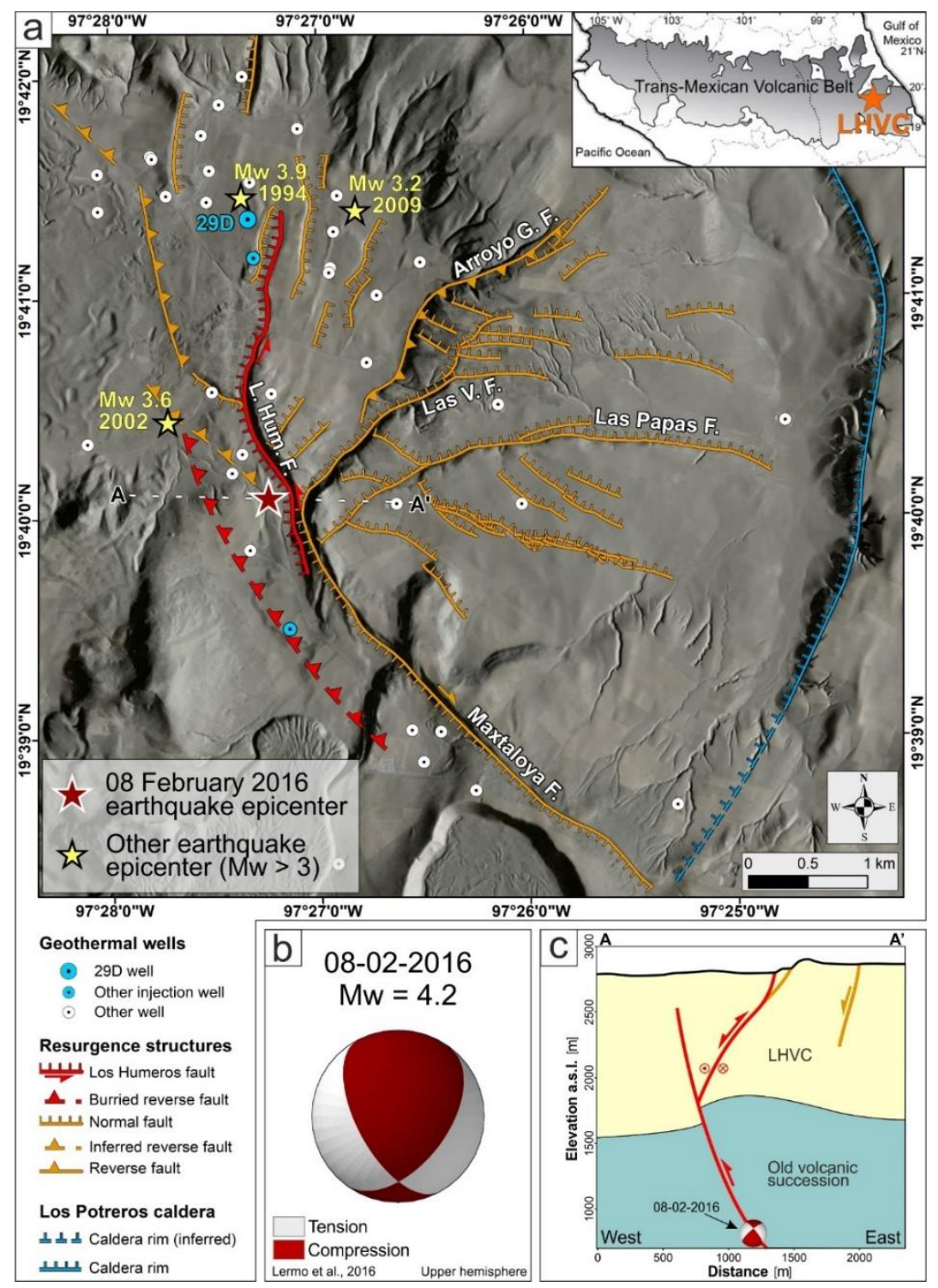

Figure 6.1: (a) Overview of the Los Humeros Volcanic Complex (LHVC) situated in the Eastern TransMexican Volcanic Belt, modified after Norini et al. (2019). The Los Potreros caldera rim (blue line), fault structures (orange and red lines), the epicenters of the most significant ( $\mathrm{Mw}>3.0)$ earthquakes (red and yellow stars, (Lermo Samaniego et al., 2016) and the production and injection wells of the Los Humeros Geothermal Field are presented. (b) The focal mechanism solution of the 08 February 2016 earthquake (from Lermo Samaniego et al., 2016). (c) W-E cross-section along the location of the 8 February 2016 earthquake showing the geometry and kinematics of the fault structures based on Norini et al. (2019) and this study. The trace of the section is shown in (a). 
We have employed radar interferometry using Sentinel-1 images to constrain fault geometry and kinematics at the Los Humeros Geothermal Field in Mexico (LHGF, Figure 6.1a). We have studied the coseismic deformation due to the $\mathrm{Mw}=4.2$ earthquake on February 8,2016 . The epicenter of this event had been located along the trace of the Los Humeros fault (Figures 6.1a,b and 6.2) (Lermo Samaniego et al., 2016), which had previously been interpreted as a normal fault, as indicated by the topography and displacements of geological units (Figure 6.1c). However, surface motions mapping the coseimic deformation of the and the focal mechanism solution based on seismological data indicated reverse movement with a left-lateral component (Figure 6.1b). Initial results showed that the proposed mechanism of the moment tensor solution does not resolve the measured coseismic surface deformation pattern (Békési et al., 2019b). In this study, we have revised our earlier elastic dislocation models by inverting the InSAR-derived surface movements with constraints from existing geological and geophysical models. Our findings for the source parameter of the earthquake have been corroborated by an InSAR time-series analysis, indicating prolonged surface motions after the event, and an investigation of the underlying processes.

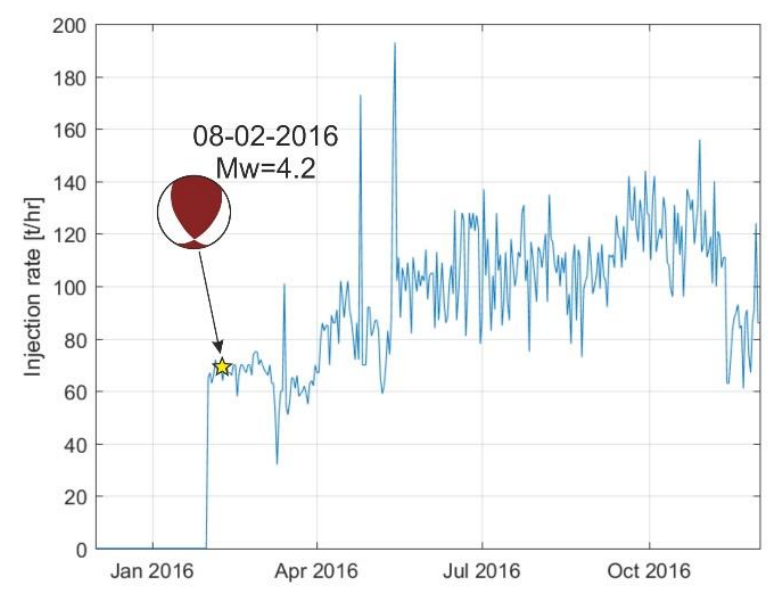

Figure 6.2: Injection rates in the H-29D well during 2016 (courtesy of the Comision Federal de Electricidad-CFE). The 8 February, 2016 earthquake occurred seven days after the onset of injection.

\subsection{The Los Humeros Geothermal Field}

The LHGF has been exploited since 1990 by the national Mexican electrical company (Comisión Federal de Electricidad (CFE)). 25 wells are presently producing a total of $6 \mathrm{Mt}$ of steam yearly, with an installed capacity of ca. $95 \mathrm{MW}$ of electric power (Gutiérrez-Negrín, 2019) (Figure 6.1a). Further exploitation of the geothermal field is being planned, in particular in the area northwest of the current production zone, where temperatures locally reach $400{ }^{\circ} \mathrm{C}$ at $2.5 \mathrm{~km}$ depth (Gutiérrez-Negrín, 2019). 
The geothermal field is situated within the Los Humeros Volcanic Complex (LHVC) in the Eastern sector of the Trans-Mexican Volcanic Belt, Mexico. It consists of two nested calderas (Figure 6.1). The Los Humeros Caldera was formed $160 \mathrm{ka}$ ago, with the younger (70 ka) Los Potreros Caldera nested in the western part, hosting the geothermal field (e.g. Carrasco-Núñez et al., 2018). The geothermal reservoir is built up by 10.5-1.5 Ma years old pre-caldera fractured andesites with an average depth of $1.5 \mathrm{~km}$ (Old Volcanic Succession unit) (Figure 6.1c). The cap rock of the hydrothermal system is mostly composed of welded ignimbrites and post-calderas volcanic deposits (rhyodacite, andesite, and basaltic andesite) of the LHVC unit (Figure 6.1c) (Norini et al., 2019; Norini et al., 2015). The LHGF is controlled by the recent and still active fault system in the central part of the Los Potreros caldera (Figure 1, Norini et al., 2015) by providing permeability pathways for geothermal fluids. These faults are considered to be resurgent structures that might be related to shallow magmatic intrusions (Norini et al., 2019).

The topographic expression of the resurgence fault system is represented by rectilinear and curvilinear prominent fault scarps displacing by tens of meters Upper-PleistoceneHolocene volcanic deposits in the center of the Los Potreros caldera (Figure 6.1a-c). The main fault swarm, represented by the Maxtaloya fault, the Los Humeros fault and some subparallel fault strands, is slightly curvilinear and runs NNW-SSE for $\approx 8 \mathrm{~km}$ (Figure 6.1). Multiple N-S, NE-SW and E-W curvilinear splays depart from the main NNW-SSE fault swarm, depicting a complex deformation pattern (e.g. Arroyo Grande, Las Viboras and Las Papas faults, Figure 6.1a) (Calcagno et al., 2018; Norini et al., 2019). All these faults invariably displace Holocene pyroclastic deposits, with vertical displacement rates of up to $10 \mathrm{~mm} / \mathrm{yr}$ (Norini et al., 2019; Norini et al., 2015).

Reverse and normal displacements along these faults have been interpreted as the expression of changing stress field in the subsurface, as also documented by well logs and geophysical data (Carrasco-Núñez et al., 2017; Corbo-Camargo et al., 2020; Lermo et al., 2008; Lermo Samaniego et al., 2016; Lorenzo-Pulido, 2008; Norini et al., 2019; Norini et al., 2015; Rocha et al., 2010). The most probable origin of the local stress field has been suggested to be the pressurization of the shallow magmatic and/or hydrothermal system of the caldera complex (Montanari et al., 2017; Norini et al., 2019; Norini et al., 2015).

The Los Humeros fault exhibits a prominent fault scarp with a maximum elevation of 70$80 \mathrm{~m}$ above the caldera floor, showing a westward dip and dominant dip-slip normal displacement of a hydrothermally altered pumice fall deposit and underlying lava flows with a minor component of left-lateral motion (Norini et al., 2019; Norini et al., 2015). Partly buried, eastward dipping, NNW-SSE reverse faults have also been identified $0.5-1 \mathrm{~km}$ to the west of the Los Humeros fault scarp by means of fieldwork, well logs, magnetotelluric sounding and seismic data (Corbo-Camargo et al., 2020; Lermo Samaniego et al., 2016; Norini et al., 2019) (Figure 6.1a-c). These data indicated that the Los Humeros and the main reverse fault planes merge at about $1 \mathrm{~km}$ depth (Bonini et al., 2021; Carrasco-Núñez et al., 2017; Corbo-Camargo et al., 2020; Norini et al., 2019) (Figure 6.1c), although the subsurface 
geometry of these structures is rather uncertain, due to the limitations of the geological and geophysical datasets.

Changes in pressure of the shallow magmatic/hydrothermal system may have induced cyclic inversion of the dip-slip resurgence faults (cycling shifting between uplift and subsidence) (Norini et al., 2019). Also, the operation of the LHGF, with extraction and injection of fluids in the crust, may have induced ground motions superimposed on the longterm geological deformation signal (e.g. Békési et al., 2019a). Indeed, a shift between normal and reverse movements along the resurgence faults may have been induced in the shallow subsurface (down to about $1500 \mathrm{~m}$ of depth, i.e. the mean production depth, GutiérrezNegrín, 2019) (Figure 6.1c) by changing pressure in the geothermal reservoir due to the natural evolution the hydrothermal/magmatic system and the extraction and injection of fluids, as discussed in the next sections.

\subsection{InSAR processing}

We used SAR images from ESA's Sentinel-1A and Sentinel-1B satellites. To map the coseismic deformation due to the February 8, 2016 earthquake, we used one ascending and one descending image pair (with acquisition dates of 29 January 2016 - 10 February 2016 and 7 February 2016 - 19 February 2016, respectively). We processed the individual interferograms using GAMMA software (Werner et al., 2000). We applied a 30-m resolution Shuttle Radar Topography Mission Digital Elevation Model (USGS 1 ARC-second SRTM DEM, https://doi.org/10.5066/F7DF6PQS) to remove the topographic phase and obtain the differential interferograms. The interferogram pairs spanning the coseismic deformation showed unwrapping errors along the surface rupture occurred due to the lack of coherence; therefore, we masked the surface rupture area the interferograms for further modeling and interpretation (white area in the center of the fringe pattern Figure $6.3 \mathrm{a}, \mathrm{d}$ ). Other InSAR data with larger wavelength (such as ALOS-2 observations) were also considered to overcome the decorrelation of Sentinel-1 interferograms, but there were no acquisitions mapping the studied coseismic deformation.

We further performed a time-series analysis of 20 Sentinel-1 images of descending track after the coseismic deformation, between 19 February 2016 and 16 May 2019. For the time series analysis we were only interested in the long-term deformation signal, therefore we picked Sentinel-1 images acquired on descending orbit every two months, making sure to avoid the co-seismic displacement due to the 8 Feb 2016 seismic event. We selected a single master image acquired on 13 February 2017 based on the minimization of the temporal and perpendicular baselines. We followed the Persistent Scatterer (PS) method using the MATLAB-based workflow of STAMPS (Hooper et al., 2012). PS candidates were selected based on their phase characteristics, and the number of PS were reduced in an iterative process through the estimation of phase noise. The wrapped phase of the final PS selection was corrected for spatially uncorrelated DEM error. After phase unwrapping, the spatially correlated error terms were estimated and removed from the interferograms (Hooper et al., 2007). The time series displacements were finally obtained from the corrected interferograms. 


\subsection{Models for the coseismic deformation}

\subsubsection{Methodology}

The ground deformation due to the 8 February, 2016 earthquake suggests movements along a single rupture (Figure 6.3a, d). The ascending interferogram shows movements towards the satellite line of sight (LOS) at both sides of the fault, up to $42 \mathrm{~mm}$ and $87 \mathrm{~mm}$ in the eastern and western side of the rupture, respectively (Figure 6.3a). The descending interferogram shows movements away from the satellite in the eastern block, with a maximum displacement of $-105 \mathrm{~mm}$, and movements of the western block towards the satellite with up to $40 \mathrm{~mm}$ (Figure 6.2d). The focal mechanism solution based on seismological data by Lermo Samaniego et al. (2016) indicated reverse movement with a left-lateral component at $1900 \mathrm{~m}$ depth, but the proposed mechanism does not resolve the measured coseismic surface deformation pattern (Békési et al., 2019b). We performed a Bayesian inversion with a significantly shallower single fault model and uniform slip (Model 1) on a rectangle (Okada, 1985) to reveal the source parameters of the seismic event. Since the volcanic structures of the area commonly have a curved geometry (e.g. Carrasco-Núñez et al., 2018), we also tested fault models with varying dip. We approximated the curved geometry with a segmented fault based on two rectangles with uniform slip in an elastic halfspace (Model 2, Model 3).

To find the source parameters and uncertainties of the fault, we inverted the Sentinel-1 ascending and descending interferograms simultaneously using the Bayesian approach implemented in the Geodetic Bayesian Inversion Software (GBIS, Bagnardi and Hooper (2018)). The algorithm adopts the Markov Chain Monte Carlo method with automatic step size selection using the Metropolis-Hastings algorithm, to find the posterior probability density functions (PDFs) of the model parameters. Prior to the inversion, the InSAR data were subsampled using an adoptive quadtree sampling algorithm (Bagnardi and Hooper, 2018; Decriem et al., 2010), aiming to reduce the computational costs. Data errors required for the Bayesian inversion were simulated using an exponential function with nugget, fitted to the experimental semi-variograms calculated from the data (Bagnardi and Hooper, 2018). In each inversion procedure we performed, the PDFs were sampled through $10^{6}$ iterations.

In case of the single-fault inversion, we used the already existing rectangular dislocation model with uniform slip (Okada, 1985) in GBIS. The 9 parameters in case of the single fault model include the location ( $\mathrm{X}$ and $\mathrm{Y}$ coordinates and depth of the midpoint of the top edge), length, width, strike, dip, strike-slip, and dip-slip of the dislocation (Table 6.1). Subsequently, to approximate a curved fault geometry, we added a new forward model in GBIS. The model for the segmented fault consists of two rectangular dislocations connected to each other at depth, with the upper edge of the lower dislocation connected to the lower edge of the upper dislocation. In order to ensure the connection between the dislocations, we assumed that the two active fault segments have identical length and strike. We inverted the model with identical and different slip values for the upper and lower dislocations (Model 2 and Model 3, Table 6.1). Under these assumptions we had 11 model parameters with the identical and 13 model parameters with different dip-slip and strike-slip at the two segments. The model 
parameters include the location (X and $\mathrm{Y}$ coordinates and depth of the midpoint of the top edge), length, width, strike, dip, strike-slip, and dip-slip of the upper dislocation and the width, dip, strike-slip, and dip-slip of the lower dislocation.

\begin{tabular}{|c|c|c|c|c|c|c|}
\hline & & & $\begin{array}{l}\text { This } \\
\text { study - } \\
\text { single } \\
\text { fault } \\
\text { (Model } \\
1 \text { ) }\end{array}$ & $\begin{array}{c}\text { This study } \\
- \\
\text { segmented } \\
\text { fault with } \\
\text { identical } \\
\text { slip (Model } \\
\text { 2) }\end{array}$ & $\begin{array}{l}\text { This study - } \\
\text { segmented } \\
\text { fault with } \\
\text { independent } \\
\text { slip } \\
\text { (Model 3) }\end{array}$ & $\begin{array}{l}\text { Lermo et al. - } \\
\text { seismological } \\
\text { model }\end{array}$ \\
\hline & Lower & Upper & $\begin{array}{l}\text { Optimal } \\
(2.5 \%- \\
97.5 \%)\end{array}$ & $\begin{array}{l}\text { Optimal } \\
(2.5 \%- \\
97.5 \%)\end{array}$ & $\begin{array}{l}\text { Optimal } \\
(2.5 \%- \\
97.5 \%)\end{array}$ & \\
\hline $\begin{array}{c}\mathrm{X} \\
\text { coordinate* } \\
{[\mathrm{m}]}\end{array}$ & -4600 & -4400 & $\begin{array}{l}-4506 \\
(-4520- \\
-4496)\end{array}$ & $\begin{array}{c}-4497 \\
(-4512-- \\
4480)\end{array}$ & $\begin{array}{c}-4460 \\
(-4489-- \\
4453)\end{array}$ & \\
\hline $\begin{array}{c}\mathrm{Y} \\
\text { coordinate* } \\
{[\mathrm{m}]}\end{array}$ & -1050 & -750 & $\begin{array}{c}-855 \\
(-864-- \\
843)\end{array}$ & $\begin{array}{c}-860 \\
(-874-- \\
849)\end{array}$ & $\begin{array}{c}-846 \\
(-856--834)\end{array}$ & \\
\hline Length [m] & 1000 & 2000 & $\begin{array}{c}1506 \\
(1485- \\
1525)\end{array}$ & $\begin{array}{c}1526 \\
(1502- \\
1551)\end{array}$ & $\begin{array}{c}1578 \\
(1539-1587)\end{array}$ & \\
\hline Width $_{1}[\mathrm{~m}]$ & 200 & 2000 & $\begin{array}{c}1104 \\
(1063- \\
1145)\end{array}$ & $\begin{array}{c}208 \\
(201-311)\end{array}$ & $\begin{array}{c}480 \\
(409-540)\end{array}$ & \\
\hline Depth* [m] & 0 & 500 & $\begin{array}{c}0.3 \\
(0.2- \\
10.6)\end{array}$ & $\begin{array}{c}17 \\
(3-31)\end{array}$ & $\begin{array}{c}0.1 \\
(0-4)\end{array}$ & $1900 \pm 300(?)$ \\
\hline $\operatorname{Dip}_{1} * *\left[{ }^{\circ}\right]$ & -85 & -45 & $\begin{array}{c}-64 \\
(-65-- \\
63)\end{array}$ & $\begin{array}{c}-57 \\
(-62--52)\end{array}$ & $\begin{array}{c}-58 \\
(-62--57)\end{array}$ & 61 \\
\hline $\begin{array}{l}\text { Strike-slip }_{1} \\
{[\mathrm{~m}]}\end{array}$ & -0.5 & 0.0 & $\begin{array}{c}-0.059 \\
(-0.076- \\
-0.047)\end{array}$ & $\begin{array}{c}-0.048 \\
(-0.065-- \\
0.033)\end{array}$ & $\begin{array}{c}-0.0 \\
(-0.009--0.0)\end{array}$ & \\
\hline Dip-slip $1[\mathrm{~m}]$ & -1.0 & 0.0 & $\begin{array}{c}-0.29 \\
(-0.295- \\
-0.28)\end{array}$ & $\begin{array}{c}-0.29 \\
(-0.3-- \\
0.28)\end{array}$ & $\begin{array}{c}-0.226 \\
(-0.255-- \\
0.22)\end{array}$ & \\
\hline Strike ${ }^{* *}\left[{ }^{\circ}\right]$ & 330 & 350 & $\begin{array}{c}340.8 \\
(340.1- \\
341.5)\end{array}$ & $\begin{array}{l}340.7 \\
(340- \\
341.5)\end{array}$ & $\begin{array}{c}340.4 \\
(339.7- \\
341.1)\end{array}$ & 169 \\
\hline
\end{tabular}




\begin{tabular}{|c|c|c|c|c|c|c|c|}
\hline Width $_{2}[\mathrm{~m}]$ & 200 & 2000 & & $\begin{array}{c}852 \\
(751-895)\end{array}$ & \multicolumn{2}{|c|}{$\begin{array}{c}442 \\
(348-580)\end{array}$} & \\
\hline $\operatorname{Dip}_{2}\left[{ }^{\circ}\right]$ & -89.999 & -55 & & $\begin{array}{c}-67.2 \\
(-69.1-- \\
65)\end{array}$ & \multicolumn{2}{|c|}{$\begin{array}{c}-70 \\
(-71.9--67.8)\end{array}$} & \\
\hline $\begin{array}{l}\text { Strike-slip } 2 \\
{[\mathrm{~m}]}\end{array}$ & -0.5 & 0.0 & & & \multicolumn{2}{|c|}{$\begin{array}{c}-0.194 \\
(-0.265-- \\
0.149)\end{array}$} & \\
\hline Dip-slip2 $[\mathrm{m}]$ & -1.0 & 0.0 & & & \multicolumn{2}{|c|}{$\begin{array}{c}-0.396 \\
(-0.451- \\
0.331)\end{array}$} & \\
\hline $\begin{array}{l}\text { UTMX }{ }^{* * * *} \\
{[\mathrm{~m}]}\end{array}$ & & & 662219 & 662228 & \multicolumn{2}{|c|}{662265} & $\begin{array}{c}662036 \pm 300 \\
(?)\end{array}$ \\
\hline $\begin{array}{l}\mathrm{UTMY}^{* * *} \\
{[\mathrm{~m}]}\end{array}$ & & & $\begin{array}{c}2175 \\
686\end{array}$ & 2175681 & \multicolumn{2}{|c|}{2175695} & $\begin{array}{c}2175515 \pm 300 \\
(?)\end{array}$ \\
\hline \multirow[b]{2}{*}{ Rake $\left[^{\circ}\right]$} & & & & & $\begin{array}{c}\text { Fault } \\
1\end{array}$ & $\begin{array}{c}\text { Fault } \\
2\end{array}$ & \multirow[b]{2}{*}{42} \\
\hline & & & $(75-81)$ & $\begin{array}{c}80 \\
(77-84)\end{array}$ & $\begin{array}{c}90 \\
(88- \\
90)\end{array}$ & $\begin{array}{c}58 \\
(51- \\
72)\end{array}$ & \\
\hline $\mathrm{Mw}^{* * * * *}$ & & & 4.36 & 4.35 & \multicolumn{2}{|c|}{4.35} & 4.2 \\
\hline $\begin{array}{c}\text { RMS asc } \\
{[\mathrm{mm}]}\end{array}$ & & & 2.79 & 2.35 & \multicolumn{2}{|c|}{2.27} & \\
\hline $\begin{array}{l}\text { RMS dsc } \\
{[\mathrm{mm}]}\end{array}$ & & & 3.33 & 3.32 & \multicolumn{2}{|c|}{3.15} & \\
\hline
\end{tabular}

*In case of this study, it marks the coordinates of the center of the top edge of the rectangular plane. **Negative dip angles are due to convention signs in GBIS (dislocations dipping to the west have negative sign, Bagnardi and Hooper (2018)), and strike values are therefore oriented northwards. In the main text we converted negative dip values and corresponding strike values to match the focal mechanism solution for easier comparison. ***In case of this study, these are the UTM14N coordinates of the center of the top edge of the (upper) rectangular plane. $* * * * \mathrm{Mw}$ values of this study are calculated with the optimal fault parameters and a shear modulus of $8 \mathrm{GPa}$.

Table 6.1: Parameters, uncertainties (2.5\% - 97.5\% confidence intervals), and RMS misfits of the single fault model (Model 1), the segmented fault models with identical slip (Model 2), and independent slip (Model 3), and the seismological solution of Lermo Samaniego et al. (2016) for the 8 February, 2016, Mw=4.2 Los Humeros earthquake. The uncertainties of the hypocenter locations by Lermo Samaniego et al. (2016) are reported to be $<300 \mathrm{~m}$ in all 3 directions, however the exact values are not known. The coordinates of the faults are also reported in UTM zone $14 \mathrm{~N}$, and the rakes are calculated for comparison with the focal mechanism solution. 
For all models we approximated the subsurface with an elastic half-space with a Poisson's ratio $v=0.25$. This value is considered as a lower bound for the Poisson's ratio of the geological units of the area, calculated based on the mechanical rock property database of Los Humeros (Weydt et al., 2018; Weydt et al., 2021). We approximate the Poisson's ratio of the LHVC units (subdivided into a post-caldera unit, caldera unit, and pre-caldera unit) between $0.265-0.27$, with and uncertainty of \pm 0.02 . The Poisson's ratio of the underlying limestone basement is estimated to be $0.28 \pm 0.02$. In order to account for the uncertainties of the Poisson's ratio and its effect on the resulting model parameters and their uncertainties, we have tested the single fault model (Model 1) with Poisson's ratios of $\mu=0.25$ and $\mu=0.3$. We found that there is negligible influence of the variation of Poisson's ratio on the resulting model parameters, the uncertainties of the resulting model parameters largely overlap (Figure Figure 6.6a). Additionally, we find an elastic half-space a reasonable approximation, since the geological units do not have significantly different Poisson's ratios. Vp/Vs ratios based on seismic tomography (Toledo et al., 2020) near the activated fault segment also do not show any significant variations within the LHVC sediments, supporting the applicability of elastic half-space for this study.

We set up constraints based on the 3D geological model of Los Humeros as constructed through the use of geological and geophysical observations, and partly on the focal mechanism solution from seismological data (Lermo Samaniego et al., 2016) to find reasonable model parameters (Table 6.1). We selected lower and upper bounds of the model parameters in order to account for a wide range of possible solutions (Table 6.1), taking into account the uncertainties of the fault models and the seismological data. For instance, we allowed for a fault width of 200-2000 m and a depth of the top of the fault between 0-500 m, resulting in activated fault segments(s) from the surface down to $2500 \mathrm{~m}$ depth, with a preferable length. We chose the dip and strike to vary between $45^{\circ}-85^{\circ}$ and $150^{\circ}-170^{\circ}$, respectively (Table 6.1).

In case of the single fault model, we inverted for all the 9 model parameters simultaneously. In case of the segmented fault models, we followed the methodology of Funning et al. (2005) for two-fault models. We fixed one fault segment and inverted for the other one iteratively. We performed a parameter search for the location, strike and dip of the faults based on prior information, keeping the rest of the parameters of both faults fixed to obtain a first model reproducing the geometry of the observed ground deformation pattern. Then we updated the model bounds and inverted for all the parameters.

\subsubsection{Model 1 - single fault}

The upper and lower bounds and inversion results of parameters of the single fault model (Model 1) are listed in Table 6.1. Contrary to the focal depth of $1900 \mathrm{~m}$ derived from seismological data (Lermo Samaniego et al., 2016), the observed surface movements could only be reproduced by a fault activation at a shallower depth, extending from the surface down to $\sim 1000 \mathrm{~m}$ depth (Figure 6.4a). The inferred fault has reverse kinematics with a minor left-lateral component (strike $=161^{\circ} \operatorname{dip}=64^{\circ}$, rake $=78^{\circ}$ ). A good fit with both the ascending 
and descending InSAR data was achieved; the model mismatch is quantified in a root-meansquare (RMS) misfit of the order of $3 \mathrm{~mm}$ (Table 6.1).

\subsubsection{Model 2 - segmented fault, identical slip}

The segmented fault model approximating the curved geometry of the inferred fault structure was first tested with identical slip values for the upper and lower dislocation (Model 2). Model 2 shows a slightly improved fit with the InSAR data compared to Model 1 (Table 6.1). The fault kinematics in case of Model 2 agree with the single fault solution. The width of the upper dislocation is significantly smaller than the lower one $(208 \mathrm{~m}$ and $852 \mathrm{~m}$, respectively, Figure $6.4 \mathrm{~b}$, Table 6.1), and the active fault segments extend from the surface down to $\sim 1000 \mathrm{~m}$ depth. The dip angle increases with depth, with $57^{\circ}$ in case of the upper dislocation, and $67^{\circ}$ for the lower dislocation.

\subsubsection{Model 3 - segmented fault, independent slip}

We also performed the inversion leaving the dip-slip and strike-slip component of the lower fault segment independent from the values of the upper segment. This configuration allows us to mimic the change in the slip components with varying dip angles and depth. We set up the bounds of the strike-slip components of the two dislocations in order to allow only left-lateral movements. It was important to avoid inconsistent lateral movements along the two connected dislocations. The parameters and uncertainties of the best-fitting model (referred to as Model 3) are presented in Figure 6.3 and Table 6.1. Model 3 has mostly similar parameters as Model 2, although only the lower fault is having left-lateral kinematics (Figure 6.4c, Table 6.1). Another difference with the results from Model 2 is that the two fault segments have similar widths (480 m and $442 \mathrm{~m}$, Figure 6.4c, Table 6.1). The misfit of Model 3 has slightly improved compared to the previous models (Table 6.1). The left-lateral component of the lower dislocation inferred from Model 3 (rake $=58^{\circ}$, Table 6.1) is comparable with the focal mechanism solution by Lermo Samaniego et al. (2016) (rake $\left.=42^{\circ}\right)$. Due to the similar rake values to the seismological solution and the lowest overall misfit, Model 3 represents the most realistic source parameters solution of the 8 February 2016 earthquake. 

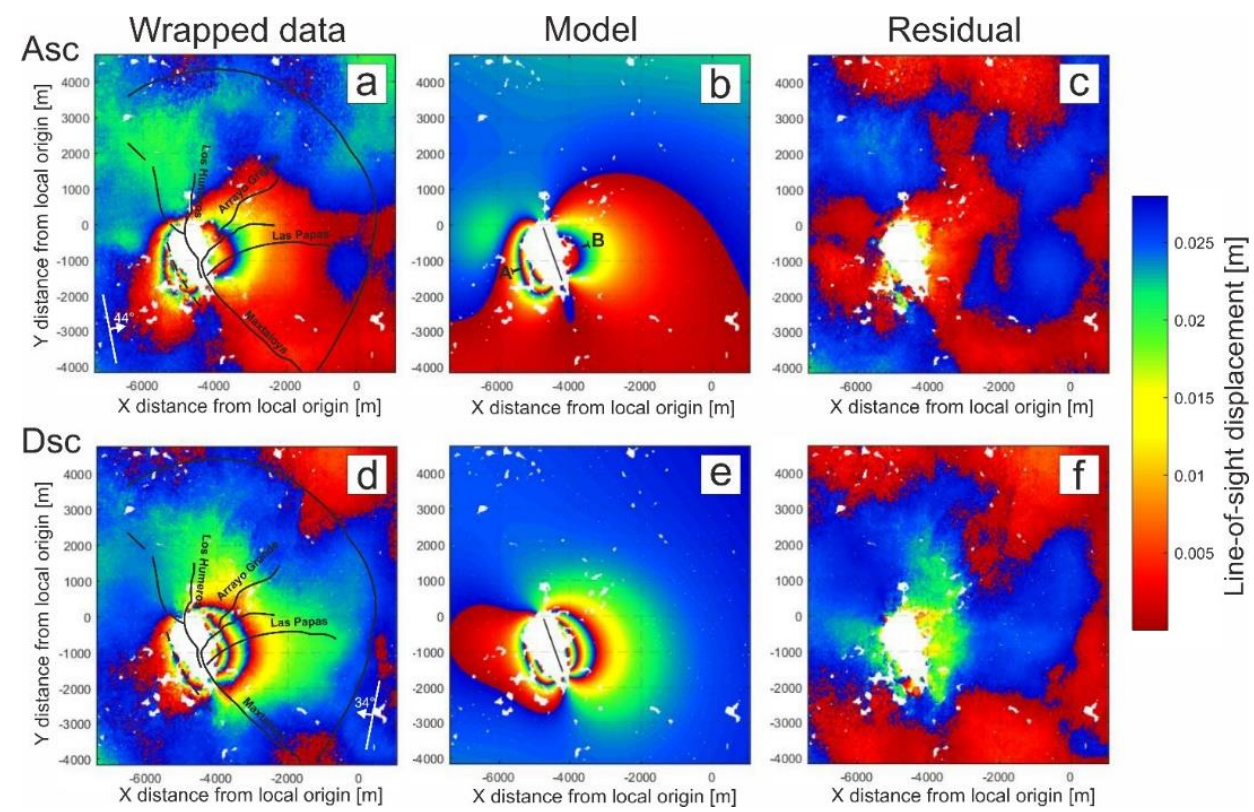

Figure 6.3: Comparison between the data and the best fitting model (Model 3), mapping the coseismic deformation of the 8 February 2016 earthquake. Observed (a, d), modeled (b, e), and residual (c, f) displacements in the LOS direction are presented for ascending (top) and descending (bottom) satellite passes. Arrows in (a) and (d) indicate the flight direction of the satellite and the look direction with the corresponding incidence angles. The simplified outline of the mapped and inferred structures after Calcagno et al. (2018) and Norini et al. (2019) are shown in (a) and (d). The surface projection of the modeled fault is plotted in (b) and (e).

The strike-slip components of the dislocations are marked by relatively large uncertainties (up to a variation of $30 \%-37 \%$ within $2.5 \%-97.5 \%$ confidence intervals) compared to the dip-slip components (up to a variation of $4 \%-16 \%$ ) in case of all models (Table 6.1, Figure 6.6). This can be explained by the fact that the N-S oriented movements, and therefore the strike-slip component, are less constrained by the InSAR data due to the satellite view geometries. 

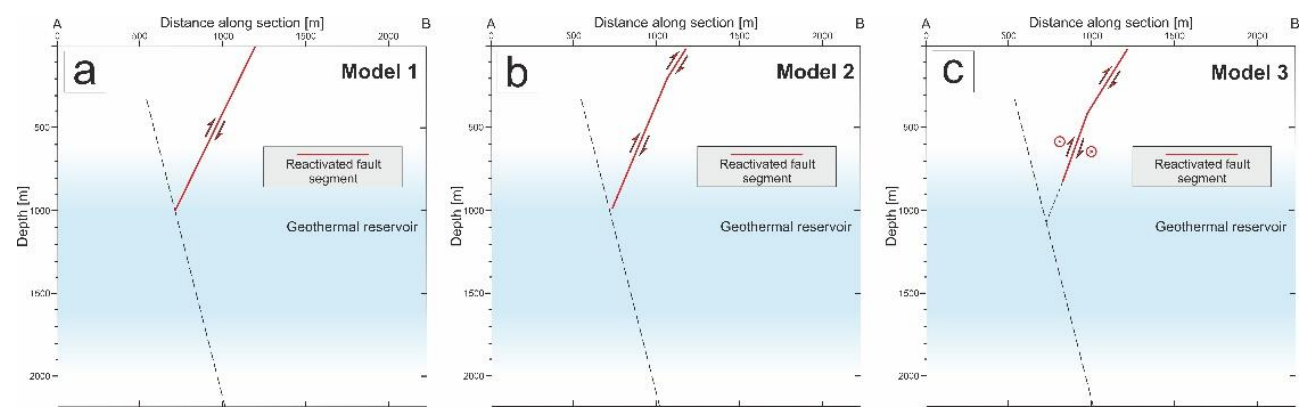

Figure 6.4: Schematic cross-section illustrating the geometry and kinematics of the reactivated fault segments (red solid lines) to compare the different models ((a) Model 1, (b) Model 2, (c) Model 3). The supposed geometry of the buried reverse fault from Norini et al. (2019), connected to the reactivated Los Humeros fault is plotted with black dashed line. The average extent of the reservoir inferred from well data (Carrasco-Núñez et al., 2017) and seismic tomography (Toledo et al., 2020) is shown with blue (the shading indicates the uncertainty of reservoir extent). The trace of the section is shown in Figure $6.3 b$.

\subsection{Deformation between February 2016-May 2019}

The velocity map of the study area covering the LHVC with average yearly LOS movement rates after the coseismic deformation, between 19 February 2016 and 26 May 2019 is presented in Figure 6.5. Movements away from the satellite ( subsidence) are concentrated within the Los Potreros caldera with up to $8 \mathrm{~mm} /$ year near the inner-caldera structures (Figure $6.5 \mathrm{a}, \mathrm{b}$ ). The $8 \mathrm{~mm} /$ year rate is in agreement with previous studies based on Envisat data between 2003-2007 (Békési et al., 2019a; Cigna et al., 2019). The Los Humeros fault in the north, and the Maxtaloya fault in the south appear to constrain the deforming area in the west. Subsidence is in general consistent with the location of the active production wells (Figure 6.5a).

An inconsistency between deformation and geothermal production is observed near the Las Papas fault. Subsidence of this area with comparable rates was not observed previously by Békési et al. (2019a), but it is possible that they mapped the signal within the topographic error term and removed it from the interferograms. Results of this study show that the center of the Los Potreros caldera floor experiences deformation up to $7 \mathrm{~mm} /$ year (Figure 6.5b), although it was not under production during the period of the PSI analysis. The location of the deformation signal corresponds to the easternmost cluster of seismic events observed between September 2017 and September 2018 (Gaucher et al., 2019) (Figure 6.5a). Furthermore, the observed subsidence is consistent with the previously studied coseismic motion of the eastern fault block (Figure 6.3d). Afterslip on the seismogenic fault and the viscoelastic relaxation after the main seismic event must contribute to the deformation signal. However, additional long-term volcano-tectonic activity may be partly responsible for the observed subsidence. 


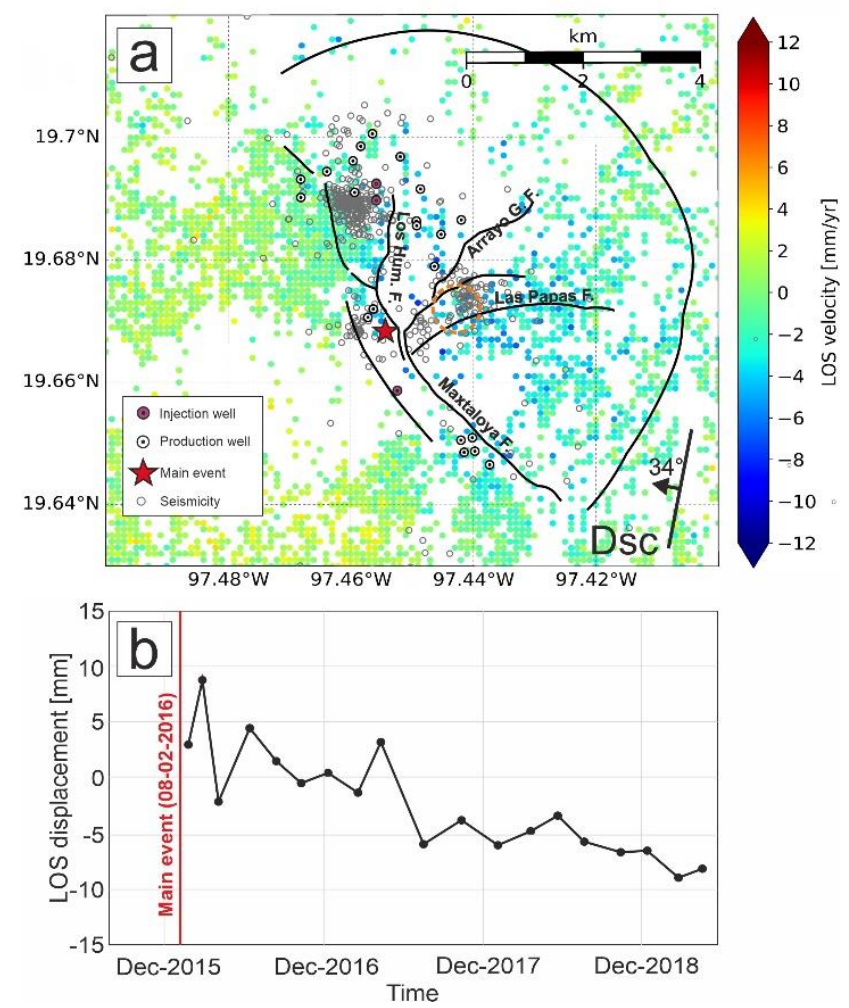

Figure 6.5: (a) Mean PS velocities in mm/year in the direction of the satellite line of sight (LOS) at the LHGF, observed on descending satellite orbits, after the Mw 4.2 event. Only PS points with a with a standard deviation $<2 \mathrm{~mm} /$ year are included. Negative LOS velocities indicate movement away from the satellite ( $\sim$ subsidence) and positive values indicate movement towards the satellite ( uplift). The The main structures modified after Calcagno et al. (2018), Norini et al. (2019), the wells operating during the period of the InSAR time series (19 February 2016 - 16 May 2019) and the natural and induced earthquakes between 2017 September and 2018 September after Gaucher et al. (2019) are also shown. (b) Time series plot of the mean LOS velocities from vicinity of the Las Papas fault, highlighted in (a) with the dashed orange circle.

\subsection{Discussion}

We modeled the coseismic deformation due to the 8 February, 2016, Mw=4.2 earthquake at Los Humeros with the effect of a single dislocation (Model 1), and also with two connected rectangular dislocations representing two fault segments to approximate a curved fault geometry (Model 2, Model 3). We jointly inverted the ascending and descending interferograms using a Bayesian approach in order to constrain the fault parameters and associated uncertainties. We based our models on prior information on the geometry of the mapped and inferred fault structures after Calcagno et al. (2018) and Norini et al. (2019). Our models are able to resolve the observed ground deformation pattern and suggest fault 
reactivation at very shallow depth $(<1 \mathrm{~km})$. Additionally, our current models are in agreement with the surface trace of the mapped fault structures (Figure 6.3).

The observed surface movements together with the modeling results indicate a reverse kinematics with a left-lateral component (Table 6.1), interpreted as the reactivation of the Los Humeros fault (Figures 6.3 and 6.4). The reverse movement and the geometry of the Los Humeros fault are in good agreement with the focal mechanism solutions of Lermo Samaniego et al. (2016) $\left(\right.$ strike $=169^{\circ}$, dip $=61^{\circ}$, rake $=42^{\circ}$, Table 6.1). However, Lermo Samaniego et al. (2016) observed a significant left-lateral component. We tested the segmented fault models with identical slip of the upper and lower dislocation (Model 2) and we also performed the inversion with different slip values (Model 3). A significant left-lateral movement (rake $=58^{\circ}$, Table 6.1 ) could only be reproduced by Model 3 , and is only attributed to the lower fault segment. The inconsistency between the strike-slip components of the geodetic models and the seismological solution can partly originate from the uncertainty of the N-S oriented movements due to the satellite orbits. To better constrain the strike-slip kinematics through the InSAR inversion, an independent observation with a different view geometry would be required. Still, the strike-slip components necessary to reproduce the rake values of the moment tensor solution $\left(42^{\circ}\right)$ fell outside the confidence intervals of the fault models (Table1, Figure 6.6). The mismatch in the magnitude of strike-slip component could further be explained by the uncertainty assigned to the focal mechanism inversion of Lermo Samaniego et al. (2016), limited to the polarities of the P-wave arrivals at the vertical components of five seismic stations. Additionally, errors in the moment tensor solution may occur due to uncertainties in the velocity model adopted by Lermo Samaniego et al. (2016) (e.g. Vasyura-Bathke et al., 2021).The inferred independent slip values of the upper and lower dislocation (Model 3) could also suggest that the kinematics of the Los Humeros fault varies with depth and dip angle.

There is no specific indication of the hypocenter location error of the 8 February 2016 earthquake by Lermo Samaniego et al. (2016), however they report a maximum error of 300 $\mathrm{m}$ in all directions (longitude, latitude and depth) for a subset of seismic events. The error of up to $300 \mathrm{~m}$ can be considered relatively low, but still the uncertainties of the horizontal coordinates inferred from the seismological model largely overlap with the results of this study (Table 6.1).

The InSAR data can be fitted with the reactivation of the Los Humeros fault extending from the surface down to $\sim 800-1000 \mathrm{~m}$ depth, but no displacements can be inferred at larger depths. One explanation of the depth extent of the reactivation is that the Los Humeros fault is connected to a reverse fault at this depth, indicated with the black dashed line in Figure 6.4. While this fault was not identified by several studies (Carrasco-Núñez et al., 2017; Ferriz, 1982; Norini et al., 2015) the existence of the buried reverse fault structure is suggested by e.g. Lermo et al. (2008) and Norini et al. (2019). The occurrence of the earthquake at a maximum depth of $1 \mathrm{~km}$ would require the presence of stress-resistant material in shallow depth. Seismic tomography results show a significant positive $\mathrm{Vp}$ anomaly near the seismic event, delineating a relatively rigid body between $\sim 500-1500 \mathrm{~m}$ depth (Toledo et al., 2020 ), 
that could build up stresses for a $\mathrm{Mw}=4.2-4.35$ rupture. Toledo et al. (2020) estimated the top of the pre-caldera group (hosting the geothermal reservoir) to $\sim 600 \mathrm{~m}$ depth in the vicinity of the earthquake, which is significantly shallower than the average reservoir depth of approximately $1000 \mathrm{~m}$. This would suggest that the reactivated fault segment inferred from our study extends also within the upper part of the reservoir (Figure 6.4). The very shallow fault reactivation inferred from the InSAR inversion could suggest that the earthquake hypocenter is located near the bottom of the rupture that is often observed (e.g. Gaudreau et al., 2019; Karasözen et al., 2016). Compared to our models, the earthquake was originated significantly deeper (1900 m) according to the seismological solution (Table 6.1, Figure 6.4). The uncertainty of the hypocentral depth based on the seismological model is estimated to be as low as $300 \mathrm{~m}$ (Lermo et al., 2008), and the depth of the fault plane is estimated to be up to $1100 \mathrm{~m}$ (within $97.5 \%$ confidence interval in case of Model 2, Table 6.1) according to the geodetic models, showing that the uncertainties of the two models do not overlap. Such a large difference in source depth of $\sim 900 \mathrm{~m}$ cannot be explained by the limitations of our models, for instance the assumption of an elastic half-space. Lermo Samaniego et al. (2016) used a 1D P-wave velocity model (Lermo et al., 2008) and first arrivals from five seismic stations. The velocity model of Lermo et al. (2008) adopts significantly different values from from the results of more recent studies, especially at shallow depth (Löer et al., 2020; Toledo et al., 2020). Also, due to the largely heterogenous subsurface of the study area, the hypocentral depth might be biased as a result of differences in seismic velocities from the 1D model. All these limitations of the seismological model may explain the differences in estimated focal depths.

The calculated moment magnitude from all three slip models based on the InSAR data is approximately 4.35, using a shear modulus of $8 \mathrm{GPa}$ (Table 6.1). We estimated the shear modulus of the volcano-sedimentary units of the LHVC based on the mechanical rock property database of Los Humeros (Weydt et al., 2018; Weydt et al., 2021). The estimated moment magnitude of 4.35 is larger than the $\mathrm{Mw}=4.2$ value reported by Lermo Samaniego et al. (2016), corresponding to an approximately 1.7 times larger seismic moment $\left(3.8 \times 10^{15}\right.$ $\mathrm{Nm}$ in case of model 3, compared to $2.2 \times 10^{15} \mathrm{Nm}$ of the seismological solution). Using a shear modulus of $5 \mathrm{GPa}$ would result in a modeled moment magnitude of 4.2, although such value for the shear modulus would underestimate the actual properties. Still, the uncertainties of the rock mechanical properties of different rock types can be as large as $4 \mathrm{GPa}$ (Weydt et al., 2018), leading to relatively high uncertainties $( \pm 0.15)$ of the estimated moment magnitudes. Weston et al. (2012) found that there is a slight trend for an overestimation of the moment magnitude for thrust events studied using InSAR. This discrepancy can be explained by modeling errors due to the absence of InSAR observations in the near-fault zone due to the lack of coherence and/or the limitations of the seismological solution, such as the influence of a curved fault geometry on the estimation of moment magnitude (e.g. ContrerasArratia and Neuberg, 2020). Another factor is the mapping of potential deformation from aftershocks, afterslip and viscoelastic relaxation in the interferograms. Additionally, we approximate the subsurface with an elastic half-space instead of a layered media. This can 
also contribute to the overestimation of the moment magnitude, especially due to a shallower source depth compared to the seismological solution (Weston et al., 2012).

Our model results show remaining misfits with both the ascending and descending data (Figure $6.2 \mathrm{c}$, f). These can be explained by the model assumptions that we applied. The fault surfaces have significant irregularities, and the interferograms suggest movements along several fault structures not present in our models (Figure 6.2 a, d). For instance, both the ascending and descending data show misfits with the modeling results northeast to the surface trace of the faults. This is explained by the unmapped dislocation along the NE-SW striking Arrayo Grande fault. Also, the termination of the Los Humeros fault and its potential connection to the sub-parallel Maxtolya fault in the south might be responsible for a more complex slip distribution. The dip angle of the faults in the area is also likely to change with depth, as suggested by both geological and geophysical data (e.g. Carrasco-Núñez et al., 2018; Norini and Groppelli, 2020; Urbani et al., 2020).

Over geological time scales, the Los Humeros fault with normal kinematics has induced the lowering of the western fault block, creating the present-day topography. However, active ground movements based on the InSAR observations indicate the reverse reactivation of the Los Humeros structure. A possible source of subsidence of the eastern fault block observed on the coseismic interferogram and prolonged surface motions (Figure 6.3d, Figure 6.5a, b) is the depressurization of the hydrothermal system. This pressure source could also explain the local radial stress field observed by Norini et al. (2019). Connection between the shallow fault reactivation and the deep pressure source is ensured by the buried reverse structure inferred from Norini et al. (2019) and this study (Figure 6.4). Norini et al. (2019) and Urbani et al. (2020) suggested the resurgence of the Los Potreros caldera floor east of the Los Humeros fault, that is supported by the presence of intrusive-like bodies on seismic tomography images (Toledo et al., 2020). Although the current subsidence of the caldera floor indicate depressurization at depth (Figure 5a,b), resurgence of the caldera floor can still exist in a larger time scale. In such a case, recent subsidence might be related to an episodic pause in the overall resurgence process.

The correlation between the 08 February 2016 earthquake and the increase of the injection rate in the $\mathrm{H}-29$ well is obvious (Figure 6.2). Since the earthquake occurred seven days after the onset of injection, it is likely that poro-elastic stress changes due to fluid injection are partly responsible for the triggering of the event. Additionally, the depressurization of the hydrothermal system due to production from several other geothermal wells may also have contributed to the occurrence of the earthquake. However, it is difficult to distinguish between the different factors contributing to the observed ground motions, also due to the lack of interferometric coherence observed in the near-fault zone.

Coseismic deformation mapped with radar satellite data provides independent observations to constrain the location, geometry, and kinematics of the seismic event. Our study demonstrates that ground movements mapped with InSAR and guided by other geological and geophysical observations can significantly contribute to our understanding of the fault structures and processes that control the geothermal reservoir. 


\subsection{Conclusions}

We have reproduced the coseismic surface deformation of the February, 2016, Mw=4.2 earthquake at Los Humeros, with a two-component rectangular dislocation model approximating the curved geometry of the fault structures of the LHVC. We have constrained the model parameters and the underlying uncertainties with a Bayesian inversion. The results imply fault reactivation at very shallow depth, down to $1 \mathrm{~km}$.

Models suggest that fault kinematics changes with depth, with a purely reverse kinematics of the upper dislocation, and significant left-lateral component of the lower dislocation $\left(\right.$ rake $\left.=58^{\circ}\right)$. Our model reproduces the observed ground movements with high precision, and fits with the surface trace of the Los Humeros structure, that was previously interpreted as a normal fault. The reactivated Los Humeros fault in the north and the Maxtaloya fault in the south and their potential continuation to a buried fault structure in larger depth act as major boundaries of the subsiding area observed after the coseismic deformation, for the period of February 2016 and May 2019. A potential explanation of the reverse reactivation of the Los Humeros fault and corresponding downward movement of the eastern fault block can be the depressurization of the whole hydrothermal system. Such depressurization might occur due to the exploitation of the geothermal field and/or due to natural pressure/temperature changes related to magmatic activity.

Our study demonstrates the added value of employing InSAR monitoring and inverse modeling under geological and geophysical constraints. It can help improve the understanding of the complex processes of geothermal sites. Such information is highly valuable for future operations of the field and can contribute to our understanding of SHGS in general.

\subsection{Supplement}
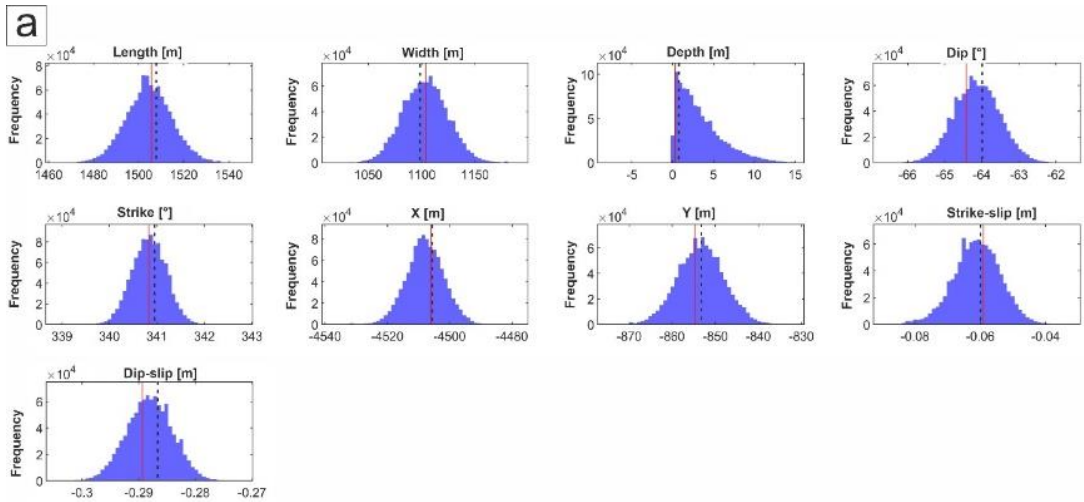

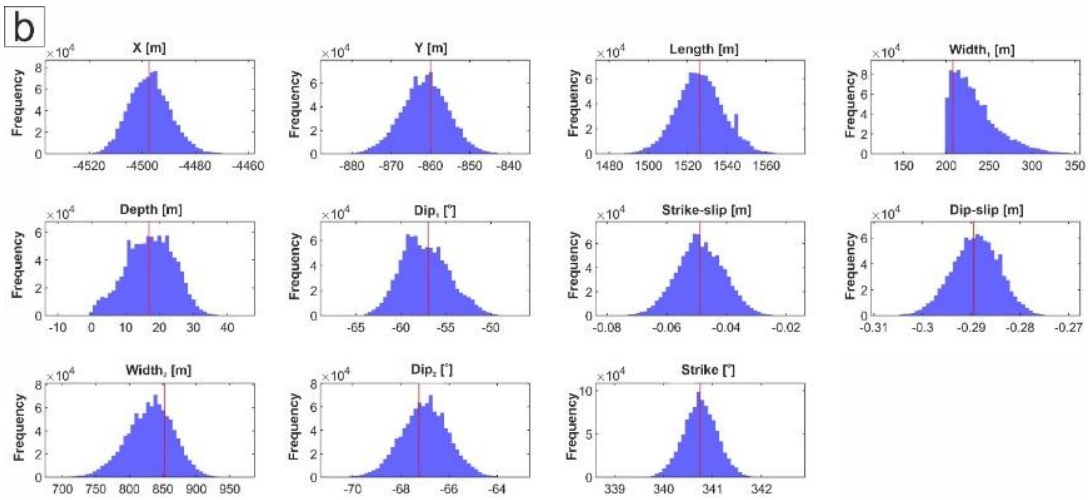

\section{C}
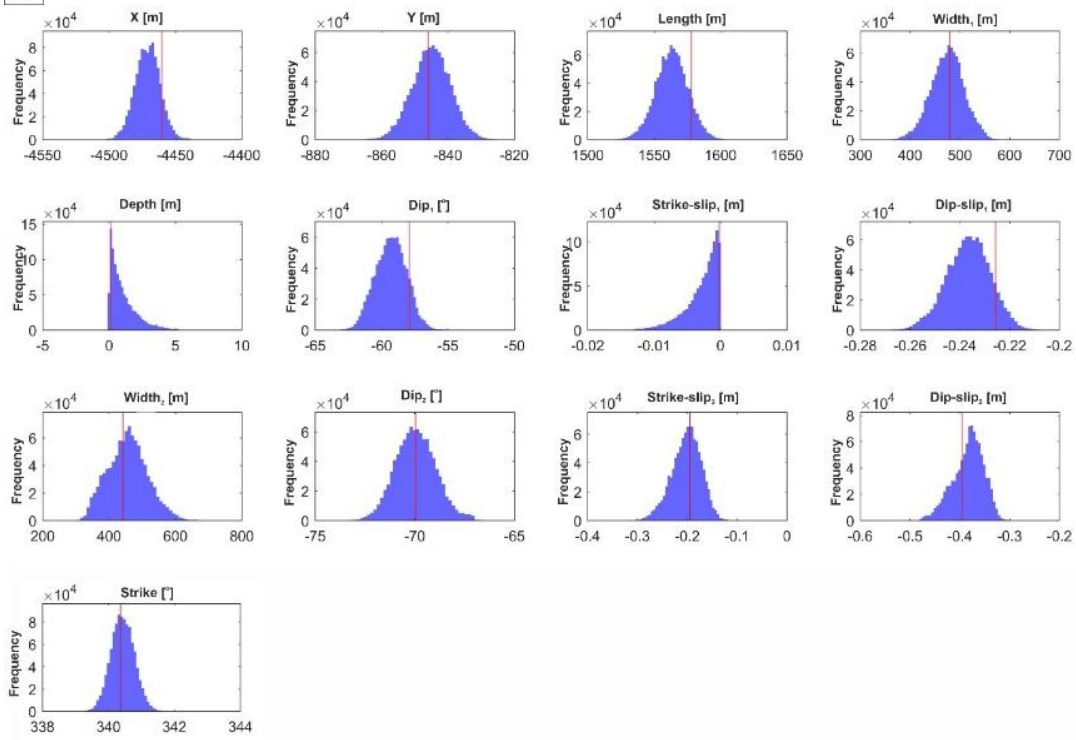

Figure 6.6: Posterior probability density distributions (PDFs) for the model parameters from (a) Model 1, (b) Model 2, (c) Model 3. The red lines represent the optimal values listed in Table 6.1. The black dashed lines in (a) indicate optimal values of the modified Model 1, where the Poisson's ratio of the elastic half-space was set to 0.3 . 


\section{Synthesis}


This thesis presents and demonstrates novel approaches for the characterization of geothermal reservoirs with a number of case studies. The characterization employs borehole temperature measurements and surface movement observations. Numerical models for sedimentary basin settings were constructed to describe the thermal state of the lithosphere (Chapter 2 and Chapter 3), with the main focus on the uppermost part of the subsurface. The application of temperature data and temperature models allowed to reveal the driving mechanisms responsible for temperature anomalies, and to constrain the thermal properties of various geological units. Additionally, employing ground motion data and predictions helped to approximate the underlying deformation processes and associated properties. The ground motion studies targeted a sedimentary basin (Chapter 4) and a volcanic region (Chapter 5 and Chapter 6). Data were generated with the InSAR technique; models for surface movements were constructed based on analytical solutions for various sources. Advanced inverse modeling methods were applied to constrain both the temperature and geodetic/geomechanical models with large numbers of observations (i.e. temperature measurements and InSAR data). External geological and geophysical information were integrated for the interpretation of the modeling results.

In this chapter, I combine and review the results of all chapters to summarize their added value to the understanding of geothermal reservoirs. First, general conclusions on the temperature models and on the interpretation of ground deformation observations are described. Then I discuss the role of inversion techniques. Finally, the importance of integrating approaches, with main focus on thermal models and ground motion estimates, including potential ways forward are presented.

\subsection{Thermal structure of sedimentary basins}

Physics-based temperature models describing the thermal state within the lithosphere were constructed for Hungary (Chapter 2) and for the Netherlands (Chapter 3). All models solved the heat equation in steady-state, assuming conduction as the main heat transfer mechanism. The applicability of steady-state models to the Netherlands is possible because of the fact that lithosphere extension and subsequent basin inversion took place $100 \mathrm{My}$ and $\sim 65$ My ago (Van Wees et al., 2009), hence their influence on the present-day temperature field is negligible. Chapter 3 proves how this approach can be used to successfully approximate the temperature distribution in sedimentary basin settings where steady-state conditions apply. Limberger et al. (2018) also demonstrated that the major features of the thermal field within the European lithosphere can be captured by a steady-state conductive approach. Therefore, the workflow presented in Chapter 3 can be adopted to various regions with steady-state conductive thermal regimes.

In regions with recent tectonic activity and erosion or sedimentation, such as the Pannonian basin (Chapter 2), the effect of transient processes is still seen in the present-day temperatures. Steady-state models which adopt constant temperatures as top and bottom boundary conditions are not applicable for these areas. In Chapter 2, we have demonstrated that transient thermal effects related to lithosphere extension and subsequent basin inversion can be approximated by choosing appropriate steady-state boundary conditions on a 
lithosphere scale. They can be derived from the (tectonic) surface heat flow, and adopted as a laterally variable basal boundary condition at the lithosphere-asthenosphere boundary. Alternatively, transient thermal models can be constructed in order to directly account for the variations in subsurface temperatures through time. However, the steady-state approach on regional scales is computationally much more efficient and enables the incorporation of large amounts of temperature measurements into the models in a fast and effective way.

In both study areas (Chapter 2 and Chapter 3), the conductive thermal regime is disturbed locally by convection within the upper $5 \mathrm{~km}$ of the subsurface. Such convective heat transfer in sedimentary basin settings can develop in both porous sediments and fractured or karstified rocks, depending on their large-scale hydraulic properties. With sufficiently high fluid temperatures, these areas exhibit good prospects for geothermal exploitation. The identification of such regions is therefore highly relevant. It can be obtained by identifying areas with misfits between temperature observations and models: when regional-scale conductive thermal models are employed with reasonable prior values for the thermal properties of geological units, the areas with strong misfits most likely correspond to nonconductive heat transfer.

My approach has been to incorporate temperature measurements into the model and update the thermal properties of the geological units to better match temperature data. Adopting ranges of variations of thermal properties wider than physically warranted (e.g. increased thermal conductivity) within layers where convection may occur resulted in an improved approximation of the thermal effect of convection. However, the inferred thermal properties at convection-dominated regimes are less appropriate and require cautious interpretation. I want to note here, however, that physics-based thermal models are also largely dependent on conceptual constraints: only few temperature measurements are available from the deeply buried carbonate platforms in the Netherlands and the models require prior assumptions on the geometry and properties of geological units - this forms an additional argument for the match of convection areas with conduction models.

In the Netherlands, convection may occur in deeply buried carbonate platforms (Bonté et al., 2012; Lipsey et al., 2016). The observed local temperature profile has successfully been reproduced by the optimization of the thermal conductivity of the geological units in the conductive models (Chapter 3). Anomalies in the thermal conductivity maps resulting from inverting the temperature maps show good correlations with the areal extent of the carbonates in the model. The subsurface thermal field in exploitable depth above the carbonates $(\sim<5$ $\mathrm{km}$ ) is primarily controlled by the thermal properties of various geological units (Chapter 3), as is generally the case for steady-state conductive regions. Temperature anomalies are largely attributed to the presence of salt structures, corresponding to their high thermal conductivity. In contrast, relatively low temperatures are present above and within extensive shale layers with coal content, explained by its insulation effect due to low thermal conductivity.

In contrast to the Netherlands, outcropping karstified carbonate rocks with considerable thickness and subsurface continuations are present in the Pannonian basin. Gravity-driven 
flow systems within these carbonate rocks have major influence on the thermal field (e.g. Mádl-Szőnyi and Tóth, 2015). Even with the updated thermal properties of the corresponding geological units, conductive thermal models failed to reproduce the observed temperature field of these convection-dominated regions in the shallow subsurface (Chapter 2). Therefore, temperature modeling incorporating both conductive and convective heat transfer mechanisms are necessary to approximate the thermal structure of such regions.

In the Hungarian part of the Pannonian basin (Chapter 2), the identified thermal anomalies are largely influenced by the transient thermal effect of lithosphere extension and sedimentation. The highest geothermal gradients can be primarily associated with the thinnest parts of the lithosphere. However, local anomalies due to the cooling effect of recent sedimentation and increased temperatures in the vicinity of buried basement highs with high thermal conductivity were observed, showing good correlations with the surface heat flow (Lenkey et al., 2002; Lenkey et al., 2021). This study (Chapter 2) confirmed that the complex understanding of the evolution of sedimentary basins is crucial to assess the subsurface thermal field and geothermal potential of regions with recent/active tectonic activity.

\subsection{Interpretation of surface movements for geothermal reservoir characterization}

Chapters 4-6 provide a demonstration of the applicability of InSAR-based techniques for geothermal areas with various geological settings, highlighting the relevant subsurface processes and properties that can be potentially constrained. Ground motion estimates using the InSAR technique were generated for two geothermal areas in different plate-tectonic settings; the Szentes geothermal field in Hungary (Chapter 4) and the Los Humeros geothermal field in Mexico (Chapter 5 and Chapter 6). Szentes is a water-dominated system, where the produced geothermal energy is used for direct heat applications. Los Humeros is a steam-dominated superhot geothermal system with reservoir temperatures reaching $380^{\circ} \mathrm{C}$, providing excellent conditions for geothermal power generation. InSAR monitoring and modeling have proven to be successful for reservoir characterization of both sites. However, the applicability and limitations of ground motion predictions combined with inverse modeling are strongly site-dependent.

The Szentes geothermal area, a conduction-dominated geothermal play in a sedimentary basin setting, is a good example of surface movements that can be linked to geothermal exploitation. This is related to the fact that the magnitude of movements related to tectonic activity are negligible compared to production-induced ground deformation.

In contrast to the Szentes area, Los Humeros is marked by recent magmatic activity, that may also contribute to the observed ground deformation pattern. It is often the case for geothermal areas located in active regions (e.g. Keiding et al., 2010). Therefore, the detailed understanding of the evolution of the study area and the integration of various geophysical and geological models for the interpretation of surface movements is of critical importance.

At Szentes, the reservoir comprises sandstones with high porosity ( 25\%), with frequent clay interbeds. Pressure depletion has caused compaction of the reservoir-system as well as the highly compressible aquitards. This has resulted in laterally extensive ground motion 
anomalies with considerable magnitudes, which are well detectable in InSAR measurements. The observed ground movements combined with inverse modeling allowed to infer subsurface properties such as the (de)compaction coefficient of the Szentes reservoir system. Additionally, permanent deformation of the reservoir, attributed to largely irreversibly compressible materials such as clay layers and intergranular clay films, has been identified.

The Los Humeros reservoir is comprised of low-porosity andesite rocks, and the geothermal system is largely controlled by fault structures, providing secondary permeability. Surface deformation observations and monitoring at the Los Humeros (Chapter 5 and Chapter 6) facilitated the characterization of the fault structures controlling the geothermal reservoir. Compartmentalization of the reservoir was identified and fluid pathways were inferred based on the surface movement pattern. This contributed to the understanding of interactions between geothermal wells. Chapter 6 demonstrates the added value of employing InSAR monitoring and inverse modeling under geological and geophysical constraints. Such a methodological approach was proven to be useful for the assessment of an induced seismic event, and the active kinematics and behavior of fault structures.

\subsection{Applicability of inversion methods for temperature measurements and ground deformation data}

In this thesis I have demonstrated the effectiveness and importance of inversion methods using both temperature and surface movement data. The thesis also highlights how the a priori selection of model parameters and associated uncertainties influences the performance of the inversion procedures. Therefore, the direct or indirect integration of various external subsurface models to the prior temperature/geomechanical model is paramount.

In case of both regional-scale temperature models and models for surface movements, large number of observations - temperature measurements and ground motion observations - are available. If large calibration datasets are combined with computationally demanding, complex forward models, such as in the case of the regional-scale thermal models (Chapter 2 and Chapter 3), data assimilation methods have proven to be efficient. Emerick and Reynolds (2013b) showed that for non-linear forward models combined with large amounts of observations, the Ensemble Smoother with Multiple Data Assimilation (ES-MDA) is a good choice. In Chapters $2-4$, novel approaches for the integration of large numbers of observation datasets for temperature/geomechanical models, using ES-MDA have been presented. Chapters $2-4$ have demonstrated that uncertainties due to measurement errors and prior model parameters can be successfully incorporated through the ES-MDA procedure. The misfits between observations and model predictions have largely decreased.

In case of ground motion modeling, analytical forward models were used (Chapters 4 6). These do not necessarily require data assimilation techniques. Other probabilistic methods (such as Bayesian inversion in Chapter 6) can perform successfully for the estimation of the model parameters. However, ensemble-based inversion may become more important with the application of more complex geomechanical models (e.g. Candela et al., 2021). The aim is to better understand reservoir behavior through time, provide improved estimates on future 
production/injection scenarios of geothermal sites, and hence support informed decision making.

Since geothermal systems exhibit coupled thermo-hydro-mechanical-chemical processes, the role of the different mechanisms and their interplay have to be assessed and taken into account. Numerical coupled modeling is becoming increasingly important in deep geothermal applications, especially when stimulation of the reservoir is necessary. These models, however, require faithful input in order to reduce exploration and production risks associated with deep geothermal activities, both technical and environmental. The incorporation of various surface and subsurface measurements to coupled numerical models through data assimilation techniques could allow for the future growth of geothermal applications.

\subsection{Integrated approach for geothermal reservoir characterization}

The present-day temperature distribution and host rock properties of a geothermal system are largely dependent on plate tectonic settings. In order to successfully apply any geophysical methods towards the characterization of geothermal fields, interpretive models can gain considerably from the in-depth understanding of geological history and underlying geodynamic processes. First-order thermal, hydrological and mechanical (basin) models can facilitate to constrain these processes. In this thesis, this is well- demonstrated, for instance, by the relevance of large-scale temperature models (Chapter 2) for the interpretation of observed ground motion anomalies at the Szentes geothermal site (Chapter 4). The thermal structure of the Szentes region is largely controlled by Neogene lithospheric extension and the resulting syn- and post-rift sedimentation. Since present-day ground motions due to tectonic activity are negligible for the area, and convection-induced uplift and subsidence is not likely to occur locally, the observed surface movements can be attributed to the deformation of the reservoir system due to geothermal activities. Additionally, to quantify the causes of surface deformation, knowledge on the depositional environments of sediments and on the resulting lithologies is proven to be essential.

Los Humeros is an excellent example of the added value of geophysical models to the understanding of the evolution of the geothermal system, and the importance of prior knowledge on the geological history for the interpretation of the models. At Los Humeros, major questions on the heat source of the geothermal reservoir still arise. It might be a single deep magma reservoir or alternatively multiple shallow magmatic intrusions (e.g. Urbani et al., 2020). Various geophysical imaging and modelling studies (e.g. magnetotellurics, earthquake tomography; Arzate et al., 2018; Toledo et al., 2020) suggest potential locations of intrusive bodies. Ground deformation observations in Chapter 5 also indicate the deformation of the center of the Los Potreros caldera. This could be related to magmatic activity, but also to geothermal production activities. An integrated study with multiple geophysical methods might shed light on the interplay and the relative importance of these processes. In general, to fully understand the role of magmatic and or tectonic processes at active areas, geophysical investigations prior to geothermal production should be conducted as a baseline, in order to map the undisturbed state of a geothermal system. 
Los Humeros exhibits a complex thermal structure. The transient thermal behavior depends on the conductive cooling of magma body(s) and on the convective hydrothermal system hosting the geothermal reservoir. To identify the locations and characteristics of the one or more heat sources, measurements beyond the already drilled geothermal wells are required. Their locations must extend beyond the Los Potreros Caldera, and possibly to larger depths as well. Observations from these locations could facilitate the better understanding of the geothermal system, which is crucial for the planning of further extension of the field.

Besides the applicability of thermal models for the interpretation of ground motion predictions, surface movement predictions can also be used to identify unrevealed temperature anomalies. For instance, the injection of cold water into geothermal reservoirs commonly induce volumetric strains due to thermal and/or poro-elastic stress changes. Therefore, surface movement observations near injection wells might help to identify flow directions of re-injected fluids (e.g. Chapter 5), and help to infer for temperature changes further away from the injection wells.

In general, subsurface models are largely limited by the availability and quality of observations. Surely, methodological advancements and inverse modelling as used in this thesis are key for an improved approximation of subsurface processes and properties, but their success critically relies on sufficient data quality and density to constrain the models. Consequently, integration of multi-disciplinary models and datasets is of paramount for the understanding of complex processes occurring at geothermal sites. To this end, the detailed assessment of all information that is available is required in a multi-disciplinary approach, in order to provide sufficient prior knowledge and control for the models. In the process, a strong communication between different fields of research is vital for the better understanding of geothermal reservoirs.

This thesis demonstrates that the identification of temperature and ground motion anomalies and the understanding of physical processes and properties behind them can significantly contribute to map potential areas and to plan exploitation strategies for geothermal utilization. Additionally, continuous monitoring of operating geothermal fields using InSAR measurements and inverse modeling has been proven to be a valuable addition to conventional geophysical methods for geothermal field management, and is expected to become a widely used technology in the future. 


\section{Summary}

Geothermal energy, the heat that can be extracted from the Earth's subsurface, could play an important role in the energy transition towards renewable energy sources. However, the global increase in geothermal applications is relatively slow compared to other renewables, related to the economic uncertainty of geothermal operations. Therefore, a detailed understanding of geothermal reservoirs is necessary, not only to map their potential but also to reduce the risks of geothermal projects by quantifying subsurface uncertainties.

In this thesis I aim to provide novel approaches for improving geothermal reservoir characterization with the use of temperature measurements and ground deformation observations. To achieve this, country-scale thermal models (Chapter 2 and Chapter 3) and site-specific source models for surface movements (Chapters 4-6) were constructed. Models were constrained by independent geological and geophysical data, assessing the thermal field, deformation processes, and associated properties of the geothermal reservoirs. Access to datasets for the case studies from Hungary (Chapter 2 and Chapter 4) and the Netherlands (Chapter 3) were provided through collaborations with Hungarian partners and TNO. Various geological and geophysical datasets together with conceptual models were available within the framework of the EU-funded GEMex project, which facilitated the interpretation of ground deformation at the Mexican Los Humeros geothermal field (Chapter 5 and Chapter $6)$.

Chapter 2 presents a new lithosphere-scale temperature model of the Hungarian part of the Pannonian basin. Steady-state conductive temperature models were constructed and constrained with close to 4000 subsurface temperature measurements from the Geothermal Database of Hungary. The prior thermal properties and basal boundary condition of the model were updated using the Ensemble Smoother with Multiple Data Assimilation (ES-MDA) technique. The updated models were capable to reproduce the transient thermal effect of lithospheric extension and the sedimentary infill of the Pannonian Basin. Results showed that the hottest areas below $3 \mathrm{~km}$ are linked to the basement highs surrounded by deep sub-basins of the Great Hungarian Plain. Models provide an indication for potential sites for future enhanced geothermal systems (EGS) in Hungary and can serve as an input for further detailed geothermal resource assessment studies.

In Chapter 3, subsurface temperature models for the Netherlands were constructed using a similar workflow as described in Chapter 2. In contrast to the Pannonian Basin, lithosphere extension has negligible influence on the present-day thermal field of the Netherlands. Therefore, steady-state conditions apply, which facilitated the use of constant temperature boundary conditions at the top and bottom of the models. The sedimentary part of the model adopts the high-resolution geological model of the onshore Netherlands (DGM-deep v4.0), comprising 14 units. Misfits of the prior model were significantly reduced through the data assimilation procedure, demonstrating the effectiveness of ES-MDA as a tool for calibrating 
temperature models, supporting high-resolution external constraints. Models revealed areas in the Netherlands where convection in deeply buried carbonate platforms may occur, and which therefore can be suitable for deep geothermal development.

Chapter 4 focuses on ground movements observed at the Szentes geothermal area in southeast Hungary. Surface movement estimates were generated using Persistent Scatterer interferometry, and were modeled using a disk-shaped reservoir embedded in an elastic halfspace, subjected to a uniform pressure change. Model parameters and corresponding uncertainties were quantified with ES-MDA. Ground movements together with the modeling results showed that uplift of the Szentes geothermal field occurred during the observation period, which we explain by pore pressure increase due to natural recharge. However, the northeastern part of the field experienced prolonged subsidence. The estimated (de)compaction coefficients suggest that both elastic and permanent deformation occurred during the depletion periods, followed by the elastic recovery of the reservoir-system.

In Chapter 5, ground deformation observations at the Los Humeros geothermal field in Mexico is presented, for the period of $\sim 4$ years between 2003-2007. The geothermal field is a superhot geothermal system with reservoir temperatures reaching $380{ }^{\circ} \mathrm{C}$, located inside the quaternary Los Humeros caldera, in the Eastern Trans-Mexican Volcanic Belt. The subsidence pattern derived from the ground deformation observations and inverse modeling, indicated that the geothermal field is controlled by sealing faults separating the reservoir into several blocks. Results show that relatively small volume changes exist at depth, suggesting that the pressure within the reservoir is well supported and that recharge is taking place.

Chapter 6 presents surface movements and inferred source parameters of the 8 February 2016, Mw=4.2 earthquake at Los Humeros, and prolonged ground motions between 20162019. Interferograms based on two image pairs acquired by the Sentinel-1 satellites were constructed, and inverse modeling for the coseismic ground movements was performed, using Okada's solution for rectangular dislocation(s). Models suggest the reverse reactivation of the Los Humeros normal fault at a shallow depth $(<1000 \mathrm{~m})$, with a more significant left lateral component below $\sim 400 \mathrm{~m}$ depth. A potential explanation of the reverse reactivation of the Los Humeros fault and following downward movement of the eastern fault block is the depressurization of the whole hydrothermal system.

Effective exploration and safe and sustainable production of subsurface resources require knowledge of the subsurface processes, the driving parameters and their uncertainties. For the understanding of the complex processes occurring at geothermal sites, the integration of multi-disciplinary models and datasets is paramount. By facilitating this integration and quantification, inversion methods demonstrate their effectiveness in the case studies of this thesis. 


\section{Samenvatting}

Geothermische energie, gedefinieerd als de warmte die uit de ondergrond van de aarde kan worden gewonnen, kan een belangrijke rol spelen in de energietransitie naar hernieuwbare energiebronnen. De mondiale groei van geothermische toepassingen is echter langzaam in vergelijking met de groei van alternatieven voor duurzame energie. Dit is gerelateerd aan veel voorkomende onzekerheid omtrent de economische haalbaarheid van geothermische operaties. Daarom is een gedetailleerd begrip van geothermische reservoirs vereist, en dan niet alleen van het geothermische potentieel maar ook van de risico's die aan exploitatie kleven door de onzekerheden die kennis van de ondergrond altijd met zich meedraagt.

In dit proefschrift wil ik nieuwe richtingen inslaan naar geothermische reservoir karakterisatie, met gebruikmaking van temperatuurmetingen en bodembewegingsdata. Daartoe zijn nationale en regionale thermische modellen (Hoofdstukken 2 en 3) en locatiespecifieke bronmodellen voor bodembeweging (Hoofdstukken 4 - 6) geconstrueerd. Onafhankelijke externe geologische en geofysische informatie is gebruikt om de modellen van ondergrondse temperatuurverdeling en deformatie, en de bijbehorende parameters nader te bepalen. Toegang tot data van de studies in Hongarije (Hoofdstukken 2 en 4) en Nederland (Hoofdstuk 3) zijn verkregen door samen te werken met Hongaarse partners en TNO. Verder waren verscheidene geologische en geofysische datasets en conceptuele modellen beschikbaar in het kader van het door de EU gesponsorde GEMex project. Dit faciliteerde de interpretatie van oppervlaktedeformatie in het Mexicaanse Los Humeros geothermische veld (Hoofdstuk 5 en 6)

Hoofdstuk 2 presenteert een nieuw model op lithosfeerschaal van het Hongaarse deel van het Pannoonse bekken. Daarvoor zijn eerst statische temperatuurmodellen geconstrueerd op basis van thermische geleiding. De waarden voor de thermische eigenschappen en de randcondities aan de modelbasis zijn vervolgens nader bepaald door bijna 4000 ondergrondse temperatuurmetingen uit de geothermische database van Hongarije te gebruiken in een Ensemble Smoother met Multiple Data Assimilation (ES-MDA) techniek. Met de verbeterde modellen kon het tijdsafhankelijke thermische effect van extensie van de lithosfeer en de sedimentaire opvulling van het Pannoonse bekken met succes worden gereproduceerd. De resultaten lieten zien dat de heetste gebieden, gesitueerd op een diepte van meer dan $3 \mathrm{~km}$, zijn verbonden aan de hooggelegen delen van het grondgebergte, die omringd worden door diepe sub-bekkens van de Grote Hongaarse Laagvlakte. De modellen geven een indicatie voor potentiële locaties voor toekomstige Enhanced Geothermal Systems in Hongarije en kunnen dienen als input voor meer gedetailleerde geothermische exploratie studies.

In Hoofdstuk 3 zijn ondergrondse temperatuurmodellen voor Nederland geconstrueerd met een vergelijkbare workflow als in Hoofdstuk 2. In tegenstelling tot het Pannoonse bekken geeft lithosferische extensie een te verwaarlozen bijdrage aan de huidige 
temperatuurverdeling in Nederland. Daarom gelden hier statische condities, welke het gebruik van constante-temperatuur randcondities aan de onder- en bovenkant van het model mogelijk maken. Het sedimentaire deel van het model gebruikt het hoge-resolutie model van onshore Nederland (DGM-deep v4.0), bestaande uit 14 stratigrafische eenheden. Misfits van het startmodel werden aanzienlijk gereduceerd door het gebruik van de data assimilatie procedure. Daarmee werd de effectiviteit van ES-MDA als een hulpmiddel om temperatuurmodellen te kalibreren, en het gebruik van hoge-resolutie externe condities, gedemonstreerd. De modellen hebben geholpen om gebieden in Nederland waar convectie in diepe carbonaatplatforms plaatsvindt aan het licht te brengen. Deze kunnen geschikt zijn voor diepe geothermische toepassingen.

Hoofdstuk 4 richt zich op bodembeweging die is waargenomen in de Szentez geothermische regio in zuidoost Hongarije. Schattingen van de bodembeweging werden verkregen met behulp van satellietwaarnemingen met interferometrische radar, en werden gemodelleerd met behulp van een cilindrisch reservoir in een elastische half-ruimte, waarin een uniforme drukverandering werd opgelegd. De modelparameters en de bijbehorende onzekerheid werden gekwantificeerd met ES-MDA. De bodembeweging en de bijbehorende modeluitkomsten lieten bodemstijging zien gedurende de observatieperiode. Deze worden verklaard door druktoename door natuurlijke grondwateraanvulling. Het noordoostelijke deel van het veld laat echter doorgaande daling zien. De geschatte compactie- en decompactiecoëfficiënten suggereren dat er zowel elastische als permanente deformatie is opgetreden tijdens de depletieperiodes, gevolgd door elastische deformatie tijdens de daaropvolgende drukopbouw.

In Hoofdstuk 5 worden bodembewegingsobservaties in het Los Humeros geothermisch veld in Mexico gepresenteerd voor de 4 jaar durende periode tussen 2003 en 2007. Dit geothermische veld, gelegen in de kwartaire Los Humeros caldera in de Oostelijke transMexicaanse vulkanische gordel, is een superheet geothermisch systeem met temperaturen tot $380^{\circ} \mathrm{C}$. Het bodemdalingsprofiel, afgeleid uit de bodembewegingsobservaties en de inverse modellering, duidt erop dat het geothermische veld wordt gecontroleerd door nietdoorlatende breuken die het reservoir in een aantal blokken verdelen. De resultaten laten relatief kleine volumeveranderingen zien in het reservoir, hetgeen suggereert dat de reservoirdruk op peil blijft door natuurlijke aanvulling.

Hoofdstuk 6 presenteert bodembeweging en daaruit afgeleide bronparameters door de $\mathrm{Mw}=4.2$ aardbeving van 8 februari 2016, en de doorgaande bodembeweging tussen 2016 en 2019. Twee beeldparen, verkregen met de Sentinel-1 satellieten, zijn gebruikt om interferogrammen te construeren voor de co-seismische deformatie. Deze werden vervolgens in een invers model met Okada's oplossingen voor rechthoekige dislocaties gebruikt. De modellen suggereren een opschuivende reactivatie van de Los Homeros breuk op geringe diepte $(<1000 \mathrm{~m})$, met een significante links-zijwaartse reactivatie beneden $\sim 400 \mathrm{~m}$ diepte. Een mogelijke verklaring van de opschuivende reactivatie en de daaropvolgende neerwaartse beweging van het oostelijke blok langs de Los Humeros breuk wordt gevormd door de drukdaling in het gehele hydrothermische systeem. 
Effectieve exploratie en veilige en duurzame exploitatie van aardse hulpbronnen vereist kennis van de ondergrondse processen, de belangrijkste parameters en hun onzekerheden. Voor een begrip van de complexe processen die bij aardwarmtewinning spelen is een integratie van multi-disciplinaire modellen en datasets cruciaal. De studies in dit proefschrift demonstreren het belang en effectiviteit van inverse methoden, omdat die deze integratie en kwantificatie mogelijk maken. 


\section{Acknowledgements}

The past few years of my life have been filled with plenty of new experiences and memorable moments thanks to so many great people around me, who inspired and supported me to deliver this thesis.

First, I would like to thank my promoters, Jan-Diederik and Sierd, and my co-promoters, Peter and Damien for giving me the opportunity to carry out my $\mathrm{PhD}$ in an excellent research environment both in the Tectonics group and in TNO.

Jan-Diederik, your bright ideas and enthusiasm gave me constant motivation from the beginning of my project. Thank you for introducing me to the state-of-the-art in geothermal energy research. I really enjoyed our discussions even if it required a lot of concentration from my side to keep up with your thoughts.

I am really grateful for Sierd for setting up my connections to Tectonics group already during my master studies. Also, great thanks for carefully checking many of my papers and thesis, and for supporting me with advices on academic issues.

Peter, thank you for being there anytime I requested a (scientific) discussion, you always sensed how much support I needed. You inspired me with your great knowledge and downto-earth approach. Thank you for the thoughtful and enthusiastic supervision, often accompanied by a good coffee and nice conversations in TNO.

Damien, thank you for all the lively and cheerful conversations during the first few years of my PhD track, your positive attitude and constructive feedback were greatly appreciated.

Fred, I always considered you as one of my co-promoters with all your support on practical matters and teaching.

My sincere appreciation goes to the members of the reading committee: Hanneke Paulssen, Chris Spiers, Freek van der Meer, Thomas Kohl and David Bruhn.

I am grateful for the opportunity of being part of the IMAGE and GEMex projects. It has been a pleasure to participate at project meetings, discuss and work with people from various institutes and companies. These multi-disciplinary projects allowed me to put my findings into perspective.

I would like to thank László Lenkey and Frank Horváth for their contributions to my first study on the Pannonian Basin. Laci, you also provided me with a background in geothermics during my studies, that served as a good basis of my $\mathrm{PhD}$. 
Joana, I really appreciate your help and support with InSAR processing and your constructive feedback on my manuscripts. I really enjoyed our long conversations also beyond scientific questions.

I thank all my colleagues from the Tectonics group for providing me with a great atmosphere and interesting discussions: Liviu, Ylona, Ernst, Jeroen, Dimitrios, Magdala, Inge, Nevena, Lukman, Fauzi, Job, István and all the other Tectos. Thanks to my Hungarian friends, Attila and Dani, for moderating my homesickness with plenty of fun gatherings. I really enjoyed the (pre-covid) activities outside the office, including bouldering sessions, dinners and outings with the excellent company of Antoine, Tracy, Jon, Marije, Nemanja, Simon, Elisa. Jon, as my paranymph I learnt so much from you and I really appreciate your guidance in the beginning of my $\mathrm{PhD}$.

Many thanks to all TNO colleagues I was in contact with for the welcoming environment and great atmosphere. Maartje, Mark, Hans, your support and feedback on thermal modeling and on the geology of the Dutch subsurface were much appreciated. Big thanks to the whole Geomechanics group for considering me as a part of the team and inviting me to many fun gatherings, I really enjoyed your company!

I learnt a lot from being a teaching assistant of the Unconventional and Sustainable Georesources course. I would like to thank all my students for their contributions, patience, and great questions.

I would like to express my gratitude to my new colleagues in the Institute of Earth Physics and Space Science in Hungary for the friendly environment and flexibility that allowed me to finish the final touches on my thesis.

Finally, I would like to say köszönöm to my family and Hungarian friends who never forgot about me even if we lived far away from each other. Zsófik, Tündi, Gréta, thank you for finding the time to come and visit me in Utrecht. Thank you Anya for all your attempts to understand my research and being available for a chat anytime. I would like to say special thanks to my little daughter, Anna, for being so comfortable with me working on my thesis. All the time spent together allowed me to recharge and brought plenty of joy to everyday life. At last but not least, I would like to thank my amazing husband, Kristof, for the constant care and support in a fun and loving atmosphere. I believe I am on the best possible path with you by my side, evidenced by this thesis and many other aspects of our lives. 


\section{References}

Agemar, T., Schellschmidt, R., and Schulz, R., 2012, Subsurface temperature distribution in Germany: Geothermics, v. 44, p. 65-77.

Allis, R. G., 2000, Review of subsidence at Wairakei field, New Zealand: Geothermics, v. 29 , no. 4-5, p. 455-478.

Almasi, I., 2002, Petroleum hydrogeology of the Great Hungarian Plain, Eastern Pannonian Basin, Hungary.

Artemieva, I. M., 2019, Lithosphere structure in Europe from thermal isostasy: Earth-Science Reviews, v. 188, p. 454-468.

Arzate, J., Corbo-Camargo, F., Carrasco-Núñez, G., Hernández, J., and Yutsis, V., 2018, The Los Humeros (Mexico) geothermal field model deduced from new geophysical and geological data: Geothermics, v. 71, p. 200-211.

Atefi-Monfared, K. A., and Rothenburg, L., 2011, Ground surface displacements and tilt monitoring for reconstruction of reservoir deformations: International Journal of Rock Mechanics and Mining Sciences, v. 48, no. 7, p. 1113-1122.

Bada, G., Horváth, F., Dövényi, P., Szafián, P., Windhoffer, G., and Cloetingh, S., 2007, Present-day stress field and tectonic inversion in the Pannonian basin: Global and Planetary Change, v. 58, no. 1-4, p. 165-180.

Bagnardi, M., and Hooper, A., 2018, Inversion of surface deformation data for rapid estimates of source parameters and uncertainties: A Bayesian approach: Geochemistry, Geophysics, Geosystems, v. 19, no. 7, p. 2194-2211.

Balázs, A., Burov, E., Matenco, L., Vogt, K., Francois, T., and Cloetingh, S., 2017, Symmetry during the syn-and post-rift evolution of extensional back-arc basins: The role of inherited orogenic structures: Earth and Planetary Science Letters, v. 462, p. 86-98.

Balázs, A., Matenco, L., Magyar, I., Horváth, F., and Cloetingh, S., 2016, The link between tectonics and sedimentation in back-arc basins: New genetic constraints from the analysis of the Pannonian Basin: Tectonics, v. 35, no. 6, p. 1526-1559.

Báldi, T., and Royden, L. H., 1986, Mid-Tertiary stratigraphy and paleogeographic evolution of Hungary, Akadémiai Kiadó.

Bálint, A., and Szanyi, J., 2015, A half century of reservoir property changes in the Szentes geothermal field, Hungary: Central European Geology, v. 58, no. 1-2, p. 28-49.

Balla, Z., 1986, Palaeotectonic reconstruction of the central Alpine-Mediterranean belt for the Neogene: Tectonophysics, v. 127, no. 3, p. 213-243.

Balla, Z., 1988, Clockwise paleomagnetic rotations in the Alps in the light of the structural pattern of the Transdanubian Range (Hungary): Tectonophysics, v. 145, no. 3-4, p. 277-292.

Batzle, M., and Wang, Z., 1992, Seismic properties of pore fluids: Geophysics, v. 57, no. 11, p. 1396-1408.

Baù, D., Ferronato, M., Gambolati, G., Teatini, P., and Alzraiee, A., 2015, Ensemble smoothing of land subsidence measurements for reservoir geomechanical characterization: International Journal for Numerical and Analytical Methods in Geomechanics, v. 39, no. 2, p. 207-228. 
Beglinger, S. E., van Wees, J.-D., Cloetingh, S., and Doust, H., 2012, Tectonic subsidence history and source-rock maturation in the Campos Basin, Brazil: Petroleum Geoscience, v. 18, no. 2, p. 153-172.

Bekaert, D., Hooper, A., and Wright, T., 2015, A spatially variable power law tropospheric correction technique for InSAR data: Journal of Geophysical Research: Solid Earth, v. 120 , no. 2, p. 1345-1356.

Békési, E., Fokker, P. A., Martins, J. E., Limberger, J., Bonté, D., and Van Wees, J.-D., 2019a, Production-induced subsidence at the los humeros geothermal field inferred from PS-InSAR: Geofluids, v. 2019, Article ID 2306092, p. 12.

Békési, E., Fokker, P. A., Martins, J. E., Norini, G., and van Wees, J.-D., 2021, Source parameters of the 8 February 2016, Mw $=4.2$ Los Humeros earthquake by the inversion of InSAR-based ground deformation: Geothermics, v. 94, p. 102133.

Békési, E., Fokker, P. A., Martins, J. E., and van Wees, J.-D., Inversion of coseismic deformation due to the 8th February 2016, Mw 4.2 earthquake at Los Humeros (Mexico) inferred from DInSAR, in Proceedings Proceedings of the European Geothermal Congress2019b.

Békési, E., Lenkey, L., Limberger, J., Porkoláb, K., Balázs, A., Bonté, D., Vrijlandt, M., Horváth, F., Cloetingh, S., and van Wees, J.-D., 2018, Subsurface temperature model of the Hungarian part of the Pannonian Basin: Global and Planetary Change, v. 171, p. 48-64.

Berczi, I., 1988, Preliminary Sedimentological Investigation of a Neogene Depression in the Great Hungarian Plain: Chapter 10.

Bertini, G., Casini, M., Gianelli, G., and Pandeli, E., 2006, Geological structure of a longliving geothermal system, Larderello, Italy: Terra Nova, v. 18, no. 3, p. 163-169.

Bonini, M., Maestrelli, D., Corti, G., Del Ventisette, C., Moratti, G., Carrasco-Núñez, G., Giordano, G., Lucci, F., Norini, G., and Piccardi, L., 2021, Modelling intra-caldera resurgence settings: Laboratory experiments with application to the Los Humeros Volcanic Complex (Mexico): Journal of Geophysical Research: Solid Earth, p. e2020JB020438.

Bonté, D., Van Wees, J.-D., and Verweij, J., 2012, Subsurface temperature of the onshore Netherlands: new temperature dataset and modelling: Netherlands Journal of Geosciences, v. 91, no. 4, p. 491-515.

Boxem, T. P. A., 2010, Steady state 1D temperature modeling of the onshore Dutch subsurface: Netherlands Institute of Applied Science TNO - National Geological Survey (Utrecht).

Breede, K., Dzebisashvili, K., Liu, X., and Falcone, G., 2013, A systematic review of enhanced (or engineered) geothermal systems: past, present and future: Geothermal Energy, v. 1, no. 1, p. 1-27.

Calcagno, P., Evanno, G., Trumpy, E., Gutiérrez-Negrín, L. C., Macías, J. L., CarrascoNúñez, G., and Liotta, D., 2018, Preliminary 3-D geological models of Los Humeros and Acoculco geothermal fields (Mexico)-H2020 GEMex Project: Advances in Geosciences, v. 45, p. 321.

Candela, T., Chitu, A., Peters, E., Pluymaekers, M., Hegen, D., Koster, K., and Fokker, P., 2021, A data assimilation framework to constrain the driving process of anthropogenically induced subsidence, under revision, https://doi.org/10.31223/X5T02M. 
Candela, T., Koster, K., Stafleu, J., Visser, W., and Fokker, P., 2020, Towards regionally forecasting shallow subsidence in the Netherlands: Proceedings of the International Association of Hydrological Sciences, v. 382, p. 427-431.

Candela, T., Osinga, S., van der Veer, E., ter Heege, J., and Fokker, P., Improving Reservoir Exploitation Using Fast Geomechanical Modelling Coupled With Surface Displacement Data Assimilation, in Proceedings SPE Reservoir Characterisation and Simulation Conference and Exhibition2017, Society of Petroleum Engineers.

Carrasco-Núñez, G., López-Martínez, M., Hernández, J., and Vargas, V., 2017, Subsurface stratigraphy and its correlation with the surficial geology at Los Humeros geothermal field, eastern Trans-Mexican Volcanic Belt: Geothermics, v. 67, p. 117.

Carrasco-Núñez, G., Bernal, J. P., Davila, P., Jicha, B., Giordano, G., and Hernández, J., 2018, Reappraisal of Los Humeros volcanic complex by new U/Th zircon and 40Ar/39Ar dating: Implications for greater geothermal potential: Geochemistry, Geophysics, Geosystems, v. 19, no. 1, p. 132-149.

Cavalié, O., Doin, M. P., Lasserre, C., and Briole, P., 2007, Ground motion measurement in the Lake Mead area, Nevada, by differential synthetic aperture radar interferometry time series analysis: Probing the lithosphere rheological structure: Journal of Geophysical Research: Solid Earth, v. 112, no. B3.

Čermák, V., and Bodri, L., 1986, Two-dimensional temperature modelling along five EastEuropean geotraverses: Journal of Geodynamics, v. 5, no. 2, p. 133-163.

Chapman, D., 1986, Thermal gradients in the continental crust: Geological Society, London, Special Publications, v. 24, no. 1, p. 63-70.

Cid, H. E., Carrasco-Núnez, G., Manea, V. C., Vega, S., and Castano, V., 2021, The role of microporosity on the permeability of volcanic-hosted geothermal reservoirs: A case study from Los Humeros, Mexico: Geothermics, v. 90, p. 102020.

Cigna, F., Tapete, D., Garduño-Monroy, V. H., Muñiz-Jauregui, J. A., García-Hernández, O. H., and Jiménez-Haro, A., 2019, Wide-area InSAR survey of surface deformation in urban areas and geothermal fields in the eastern Trans-Mexican Volcanic Belt, Mexico: Remote Sensing, v. 11, no. 20, p. 2341.

Cloetingh, S., Van Wees, J. D., Ziegler, P., Lenkey, L., Beekman, F., Tesauro, M., Förster, A., Norden, B., Kaban, M., and Hardebol, N., 2010, Lithosphere tectonics and thermo-mechanical properties: an integrated modelling approach for Enhanced Geothermal Systems exploration in Europe: Earth-Science Reviews, v. 102, no. 34, p. 159-206.

Contreras-Arratia, R., and Neuberg, J. W., 2020, Towards reconciling seismic and geodetic moment estimations: Case Bárðarbunga: Journal of Volcanology and Geothermal Research, v. 408, p. 107034.

Corbo-Camargo, F., Arzate, J., Fregoso, E., Norini, G., Carrasco-Núñez, G., Yutsis, V., Herrera, J., and Hernández, J., 2020, Shallow structure of Los Humeros (LH) caldera and geothermal reservoir from magnetotellurics and potential field data: Geophysical Journal International, v. 223, no. 1, p. 666-675.

Csontos, L., and Nagymarosy, A., 1998, The Mid-Hungarian line: a zone of repeated tectonic inversions: Tectonophysics, v. 297, no. 1, p. 51-71.

Csontos, L., and Vörös, A., 2004, Mesozoic plate tectonic reconstruction of the Carpathian region: Palaeogeography, Palaeoclimatology, Palaeoecology, v. 210, no. 1, p. 1-56.

Daniilidis, A., and Herber, R., 2017, Salt intrusions providing a new geothermal exploration target for higher energy recovery at shallower depths: Energy, v. 118, p. 658-670. 
De Jager, J., 2007, Geological development: Geology of the Netherlands. Royal Netherlands Academy of Arts and Sciences, Amsterdam, v. 5, p. 26.

Decriem, J., Árnadóttir, T., Hooper, A., Geirsson, H., Sigmundsson, F., Keiding, M., Ófeigsson, B., Hreinsdóttir, S., Einarsson, P., and LaFemina, P., 2010, The 2008 May 29 earthquake doublet in SW Iceland: Geophysical Journal International, v. 181 , no. 2, p. 1128-1146.

Deichmann, N., and Giardini, D., 2009, Earthquakes induced by the stimulation of an enhanced geothermal system below Basel (Switzerland): Seismological Research Letters, v. 80, no. 5, p. 784-798.

Donders, T., Weijers, J., Munsterman, D., Kloosterboer-van Hoeve, M., Buckles, L., Pancost, R., Schouten, S., Damsté, J. S., and Brinkhuis, H., 2009, Strong climate coupling of terrestrial and marine environments in the Miocene of northwest Europe: Earth and Planetary Science Letters, v. 281, no. 3-4, p. 215-225.

Doornenbal, H., and Stevenson, A., 2010, Petroleum geological atlas of the Southern Permian Basin area, EAGE.

Dövényi, P., Homola, V., Horváth, F., Kohl, T., and Rybach, L., 2005, European HDR/EGS resources: Future potential development in Hungary: Order, no. G109/05, p. 22.13.

Dövényi, P., and Horváth, F., 1988, A Review of Temperature, Thermal Conductivity, and Heat Flow Data for the Pannonian Basin: In: Horvath, F, Royden, LH, The Pannonian Basin, Am. Assoc. Petrol. Geol. Memoir, 45, 195-233.

Dövényi, P., Horváth, F., and Drahos, D., 2002, Geothermal thermic map (Hungary): Atlas of Geothermal Resources in Europe. Publ. No. EUR, v. 17811, p. 267.

Du, Y., Feng, G., Li, Z., Peng, X., Zhu, J., and Ren, Z., 2017, Effects of External Digital Elevation Model Inaccuracy on StaMPS-PS Processing: A Case Study in Shenzhen, China: Remote Sensing, v. 9, no. 11, p. 1115.

Duin, E., Doornenbal, J., Rijkers, R., Verbeek, J., and Wong, T. E., 2006, Subsurface structure of the Netherlands-results of recent onshore and offshore mapping: Netherlands Journal of Geosciences, v. 85, no. 4, p. 245.

Emerick, A. A., and Reynolds, A. C., 2013a, Ensemble smoother with multiple data assimilation: Computers \& Geosciences, v. 55, p. 3-15.

Emerick, A. A., and Reynolds, A. C., 2013b, Investigation of the sampling performance of ensemble-based methods with a simple reservoir model: Computational Geosciences, v. 17, no. 2, p. 325-350.

Faccenna, C., Becker, T. W., Auer, L., Billi, A., Boschi, L., Brun, J. P., Capitanio, F. A., Funiciello, F., Horvàth, F., and Jolivet, L., 2014, Mantle dynamics in the Mediterranean: Reviews of Geophysics, v. 52, no. 3, p. 283-332.

Ferretti, A., Prati, C., and Rocca, F., 2001, Permanent scatterers in SAR interferometry: IEEE Transactions on geoscience and remote sensing, v. 39, no. 1, p. 8-20.

Ferriz, H., 1982, Geologic and preliminary reservoir data on the Los Humeros geothermal system, Puebla, México, No. SGP-TR-60; CONF-821214-3.: Stanford Univ., CA.

Ferriz, H., and Mahood, G. A., 1984, Eruption rates and compositional trends at Los Humeros volcanic center, Puebla, Mexico: Journal of Geophysical Research: Solid Earth, v. 89, no. B10, p. 8511-8524.

Fodor, L., Bada, G., Csillag, G., Horváth, E., Ruszkiczay-Rüdiger, Z., Palotás, K., Síkhegyi, F., Timár, G., Cloetingh, S., and Horváth, F., 2005, An outline of neotectonic structures and morphotectonics of the western and central Pannonian Basin: Tectonophysics, v. 410, no. 1-4, p. 15-41. 
Fodor, L. I., Gerdes, A., Dunkl, I., Koroknai, B., Pécskay, Z., Trajanova, M., Horváth, P., Vrabec, M., Jelen, B., and Balogh, K., 2008, Miocene emplacement and rapid cooling of the Pohorje pluton at the Alpine-Pannonian-Dinaridic junction, Slovenia: Swiss Journal of Geosciences, v. 101, no. 1, p. 255-271.

Fokker, P., Wassing, B., van Leijen, F., Hanssen, R., and Nieuwland, D., 2016, Application of an ensemble smoother with multiple data assimilation to the Bergermeer gas field, using PS-InSAR: Geomechanics for Energy and the Environment, v. 5, p. 1628.

Fokker, P. A., and Osinga, S., 2018, On the Use of Influence Functions for Subsidence Evaluation: American Rock Mechanics Association.

Freymark, J., Sippel, J., Scheck-Wenderoth, M., Bär, K., Stiller, M., Fritsche, J.-G., and Kracht, M., 2017, The deep thermal field of the Upper Rhine Graben: Tectonophysics, v. 694, p. 114-129.

Fuchs, S., Balling, N., and Mathiesen, A., 2020, Deep basin temperature and heat-flow field in Denmark-New insights from borehole analysis and 3D geothermal modelling: Geothermics, v. 83, p. 101722.

Funning, G. J., Parsons, B., Wright, T. J., Jackson, J. A., and Fielding, E. J., 2005, Surface displacements and source parameters of the 2003 Bam (Iran) earthquake from Envisat advanced synthetic aperture radar imagery: Journal of Geophysical Research: Solid Earth, v. 110, no. B9.

Gaucher, E., Toledo, T., Metz, M., Figueroa-Soto, A. G., and Calò, M., One year of passive seismic monitoring of the Los Humeros (Mexico) geothermal field, in Proceedings European Geothermal Congress, 2019.

Gaudreau, É., Nissen, E., Bergman, E. A., Benz, H. M., Tan, F., and Karasözen, E., 2019, The August 2018 Kaktovik earthquakes: Active tectonics in northeastern Alaska revealed with InSAR and seismology: Geophysical Research Letters, v. 46, no. 24, p. 14412-14420.

Geertsma, J., 1973, Land subsidence above compacting oil and gas reservoirs: Journal of petroleum technology, v. 25, no. 06, p. 734-744.

Geluk, M., Wong, T., Batjes, D., and De Jager, J., 2007, Permian: Geology of the Netherlands, p. 63-83.

Geluk, M. C., 2005, Stratigraphy and tectonics of Permo-Triassic basins in the Netherlands and surrounding areas, Utrecht University.

Goldscheider, N., Mádl-Szőnyi, J., Erőss, A., and Schill, E., 2010, Thermal water resources in carbonate rock aquifers: Hydrogeology Journal, v. 18, no. 6, p. 1303-1318.

Gordon, D., and Flemings, P., 1998, Generation of overpressure and compaction-driven fluid flow in a Plio-Pleistocene growth-faulted basin: Eugene Island, v. 330, p. 177-196.

Goutorbe, B., Lucazeau, F., and Bonneville, A., 2007, Comparison of several BHT correction methods: a case study on an Australian data set: Geophysical Journal International, v. 170 , no. 2, p. 913-922.

Grunnberg, L., Properties of seawater concentrations, in Proceedings Third International Symposium on Fresh Water from the Sea, Dubrovnik, 1970, Volume 1.

Guillou-Frottier, L., Carrè, C., Bourgine, B., Bouchot, V., and Genter, A., 2013, Structure of hydrothermal convection in the Upper Rhine Graben as inferred from corrected temperature data and basin-scale numerical models: Journal of Volcanology and Geothermal Research, v. 256, p. 29-49. 
Gutiérrez-Negrín, L. C., Current status of geothermal-electric production in Mexico, in Proceedings IOP Conference Series: Earth and Environmental Science2019, Volume 249, IOP Publishing, p. 012017.

Haas, J., Budai, T., Csontos, L., Fodor, L., and Konrád, G., 2010, Pre-Cenozoic geological map of Hungary, 1: 500 000: Geological Institute of Hungary, Budapest.

Haas, J., Budai, T., Csontos, L., Fodor, L., Konrád, G., and Koroknai, B., 2014, Geology of the pre-Cenozoic basement of Hungary: Geological and Geophysical Institute of Hungary, Budapest, p. 1-71.

Haenel, R., 1980, Atlas of subsurface temperatures in the European Community, Commission of the European Communities, Directorate-General Scientific and ....

Haenel, R., Rybach, L., and Stegena, L., 1988, Fundamentals of geothermics, Handbook of terrestrial heat-flow density determination, Springer, p. 9-57.

Haenel, R., and Staroste, E., 1988, Atlas of geothermal resources in the European Community, Austria and Switzerland, ESC.

Hámor, G., 2001, Genesis and evolution of the Pannonian Basin: Geology of Hungary: Eötvös Univ. Press, Budapest, p. 193-265.

Hanssen, R. F., 2001, Radar interferometry: data interpretation and error analysis, Springer Science \& Business Media.

Hantschel, T., and Kauerauf, A. I., 2009, Fundamentals of basin and petroleum systems modeling, Springer Science \& Business Media.

Harangi, S., and Lenkey, L., 2007, Genesis of the Neogene to Quaternary volcanism in the Carpathian-Pannonian region: Role of subduction, extension, and mantle plume: Geological society of America special papers, v. 418, p. 67-92.

Hasterok, D., and Chapman, D., 2011, Heat production and geotherms for the continental lithosphere: Earth and Planetary Science Letters, v. 307, no. 1, p. 59-70.

Heimlich, C., Gourmelen, N., Masson, F., Schmittbuhl, J., Kim, S.-W., and Azzola, J., 2015, Uplift around the geothermal power plant of Landau (Germany) as observed by InSAR monitoring: Geothermal Energy, v. 3, no. 1, p. 1-12.

Hochstein, M. P., 1990, Classification and assessment of geothermal resources: Small geothermal resources: A guide to development and utilization, UNITAR, New York, p. 31-57.

Hofmann, T., and Schönlaub, H. P., 2007, Geo-Atlas Österreich: die Vielfalt des geologischen Untergrundes, Böhlau Verlag Wien.

Hole, J., Bromley, C., Stevens, N., and Wadge, G., 2007, Subsidence in the geothermal fields of the Taupo Volcanic Zone, New Zealand from 1996 to 2005 measured by InSAR: Journal of volcanology and geothermal research, v. 166, no. 3-4, p. 125-146.

Hooper, A., Bekaert, D., Spaans, K., and Arıkan, M., 2012, Recent advances in SAR interferometry time series analysis for measuring crustal deformation: Tectonophysics, v. 514, p. 1-13.

Hooper, A., Segall, P., and Zebker, H., 2007, Persistent scatterer interferometric synthetic aperture radar for crustal deformation analysis, with application to Volcán Alcedo, Galápagos: Journal of Geophysical Research: Solid Earth, v. 112, no. B7.

Hooper, A., Spaans, K., Bekaert, D., Cuenca, M. C., Arıkan, M., and Oyen, A., 2010, StaMPS/MTI manual: Delft Institute of Earth Observation and Space Systems Delft University of Technology, Kluyverweg, v. 1, p. 2629.

Horton, C., and Rogers Jr, F., 1945, Convection currents in a porous medium: Journal of Applied Physics, v. 16, no. 6, p. 367-370. 
Horváth, F., 1993, Towards a mechanical model for the formation of the Pannonian basin: Tectonophysics, v. 226, no. 1-4, p. 333-357.

Horváth, F., Bada, G., Szafián, P., Tari, G., Ádám, A., and Cloetingh, S., 2006, Formation and deformation of the Pannonian Basin: constraints from observational data: Geological Society, London, Memoirs, v. 32, no. 1, p. 191-206.

Horváth, F., and Cloetingh, S., 1996, Stress-induced late stage subsidence anomalies in the Pannonian Basin: Tectonophysics, v. 266, p. 287-300.

Horváth, F., Musitz, B., Balázs, A., Végh, A., Uhrin, A., Nádor, A., Koroknai, B., Pap, N., Tóth, T., and Wórum, G., 2015, Evolution of the Pannonian basin and its geothermal resources: Geothermics, v. 53, p. 328-352.

Horváth, F., and Rumpler, J., 1984, The Pannonian basement: Acta Geologica Hungarica, v. 27, no. 3-4, p. 229-235.

Hurter, S., and Haenel, R., 2002, Atlas of geothermal resources in Europe.

Hurtig, E., Cermak, V., Haenel, R., and Zui, V., 1992, Geothermal atlas of Europe.

Huttrer, G. W., Geothermal power generation in the world 2015-2020 update report, in Proceedings Proceedings World Geothermal Congress2020, Volume 2020, p. 17.

Juhász, G., 1991, Lithostratigraphical and sedimentological framework of the Pannonian (sl) sedimentary sequence in the Hungarian Plain (Alföld), Eastern Hungary: Acta Geologica Hungarica, v. 34, no. 1-2, p. 53-72.

Kaiser, B. O., Cacace, M., and Scheck-Wenderoth, M., 2013, 3D coupled fluid and heat transport simulations of the Northeast German Basin and their sensitivity to the spatial discretization: different sensitivities for different mechanisms of heat transport: Environmental earth sciences, v. 70, no. 8, p. 3643-3659.

Kalkman, A., Veldkamp, H., Boxem, T., Koornneef, J., Halter, M., 2016, Ultra-Diepe Geothermie - Casus Almere en Barendrecht: Netherlands Institute of Applied Science TNO - National Geological Survey, TNO R11224.

Karasözen, E., Nissen, E., Bergman, E. A., Johnson, K. L., and Walters, R. J., 2016, Normal faulting in the Simav graben of western Turkey reassessed with calibrated earthquake relocations: Journal of Geophysical Research: Solid Earth, v. 121, no. 6, p. 4553-4574.

Karátson, D., Telbisz, T., Harangi, S., Magyari, E., Dunkl, I., Kiss, B., Jánosi, C., Veres, D., Braun, M., and Fodor, E., 2013, Morphometrical and geochronological constraints on the youngest eruptive activity in East-Central Europe at the Ciomadul (Csomád) lava dome complex, East Carpathians: Journal of Volcanology and Geothermal Research, v. 255, p. 43-56.

Keiding, M., Árnadóttir, T., Jónsson, S., Decriem, J., and Hooper, A., 2010, Plate boundary deformation and man-made subsidence around geothermal fields on the Reykjanes Peninsula, Iceland: Journal of Volcanology and Geothermal Research, v. 194, no. 4, p. 139-149.

Kim, K.-H., Ree, J.-H., Kim, Y., Kim, S., Kang, S. Y., and Seo, W., 2018, Assessing whether the $2017 \mathrm{Mw} 5.4$ Pohang earthquake in South Korea was an induced event: Science, v. 360 , no. 6392 , p. $1007-1009$.

Kiyoo, M., 1958, Relations between the eruptions of various volcanoes and the deformations of the ground surfaces around them: Earthq Res Inst, v. 36, p. 99-134.

Kombrink, H., 2008, The Carboniferous of the Netherlands and surrounding areas; a basin analysis. Geologica Ultraiectina (294), Departement Aardwetenschappen. 
Kombrink, H., Doornenbal, J., Duin, E., Den Dulk, M., Ten Veen, J., and Witmans, N., 2012, New insights into the geological structure of the Netherlands; results of a detailed mapping project: Netherlands Journal of Geosciences, v. 91, no. 4, p. 419-446.

Kooi, H., 2016, Groundwater flow as a cooling agent of the continental lithosphere: Nature Geoscience, v. 9, no. 3, p. 227.

Kovács, I., Zajacz, Z., and Szabó, C., 2004, Type-II xenoliths and related metasomatism from the Nógrád-Gömör Volcanic Field, Carpathian-Pannonian region (northern Hungary-southern Slovakia): Tectonophysics, v. 393, no. 1, p. 139-161.

Lankreijer, A., Bielik, M., Cloetingh, S., and Majcin, D., 1999, Rheology predictions across the western Carpathians, Bohemian massif, and the Pannonian basin: implications for tectonic scenarios: Tectonics, v. 18, no. 6, p. 1139-1153.

Lapwood, E., Convection of a fluid in a porous medium, in Proceedings Mathematical Proceedings of the Cambridge Philosophical Society1948, Volume 44, Cambridge University Press, p. 508-521.

Lenkey, L., 1999, Geothermics of the Pannonian basin and its bearing on the tectonics of basin evolution: $\mathrm{PhD}$ thesis, Vrije Universiteit, Amsterdam, p. 215.

Lenkey, L., Dövényi, P., Horváth, F., and Cloetingh, S., 2002, Geothermics of the Pannonian basin and its bearing on the neotectonics: EGU Stephan Mueller Special Publication Series, v. 3, p. 29-40.

Lenkey, L., Mihályka, J., and Paróczi, P., 2021, Review of geothermal conditions of Hungary: Földtani Közlöny, v. 151, no. 1, p. 65-65.

Lenkey, L., Raáb, D., Goetzl, G., Lapanje, A., Nádor, A., Rajver, D., Rotár-Szalkai, Á., Svasta, J., and Zekiri, F., 2017, Lithospheric scale 3D thermal model of the AlpinePannonian transition zone: Acta Geodaetica et Geophysica, p. 1-22.

Lenkey, L., and Surányi, G., 2006, Study of the heat production of Neogene volcanic rocks from Hungary (in Hungarian): Magyar Geofizika, v. 47/4.

Lermo, J., Antayhua, Y., Quintanar, L., and Lorenzo, C., 2008, Estudio sismológico del campo geotérmico de Los Humeros, Puebla, México. Parte I: Sismicidad, mecanismos de fuente y distribución de esfuerzos: Geotermia, p. 25.

Lermo Samaniego, J. F., Lorenzo, C., Antayhua, Y., Ramos, E., and Jiménez, N., Sísmica pasiva en el campo geotérmico de los Humeros, Puebla-México y su relación con los pozos inyectores, in Proceedings XVIII Congreso Peruano de Geología2016.

Limberger, J., Bonte, D., de Vicente, G., Beekman, F., Cloetingh, S., and van Wees, J., 2017, A public domain model for 1D temperature and rheology construction in basementsedimentary geothermal exploration: an application to the Spanish Central System and adjacent basins: Acta Geodaetica et Geophysica, p. 1-14.

Limberger, J., Calcagno, P., Manzella, A., Trumpy, E., Boxem, T., Pluymaekers, M., and van Wees, J.-D., 2014, Assessing the prospective resource base for enhanced geothermal systems in Europe: Geothermal Energy Science, v. 2, no. 1, p. 55-71.

Limberger, J., van Wees, J.-D., Tesauro, M., Smit, J., Bonté, D., Békési, E., Pluymaekers, M., Struijk, M., Vrijlandt, M., and Beekman, F., 2018, Refining the thermal structure of the European lithosphere by inversion of subsurface temperature data: Global and Planetary Change, v. 171, p. 18-47.

Lipsey, L., Pluymaekers, M., Goldberg, T., van Oversteeg, K., Ghazaryan, L., Cloetingh, S., and van Wees, J.-D., 2016, Numerical modelling of thermal convection in the Luttelgeest carbonate platform, the Netherlands: Geothermics, v. 64, p. 135-151.

Löer, K., Toledo, T., Norini, G., Zhang, X., Curtis, A., and Saenger, E. H., 2020, Imaging the Deep Structures of Los Humeros Geothermal Field, Mexico, Using Three- 
Component Seismic Noise Beamforming: Seismological Society of America, v. 91, no. 6, p. 3269-3277.

Lorenzo-Pulido, C., 2008, Borehole geophysics and geology of well h-43, Los Humeros geothermal field, Puebla, México: Geothermal Training Programme Report, v. 9, p. 23.

Lu, S.-M., 2018, A global review of enhanced geothermal system (EGS): Renewable and Sustainable Energy Reviews, v. 81, p. 2902-2921.

Luijendijk, E., Ter Voorde, M., Van Balen, R., Verweij, H., and Simmelink, E., 2011, Thermal state of the Roer Valley Graben, part of the European cenozoic rift system: Basin Research, v. 23, no. 1, p. 65-82.

Lund, J. W., and Toth, A. N., 2020, Direct utilization of geothermal energy 2020 worldwide review: Geothermics, p. 101915.

Mádl-Szőnyi, J., Czauner, B., Iván, V., Tóth, Á., Simon, S., Erőss, A., Bodor, P., Havril, T., Boncz, L., and Söreg, V., 2017, Confined carbonates-Regional scale hydraulic interaction or isolation?: Marine and Petroleum Geology.

Mádl-Szőnyi, J., Pulay, E., Tóth, Á., and Bodor, P., 2015, Regional underpressure: a factor of uncertainty in the geothermal exploration of deep carbonates, Gödöllö Region, Hungary: Environmental Earth Sciences, v. 74, no. 12, p. 7523-7538.

Mádl-Szőnyi, J., and Tóth, Á., 2015, Basin-scale conceptual groundwater flow model for an unconfined and confined thick carbonate region: Hydrogeology Journal, v. 23, no. 7, p. 1359-1380.

Mádl-Szőnyi, J., and Tóth, J., 2009, A hydrogeological type section for the Duna-Tisza Interfluve, Hungary: Hydrogeology journal, v. 17, no. 4, p. 961-980.

Maghsoudi, Y., van der Meer, F., Hecker, C., Perissin, D., and Saepuloh, A., 2018, Using PS-InSAR to detect surface deformation in geothermal areas of West Java in Indonesia: International journal of applied earth observation and geoinformation, $\mathrm{v}$. 64, p. 386-396.

Magyar, I., Geary, D. H., and Müller, P., 1999, Paleogeographic evolution of the Late Miocene Lake Pannon in Central Europe: Palaeogeography, Palaeoclimatology, Palaeoecology, v. 147, no. 3, p. 151-167.

Magyar, I., Radivojević, D., Sztanó, O., Synak, R., Ujszászi, K., and Pócsik, M., 2013, Progradation of the paleo-Danube shelf margin across the Pannonian Basin during the Late Miocene and Early Pliocene: Global and Planetary Change, v. 103, p. 168173.

Magyar, I., and Sztanó, O., 2008, Is there a Messinian unconformity in the Central Paratethys: Stratigraphy, v. 5, no. 3-4, p. 245-255.

Márton, E., and Fodor, L., 2003, Tertiary paleomagnetic results and structural analysis from the Transdanubian Range (Hungary): rotational disintegration of the Alcapa unit: Tectonophysics, v. 363, no. 3, p. 201-224.

Matenco, L., Munteanu, I., Ter Borgh, M., Stanica, A., Tilita, M., Lericolais, G., Dinu, C., and Oaie, G., 2016, The interplay between tectonics, sediment dynamics and gateways evolution in the Danube system from the Pannonian Basin to the western Black Sea: Science of the Total Environment, v. 543, p. 807-827.

Matenco, L., and Radivojević, D., 2012, On the formation and evolution of the Pannonian Basin: Constraints derived from the structure of the junction area between the Carpathians and Dinarides: Tectonics, v. 31, no. 6.

Merten, S., Matenco, L., Foeken, J., Stuart, F., and Andriessen, P., 2010, From nappe stacking to out-of-sequence postcollisional deformations: Cretaceous to Quaternary 
exhumation history of the SE Carpathians assessed by low-temperature thermochronology: Tectonics, v. 29, no. 3.

Mindlin, R. D., 1936, Force at a point in the interior of a semi-infinite solid: Physics, v. 7, no. 5 , p. 195-202.

Moeck, I., and Beardsmore, G., A new 'geothermal play type'catalog: Streamlining exploration decision making, in Proceedings Proceedings of the Thirty-Ninth Workshop on Geothermal Reservoir Engineering, Stanford University, Stanford, California2014.

Moeck, I. S., 2014, Catalog of geothermal play types based on geologic controls: Renewable and Sustainable Energy Reviews, v. 37, p. 867-882.

Montanari, D., Bonini, M., Corti, G., Agostini, A., and Del Ventisette, C., 2017, Forced folding above shallow magma intrusions: Insights on supercritical fluid flow from analogue modelling: Journal of Volcanology and Geothermal Research, v. 345, p. 67-80.

Muffler, L. J., 1979, Assessment of geothermal resources of the United States, 1978: Geological Survey, Reston, VA (USA). Geologic Div.

Nádor, A., Kujbus, A., and Tóth, A., 2019, Geothermal energy use, country update for Hungary, European Geothermal Congress: den Haag, Netherlands.

Nagymarosy, A., and Muller, P., 1988, Some Aspects of Neogene Biostratigraphy in the Pannonian Basin: Chapter 6: In: Horvath, F, Royden, LH, The Pannonian Basin, Am. Assoc. Petrol. Geol. Memoir.

Nikkhoo, M., Walter, T. R., Lundgren, P. R., and Prats-Iraola, P., 2016, Compound dislocation models (CDMs) for volcano deformation analyses: Geophysical Journal International, v. 208, no. 2, p. 877-894.

Norini, G., Carrasco-Núñez, G., Corbo-Camargo, F., Lermo, J., Rojas, J. H., Castro, C., Bonini, M., Montanari, D., Corti, G., and Moratti, G., 2019, The structural architecture of the Los Humeros volcanic complex and geothermal field: Journal of Volcanology and Geothermal Research, v. 381, p. 312-329.

Norini, G., and Groppelli, G., 2020, Comment on "Estimating the depth and evolution of intrusions at resurgent calderas: Los Humeros (Mexico)" by Urbani et al.(2020): Solid Earth, v. 11, no. 6, p. 2549-2556.

Norini, G., Groppelli, G., Sulpizio, R., Carrasco-Núñez, G., Dávila-Harris, P., Pellicioli, C., Zucca, F., and De Franco, R., 2015, Structural analysis and thermal remote sensing of the Los Humeros Volcanic Complex: Implications for volcano structure and geothermal exploration: Journal of Volcanology and Geothermal Research, v. 301, p. 221-237.

Okada, Y., 1985, Surface deformation due to shear and tensile faults in a half-space: Bulletin of the seismological society of America, v. 75, no. 4, p. 1135-1154.

Okada, Y., 1992, Internal deformation due to shear and tensile faults in a half-space: Bulletin of the Seismological Society of America, v. 82, no. 2, p. 1018-1040.

Olasolo, P., Juárez, M., Morales, M., and Liarte, I., 2016, Enhanced geothermal systems (EGS): A review: Renewable and Sustainable Energy Reviews, v. 56, p. 133-144.

Osvald, M., Szanyi, J., Medgyes, T., Kóbor, B., and Csanádi, A., 2017, Geothermal energy developments in the district heating of Szeged: European Geologist European Geologist, p. 30.

Parks, M., Sigmundsson, F., Sigurðsson, Ó., Hooper, A., Hreinsdóttir, S., Ófeigsson, B., and Michalczewska, K., 2020, Deformation due to geothermal exploitation at 
Reykjanes, Iceland: Journal of Volcanology and Geothermal Research, v. 391, p. 106438.

Pavelić, D., Avanić, R., Bakrač, K., and Vrsaljko, D., 2001, Early Miocene braided river and lacustrine sedimentation in the Kalnik mountain area (Pannonian Basin System, NW Croatia): Geologica Carpathica, v. 52, no. 6, p. 375-386.

Pharaoh, T., Dusar, M., Geluk, M., Kockel, F., Krawczyk, C., Krzywiec, P., ScheckWenderoth, M., Thybo, H., Vejbæk, O., and Van Wees, J. D., 2010, Tectonic evolution, Petroleum geological atlas of the Southern Permian Basin area, EAGE Publications bv (Houten), p. 25-57.

Pijnenburg, R., Verberne, B., Hangx, S., and Spiers, C., 2019, Intergranular clay films control inelastic deformation in the Groningen gas reservoir: Evidence from split-cylinder deformation tests: Journal of Geophysical Research: Solid Earth, v. 124, no. 12, p. 12679-12702.

Piller, W. E., Harzhauser, M., and Mandic, O., 2007, Miocene Central Paratethys stratigraphy-current status and future directions: Stratigraphy, v. 4.

Pinti, D. L., Castro, M. C., Lopez-Hernandez, A., Han, G., Shouakar-Stash, O., Hall, C. M., and Ramírez-Montes, M., 2017, Fluid circulation and reservoir conditions of the Los Humeros Geothermal Field (LHGF), Mexico, as revealed by a noble gas survey: Journal of Volcanology and Geothermal Research, v. 333, p. 104-115.

Pogácsás, G., Lakatos, L., Újszászi, K., Vakarcs, G., Várkonyi, L., Várnai, P., and Révész, I., 1988, Seismic facies, electro facies and Neogene sequence chronology of the Pannonian Basin: Acta Geologica Hungarica, v. 31, no. 3-4, p. 175-207.

Ratschbacher, L., Frisch, W., Linzer, H. G., and Merle, O., 1991, Lateral extrusion in the Eastern Alps, part 2: structural analysis: Tectonics, v. 10, no. 2, p. 257-271.

Ravnik, D., Rajver, D., Poljak, M., and Živčić, M., 1995, Overview of the geothermal field of Slovenia in the area between the Alps, the Dinarides and the Pannonian basin: Tectonophysics, v. 250, no. 1-3, p. 135-149.

Receveur, M., Sigmundsson, F., Drouin, V., and Parks, M., 2018, Ground deformation due to steam cap processes at Reykjanes, SW-Iceland: effects of geothermal exploitation inferred from interferometric analysis of Sentinel-1 images 2015-2017: Geophysical Journal International, v. 216, no. 3, p. 2183-2212.

Reijmer, J. J., Johan, H., Jaarsma, B., and Boots, R., 2017, Seismic stratigraphy of Dinantian carbonates in the southern Netherlands and northern Belgium: Netherlands Journal of Geosciences, v. 96, no. 4, p. 353-379.

REN21, 2020, Renewables 2020 Global Status Report.

Rezessy, G., Szanyi, J., and Hámor, T., 2005, Report on development of geothermal energy inventory (in Hungarian): Hungarian Geological Survey, Budapest, p. 82.

Rijkers, R., and Van Doorn, T. H., 1997, Atlas of Geothermal resources in the European Community, the Netherlands. Netherlands Institute of Applied Geoscience TNONational Geological Survey: Report 97-24-A.

Rocha, S., Ramirez, G., Jimenez, E., and Pulido, C., 2010, Results of geological-geophysics drilling of the well H-43, geothermal filed Los Humeros, Pue: Mexico. In: Proc. World Geothermal Congr, p. 1-11.

Rotár-Szalkai, Á., Nádor, A., Szőcs, T., Maros, G., Goetzl, G., and Zekiri, F., 2017, Outline and joint characterization of Transboundary geothermal reservoirs at the western part of the Pannonian basin: Geothermics, v. 70, p. 1-16.

Royden, L., Horváth, F., and Rumpler, J., 1983, Evolution of the Pannonian Basin System: 1. Tectonics: Tectonics, v. 2, no. 1, p. 63-90. 
Royden, L., and Keen, C., 1980, Rifting process and thermal evolution of the continental margin of eastern Canada determined from subsidence curves: Earth and Planetary Science Letters, v. 51, no. 2, p. 343-361.

Rühaak, W., 2015, 3-D interpolation of subsurface temperature data with measurement error using kriging: Environmental earth sciences, v. 73, no. 4, p. 1893-1900.

Saeid, S., Al-Khoury, R., and Barends, F., 2013, An efficient computational model for deep low-enthalpy geothermal systems: Computers \& geosciences, v. 51, p. 400-409.

Samsonov, S. V., Feng, W., and Fialko, Y., 2017, Subsidence at Cerro Prieto Geothermal Field and postseismic slip along the Indiviso fault from 2011 to 2016 RADARSAT2 DInSAR time series analysis: Geophysical Research Letters, v. 44, no. 6, p. 27162724.

Schatz, J. F., and Simmons, G., 1972, Thermal conductivity of earth materials at high temperatures: Journal of Geophysical Research, v. 77, no. 35, p. 6966-6983.

Schmeling, H., and Marquart, G., 2014, A scaling law for approximating porous hydrothermal convection by an equivalent thermal conductivity: theory and application to the cooling oceanic lithosphere: Geophysical Journal International, v. 197, no. 2, p. 645-664.

Schmid, S. M., Bernoulli, D., Fügenschuh, B., Matenco, L., Schefer, S., Schuster, R., Tischler, M., and Ustaszewski, K., 2008, The Alpine-Carpathian-Dinaridic orogenic system: correlation and evolution of tectonic units: Swiss Journal of Geosciences, v. 101, no. 1, p. 139-183.

Sclater, J., Royden, L., Horvath, F., Burchfiel, B., Semken, S., and Stegena, L., 1980, The formation of the intra-Carpathian basins as determined from subsidence data: Earth and Planetary Science Letters, v. 51, no. 1, p. 139-162.

Segall, P., 1992, Induced stresses due to fluid extraction from axisymmetric reservoirs: Pure and Applied Geophysics, v. 139, no. 3-4, p. 535-560.

Segall, P., 2010, Earthquake and volcano deformation, Princeton University Press.

Sekiguchi, K., 1984, A method for determining terrestrial heat flow in oil basinal areas: Tectonophysics, v. 103 , no. 1, p. 67-79.

Smit, J., van Wees, J.-D., and Cloetingh, S., 2018, Early Carboniferous extension in East Avalonia: $350 \mathrm{My}$ record of lithospheric memory: Marine and Petroleum Geology, v. 92, p. 1010-1027.

Szabó, C., Harangi, S., and Csontos, L., 1992, Review of Neogene and Quaternary volcanism of the Carpathian-Pannonian region: Tectonophysics, v. 208, no. 1-3, p. 243-256.

Szanyi, J., Bálint, A., Osvald, M., Kovács, B., Czinkota, I., and Nagygál, J., 2016, Sustainability of Szentes Geothermal Field operations.

Szanyi, J., and Kovács, B., 2010, Utilization of geothermal systems in South-East Hungary: Geothermics, v. 39, no. 4, p. 357-364.

Sztanó, O., Szafián, P., Magyar, I., Horányi, A., Bada, G., Hughes, D. W., Hoyer, D. L., and Wallis, R. J., 2013, Aggradation and progradation controlled clinothems and deepwater sand delivery model in the Neogene Lake Pannon, Makó Trough, Pannonian Basin, SE Hungary: Global and Planetary Change, v. 103, p. 149-167.

Tari, G., Dövényi, P., Dunkl, I., Horváth, F., Lenkey, L., Stefanescu, M., Szafián, P., and Tóth, T., 1999, Lithospheric structure of the Pannonian basin derived from seismic, gravity and geothermal data: Geological Society, London, Special Publications, v. 156, no. 1, p. 215-250.

Tari, G., Horváth, F., and Rumpler, J., 1992, Styles of extension in the Pannonian Basin: Tectonophysics, v. 208, no. 1-3, p. 203-219. 
Ten Veen, J., Van Gessel, S., and Den Dulk, M., 2012, Thin-and thick-skinned salt tectonics in the Netherlands; a quantitative approach: Netherlands Journal of Geosciences, v. 91, no. 4, p. 447-464.

Ter Voorde, M., Van Balen, R., Luijendijk, E., and Kooi, H., 2014, Weichselian and Holocene climate history reflected in temperatures in the upper crust of the Netherlands: Netherlands Journal of Geosciences, v. 93, no. 3, p. 107-117.

Tesauro, M., Kaban, M. K., and Cloetingh, S. A., 2008, EuCRUST-07: A new reference model for the European crust: Geophysical Research Letters, v. 35, no. 5.

Tesauro, M., Kaban, M. K., and Cloetingh, S. A., 2009, A new thermal and rheological model of the European lithosphere: Tectonophysics, v. 476, no. 3, p. 478-495.

Theissen, S., and Rüpke, L., 2010, Feedbacks of sedimentation on crustal heat flow: New insights from the Vøring Basin, Norwegian Sea: Basin Research, v. 22, no. 6, p. 976-990.

Tiliţă, M., Matenco, L., Dinu, C., Ionescu, L., and Cloetingh, S., 2013, Understanding the kinematic evolution and genesis of a back-arc continental "sag" basin: The Neogene evolution of the Transylvanian Basin: Tectonophysics, v. 602, p. 237-258.

Toledo, T., Gaucher, E., Jousset, P., Jentsch, A., Haberland, C., Maurer, H., Krawczyk, C., Calò, M., and Figueroa, A., 2020, Local Earthquake Tomography at Los Humeros Geothermal Field (Mexico): Journal of Geophysical Research: Solid Earth, v. 125, no. 12, p. e2020JB020390.

Tóth, G., Rman, N., Ágnes, R.-S., Kerékgyártó, T., Szőcs, T., Lapanje, A., Černák, R., Remsík, A., Schubert, G., and Nádor, A., 2016, Transboundary fresh and thermal groundwater flows in the west part of the Pannonian Basin: Renewable and Sustainable Energy Reviews, v. 57, p. 439-454.

Tóth, J., and Almási, I., 2001, Interpretation of observed fluid potential patterns in a deep sedimentary basin under tectonic compression: Hungarian Great Plain, Pannonian Basin: Geofluids, v. 1, no. 1, p. 11-36.

Trugman, D. T., Borsa, A. A., and Sandwell, D. T., 2014, Did stresses from the Cerro Prieto Geothermal Field influence the El Mayor-Cucapah rupture sequence?: Geophysical Research Letters, v. 41, no. 24, p. 8767-8774.

Urban, E., and Lermo, J. F., 2013, Local seismicity in the exploitation of Los Humeros geothermal Field, Mexico: Proceedings of thirty-eighth workshop on geothermal reservoir engineering.

Urbani, S., Giordano, G., Lucci, F., Rossetti, F., Acocella, V., and Carrasco-Núñez, G., 2020, Estimating the depth and evolution of intrusions at resurgent calderas: Los Humeros (Mexico): Solid Earth, v. 11, no. 2, p. 527-545.

Ustaszewski, K., Kounov, A., Schmid, S. M., Schaltegger, U., Krenn, E., Frank, W., and Fügenschuh, B., 2010, Evolution of the Adria-Europe plate boundary in the northern Dinarides: From continent-continent collision to back-arc extension: Tectonics, v. 29, no. 6.

Vakarcs, G., Vail, P., Tari, G., Pogácsás, G., Mattick, R., and Szabó, A., 1994, Third-order Middle Miocene-Early Pliocene depositional sequences in the prograding delta complex of the Pannonian Basin: Tectonophysics, v. 240, no. 1-4, p. 81-106.

Van Adrichem Boogaert, H., and Kouwe, W., 1993, Stratigraphic nomenclature of the Netherlands, revision and update by RGD and NOGEPA: Mededelingen Rijks Geologische Dienst, v. 50. 
Van Balen, R., and Cloetingh, S., 1995, Neural network analyses of stress-induced overpressures in the Pannonian Basin: Geophysical journal international, v. 121, no. 2, p. 532-544.

Van Balen, R., Lenkey, L., Horvath, F., and Cloetingh, S., 1999, Two-dimensional modelling of stratigraphy and compaction-driven fluid flow in the Pannonian Basin: Geological Society, London, Special Publications, v. 156, no. 1, p. 391-414.

van der Meer, F., Hecker, C., van Ruitenbeek, F., van der Werff, H., de Wijkerslooth, C., and Wechsler, C., 2014, Geologic remote sensing for geothermal exploration: A review: International journal of applied earth observation and geoinformation, v. 33, p. 255269.

Van Hulten, F., and Poty, E., 2008, Geological factors controlling Early Carboniferous carbonate platform development in the Netherlands: Geological Journal, v. 43, no. 2-3, p. 175-196.

Van Oversteeg, K., Lipsey, L., Pluymaekers, M., Van Wees, J. D., Fokker, P. A., and Spiers, C., Fracture permeability assessment in deeply buried carbonates and implications for enhanced geothermal systems: inferences from a detailed well study at Luttelgeest-01, The Netherlands, in Proceedings Proceedings Thirty-Eighth Workshop on Geothermal Reservoir Engineering, Stanford University, Stanford, California2014.

Van Wees, J.-D., Kronimus, A., Van Putten, M., Pluymaekers, M., Mijnlieff, H., Van Hooff, P., Obdam, A., and Kramers, L., 2012, Geothermal aquifer performance assessment for direct heat production-Methodology and application to Rotliegend aquifers: Netherlands Journal of Geosciences, v. 91, no. 4, p. 651-665.

van Wees, J.-D., Pluymaekers, M., Bonté, D., van Gessel, S., and Veldkamp, H., 2017, Unlocking geothermal energy from mature oil and gas basins: a success story from the Netherlands, Perspectives for Geothermal Energy in Europe, World Scientific, p. 187-214.

Van Wees, J.-D., Stephenson, R., Ziegler, P., Bayer, U., McCann, T., Dadlez, R., Gaupp, R., Narkiewicz, M., Bitzer, F., and Scheck, M., 2000, On the origin of the southern Permian Basin, Central Europe: Marine and Petroleum Geology, v. 17, no. 1, p. 43 59.

Van Wees, J., Van Bergen, F., David, P., Nepveu, M., Beekman, F., Cloetingh, S., and Bonté, D., 2009, Probabilistic tectonic heat flow modeling for basin maturation: Assessment method and applications: Marine and Petroleum Geology, v. 26, no. 4, p. 536-551.

van Wees, J. D., Veldkamp, H., Brunner, L., Vrijlandt, M., de Jong, S., Heijnen, N., van Langen, C., and Peijster, J., 2020, Accelerating geothermal development with a play-based portfolio approach: Netherlands Journal of Geosciences, v. 99.

Vasco, D., Rucci, A., Ferretti, A., Novali, F., Bissell, R., Ringrose, P., Mathieson, A., and Wright, I., 2010, Satellite-based measurements of surface deformation reveal fluid flow associated with the geological storage of carbon dioxide: Geophysical Research Letters, v. 37, no. 3.

Vasco, D., Rutqvist, J., Ferretti, A., Rucci, A., Bellotti, F., Dobson, P., Oldenburg, C., Garcia, J., Walters, M., and Hartline, C., 2013, Monitoring deformation at the Geysers Geothermal Field, California using C-band and X-band interferometric synthetic aperture radar: Geophysical Research Letters, v. 40, no. 11, p. 2567-2572. 
Vasco, D. W., Karasaki, K., and Nakagome, O., 2002, Monitoring production using surface deformation: the Hijiori test site and the Okuaizu geothermal field, Japan: Geothermics, v. 31, no. 3, p. 303-342.

Vass, I., Tóth, T. M., Szanyi, J., and Kovács, B., 2018, Hybrid numerical modelling of fluid and heat transport between the overpressured and gravitational flow systems of the Pannonian Basin: Geothermics, v. 72, p. 268-276.

Vasyura-Bathke, H., Dettmer, J., Dutta, R., Mai, P. M., and Jonsson, S., 2021, Accounting for theory errors with empirical Bayesian noise models in nonlinear centroid moment tensor estimation: Geophysical Journal International, v. 225, no. 2, p. 1412 1431.

Veldkamp, J. G., and Hegen, D., 2020, Temperature modelling of the Dutch subsurface at the depth of the Dinantian: Netherlands Organisation for Applied Scientific Research TNO.

Verweij, H. M., Echternach, M. S. C., Witmans, N., and Fattah, R. A., 2012, Reconstruction of basal heat flow, surface temperature, source rock maturity, and hydrocarbon generation in salt-dominated Dutch Basins.

Verweij, J. M., 2003, Fluid flow systems analysis on geological time scale in onshore and offshore Netherlands, with special reference to the Broad Fourteens BasinPhD]: Vrije Universiteit (Amsterdam), $278 \mathrm{p}$.

Werner, C., Wegmüller, U., Strozzi, T., and Wiesmann, A., Gamma SAR and interferometric processing software, in Proceedings Proceedings of the ers-envisat symposium, gothenburg, sweden2000, Volume 1620, Citeseer, p. 1620.

Weston, J., Ferreira, A. M., and Funning, G. J., 2012, Systematic comparisons of earthquake source models determined using InSAR and seismic data: Tectonophysics, v. 532, p. 61-81.

Weydt, L. M., Bär, K., Colombero, C., Comina, C., Deb, P., Lepillier, B., Mandrone, G., Milsch, H., Rochelle, C. A., and Vagnon, F., 2018, Outcrop analogue study to determine reservoir properties of the Los Humeros and Acoculco geothermal fields, Mexico: Advances in Geosciences, v. 45, p. 281-287.

Weydt, L. M., Ramírez-Guzmán, Á. A., Pola, A., Lepillier, B., Kummerow, J., Mandrone, G., Comina, C., Deb, P., Norini, G., and Gonzalez-Partida, E., 2021, Petrophysical and mechanical rock property database of the Los Humeros and Acoculco geothermal fields (Mexico): Earth System Science Data, v. 13, no. 2, p. 571-598.

Willems, C., 2017, Doublet deployment strategies for geothermal Hot Sedimentary Aquifer exploitation: Application to the Lower Cretaceous Nieuwerkerk Formation in the West Netherlands Basin.

Wong, T. E., Batjes, D. A., and de Jager, J., 2007, Geology of the Netherlands, Edita-the Publishing House of the Royal.

Xu, Y., Shankland, T. J., Linhardt, S., Rubie, D. C., Langenhorst, F., and Klasinski, K., 2004, Thermal diffusivity and conductivity of olivine, wadsleyite and ringwoodite to 20 GPa and $1373 \mathrm{~K}$ : Physics of the Earth and Planetary Interiors, v. 143, p. 321-336.

Yang, X. M., Davis, P. M., and Dieterich, J. H., 1988, Deformation from inflation of a dipping finite prolate spheroid in an elastic half-space as a model for volcanic stressing: Journal of Geophysical Research: Solid Earth, v. 93, no. B5, p. 4249-4257.

Yao, T., 2004, Reproduction of the mean, variance, and variogram model in spectral simulation: Mathematical geology, v. 36, no. 4, p. 487-506.

Ziegler, P. A., Geological atlas of western and central Europe1990, Geological Society of London. 
Zielinski, G. W., Poprawa, P., Szewczyk, J., Grotek, I., Kiersnowski, H., and Zielinski, R. L., 2012, Thermal effects of Zechstein salt and the Early to Middle Jurassic hydrothermal event in the central Polish Basin: AAPG bulletin, v. 96, no. 10, p. 1981-1996. 


\section{About the author}

The author of this thesis was born on July 20, 1992 in Eger, Hungary. In 2014 she earned her Bachelor's degree in Earth Sciences, followed by a Master's degree in Geophysics in 2016, both at the Eötvös Loránd University, Budapest, Hungary. In September 2016 she joined the Netherlands Organisation of Applied Scientific Research (TNO) participating in a European project on integrated methods for advanced geothermal exploration (IMAGE). In March 2017 she started her PhD project in the Tectonics Research Group of the Department of Earth Sciences, Utrecht University. Her PhD was performed in strong collaboration with TNO, as part of the European IMAGE and GEMex (Cooperation in geothermal energy research Europe-Mexico) projects. 